University of Nebraska - Lincoln DigitalCommons@University of Nebraska - Lincoln

JFSP Synthesis Reports

U.S. Joint Fire Science Program

2007

\title{
A Comprehensive Guide to Fuels Treatment Practices for Ponderosa Pine in the Black Hills, Colorado Front Range, and Southwest
}

\author{
M. E. Hunter \\ Northern Arizona University \\ W.E. Shepperd \\ USDA Forest Service \\ L. B. Lentile \\ The University of the South \\ J.E. Lundquist \\ USDA Forest Service \\ M. G. Andreu \\ University of Florida \\ See next page for additional authors
}

Follow this and additional works at: http://digitalcommons.unl.edu/jfspsynthesis

Part of the Forest Management Commons, Other Forestry and Forest Sciences Commons, and the Wood Science and Pulp, Paper Technology Commons

Hunter, M. E.; Shepperd, W. E.; Lentile, L. B.; Lundquist, J. E.; Andreu, M. G.; Butler, J. L.; and Smith, F. W., "A Comprehensive Guide to Fuels Treatment Practices for Ponderosa Pine in the Black Hills, Colorado Front Range, and Southwest" (2007). JFSP Synthesis Reports. 14.

http://digitalcommons.unl.edu/jfspsynthesis/14 
Authors

M. E. Hunter, W. E. Shepperd, L. B. Lentile, J. E. Lundquist, M. G. Andreu, J. L. Butler, and F. W. Smith 
A Comprehensive Guide to Fuels Treatment Praptices for Ronderosa Pine inthe Black Hills, colorado Flónt Range, anc Southwest

M.E. Hunter, W.D. Shepperd, L.B. Lentile, J.E, Lundquist,

M.G. Andreu, J.L. Butler, and F.W. Smith
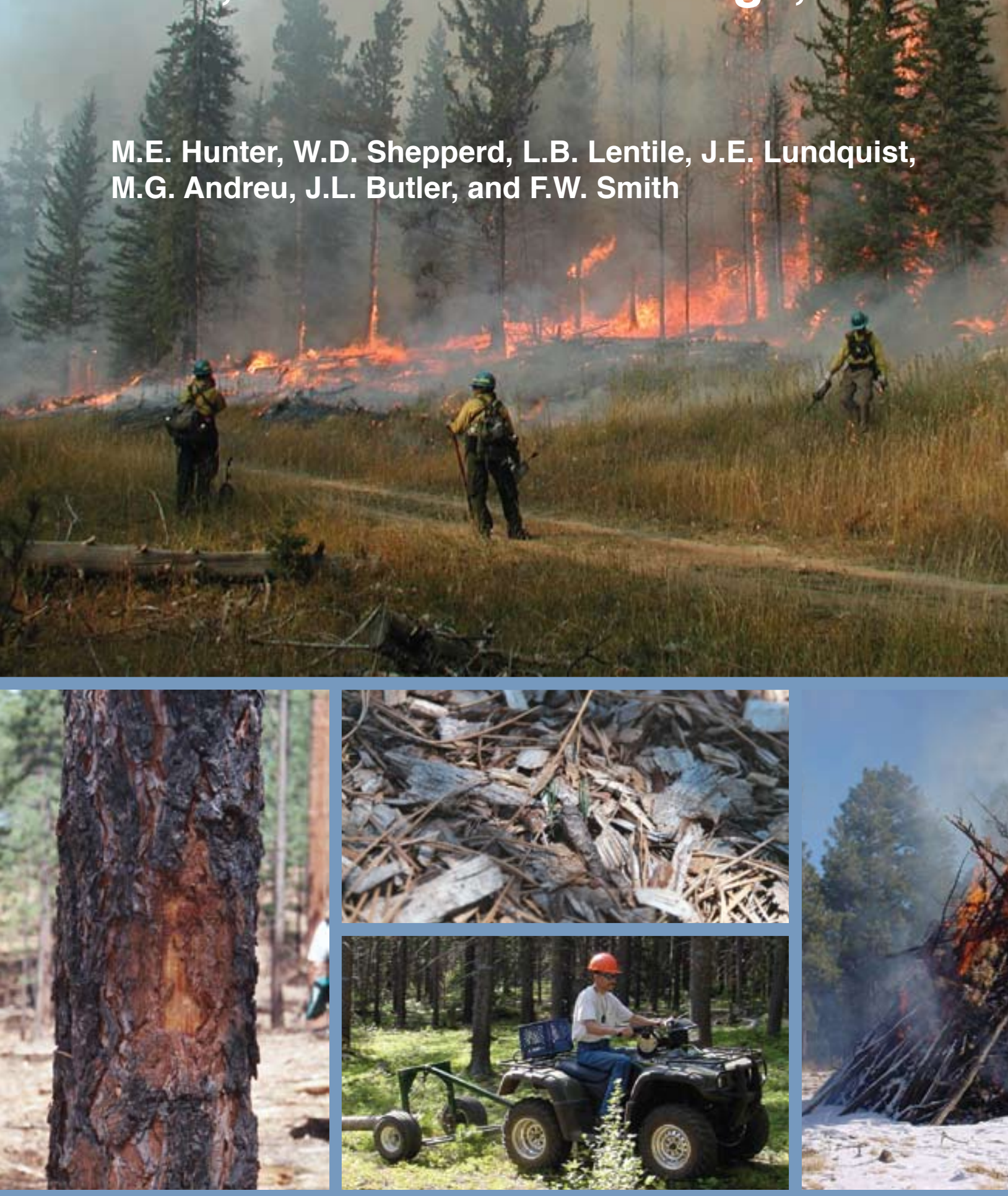

(5)
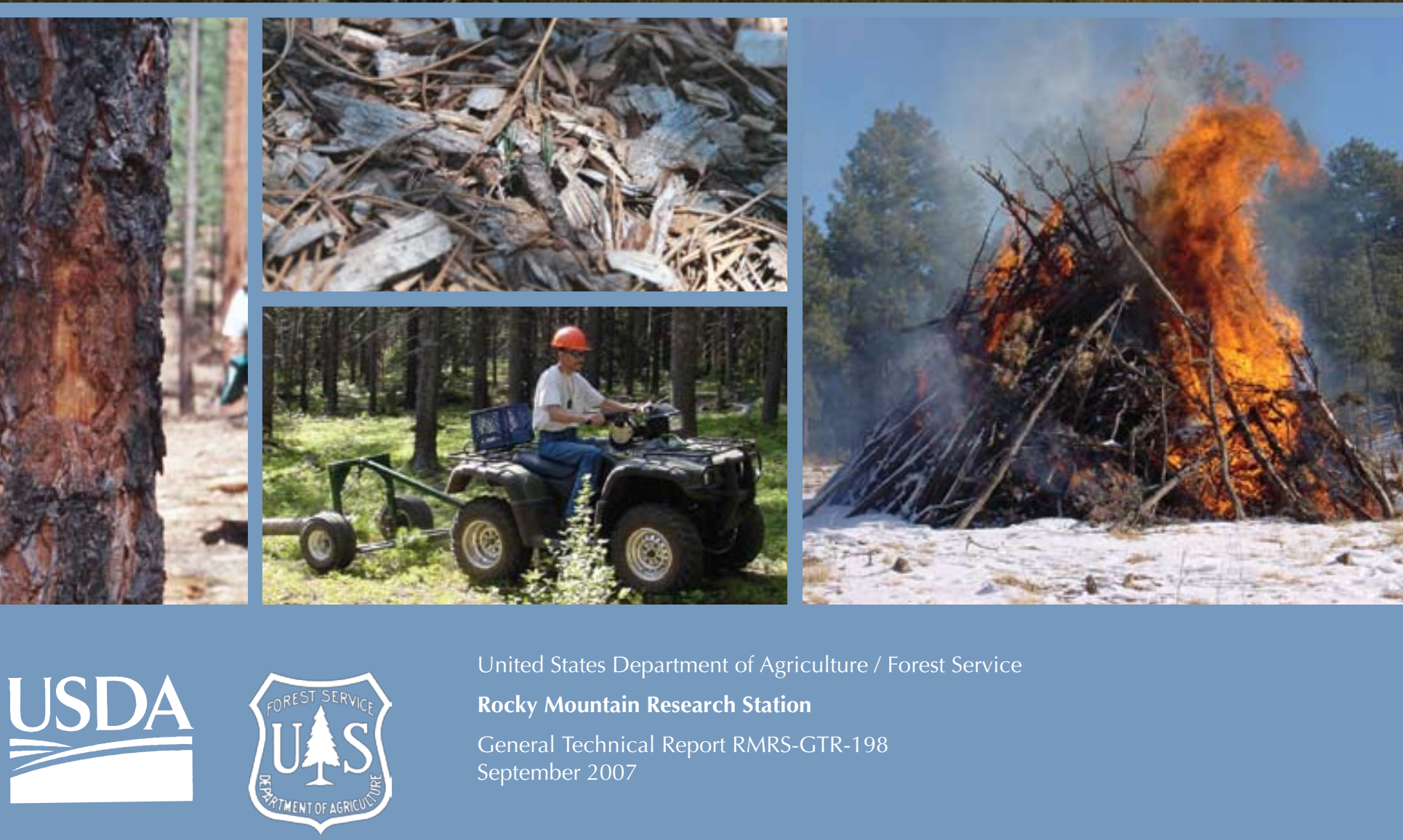

United States Department of Agriculture / Forest Service

Rocky Mountain Research Station

General Technical Report RMRS-GTR-198

September 2007 
Hunter, M.E.; Shepperd, W.D.; Lentile, J.E.; Lundquist, J.E.; Andreu, M.G.; Butler, J.L.; Smith, F.W. 2007. A comprehensive guide to fuels treatment practices for ponderosa pine in the Black Hills, Colorado Front Range, and Southwest. Gen. Tech. Rep. RMRS-GTR-198. Fort Collins, CO: U.S. Department of Agriculture, Forest Service, Rocky Mountain Research Station. $93 \mathrm{p}$.

\section{Abstract}

The objective of this paper is to present recommendations for fuels treatments in ponderosa pine forests in the Southwest, Colorado Front Range, and Black Hills of South Dakota. We have synthesized existing knowledge from the peer-reviewed literature and administrative studies and acquired local knowledge through a series of discussions with fuels treatment practitioners. We describe specific treatments, the circumstances under which they can be applied, and treatment effects. We provide recommendations related to where, how, and how often fuels treatments may be prescribed to achieve desired outcomes. Desired outcomes address social, political, economic, and ecological factors.

Key words: southwest, Black Hills, ponderosa pine, wildfire, forest thinning, prescribed fire

\section{Authors}

Molly E. Hunter School of Forestry, Northern Arizona University, Flagstaff, AZ

Wayne D. Shepperd (retired) USDA Forest Service, Rocky Mountain Research Station, Fort Collins, CO

Leigh B. Lentile Department of Forestry and Geology, The University of the South, Sewanee, TN

John D. Lundquist USDA Forest Service, Pacific Northwest Research Station, Anchorage, AK

Michael G. Andreu School of Forest Resources and Conservation, University of Florida, Plant City, FL

Jack L. Butler USDA Forest Service, Rocky Mountain Research Station, Rapid City, SD

Frederick W. Smith Forest, Rangeland, and Watershed Stewardship, Colorado State University, Fort Collins, CO

You may order additional copies of this publication by sending your mailing information in label form through one of the following media. Please specify the publication title and series number.

Fort Collins Service Center

$\begin{aligned} \text { Telephone } & (970) 498-1392 \\ \text { FAX } & (970) 498-1122 \\ \text { E-mail } & \text { rschneider@fs.fed.us } \\ \text { Web site } & \text { http://www.fs.fed.us/rmrs } \\ \text { Mailing address } & \text { Publications Distribution } \\ & \text { Rocky Mountain Research Station } \\ & \text { 240 West Prospect Road } \\ & \text { Fort Collins, CO 80526 }\end{aligned}$

Rocky Mountain Research Station Natural Resources Research Center

2150 Centre Avenue, Building A

Fort Collins, CO 80526 


\section{Executive Summary}

This comprehensive status of knowledge summary of fuels treatment practices in ponderosa pine forests of the Black Hills, Front Range and Southwest is the final report of Joint Fire Science Program Project 05-S-03. The authors gratefully acknowledge the support and encouragement of the Joint Fire Science Program Board of Directors and staff in completing this publication.

Historically, fire has been important in shaping the vegetation composition, succession, and structure of forests throughout the western United States. Low elevation ponderosa pine forests have been particularly vulnerable to altered fire regimes and much of the wildlandurban interface in the west is found among or adjacent to this forest type. In the past, relatively frequent low-severity surface or mixed-severity fires burned throughout ponderosa pine forests. Fire acted as a natural restorative agent by reducing litter, removing unhealthy trees, snags, and woody debris, thinning small trees, and creating diversity in landscapes at a spectrum of scales.

Over the past century and a half, changes in forest structure, understory and overstory conditions, fuel biomass conditions, and fire frequency have created a situation where large, infrequent, and intense fires are now the norm. Fire research has shown that physical setting, fuels, and weather combine to determine fire behavior. Recent research has addressed the role of stand and fuel structure to reduce wildfire behavior, severity, and extent. Although the need to restore historical disturbance processes is now recognized, management practices to assist hazardous fuels treatment project design and implementation have not yet been developed for fuels treatments in ponderosa pine forests.

The objective of this paper is to present management recommendations for fuels treatment based on a synthesis of existing knowledge acquired from the literature and the expertise of practitioners. We bring the expertise of fire scientists and managers in the Southwest, Colorado Front Range, and Black Hills of South Dakota together in a collaborative effort to produce a reference that provides science-based decision support for ongoing fuel reduction activities in ponderosa pine forests of these regions. We document specific conditions and practices where management intervention is appropriate to reduce fuels hazards while attempting to restore the forest community to a more natural condition. To achieve these goals, we have synthesized existing knowledge from the peer-reviewed literature and administrative studies, and acquired local knowledge through a series of interviews and discussions with local fuels treatment practitioners. We describe specific treatments, the circumstances under which they can be applied, and the expected reductions in fuels hazard. We provide recommendations related to where, how, and how often fuels treatments may be prescribed to achieve desired outcomes. Desired outcomes address social, political, economic, and ecological factors. Finally, deficits in the existing knowledge are identified. 


\section{Contents}

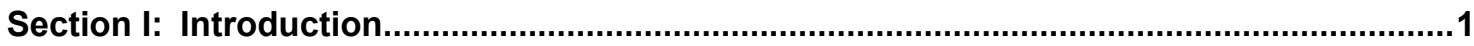

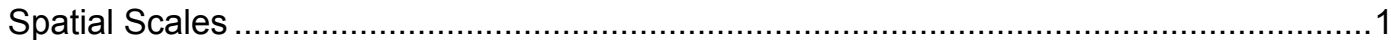

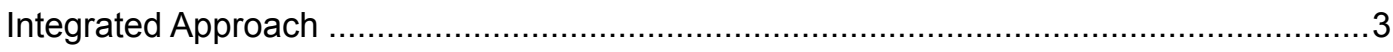

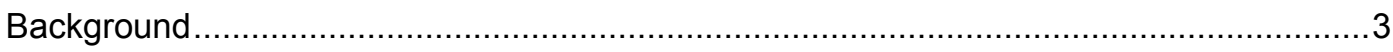

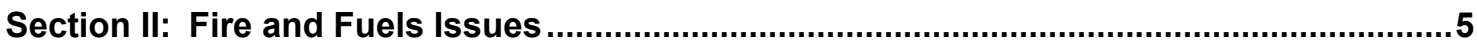

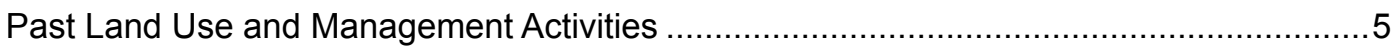

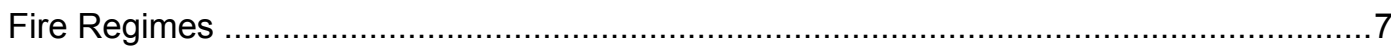

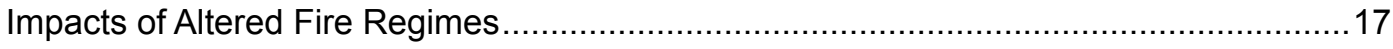

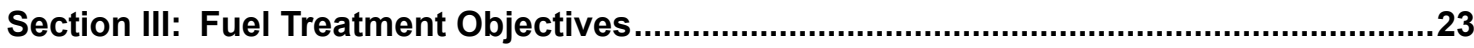

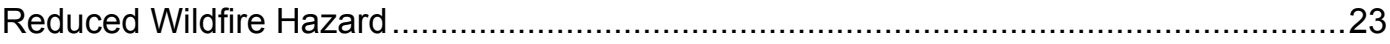

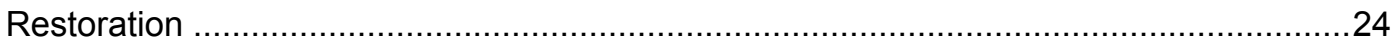

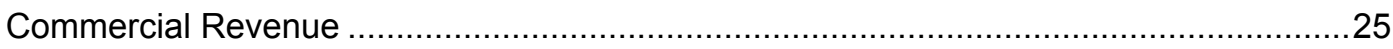

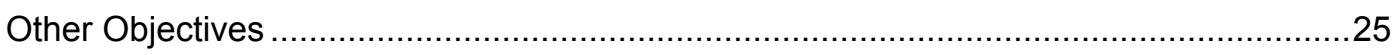

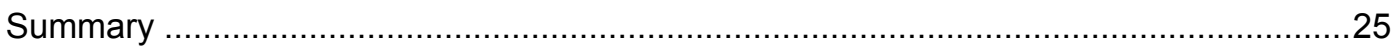

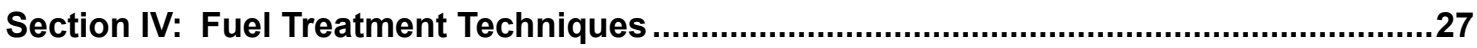

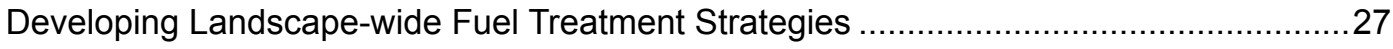

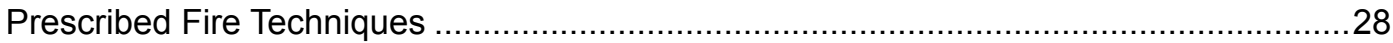

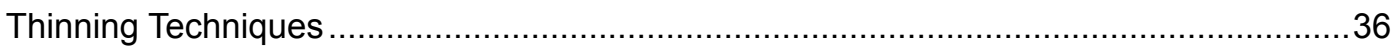

Other Mechanical and Combination (Fire + Mechanical) Techniques ...............................44

Livestock Grazing and Chemical Treatment Techniques ............................................4

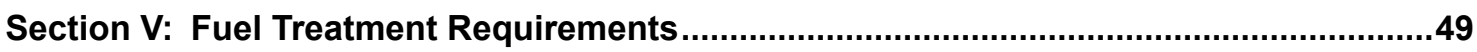

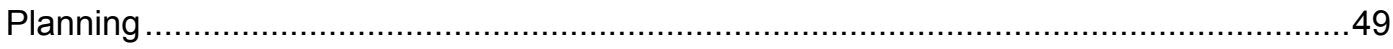

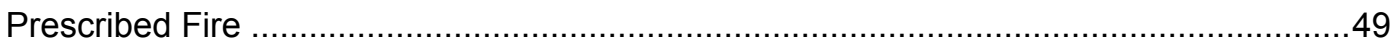

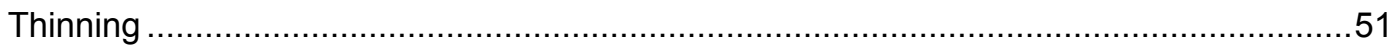

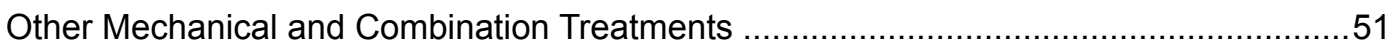

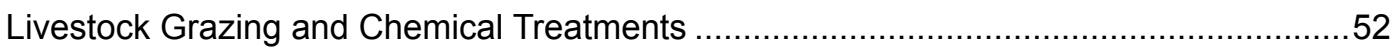

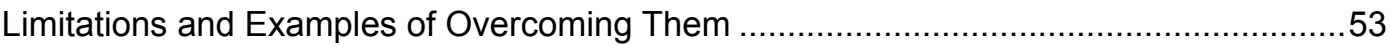

Section VI: Fuel Treatment Impacts, Mitigation, and Monitoring ......................................61

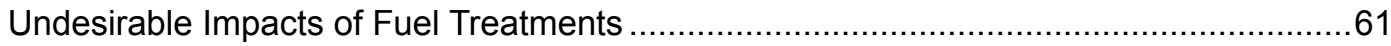

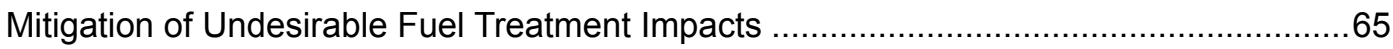

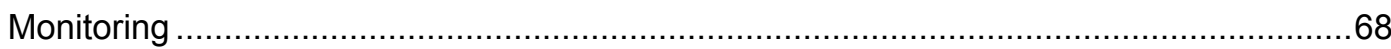

Section VII: Comprehensive Management Principles .....................................................71

Integrating Ecological Knowledge and Principles into Fuel Projects .............................. 71

Planning Fuel Treatments Within a Broad Landscape Context .......................................72

Encouraging Innovative Approaches to Fuels Treatment ............................................

Monitoring Treatment Effects and Effectiveness of Fuel Projects...................................73

Collaboration with Other Resource Managers and Interested

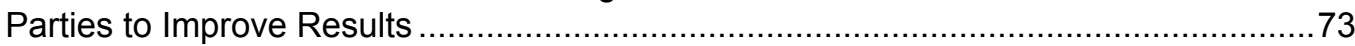

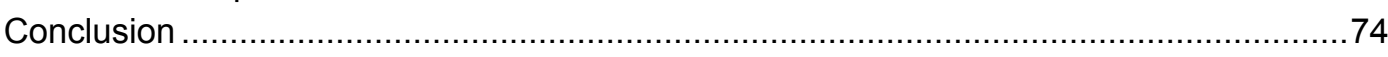

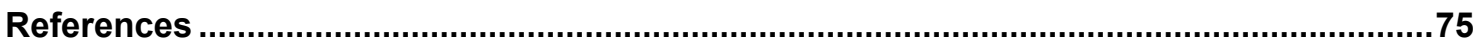

Appendix A: Models Used in Fuel Treatment Planning and Implementation ............................ 89

Appendix B: Species Referenced in Best Management Practices Guide ..............................91

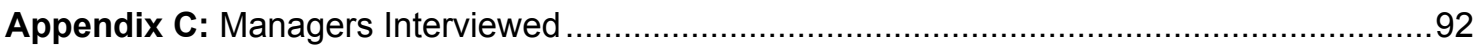




\section{Section I:}

\section{Introduction}

$\mathrm{H}$ istorically, fire was a keystone ecological process that shaped the composition and structure of plant communities across the extensive range of ponderosa pine forests (refer to Appendix B for scientific names of species listed in text). Relatively frequent, low-intensity surface fires acted as a natural thinning agent by reducing litter, burning small trees, and reducing ladder fuels. These fires were largely limited to the understory, killed few mature pines, and created an uneven-aged structure composed of small, relatively even-aged groups. In some parts of the range of ponderosa pine, small-scale stand-replacing fires were also historically significant components of the disturbance regime.

Fire suppression, grazing, and intensive forest management over the past $100+$ years have altered forest structure to eliminate much of this diversity, creating uniformly stocked landscapes of even-aged stands, many of which are densely stocked or contain dense understories of regeneration. As a result, contemporary wildfires have increased in severity across the range of ponderosa pine. The dispersal of private land holdings throughout publicly managed lands further complicates fuel treatment efforts. Fire exclusion has had other negative effects, including increased susceptibility of ponderosa pine forests to outbreaks of mountain pine beetle (MPB). Large-scale MPB outbreaks may further dramatically increase fuel loadings and the severity of fire effects.

Creation of forest structures resistant to crown fire initiation and bark beetle attack and spread is an increasingly important objective of forest management in ponderosa pine communities. Forest managers must integrate social, political, and economic values, in addition to ecological considerations, when evaluating fuels and restoration treatments. In many cases, ecological restoration and wildfire hazard reduction can be achieved simultaneously, but in other cases, these goals may be conflicting. In this document, we highlight areas where these goals may not be fully compatible and discuss how goals associated with restoration and fuel reduction can still be incorporated in management practices. Although prescribed fire and mechanical fuels treatments have been used in varying degrees across the extensive range of ponderosa pine forests, comprehensive management practices have not yet been described for fuels treatments. Nor have these treatments been evaluated in terms of landscape-scale hazard and risk reduction.

The intent of this publication is to develop management practice recommendations for fuels treatment activities in Southwest, Colorado Front Range, and Black Hills ponderosa pine. While the range of ponderosa pine forests is much larger (fig. 1) we focus our discussion on this region as it reflects the broad scope of historical fire regimes and forest structure seen in ponderosa pine forests. Recommendations are based on collaboration of research and managerial experience. It has been a joint effort between RMRS staff and collaborators at Colorado State University, University of Idaho, and University of Florida using shared data, expertise, and resources obtained from interviews with fire specialists in the Southwest, Front Range, and Black Hills. This multi-faceted approach involved all collaborators and used both published data and information from current management activities and other sources to identify appropriate management practices that can both reduce immediate fuels hazards and restore attributes of historical forest conditions in ponderosa pine forests.

\section{Spatial Scales}

The large and catastrophic wildfires found in many ponderosa pine forests today pose significant direct threats to humans and structures, as well as many natural resources considered valuable to humans, including water resources, wildlife habitat, recreation areas, and so forth. Restoration and fuel reduction treatments in ponderosa pine systems should focus on reducing the likelihood of catastrophic wildfires impacting values at risk while improving or maintaining the ecological integrity of the system. To effectively achieve this, restoration and fuel reduction treatments should be conceptualized at multiple scales, from local stands to landscapes. On the stand level, treatment prescriptions should be designed to reduce fuel loading to a level that will reduce the potential for spread of crown fire. To ensure long-term ecosystem sustainability, this is best achieved in the context of the historical stand structure and processes. Forests are 


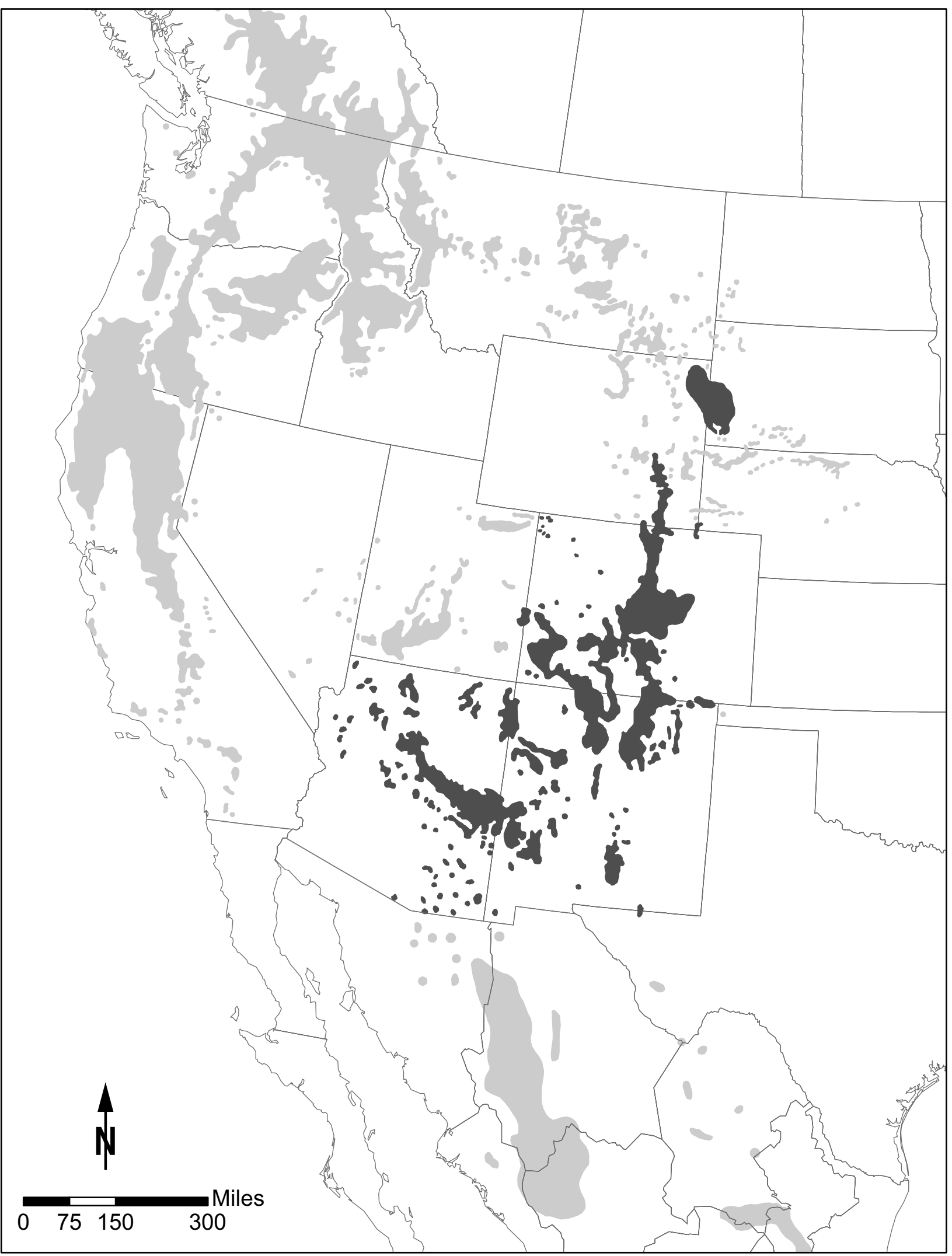

Figure 1. Shaded areas show the distribution of ponderosa pine in North America. The darker shading shows the distribution of ponderosa pine in the Black Hills, Colorado Front Range, and Southwest (Arizona, New Mexico, and southwestern Colorado), areas that are the focus of this report. 
managed for many resources that are more appropriately addressed at spatial scales larger than individual stands. Forested landscapes, for example, are usually composed of a mosaic of forest stands, which vary in fuel management and restoration needs.

Even though many areas across ponderosa pine landscapes may have deviated from historical conditions and thus be in need of restoration or fuel management, there are likely to be significant economic and logistical constraints to treating all areas. In addition, other management objectives, such as protection of sensitive wildlife habitat or structures in urban settings, may necessitate prioritization of restoration and fuel treatments across landscapes. Management needs vary across the landscape, thus what is done is just as important as where to do it. Therefore, spatial planning is critical for effectiveness in restoration, hazardous fuel reduction, and meeting other resource management objectives across ponderosa pine landscapes. In this comprehensive management practices guide, we include effective strategies for planning and implementing restoration and fuel reduction treatments at both landscape and stand scales. While the information in this guide is specific to the ponderosa pine type in the southwestern United States, Front Range of Colorado, and Black Hills of South Dakota, many aspects would be applicable in ponderosa pine forests found in other regions.

\section{Integrated Approach}

A wealth of information on various aspects of restoration and fuel reduction treatments in ponderosa pine forests is available in peer-reviewed literature, government reports, and other publications. However, this information has yet to be summarized in a comprehensive guide to restoration and fuel reduction treatments in ponderosa pine forests. In addition, many effective strategies for restoration and fuels reduction commonly used by managers remain undocumented and known only to the local practitioners who use them. We attempted to capture and document this information through a series of discussions with fire and fuel managers from various land management agencies throughout Arizona, New Mexico, Colorado, and South Dakota. To obtain a broad range of perspectives, we also spoke with a variety people from different organizations including researchers, state and private foresters, and conservationists. Appendix C provides a list of people we interviewed. We used information gained from the literature, discussions with practitioners and interested parties, as well as our own expertise to develop recommendations for management practices for restoration and fuels treatments in ponderosa pine forests of the Southwest, Front Range, and Black Hills.

\section{Background}

Ponderosa pine forests in many western states currently have the potential to burn with much higher fire intensity than they would have 100 years ago (Brown and Cook 2006; Covington and others 1994; Kaufmann and others 2003). This is largely because of management and land use practices throughout the $19^{\text {th }}$ and $20^{\text {th }}$ centuries, particularly those that lead to alteration of natural fire regimes. While past management practices have played a dominant role in altering natural fire regimes, changing climate throughout the $19^{\text {th }}$ and $20^{\text {th }}$ centuries has also been significant (Westerling and others 2006). Knowledge of the historical fire regime and resultant forest structure is thus important as it represents the conditions under which plant and animal populations in these forest communities have evolved and provides a standard for restoration (Swetnam and others 1999). A complete return to pre-Euro-American settlement conditions may not always be desirable or even possible given today's societal needs and attitudes toward forests and the possibility of a changing climate. However, presettlement forest structure does provide a benchmark for which current, unsustainable forest conditions can be compared. In cases where historical fire regimes were dominated by frequent, low intensity fires, altering current forest structure such that it more closely resembles historical forest structure should lead to forests that are ultimately less susceptible to large-scale crown fires and safer for the reintroduction of prescribed fire. The historical fire regimes, past land use and management activities, and current forest structure and its implications for current fire regimes and other ecological attributes are all presented in Section II-Fire and Fuels Issues.

While reduced risk of severe wildfire spread is generally the primary objective of fuel reduction treatments, many other resource management objectives can be met concurrently. In many ponderosa pine forests, restoration as a general rule is conducive to hazardous fuel reduction. When restoration is not a specific objective, other natural resource objectives, such as wildlife habitat or watershed health improvement or protection, can also be met in fuel reduction treatments without significantly compromising the objective of reducing wildfire hazard. Specific objectives that can be considered in restoration and fuel treatments are presented in Section III-Fuel Treatment Objectives. Several tools can be used to meet these objectives, including prescribed fire and mechanical, chemical, and biological treatments. However, 
certain techniques will be more appropriate than others depending on the specific treatment objectives. Techniques and tools used to successfully achieve fuel treatment, restoration, and other resource objectives are presented in Section IV-Fuel Treatment Techniques.

Fuel treatments alone are not always effective in meeting resource management objectives. Many factors need to be considered in the planning stages to ensure effectiveness. Part of the challenge of implementing effective fuel treatments is overcoming other resource limitations or logistical constraints, such as limited time and funding. While restoration and fuel treatments are often meant to improve the health of forested systems, they can also have adverse effects on other resources or values, such as sensitive species habitat. The effectiveness of various treatments in meeting objectives, resources needed to complete effective treatments, and limitations on use of various treatments are presented in Section V-Fuel Treatment Requirements.
It is also possible that additional work may be needed to offset the effects of some fuel treatment activities. Examples may include control of invasive species or excess tree regeneration, or modifying activities for sensitive plants or wildlife habitat. Techniques for mitigating various undesirable consequences of fuel treatment activities are discussed in Section VI-Fuel Treatment Impacts, Mitigation, and Monitoring.

Throughout our discussions with managers, we encountered many different approaches to achieving the same resource management objectives. Despite these differences, we noticed that successful treatments seemed to be accomplished when managers adhered to some common principles. We attempt to summarize those commonalities here as "management principles" that should be considered in any management program. In the final section of the document, we present several over-arching themes that we believe should be paramount in any fuel reduction or restoration treatment in ponderosa pine forests. 


\section{Section II:}

\section{Fire and Fuels Issues}

$\mathrm{H}$ umans and natural processes, such as climatic cycles and geologic substrates, have shaped ponderosa pine landscapes for long periods of time. In some cases, human impacts have been subtle and localized; while in other cases they have been profound and extensive. The latter impacts, in particular, have altered current vegetation structure, which in turn influences how disturbances such as fire are currently manifested in the landscape. It is imperative for managers to have an appreciation for how natural processes and humans have shaped forest structure and disturbance processes in the past. Understanding the historical influences of humans and natural processes on the landscape is vital for planning and implementing land management practices under a wide range of conditions. We provide that context in this section by discussing how different groups of people (Native Americans and Euro-Americans) shaped landscapes in the past. We then discuss how forest structure and fire regimes have varied with natural changes in climate and topography. Finally, we discuss how past management practices and natural factors have shaped current forest conditions and disturbance regimes in the Southwest, Front Range, and Black Hills.

\section{Past Land Use and Management Activities}

\section{Southwest}

Humans began settling the southwestern United States at least 12,000 years ago, but their populations probably did not reach large numbers until 2000 to 1000 B.C. when cultivated plants spread throughout the region and societies shifted from nomadic to agrarian (Allen 2002). It is estimated that 100,000 Native Americans occupied the upper Rio Grande Valley of New Mexico at the height of their population. Similar numbers of people settled in other population centers throughout the Southwest (Parker 2002).

These Native Americans likely had substantial impacts on forest structure around their large settlements. For example, as many as 200,000 trees of ponderosa pine, Engelmann spruce, and subalpine fir harvested up to $75 \mathrm{~km}$ from the population center were used for construction of pueblos at Chaco Canyon, a large settlement in northern New Mexico (Betancourt and others 1986). However, the imprint Native Americans had on forest structure in other areas was likely somewhat limited. Native Americans did venture into ponderosa pine forests throughout the region for hunting and gathering. Historical accounts suggest they intentionally set fires to these forests for purposes of herding game, clearing travel routes, improving forage production, or warfare (Allen 2002). While these actions certainly increased the frequency with which fires burned in some areas (Baisan and Swetnam 1997; Kaye and Swetnam 1999), it is not likely that these human ignitions significantly altered the natural fire regime over landscape or regional scales given the high frequency of lightning-caused fires in the Southwest (Allen 2002).

Euro-American and Hispanic settlers left a much more significant imprint on the landscape than Native Americans when they began settling in the region in large numbers in the late 1800s. Upon their arrival in the Southwest, they introduced domesticated sheep and cattle to the ponderosa pine forests to take advantage of the abundant forage in the open forest understory. While limited grazing began earlier in the $19^{\text {th }}$ century in certain areas (Savage and Swetnam 1990), the number of livestock on the range exploded throughout the region around 1880 (Denevan 1967; Dutton 1953). There were an estimated 4 million sheep in the state of New Mexico by 1880 (Denevan 1967) and 200,000 in the San Francisco Peaks area of Northern Arizona in 1887 (Friederici 2003). With the rangeland largely open and unregulated, overgrazing became rampant (Cooper 1960; Denevan 1967; Kaufmann and others 1998). The ubiquitous overgrazing, coupled with a severe drought in the 1890s lasting several years, caused substantial reductions in grass cover and changes in species composition in the understory of ponderosa pine forests throughout the region (Arnold 1950; Cooper 1960; Dutton 1953; Weaver 1951). By the 1910s, more active grazing management began with the creation of the Forest Service (Allen 1989; Kaufmann and others 1998). While sheep grazing has declined over the years, cattle grazing has continued in the 1990 s on public and private lands in the Southwest with 0.5 million head in Arizona and 
1.2 million head in New Mexico grazing annually (Dahms and Geils 1997).

Other significant land use and management activities common in the Southwest throughout the $20^{\text {th }}$ century include commercial logging and fire suppression. Commercial logging began in the region around the same time that large-scale livestock grazing was initiated (Allen 1989; Friederici 2003; Kaufmann and others 1998). The level of timber extraction increased steadily throughout the $20^{\text {th }}$ century and peaked in 1990 with roughly 433 million board feet extracted from public and private forests in Arizona and New Mexico in 1 year (Covington 2003). Due to lack of large trees, changing economic conditions, and increasing environmental concerns, commercial timber harvest levels have declined in much of the region since 1990, but such programs have remained active in certain areas (Friederici 2003). Organized fire suppression also began in the Southwest with the creation of the Forest Service in the 1910s (Pyne 2004). The road network created to aid timber harvest throughout the $20^{\text {th }}$ century has also greatly improved firefighting efficiency (Dahms and Geils 1997) while concurrently increasing accessibility and the potential for human caused ignitions. With the exception of some extensive and long-term wildland fire use programs (for example, Gila National Forest, Grand Canyon National Park, Saguaro National Park), most wildland fires in the Southwest continue to be suppressed (Covington 2003).

\section{Colorado Front Range}

Nomadic Native Americans traveled through the Rocky Mountains of Colorado beginning 10,000 to 15,000 years ago (Buchholtz 1983). However, it was not until 650 to 1000 A.D. that the Ute, Arapaho, and Cheyenne began settling in the Front Range more permanently, returning to the mountains from the plains each summer to take advantage of the abundant game (Buchholtz 1983; Peet 1981). While Native American populations throughout the Rocky Mountains reached up to 30,000 (Baker 2002), populations were much smaller in Colorado, probably peaking around 2,500 to 10,000 in the 1700s (Baker 2002; Buchholtz 1983). Early EuroAmerican settlers of Colorado recounted widespread intentional burning by Native Americans (Veblen 2000). However, the reliability of these accounts has been questioned (Baker 2002). While Native Americans certainly used fire for herding game in this region (Buchholtz 1983; Peet 1981), given their low population density, they were not likely to have had a significant impact on the historical fire regime in the ponderosa pine forests of the Front Range (Baker 2002).
Euro-American settlers were first lured to Colorado by the discovery of gold in the late 1850s (Buchholtz 1983; Rueth and others 2002). Thousands of prospectors from all over the country descended upon Colorado and towns such as Boulder, Golden, and Denver boomed overnight. Extensive cattle grazing and logging soon followed on the Front Range to support the rapidly growing population and industry (Veblen and Lorenz 1986; Veblen 2000). Historical photographs reveal that disturbance in the Front Range forests during this period was severe and extensive (Veblen and Lorenz 1991). Forests in the montane zone (including ponderosa pine and mixed conifer forests) were extensively logged and miners routinely set fires to these forests to facilitate prospecting (Veblen and Lorenz 1986, 1991). Although a rather large number of old trees still exist, few oldgrowth forests remain in the montane zone of the Front Range today (Kaufmann and others 2000).

With the creation of the Forest Service and the Park Service in the early 1900s, sustainable management of natural resources became a priority. Effects of rampant logging, human caused fires, and over-grazing started to lessen with tighter management of these activities and the beginning of the era of fire suppression (Brown and others 2000; Veblen and Lorenz 1991). Since the 1960s, both logging and cattle grazing have decreased dramatically throughout the region (Veblen and Lorenz 1991). Although prescribed fire programs began in the 1970s, implementation has been limited in extent (Pyne 1997). Suppression of wildfires has occurred throughout the $20^{\text {th }}$ century and most wildfires continue to be suppressed in the region. Because of its proximity to the largest cities in Colorado, the forested montane zone has been one of the most heavily used areas in the state for recreation (Myers 1974).

\section{Black Hills}

Native Americans inhabited the Dakotas in large numbers as early as 1500 , although there is no evidence of these cultures living in the Black Hills during that time (Froiland 1990). Many groups lived near the Black Hills in the 1600s and 1700s including the Cheyenne, Kiowa, and Arapaho (Froiland 1990). However, they were likely to have only occasionally ventured into the forests of the Black Hills to harvest minimal amounts of forest products (Froiland 1990; Gartner and Thompson 1973). In addition, these groups most likely preferred the open habitat and abundant game in the nearby plains (Gartner and Thompson 1973) and thus were not likely to have had an impact on the historical fire regime of the Black Hills. These groups left the region in the 1780s when they were forced westward by the Sioux (Froiland 
1990). The Sioux likely used the interior of the Black Hills to a greater extent, as early explorers found evidence of Native American presence in the Black Hills in the 1870s (Progulske 1974). There is some evidence that suggests the Sioux disrupted the natural fire regime in the foothills of the Black Hills by intentionally setting fires to herd game (Fisher and others 1987).

Word of the discovery of gold in the Black Hills in 1874 quickly spread to Euro-Americans in the east and they soon migrated to the region in large numbers forcing Native Americans to move out of the Black Hills (Froiland 1990). In addition to mining resources, the region also offered abundant timber, game, and forage for livestock, and these resources were soon extracted to support the growing population. With no land management agency in place, these resources quickly became at risk of depletion. Many large game animals including bison, pronghorn, and elk were eliminated from the Black Hills around this time. By the early $20^{\text {th }}$ century, much of the Black Hills had been logged (Raventon 1994) and as a result, very few old growth forests remain today (Boldt and Van Deusen 1974). To curb the rampant use of resources by early settlers and manage resource extraction, in 1897 the Black Hills forest reserve was created. With the creation of this reserve, the first of its kind in the United States, suppression of wildfires began in the Black Hills (Raventon 1994).

Today, the Black Hills National Forest is the most intensively managed national forest in the country, has the highest allowable timber sale quantity of any forest in the Rocky Mountain region, and supports extensive livestock grazing. However, the method and degree of resource extraction has changed dramatically since the days of the early explorers. Although unmanaged logging, grazing, and hunting were common practice in the late 1800s and early 1900s (Froiland 1990; Raventon 1994), timber harvests and livestock numbers are closely managed today (USDA Forest Service 1994). Some of the game species eliminated in the early 1900s have been reintroduced in the Black Hills (Raventon 1994). Habitat management for these populations is currently a priority (USDA Forest Service 1994). The practice of suppression continues, but acknowledgment of the ecological importance of fire and its potential benefit to different resources has led to increasing use of prescribed fire.

\section{Fire Regimes}

Many characteristics can be used to describe a fire regime. The characteristics we consider in this document are fire frequency, magnitude, extent, and seasonality.
Frequency can be thought of as the number years between fire events in a given area. Magnitude is often described as fire intensity or the rate of release of energy along a flaming front. However, since fire intensity can be difficult to measure, magnitude can also be assessed through fire severity, which can be thought of as the magnitude of the effects of fire on dominant organisms. For example, in high-severity fire regimes, the effect of the fire may be the killing of dominant trees over large areas in a stand-replacing event. In a low-severity fire regime, the effect of a fire may be relatively benign to most organisms not resulting is substantial mortality. In a mixed-severity fire regime, the effects of a fire may be a diverse array of severe and benign effects. The distinction between mixed- and high-severity fire regimes is often partly a function of the extent or scale of highseverity patches (Agee 1998).

The historical fire regime (prior to Euro-American settlement) and resultant forest structure of ponderosa pine forests is a useful reference as it reflects the states and processes under which many of the plant and animal populations found in these forests have evolved (Swetnam and others 1999). Thus, restoring the historical structure and processes of ecosystems to the extent possible provides the best alternative for sustainable ecosystem management.

Depending upon the region, ponderosa pine forests historically burned with frequent low- to more infrequent mixed-severity fire regimes, depending upon the region. Restoring historical fire regimes in many cases should therefore reduce the risk of high-severity wildfires. However, in areas where historical fire regimes may have been composed of infrequent, small-scale and patchy crown fires, restoration may not be fully conducive to reducing wildfire hazard. In such cases, fuel treatments that focus on creating conditions that promote low-intensity surface fires may reduce wildfire hazard, but may not have an ecological justification.

In forested systems, dendroecology is the most widely used tool for reconstructing historical fire regimes. Dendroecology applies dendrochronology, or the dating of tree rings, to ecological questions (Fritts and Swetnam 1989). Ponderosa pine trees are particularly adapted to the use of dendroecology to reconstruct fire histories. Ponderosa pine has thick bark that allows it to survive low-intensity surface fire and trees are able to grow new rings over injuries caused by fire, creating fire scars. By examining fire scars in the annual growth rings on individual trees and comparing them with established tree ring chronologies, the years, and in some cases, the season in which a fire burned, can be determined. 
Fire scars represent an incomplete record of fire history since some fires do not scar every tree. However, by examining fire scars on multiple trees within a stand or in several stands, mean fire return intervals (MFI), or the mean number of years between recorded fires, can be calculated at multiple scales. Fire historians often calculate different estimates of MFI based on the number of trees in a stand that record fire, for example, at least 25 percent of trees or just a few trees in a stand (Swetnam and Baisan 1996). The former is likely to represent more extensive fires that may have had a greater ecological effect on the landscape than the latter, which may indicate more localized fires.

Dendrochronology can also be used to reconstruct the historical stand structure of forests (Brown and Cook 2006; Moore and others 2004). The occurrence of highseverity fires can be determined by examining the age of trees that likely initiated in unison following such an event (Johnson and Gutsell 1994).

There are other sources of information commonly used to determine historical fire regimes. For example, historical accounts and photographs of early settlers can be used to characterize historical forest structure when lack of tree ring evidence makes dendroecological studies difficult. Such accounts can also be used to augment findings from tree ring studies. In addition, evidence of past wildfires can be recorded as deposits of ash and charcoal in lake beds. These deposits can also be extracted to determine extent and timing of past fire events.

Fire history studies in ponderosa pine forests have identified disturbance patterns that are synchronous across broad spatial scales (Swetnam and Baisan 1996). These disturbances are likely driven by regional climatic patterns that influence fuel accumulation and fuel moisture. Deviations from regional scale patterns have also been seen on local scales (Madanay and West 1983; Touchan and others 1996). For example, a higher or lower historical fire frequency can be a function of Native American burning, isolation of ridge tops, or other factors (Kaye and Swetnam 1999; Madanay and West 1983). Fire regimes also tend to vary with topographical features such as elevation, aspect, and steepness of slope. This variation in fire regimes likely created landscapes that were naturally heterogeneous in structure and disturbance processes. This heterogeneity is important for maintaining biodiversity (Reice 1994). Thus, in fuel and restoration treatments, it is imperative to have an appreciation for the range of variability in fire regimes and historical forest structure in both time and space within a given region and to incorporate this variability in treatments at the stand and landscape scale. Doing so should ensure broader goals, such as restoration and maintenance of wildlife habitat, are met. Tables of documented mean fire intervals found in the Southwest, Front Range, and Black Hills and resultant forest stand structure show the variation in these metrics across landscapes with changes in elevation, aspect, and latitude (tables 1, 2, 3, and 4).

\section{Southwest}

Prior to major Euro-American and Hispanic settlement of the region in the late $19^{\text {th }}$ century, the fire regime of ponderosa pine forests in the Southwest was characterized by frequent occurrence of low-intensity surface fires (Cooper 1960; Covington and Moore 1994a; Weaver 1951). Such fires would have burned mainly through the understory, consuming grasses, forbs, shrubs, litter, and tree seedlings and causing little damage to larger trees. Crown fires were not a component of the historical fire regime (Cooper 1960). Across the region, less conservative estimates of historical MFI ranged from 2 to 12 years (fires recorded by at least a few trees in a stand), while more conservative estimates ranged from 5 to 23 years (fires recorded by at least 25 percent of trees in a stand) (table 1). While MFI estimates varied across the region, fire regimes in all locales were characterized by frequent low intensity fire with an absence of crown fire. The majority of fires occurred in late spring and early summer, prior to the summer monsoon storms that occur July and August (Brown and others 2001b; Fule and others 2003b).

While most fire history studies have reported MFIs that fall within the regional average, certain deviations from the mean exist on a local scale. Numerous local factors can influence the fire regime in a particular area. Although rare, longer fire free intervals have been found in areas that were geographically isolated (for example, mesa tops) where fire spread would be limited from distant fire starts (Madany and West 1983; Touchan and others 1996). Fire occurrence also tends to be less frequent at higher elevations and on more northerly aspects where fuel moisture tends to be higher (Baisan and Swetnam 1990; Brown and others 2001b; Swetnam and Baisan 1996). The condition of the forests on ridge tops, where lightning is most likely to strike and ignite fires, can also be an important factor determining the historical fire frequency. For example, fire may be more likely to ignite and spread on forested ridge tops compared to rocky ridge tops (Baisan and Swetnam 1990). In certain areas, intentional burning by Native Americans may have significantly increased the historical fire frequency on a local scale (Baisan and Swetnam 1997; Kaye and Swetnam 1999).

At regional and landscape scales, long- and shortterm climatic fluctuations influenced the frequency and 
Table 1. Mean fire intervals (MFI) and their range, estimated in fire history studies at different elevations throughout the Southwest. The table includes conservative (25 percent of trees in a stand scarred) and less conservative (a few trees in a stand scarred) estimates of MFI.

\begin{tabular}{|c|c|c|c|c|c|}
\hline Site & Elevation (m) & MFI (years) & Range & $\begin{array}{l}\text { MFI (years) } \\
\text { Conservative }\end{array}$ & Range \\
\hline Southern $A Z^{a}$ & 1970 to 2100 & 8.0 & 1 to 31 & 13.1 & 4 to 31 \\
\hline Southern $A Z^{a}$ & 2270 to 2400 & 6.6 & 2 to 18 & 9.6 & 2 to 30 \\
\hline Southern AZ & 2330 to 2530 & 5.5 & 1 to 15 & 7.3 & 2 to 16 \\
\hline Southern $A Z^{a}$ & 2260 to 2840 & 3.0 & 1 to 9 & 7.3 & 2 to 13 \\
\hline Southern $N^{a}$ & 2400 to 2600 & 5.5 & 1 to 23 & 13.7 & 3 to 20 \\
\hline Southern $N^{a}$ & 2550 to 2600 & 3.5 & 1 to 10 & 6.9 & 2 to 26 \\
\hline Southern $N^{a}$ & 2600 to 2730 & 2.9 & 1 to 15 & 7.8 & 4 to 31 \\
\hline Southern $N^{a}$ & 2670 to 2800 & 5.4 & 1 to 16 & 16.5 & 4 to 41 \\
\hline Southern $\mathrm{NM}^{\mathrm{a}}$ & 2800 to 3100 & 3.0 & 1 to 15 & 13.1 & 2 to 21 \\
\hline Northern AZ ${ }^{b}$ & 2130 & 3.7 & 2 to 8 & 6.5 & 2 to 15 \\
\hline Northern AZ & 2300 & 2.5 & 1 to 12 & 5.4 & 2 to 24 \\
\hline Northern AZc & 2300 to 2370 & 3.7 & 1 to 11 & 6.4 & 2 to 11 \\
\hline Northern AZ & 2440 to 2480 & 2.6 & 1 to 13 & 7.1 & 2 to 22 \\
\hline Northern AZc & 2427 to 2537 & 5.5 & 1 to 15 & 9.0 & 4 to 21 \\
\hline Northern AZ ${ }^{\mathrm{a}}$ & 2930 to 2970 & 3.9 & 1 to 23 & 9.3 & 4 to 16 \\
\hline Northern NM ${ }^{\mathrm{a}}$ & 2220 to 2250 & 8.3 & 1 to 25 & 17.1 & 3 to 42 \\
\hline Northern NM ${ }^{a}$ & 2430 to 2470 & 9.2 & 2 to 38 & 19.0 & 3 to 30 \\
\hline Northern $\mathrm{NM}^{\mathrm{a}}$ & 2500 & 12.0 & 2 to 31 & 16.3 & 8 to 37 \\
\hline Northern $\mathrm{NM}^{\mathrm{d}}$ & 2600 & 5.5 & 1 to 12 & 8.4 & 3 to 18 \\
\hline Northern $\mathrm{NM}^{\mathrm{d}}$ & 2700 & 5.0 & 1 to 16 & 11.5 & 5 to 19 \\
\hline Northern NM ${ }^{a}$ & 3040 to 3070 & 10.1 & 2 to 29 & 23.0 & 7 to 35 \\
\hline
\end{tabular}

a From (Swetnam and Baisan 1996)

${ }^{b}$ From (Fule and others 1997)

c From (Fule and others 2003b)

d From (Touchan and others1996)

extent of fires. Historically, large fire years, defined as years in which fires occurred throughout much of the landscape, occurred in conjunction with severe droughts (Grissino-Mayer and Swetnam 2000). In particular, large fire years occurred in drought years preceded by one or two wet years - a pattern consistently seen with El Nino/Southern Oscillation cycles. This pattern has been observed in several studies throughout the Southwest (Brown and others 2001b; Fule and others 2003a; Grissino-Mayer and Swetnam 2000; Swetnam and Baisan 1996; Swetnam and Betancourt 1998). The wet years allowed for high grass production, which provided an abundant source of fine fuel conducive to ignition and surface fire spread during subsequent dry (La Nina) years. Many fire history studies also report an unusually long fire-free interval in the 1820s and 1830s, most likely due to wetter than average conditions seen during this period (Brown and others 2001b; Swetnam and Dieterich 1985).

The historical fire regimes described above, in part, maintained a very characteristic forest structure in ponderosa pine forests of the southwestern United States. On a landscape scale, forests were likely a mixture of open woodlands, meadows, and more dense forested stands (Savage 1991). Studies of historical forest structure in northern Arizona suggest that these forests were fairly open with clumps of even- or uneven-aged forests interspersed with large tree-free openings where grasses were dominant (Cooper 1960; White 1985). Clumps of trees were typically no more than half an acre in size (Cooper 1960). Grasses in the openings provided an ideal fuel for carrying low intensity surface fires, particularly when dry. Higher fuel loadings of larger fuels occurred near and in clumps of trees. This would have resulted in an occasional high intensity fire on a local scale near tree clumps, thus creating microsites favorable for pine regeneration (Arnold 1950; Cooper 1960). This dynamic led to a persistence of the clumping tree pattern as tree seedlings would have had difficulty establishing in the grassy openings (Cooper 1960; White 1985). Density of ponderosa pine trees varied throughout the region (see table 2). It is important to note that these numbers 
Table 2. Reported density of presettlement ponderosa pine trees as evidenced by age structure studies of old growth ponderosa pine forests.

\begin{tabular}{|c|c|c|c|}
\hline Site & Elevation $(\mathbf{m})$ & Density (trees/acre) & Citation \\
\hline Central AZ & 2400 & $\sim 120^{*}$ & Cooper 1960 \\
\hline Northern AZ & 2120 to 2570 & 23 & Covington and Moore 1994a \\
\hline Northern AZ & 2270 to 2600 & 56 & Covington and Moore $1994 a$ \\
\hline Southern UT & 2150 to 2260 & $38^{*}$ & Madnay and West 1983 \\
\hline Northern AZ & 2255 & 15 & White 1985 \\
\hline Northern AZ & 2600 to 2670 & 40 to 45 & Rasmussen 1941 \\
\hline Northern AZ & 2400 to 2470 & 23 & Covington and others 1997 \\
\hline Northern AZ & 2175 to 2450 & 26 & Fule and others 1997 \\
\hline Northern AZ & 2290 & 18 to 43 & Fule and others 2002a \\
\hline Northern AZ & 2125 to 2290 & 19 to 32 & Fule and others 2006 \\
\hline Central NM & 2610 & 32 & Moore and others 2004 \\
\hline Central NM & 2,500 & 50 & Moore and others 2004 \\
\hline Northern AZ & 2,240 & 11 & Moore and others 2004 \\
\hline Northern AZ & 2,240 & 10 & Moore and others 2004 \\
\hline Northern AZ & 2,250 & 33 & Moore and others 2004 \\
\hline Northern AZ & 2,250 & 29 & Moore and others 2004 \\
\hline Northern AZ & 2,300 & 19 & Moore and others 2004 \\
\hline Northern AZ & 2,300 & 23 & Moore and others 2004 \\
\hline Northern AZ & 2,060 & 35 & Moore and others 2004 \\
\hline Northern AZ & 2,050 & 25 & Moore and others 2004 \\
\hline Northern AZ & 2,290 & 8 & Moore and others 2004 \\
\hline Northern AZ & 2,250 & 34 & Moore and others 2004 \\
\hline Central NM & 2,760 & 27 & Moore and others 2004 \\
\hline Northern NM & 2,150 & 36 & Moore and others 2004 \\
\hline Northern NM & 2,620 & 89 & Moore and others 2004 \\
\hline
\end{tabular}

represent estimates of tree density at a specific period of time and may not reflect the range of tree density seen prior to Euro-American settlement over longer time scales and climate variability.

With the combined effect of overgrazing and drought in the late $19^{\text {th }}$ century, grass cover decreased considerably in ponderosa pine forests throughout the Southwest (Arnold 1950; Denevan 1967). An abrupt decline in fire frequency began around 1880 concurrent with the reduction of this fine fuel that would readily carry surface fire (Baisan and Swetnam 1990; Brown and others 2001b; Covington and Moore 1994a; Dieterich 1980; Swetnam and Baisan 1996). Fire frequency was also reduced with the practice of fire suppression that began with the creation of the Forest Service in the early $20^{\text {th }}$ century (Pyne 2004).

With the absence of fire and an explosive pine regeneration event in 1919 and 1920, tree density increased throughout southwestern ponderosa pine forests (Fule and others 1997; Moore and others 2004; Schubert 1974). As a result, the current forest structure deviates considerably from the historical structure. For example, in northern Arizona, estimates of number of trees per acre have increased from about 20 to 60 in the early 1900s to 270 to 850 currently (Covington and Moore 1994b; Fule and others 1997). When averaged across the region, the average number of trees per acre has increased from roughly 30 in the 1910s to 220 in the 1990s (Moore and others 2004). However, tree density also varies by substrate. For example, higher historical and contemporary tree densities occur in areas with limestone substrates (Covington and Moore 1994a).

Tree species composition has also changed in many places, from a dominance of shade-intolerant ponderosa pine trees to more shade-tolerant species such as white fir and Douglas-fir (Covington and Moore 1994b; Fule and others 1997). Tree size class distribution has changed from a structure with few large to medium diameter trees to many small diameter trees (Fule and others 1997; Moore and others 2004). There are also more standing dead trees and higher surface fuel loading in the current forests compared to historical levels, 
although there are no data available on the size of snags present in historical forests (Moore and others 2004). On a landscape scale, many forests are much more structurally homogenous (Savage 1991).

The current forest structure has led to an altered fire regime such that forests are now more likely to burn with infrequent, intense stand-replacing fires. This has been shown with increasing occurrence of large and severe fires in the Southwest since the middle of the $20^{\text {th }}$ century (Swetnam 1990), including the Rodeo-Chediski fire that burned over 400,000 acres in central Arizona in 2002 .

According to coarse scale assessments, many of the ponderosa pine forests in the Southwest are considered to be outside of their historical range of variability in terms of fire disturbance and forest structure (Aplet and Wilmer 2003). Currently, an estimated 61 percent of ponderosa pine/dry Douglas-fir forests in New Mexico have high potential for crown fire spread (Fiedler and others 2002). These areas should benefit from fuel treatments for purposes of restoration or fire hazard reduction. Given the vast areas in need of treatments and the constraints on available resources, priorities areas considered for fuel reduction treatments should be prioritized.

\section{Colorado Front Range}

Prior to the start of Euro-American settlement in the mid- $19^{\text {th }}$ century, the fire regime of ponderosa pine forests of the Front Range exhibited both similarities and differences to those of the Southwest. Here, fires have been characterized as mixed-severity, with both surface and small-scale, stand-replacing crown fires occurring at intervals anywhere between 5 and 118 years (Brown and others 1999; Brown and others 2000; Brown and Shepperd 2001; Donnegan and others 2001; Goldblum and Veblen 1992; Hadley 1994; Veblen and others 2000). The mean fire interval for surface fires (MFI) historically varied throughout the Front Range depending on latitude, elevation, and aspect (table 3 ). Across the region, less conservative estimates of MFI varied from 8 to 64 years (fires recorded by a few trees in a stand), while more conservative estimates ranged from 14 to 59 years (fires recorded by at least 25 percent of trees in a stand) (table 3). We note, however, that use of MFI alone does not consider the spatial extent of recorded fires, which is especially important in the Front Range where fires that were ecologically important at the landscape scale occurred less frequently and at a spectrum of severities (Kaufmann and others 2006)

In general, the historical frequency of surface fires decreased with elevation with more frequent surface fires in the low elevation grassland/forest ecotone and less frequent fires in higher elevation forests (table 3) (Brown and Shepperd 2001; Sherriff and Veblen, in press). The historical MFI, in general, also increased with latitude from southern Colorado to southern Wyoming (table 3). Low intensity surface fires were also likely more frequent on south-, east-, and west-facing slopes where conditions were more xeric and stands less dense (Goldblum and Veblen 1992; Veblen 2003). Historically, fires occurred throughout the growing season, but occurred slightly earlier in the southern portion of the range (Baker 2003; Brown and others 1999; Brown and Shepperd 2001; Veblen and Kitzberger 2002).

Currently, ponderosa pine forests in the Front Range include few openings and stands with conspicuous age and size limits (Brown and others 1999; Brown and others 2000; Ehle and Baker 2003; Huckaby and others 2001; Kaufmann and others 2000; Sherriff and Veblen 2007). Spatial patterns and age structure characteristics associated with past stand-replacing disturbance events appear to be an important part of the historical fire regime in ponderosa pine forests in some parts of the Front Range (Kaufmann and others 2006).

The nature of mixed-severity fire regimes and the extensive logging and burning in the Front Range during the $19^{\text {th }}$ century make assessment of the historical crown fire component of this fire regime extremely difficult. Thus, the historical extent and frequency of stand-replacing fires in the Front Range is not well understood. Only one study to date has examined historical fire regimes across the full elevational range of ponderosa pine in the Front Range. This study found that low-severity surface fires were common on only 20 percent of the landscape studies (in areas below $2100 \mathrm{~m}$ in elevation) (Sherriff and Veblen 2007). However, this study represents a unique and small portion of the Front Range.

Kaufmann and others (2006) examined the available historical fire data for the Front Range in an effort to bring some understanding to the apparent conflicts among the various studies reported in the literature. They conclude that historical fires in the Front Range were complex and burned in response to variations in weather conditions, fuels, and topography. Historical fire regime of low-severity fires that maintained savannas and open woodlands in ponderosa pine forests applies only to portions of the lowest elevations of the Front Range. At middle and higher elevations, mixed-severity fires were the most important in maintaining the structure and spatial distribution of ponderosa pine in the Front Range landscape. They further note that steep topographic and elevation gradients strongly affected the fire regime. It is likely that stand-replacing fires were more common in mesic sites at higher elevations and on north-facing 
Table 3. Summary of historical mean fire intervals (pre-1850) and their range of variability found in fire history studies at different elevations throughout the Front Range. The table includes conservative estimates of MFI (25 percent of trees in a stand scarred) and less conservative estimates of MFI (a few trees in a stand scarred).

\begin{tabular}{|c|c|c|c|c|c|}
\hline Site & Elevation (m) & MFI (years) & Range & $\begin{array}{l}\text { MFI (years) } \\
\text { Conservative }\end{array}$ & Range \\
\hline Southern $W Y^{a}$ & 1920 to 1960 & 26 to 33.5 & 8 to 82 & $\mathrm{n} / \mathrm{a}$ & $\mathrm{n} / \mathrm{a}$ \\
\hline Northern $\mathrm{CO}^{\mathrm{b}}$ & 2090 to 2200 & 16.0 & 3 to 50 & $\mathrm{n} / \mathrm{a}$ & $\mathrm{n} / \mathrm{a}$ \\
\hline Northern $\mathrm{CO}^{\mathrm{b}}$ & 2220 to 2250 & 25.5 & 4 to 52 & $\mathrm{n} / \mathrm{a}$ & $\mathrm{n} / \mathrm{a}$ \\
\hline Northern $\mathrm{CO}^{\mathrm{b}}$ & 2420 to 2590 & 29.5 & 8 to 79 & $\mathrm{n} / \mathrm{a}$ & $\mathrm{n} / \mathrm{a}$ \\
\hline Northern $\mathrm{CO}^{\mathrm{b}}$ & 2600 to 2230 & 29.0 & 11 to 69 & $\mathrm{n} / \mathrm{a}$ & $\mathrm{n} / \mathrm{a}$ \\
\hline Northern $\mathrm{CO}^{\mathrm{b}}$ & 2610 to 2630 & 21.5 & 3 to 54 & $\mathrm{n} / \mathrm{a}$ & $\mathrm{n} / \mathrm{a}$ \\
\hline Central $\mathrm{CO}^{c}$ & 1996 & 9.0 & 1 to 51 & $\mathrm{n} / \mathrm{a}$ & $\mathrm{n} / \mathrm{a}$ \\
\hline Central $\mathrm{CO}^{\mathrm{d}}$ & 1884 to 2015 & 8.3 & 1 to 29 & 14.4 & 2 to 46 \\
\hline Central $\mathrm{CO}^{\mathrm{d}}$ & 2048 to 2177 & 13.4 & 1 to 47 & 23.6 & 14 to 47 \\
\hline Central $\mathrm{CO}^{\mathrm{d}}$ & 2189 to 2432 & 17.7 & 1 to 63 & 19.3 & 1 to 63 \\
\hline Central $\mathrm{CO}^{\mathrm{d}}$ & 2440 to 2488 & 22.4 & 1 to 125 & 43.4 & 7 to 125 \\
\hline Central $\mathrm{CO}^{\mathrm{e}}$ & 2100 to 2520 & 9.2 & 1 to 29 & 59.2 & 27 to 128 \\
\hline Central $\mathrm{CO}^{f}$ & 2375 to 2685 & 15.2 & 2 to 49 & $\mathrm{n} / \mathrm{a}$ & $\mathrm{n} / \mathrm{a}$ \\
\hline Central $\mathrm{CO}^{\mathrm{b}}$ & 2380 to 2390 & 22.5 & 2 to 72 & $\mathrm{n} / \mathrm{a}$ & $\mathrm{n} / \mathrm{a}$ \\
\hline Central $\mathrm{CO}^{\mathrm{b}}$ & 2390 to 2410 & 7.5 & 2 to 82 & $\mathrm{n} / \mathrm{a}$ & $\mathrm{n} / \mathrm{a}$ \\
\hline Central COg & 2500 to 2800 & 20.9 & 11 to 145 & 41.7 & 5 to 63 \\
\hline Central $\mathrm{CO}^{\mathrm{h}}$ & 2450 to 2750 & 22.4 & 8 to 38 & $\mathrm{n} / \mathrm{a}$ & $\mathrm{n} / \mathrm{a}$ \\
\hline Central $\mathrm{CO}^{c}$ & 2621 & 18.0 & 4 to 76 & 48.0 & 4 to 102 \\
\hline Central $\mathrm{CO}^{\mathrm{b}}$ & 2630 to 2670 & 64.0 & 24 to 79 & $\mathrm{n} / \mathrm{a}$ & $\mathrm{n} / \mathrm{a}$ \\
\hline Central $\mathrm{CO}^{c}$ & 2743 & 31.0 & 2 to 116 & $\mathrm{n} / \mathrm{a}$ & $\mathrm{n} / \mathrm{a}$ \\
\hline Central $\mathrm{CO}^{\mathrm{c}}$ & 2865 & 23.0 & 1 to 88 & $\mathrm{n} / \mathrm{a}$ & $\mathrm{n} / \mathrm{a}$ \\
\hline Southern $\mathrm{CO}^{\mathrm{i}}$ & 2100 to 2500 & 7.5 & 2 to 37 & $\mathrm{n} / \mathrm{a}$ & $\mathrm{n} / \mathrm{a}$ \\
\hline Southern $\mathrm{CO}^{\mathrm{a}}$ & 2590 to 2640 & 9.5 & 2 to 41 & $\mathrm{n} / \mathrm{a}$ & $\mathrm{n} / \mathrm{a}$ \\
\hline Southern $\mathrm{CO}^{\mathrm{b}}$ & 2670 to 2690 & 10.0 & 4 to 41 & $\mathrm{n} / \mathrm{a}$ & $\mathrm{n} / \mathrm{a}$ \\
\hline Southern $\mathrm{CO}^{\mathrm{b}}$ & 2720 to 2740 & 19.0 & 4 to 54 & $\mathrm{n} / \mathrm{a}$ & $\mathrm{n} / \mathrm{a}$ \\
\hline
\end{tabular}

a Brown and others 2000

b Brown and Shepperd 2001

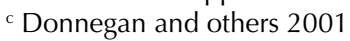

d Veblen and others 2000

e Brown and others 1999

${ }^{f}$ Goldblum and Veblen 1992

${ }^{\text {h }}$ Hadley 1994

${ }^{g}$ Laven and others 1980

i Wieder and Bower 2004

aspects where tree density is typically high and shadetolerant species such as Douglas-fir are more common (Romme and others 2000; Veblen and others 2000).

Historically, fire frequency, severity, and extent in the Front Range varied with long- and short-term climatic fluctuations. As in the Southwest, large fire years (years where fires occurred across much of the landscape) tended to occur when the growing season was drier than average and was preceded by 1 to 3 wetter than average years, a common pattern when El Nino-Southern Oscillation (ENSO) years (wet) are followed by La Nina years (dry) (Donnegan and others 2001; Veblen 2000; Veblen and others 2000). Live fine fuels (grasses) likely accumulated during wet years and subsequently cured during dry years, providing an abundant dry fuel source conducive to ignition and fire spread. However, this pattern was less pronounced in the northern portion of the Front Range where sensitivity to ENSO patterns is weaker (Veblen 2000). Long-term climatic changes may also have been responsible for decadal shifts in the historical fire regime. Increased fire activity was observed during decades with pronounced ENSO activity, and decreased fire activity was observed for decades when ENSO activity was weak (Donnegan and others 2001; Veblen 2000).

Fewer studies have examined historical tree density in old growth forests in the Front Range than in the Southwest. However, studies suggest that historical 
forest structure varied widely throughout the range with estimates of historical tree density ranging from 16 to 1380 trees per acre (Baker and others 2007). The mixedseverity fire regime likely resulted in a complex forest structure composed of openings with no trees, persistent clumps of old-growth trees, forest patches with nearly pure ponderosa pine, and patches with ponderosa pine and Douglas-fir (Kaufmann and others 2001). This complexity is the result of the wide range of environmental conditions where ponderosa pine occurs in the Front Range. Mixed-conifer forests containing ponderosa pine, lodgepole pine, limber pine, Douglas-fir, aspen, spruce, and fir can be found in various combinations in the Front Range (Kaufmann and others 2006). Historically, these mixed conifer forests were found in more mesic areas at higher elevations on north-facing aspects, and likely had higher tree density than the drier pure ponderosa pine forests found at lower elevations (Baker and others 2007; Kaufmann and others 2000). In the drier forests, both high and low intensity fires would have resulted in tree mortality and would have created openings with no trees and stands with low tree density (Kaufmann and others 2001; Kaufmann and others 2003). Old-growth forests likely persisted in areas where intervals between stand-replacing events were long. In the central portion of the Front Range, delayed tree recruitment following stand-replacing disturbance events would have allowed for openings and low density stands $(<30$ percent canopy cover) to persist across the landscape (Huckaby and others 2003; Kaufmann and others 2003). It is estimated that these openings may have accounted for up to 25 percent of the landscape in lower elevation montane forests in the central Front Range, (Kaufmann and others 2001). However, in the northern Front Range at higher elevations, others have argued that dense ponderosa pine forests may have historically made up a significant portion of the upper montane forests (Baker and others 2007; Ehle and Baker 2003; Sherriff and Veblen 2007).

Large-scale human disturbance in the mid- $19^{\text {th }}$ century (logging, grazing, burning), along with favorable climatic conditions, prompted synchronized tree regeneration events in the Front Range (Ehle and Baker 2003; Kaufmann and others 2003; Veblen and others 2000). This resulted in a rather even-aged and even-sized distribution of ponderosa pine and Douglas-fir trees in forests throughout the Front Range. Because fire suppression in the $20^{\text {th }}$ century limited mortality of trees following these recruitment pulses, current forests have much higher tree density than historical forests (Kaufmann and others 2000; Veblen and others 2000). Tree species composition has changed from dominance of shadeintolerant ponderosa pine trees to more shade-tolerate species such as Douglas-fir (Kaufmann and others 2000). Forest structure has changed from a mosaic of dense forests, openings, and old growth to a homogenous forest structure of dense trees of similar age and size classes and higher tree canopy cover (Huckaby and others 2003; Kaufmann and others 2000; Veblen and Lorenz 1991). Thus, current forest structure, particularly in low elevation forests, contains much higher tree density than historical levels in drier forests (Kaufmann and others 2000). Yet, forest structure of more mesic upper montane ponderosa pine - Douglas-fir forests at higher elevations and on north-facing slopes may not have been as severely altered, particularly in the northern Front Range (Baker and others 2007). In fact, some have argued that fire suppression has resulted in decreased tree regeneration throughout the $20^{\text {th }}$ century through the development of thick forest canopies that limit successful seedling establishment in the understory in some areas of the Front Range (Ehle and Baker 2003; Sherriff and Veblen, in press).

In places where forest structure has been severely altered, the increased forest density has led to an altered fire regime where wildfires today are more likely to burn with more severe fire effects. While stand-replacing fires certainly were a part of the historical fire regime, the stand-replacing portion of any given fire is likely much higher under current forest conditions (Kaufmann and others 2000; Schoennagel and others 2004). This has been evidenced by several high-severity wildfires that have occurred in the Front Range in recent years, including the 130,000+ acre Hayman Fire, which was unprecedented in terms of size of high-severity patches in this landscape, at least over the past 5 centuries (Kaufmann and others 2003) (fig. 2). While fire regimes may not have been significantly altered in higher elevation montane forests in the northern Front Range (Sherriff and Veblen 2007), the extent to which fire regimes have changed high elevation montane forests in other portions of the Front Range remains largely unknown (Kaufmann and others 2006).

According to a recent report by the Front Range Fuel Treatment Partnership Rountable (2006), close to 1 million acres of fire-prone forests fall in the wildland urban interface in the Front Range of Colorado and are thus a high priority for treatment. Of these, about 400,000 acres are in the lower montane ponderosa pine zone roughly split between public and private ownership. Thus, fuel treatment strategies that cross jurisdictional boundaries are needed in this region to truly protect communities from the threat of wildfire. For purposes of restoration, the lower elevation forests (below $2100 \mathrm{~m}$ ) are more likely to have significantly higher tree density today than 


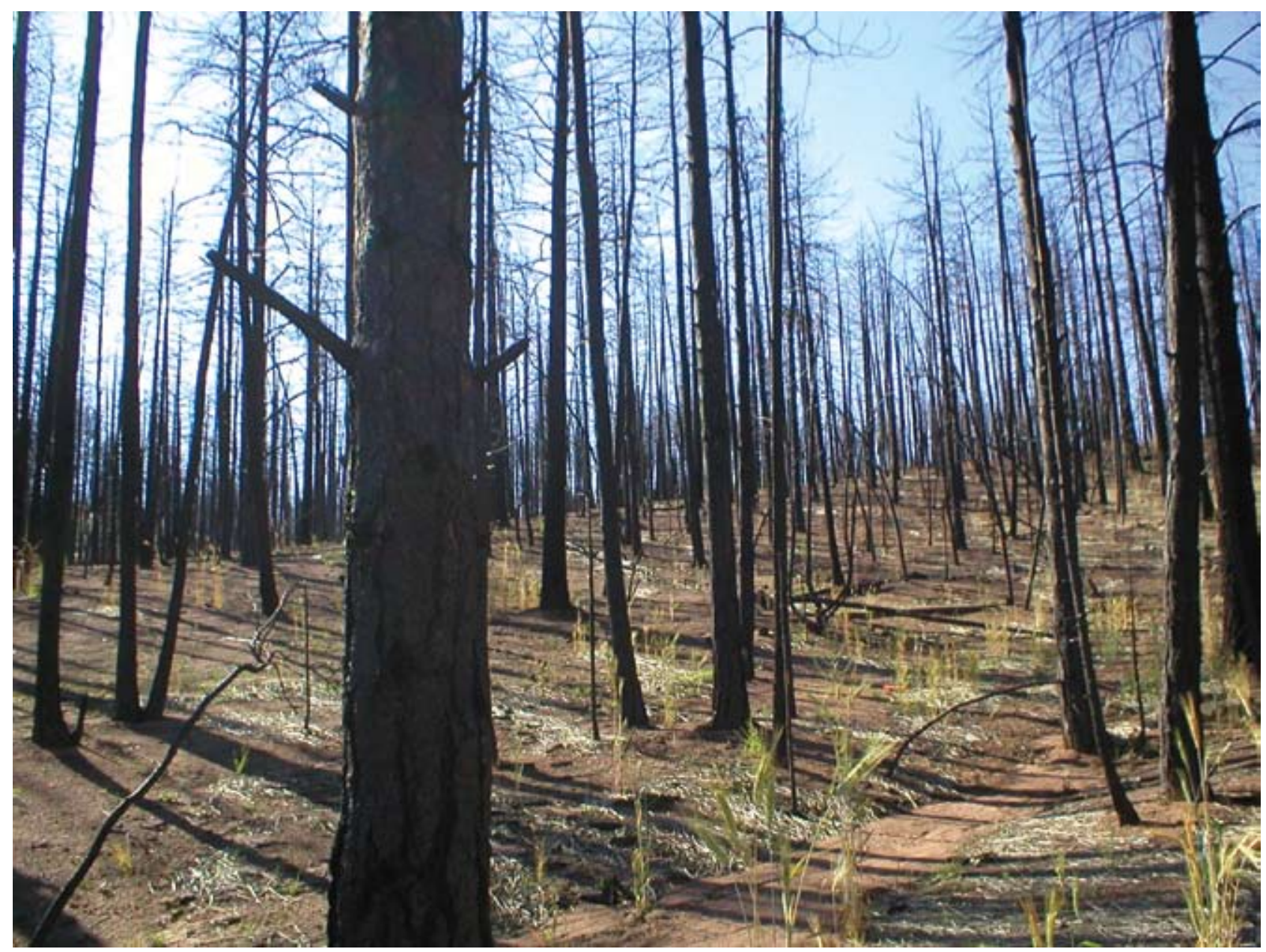

Figure 2. An example of the severe fire effects seen from the Hayman Fire, Colorado. Photo credit: Molly Hunter.

they would have had historically (Kaufmann and others 2006). Thus, restoration efforts should be prioritized in these areas. By some estimates, this makes up only 20 percent of the ponderosa pine forests in the Front Range (Sherriff and Veblen 2007). However, these estimates come from the northern Front Range in Boulder County, which has relatively little lower montane ponderosa pine, and it is unclear if similar proportions can be applied to other forests in the Front Range (Kaufmann and others 2006). In any case, lower elevation ponderosa pine forests are more likely to occur near developed urban areas in the Front Range, further underscoring the need for fuels treatment intervention in the urban interface.

\section{Black Hills}

While similarities exist in historical fire regimes of ponderosa pine forests of the Black Hills, Front Range and Southwest, certain characteristics distinguish the Black Hills ponderosa pine type forests from those of the Front Range and Southwest. The Continental climate in the Black Hills is much more conducive to the establishment and growth of ponderosa pine, owing to persistent seed crops and abundant summer rainfall (Shepperd and Battaglia 2002). The result is forest structures and fire regimes that were historically different from those in the Front Range and Southwest. While only a few studies have been conducted on the historical fire regime of the Black Hills, current evidence suggests that prior to Euro-American settlement, the fire regime of the Black Hills would have been of mixed-severity, with both surface and crown fires being important components of the ecosystem (Brown and Sieg 1996; Brown 2003; Shinneman and Baker 1997). However, most fire history studies in this region have focused on questions regarding the historical frequency of surface fires. With mean annual precipitation increasing from south to north in the Black Hills, historical surface fire frequency was higher in the southern portion compared to the northern and central portions (Brown 2003; Shinneman and Baker 1997). Less conservative estimates of the mean fire interval (MFI) ranged from 10 to 15 years in the southern Black Hills, to 30 to 33 years in 
Table 4. Summary of historical mean fire intervals (MFI) and their range of variability for a given aspect and elevation found in fire history studies in the northern, central, and southern portions of the Black Hills. Table includes more conservative (25 percent of trees in a stand scarred) and less conservative (a few trees in a stand scarred) estimates of MFI, although most studies only report the less conservative estimate.

\begin{tabular}{|c|c|c|c|c|c|c|}
\hline Site & Elevation (m) & Aspect & MFI (years) & Range & $\begin{array}{l}\text { MFI (years) } \\
\text { Conservative }\end{array}$ & Range \\
\hline Northern $^{\mathrm{a}}$ & $\mathrm{n} / \mathrm{a}$ & $\mathrm{n} / \mathrm{a}$ & 27 & $\mathrm{n} / \mathrm{a}$ & $\mathrm{n} / \mathrm{a}$ & $\mathrm{n} / \mathrm{a}$ \\
\hline Northern ${ }^{\mathrm{a}}$ & $\mathrm{n} / \mathrm{a}$ & $\mathrm{n} / \mathrm{a}$ & 14 & $\mathrm{n} / \mathrm{a}$ & $\mathrm{n} / \mathrm{a}$ & $\mathrm{n} / \mathrm{a}$ \\
\hline Northern ${ }^{b}$ & 1520 to 1550 & $\mathrm{~S}$ & 22 & 11 to 41 & $\mathrm{n} / \mathrm{a}$ & $\mathrm{n} / \mathrm{a}$ \\
\hline Northern ${ }^{b}$ & 1520 to 1500 & $\mathrm{~N}$ & 11 & 3 to 30 & $\mathrm{n} / \mathrm{a}$ & $\mathrm{n} / \mathrm{a}$ \\
\hline Northern ${ }^{b}$ & 1350 to 1390 & $\mathrm{E}$ & 16 & 4 to 34 & $\mathrm{n} / \mathrm{a}$ & $\mathrm{n} / \mathrm{a}$ \\
\hline Northern ${ }^{b}$ & 1830 to 1860 & $\mathrm{~S}$ & 13 & 22 to 42 & $\mathrm{n} / \mathrm{a}$ & $\mathrm{n} / \mathrm{a}$ \\
\hline Northern ${ }^{b}$ & 1850 to 1890 & $\mathrm{E}$ & 21 & 4 to 64 & $\mathrm{n} / \mathrm{a}$ & $\mathrm{n} / \mathrm{a}$ \\
\hline Northern ${ }^{b}$ & 1840 to 1880 & W & 31 & 14 to 64 & $\mathrm{n} / \mathrm{a}$ & $\mathrm{n} / \mathrm{a}$ \\
\hline Northern $^{b}$ & 1870 to 1910 & SE & 13 & 8 to 19 & $\mathrm{n} / \mathrm{a}$ & $\mathrm{n} / \mathrm{a}$ \\
\hline Northern ${ }^{b}$ & 1730 to 1760 & $\mathrm{E}$ & 20 & 7 to 37 & $\mathrm{n} / \mathrm{a}$ & $\mathrm{n} / \mathrm{a}$ \\
\hline Northern ${ }^{b}$ & 1740 to 1780 & SW & 17 & 2 to 33 & $\mathrm{n} / \mathrm{a}$ & $\mathrm{n} / \mathrm{a}$ \\
\hline Northern ${ }^{f}$ & 1200 to 1280 & $\mathrm{n} / \mathrm{a}$ & 13 & 1 to 43 & 15 & 4 to 42 \\
\hline Central $^{c}$ & 1660 to 1690 & $\mathrm{n} / \mathrm{a}$ & 23 & 11 to 74 & $\mathrm{n} / \mathrm{a}$ & $\mathrm{n} / \mathrm{a}$ \\
\hline Central $^{c}$ & 1670 to 1720 & $\mathrm{n} / \mathrm{a}$ & 22 & 13 to 72 & $\mathrm{n} / \mathrm{a}$ & $\mathrm{n} / \mathrm{a}$ \\
\hline Central $^{\mathrm{d}}$ & 1585 to 1768 & $\mathrm{n} / \mathrm{a}$ & 16 & 1 to 45 & 16 & 1 to 45 \\
\hline Central $^{b}$ & 2070 to 2090 & $\mathrm{~S}$ & 24 & 10 to 41 & $\mathrm{n} / \mathrm{a}$ & $\mathrm{n} / \mathrm{a}$ \\
\hline Central $^{b}$ & 1660 to 1690 & $E$ & 27 & 15 to 42 & $\mathrm{n} / \mathrm{a}$ & $\mathrm{n} / \mathrm{a}$ \\
\hline Central $^{b}$ & 1670 to 1720 & $\mathrm{~S}$ & 27 & 15 to 46 & $\mathrm{n} / \mathrm{a}$ & $\mathrm{n} / \mathrm{a}$ \\
\hline Central $^{b}$ & 1670 to 1710 & $\mathrm{~N}$ & 20 & 1 to 47 & $\mathrm{n} / \mathrm{a}$ & $\mathrm{n} / \mathrm{a}$ \\
\hline Central ${ }^{b}$ & 1720 & $\mathrm{n} / \mathrm{a}$ & 23 & 6 to 45 & $\mathrm{n} / \mathrm{a}$ & $\mathrm{n} / \mathrm{a}$ \\
\hline Central $^{\mathrm{b}}$ & 1680 to 1740 & $\mathrm{~S}$ & 20 & 1 to 47 & $\mathrm{n} / \mathrm{a}$ & $\mathrm{n} / \mathrm{a}$ \\
\hline Central $^{b}$ & 1580 to 1670 & SW & 19 & 7 to 37 & $\mathrm{n} / \mathrm{a}$ & $\mathrm{n} / \mathrm{a}$ \\
\hline Southern ${ }^{\mathrm{e}}$ & 1100 to 1530 & $\mathrm{n} / \mathrm{a}$ & 12 & 3 to 32 & $\mathrm{n} / \mathrm{a}$ & $\mathrm{n} / \mathrm{a}$ \\
\hline Southern ${ }^{\mathrm{e}}$ & 1100 to 1530 & $\mathrm{n} / \mathrm{a}$ & 10 & 2 to 23 & $\mathrm{n} / \mathrm{a}$ & $\mathrm{n} / \mathrm{a}$ \\
\hline Southern & 1100 to 1530 & $\mathrm{n} / \mathrm{a}$ & 12 & 3 to 34 & $\mathrm{n} / \mathrm{a}$ & $\mathrm{n} / \mathrm{a}$ \\
\hline Southern ${ }^{b}$ & 1470 to 1510 & $\mathrm{E}$ & 11 & 3 to 29 & $\mathrm{n} / \mathrm{a}$ & $\mathrm{n} / \mathrm{a}$ \\
\hline Southern ${ }^{b}$ & 1340 to 1350 & $\mathrm{E}$ & 10 & 2 to 18 & $\mathrm{n} / \mathrm{a}$ & $\mathrm{n} / \mathrm{a}$ \\
\hline Southern ${ }^{b}$ & 1220 to 1260 & $\mathrm{~N}$ & 12 & 3 to 34 & $\mathrm{n} / \mathrm{a}$ & $\mathrm{n} / \mathrm{a}$ \\
\hline
\end{tabular}

a Fisher and others 1987

${ }^{b}$ Brown 2003

${ }^{\mathrm{c}}$ Brown and others 2000

d Brown and Sieg 1996

e Brown and Sieg 1999

${ }^{\mathrm{f}}$ Wienk and others 2004

the central and northern Black Hills (table 4). In Devils Tower National Monument, MFI varied through time with a higher MFI occurring from 1600 to 1770 (MFI = 27 years) compared to 1779 to 1900 (MFI $=14$ years) (Fisher and others 1987). The author attributed this to the presence of the Sioux who may have intentionally set fires to herd game. Historical MFI also increased with elevation (table 4) along with precipitation and colder temperatures (Shepperd and Battaglia 2002).

Many studies report evidence of a crown fire component in this system. Evidence for this comes from historical accounts and photos from early Euro-American explorers. Journals from early explorers reveal that large treeless areas with charred snags were commonly encountered (Graves 1899). Historical photographs reveal this as well (Grafe and Horsted 2002; Progulske 1974). Pine regeneration can be prolific in the Black Hills, especially after stand-replacing disturbance (Bonnet and others 2005; Brown and others 2000; Lentile 2004; Lundquist and Negron 2000). Early explorers to the Black Hills commonly found dense, even-aged stands of ponderosa pine seedlings or saplings (Grafe and Horsted 2002; Kime 1996; Progulske 1974) or two-aged stands with dense understories of younger trees (Graves 1899). While such stands can be a result of a variety of disturbance agents (wind, disease, insects), other 
evidence (charred snags) suggests that wildfire was the cause (Grafe and Horsted 2002; Kime 1996). However, one study shows that pulses of pine recruitment may be driven more by climate than disturbance (Brown 2003). Unlike ponderosa pine forests in other parts of the United States, long fire-free periods were historically common in the Black Hills (Brown and Sieg 1996), which may have led to fuel build-up and high tree density - conditions conducive to crown fire spread. Because much of the Black Hills was repeatedly logged during the $20^{\text {th }}$ century (Boldt and Van Deusen 1974; Raventon 1994, Shepperd and Battaglia 2002), it is difficult to determine the historical extent and frequency of crown fires in this system.

Much of the precipitation in the Black Hills falls as rain from April to September (Brown 2003; Shepperd and Battaglia 2002). Thus, historically, most wildfires burned in the late summer and early fall when fuels would have been sufficiently dry to promote fire spread (Brown and Sieg 1996, 1999). In the higher elevations in the northern and central portions of the Black Hills, fires occurred more rarely and may have spread mostly in years that were drier than average. Fires did not typically occur in years that were wetter than average. Unlike ponderosa pine forests in other regions, there appears to be no effect of El Nino/La Nina cycles on the historical fire regime (Brown 2003).

The occurrence of surface fires and stand-replacing fires, coupled with other disturbance agents, led to a complex mosaic of forest structure composed of dense forests, moderately stocked forests, and treeless openings. In 1899, Henry S. Graves conducted an extensive inventory of timber resources in the Black Hills for the U.S. Geological Survey. While this assessment occurred after substantial logging had occurred in certain areas, it still provides an invaluable insight into the historical forest structure of the Black Hills. Graves identified three classes of timber: 1) less than 2,000 board feet per acre, 2) 2,000 to 5,000 board feet per acre, and 3) 5,000 to 10,000 board feet per acre. The first class was the most common in the Black Hills and the third class was the least common. Evidence of disturbance was not seen in the third class and the dense forest structure was likely a result of long fire-free periods (Graves 1899). Density of trees in classes one and two was probably limited by frequent disturbance from fire and insects. In the absence of disturbance, stands in class three would have become very dense and more susceptible to crown fire spread. In more frequently disturbed forests, stands were likely multi-aged and tree density varied from 7 to almost 300 trees per acre (Brown and Cook 2006; McAdams 1995). In forests with longer intervals between disturbances, sapling density may have been as high as 8,000 trees per acre (Baker and others 2007). As these dense, even-aged forests matured, density decreased to 150 to 200 trees per acre (Baker and others 2007).

The historical fire regime of the Black Hills has been disrupted as a result of human influence. While Native Americans were likely to have had little effect on the historical fire regime, there is some evidence that their burning practices increased the fire frequency in certain portions of this region (Fisher and others 1987). The biggest disruption in the fire regime was a sharp decrease in the fire frequency as a result of fire exclusion, logging, and grazing by Euro-Americans beginning around 1900 . Given the naturally long fire-free periods in some parts of the Black Hills, the historical fire regime may not have changed on some local scales. However, across the Black Hills landscape, fires have become less frequent during the $20^{\text {th }}$ century. In addition, the current fire-free periods are longer than the longest fire-free periods found in fire history studies (Brown and Sieg 1996, 1999).

The altered fire regime, along with other human disturbances, has led to dramatic changes in forest structure in the Black Hills since the end of the $19^{\text {th }}$ century. On a regional scale, ponderosa pine density is much higher today compared to conditions when Euro-American's first settled in the region (Grafe and Horsted 2002; McAdams 1995; Progulske 1974). In areas where tree density would have been naturally high (north-facing slopes and higher elevation forests), forest structure may not have been significantly altered since fire exclusion. While dense second-growth forests would historically have been common, old-growth forests, openings, and frequently disturbed forests of low density were also significant components of the landscape (Parrish and others 1996). As a result of extensive logging, old-growth forests are almost completely removed from the Black Hills landscape (Boldt and Van Deusen 1974). Early explorers accounted large tree-free areas presumably resulting from crown fires (Grafe and Horsted 2002; Kime 1996; Progulske 1974). Fewer of these areas exist today as a result of fire exclusion (Grafe and Horsted 2002; Progulske 1974). Areas that were formerly frequently disturbed stands with historically low tree density are now very dense stands (Grafe and Horsted 2002; McAdams 1995; Progulske 1974; USDA Forest Service 1994). There is also evidence to suggest that current average tree size is lower than historical levels (Brown and Cook 2006). While historically much of the Black Hills would have been composed of a mosaic of stands with even- or multi-aged structure, today, the Black Hills are predominantly managed with an even-aged shelterwood silvicultural system (Shepperd and Battaglia 2002). 
The increases in fuel loads and tree density and the homogenous nature of current Black Hills forest landscapes have changed the fire regime so ponderosa pine forests are now more likely to burn with infrequent and large stand-replacing fires. This is evidenced by several large wildfires that occurred in the Black Hills in the $19^{\text {th }}$ and $20^{\text {th }}$ centuries (Raventon 1994, Shepperd and Battaglia 2002). In the 1890s two large fires burned about 74,000 acres in the northern Black Hills. In the 1930s, the Rochford and McVey fires burned about 40,000 acres on the Limestone Plateau. Since 2000, seven fires have burned about 140,000 acres, including large areas of both privately- and publicly-managed forests and grasslands. This includes the largest fire to occur in recorded history in the Black Hills, the Jasper fire, which burned 81,000 acres in 2000 (Lentile 2004).

To reduce wildfire hazard, managers in the Black Hills estimate that 15,000 to 20,000 acres per year should be burned in the Black Hills using prescribed fire (USDA Forest Service 1994). Currently, fewer acres are actually burned in a given year (USDA Forest Service 2004a). Up to 44,000 acres that are commercially thinned are in need of additional fuel treatment every year and up to 13,000 acres per year of natural fuels are in need of mechanical fuel treatment in the Black Hills. About 5,000 parcels of private land are intermingled within the Black Hills National Forest, making up 19 percent of the area within the forest boundary (USDA Forest Service 1994) (fig. 3). The potential for wildfires and escaped prescribed fires occurring within this extensive wildland-urban interface poses significant challenges for managers.

For purposes of restoration, not all areas of the Black Hills would be in need of treatment. Since ponderosa pine forests in the Black Hills historically contained a mosaic of structures and stocking conditions, from relatively open stands to dense forested patches (Brown and Cook 2006), care should be taken to re-create this heterogeneity in forest structure across the landscape.

\section{Impacts of Altered Fire Regimes}

While there are differences in historical forest structure and fire regimes in ponderosa pine forests in the Southwest, Front Range, and Black Hills, all of these regions have experienced drastic changes in forest structure and subsequent changes in fire regimes in the past century. Forests that historically were relatively open once burned with frequent low- or mixed-severity fire regimes. Presently, these forests have much higher tree density and fuel loading and are more likely to burn with infrequent, severe crown fires (Brown and others 1999; Covington 2003; Covington and Moore 1994a; Huckaby and others 2003; Kaufmann and others 2000; Veblen and others 2000). However, historical forest structure and the resulting fire regime may not have changed significantly in certain areas in the Front Range and Black Hills where tree density has always been naturally high (north-facing slopes, higher elevations) (Baker and others 2007). At landscape scales, however, the fire regime has likely been altered as forests have become more dense and homogenous in nature (Huckaby and others 2003; Kaufmann and others 2000; Schoennagel and others 2004; Veblen and others 2000). Records indicate that fires across the Southwest have become larger and more severe since the mid-20 ${ }^{\text {th }}$ century (Swetnam 1990). Crown fires in the Front Range seem to be less localized and more extensive than in the past (Huckaby and others 2003). Similarly, large wildfires that have occurred in the Black Hills in recent years are likely a function of the more homogenous nature of forest structure today (Brown and Cook 2006).

These large and severe wildfires have very significant consequences for a variety of resources managed in these forests, including hydrology and soils, community and fire-fighter safety, insect and disease outbreaks, and bidoversity. Even with the absence of fire, the altered forest structure can also have negative consequences for valued resources. The dense and homogenous nature of ponderosa pine landscapes in these regions today can also have negative impacts on hydrology, insect and disease outbreaks, biodiversity, and forage production.

\section{Hydrology and Soils}

Large and severe wildfires result in more negative impacts on hydrology and soils compared to fires of lowseverity. Severe wildfires result in sudden and complete reductions in vegetative cover, which leads to increased water runoff and soil erosion (DeBano and others 1998). Such changes in hydrology can be severe enough to significantly reduce site fertility and water quality and degrade stream communities (DeBano 1991; Keane and others 2002; Landsberg and Tiedemann 2000). Full recovery of soil microbial communities reduced by severe wildfire can take up to 2 years or longer, and this can have detrimental impacts on availability of soil carbon and nitrogen (Choromanska and DeLuca 2001).

Another effect of dense and homogenous forest structure is increased evapotranspiration and interception resultant from increased tree density. This can significantly reduce the water yield from watersheds when averaged across the landscape, limiting supply for humans and riparian communities (Keane and others 2002; Stednick 1996). 


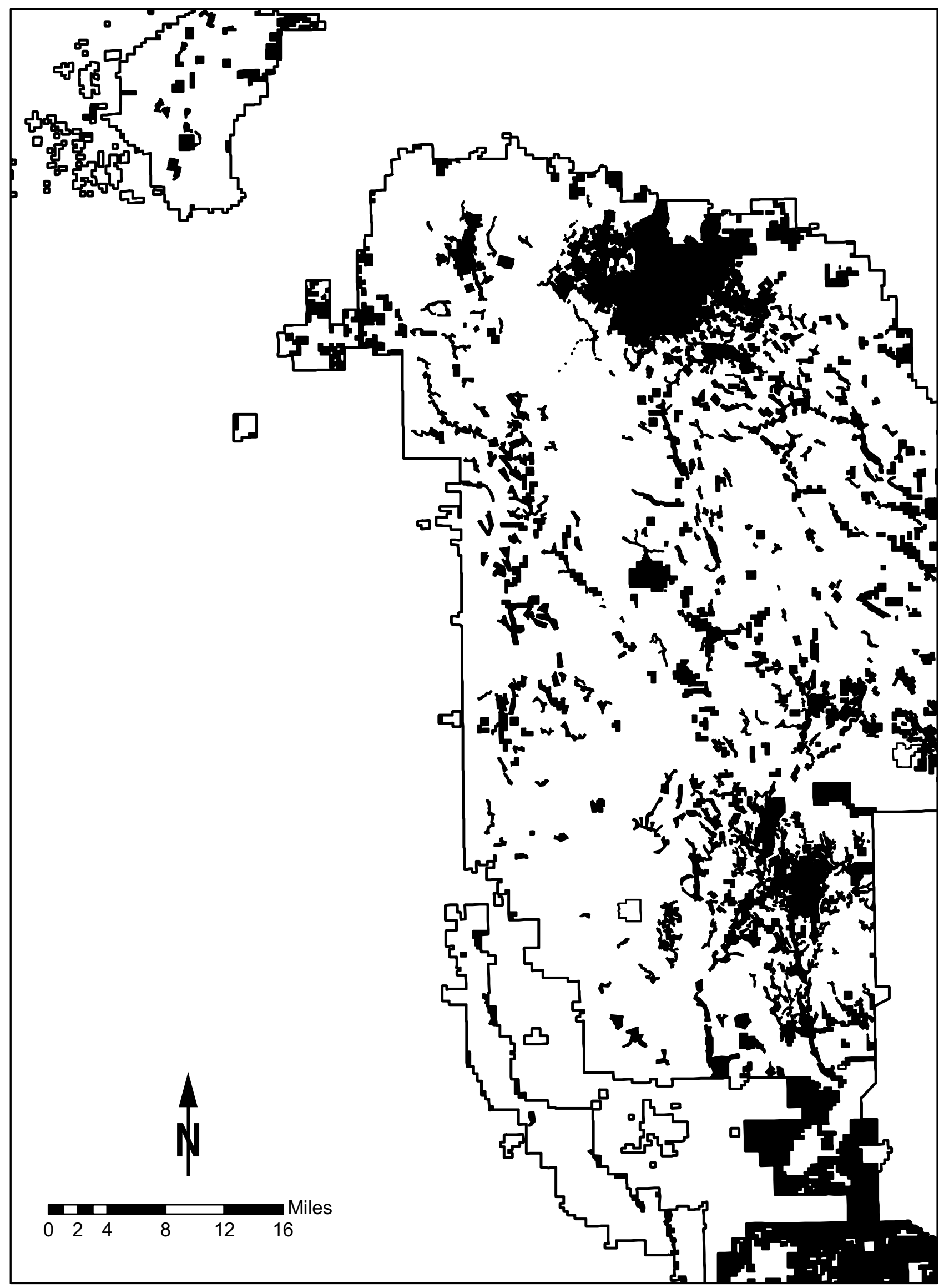

Figure 3. Map of Black Hills NF, including land ownership patterns. 


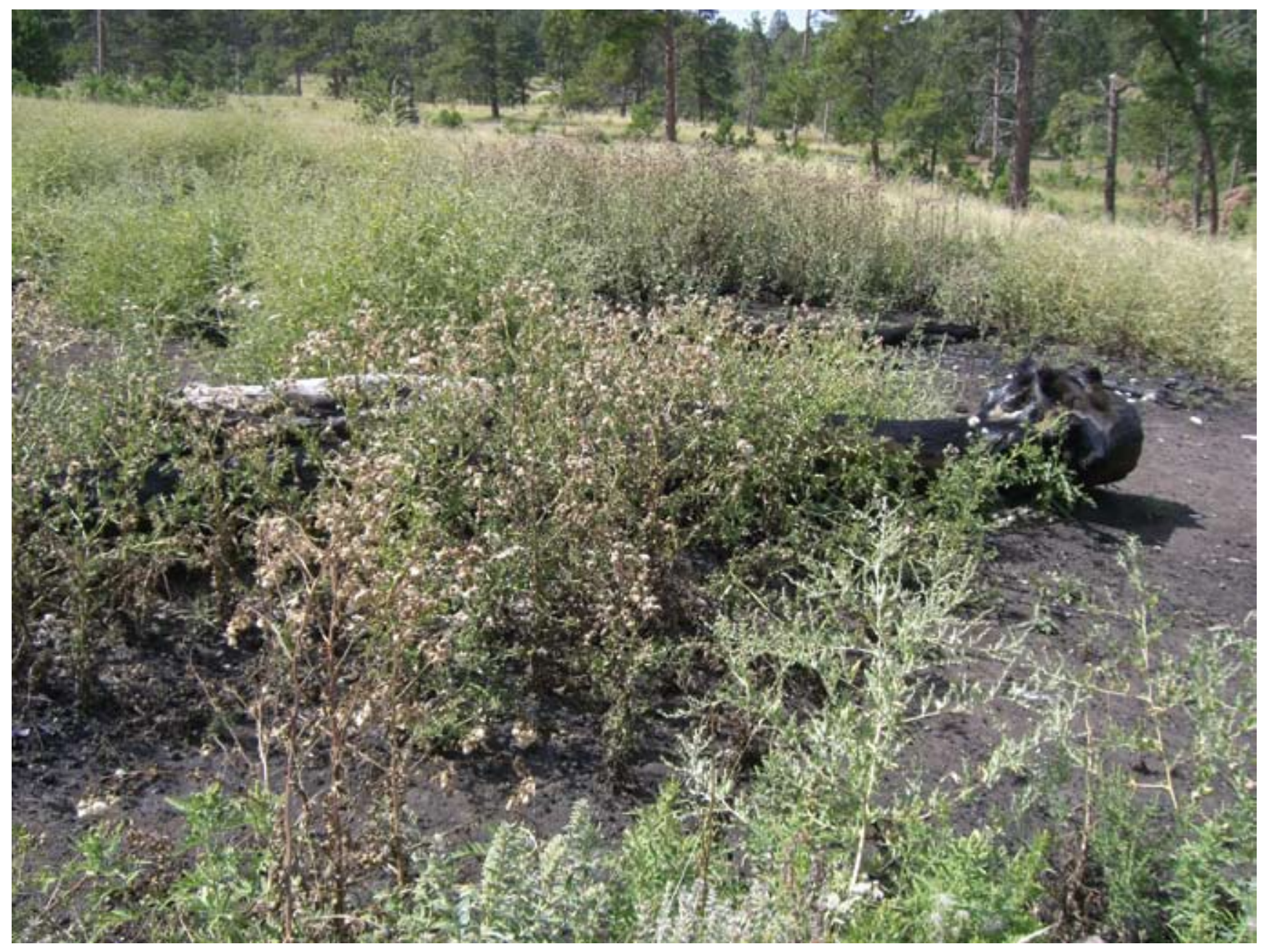

Figure 4. Burning of piles results in high fire intensity on a small scale and the resultant severe fire effects can encourage establishment of invasive species. In the Black Hills, it is common for Cirsium arvense to establish in burn pile scars. Photo credit: Molly Hunter.

\section{Non-native Plants}

Non-native, invasive plants are often well-adapted to disturbance, and establish rapidly in recently disturbed areas. High intensity disturbance events in particular promote establishment of invasive plants. Thus, severe wildfires in ponderosa pine forests create ample opportunities for establishment of non-native invasive plants (Crawford and others 2001; Hobbs and Huenneke 1992; Hunter and others 2006; Keeley and others 2003) (fig. 4). Since native plants are often not well-adapted to such high intensity disturbance, recovery of these species may be slow. With the absence of potentially competing native plants, non-native invasive plants may more readily become permanently established. If invasive plants become well-established, they may prevent reestablishment of native species and ultimately reducing biodiversity.

\section{Community and Fire-fighter Safety}

The severe wildfires commonly seen in ponderosa pine landscapes often burn as crown fires with high flame lengths. These conditions preclude direct fire suppression. Such fires need to be fought using equipment such as planes and dozers, making them considerably more costly to suppress than low-intensity surface fires (Snider and others 2003). These fires are also inherently more dangerous and pose greater threats to firefighters and communities than low intensity fires.

\section{Insect and Disease Outbreaks}

Insects and pathogens are natural components of forest ecosystems where they play many roles-some are able to damage or kill trees. The distribution, abundance, and community composition of these pests commonly 
depend on the structure of the stands within the forest landscape and the condition of the trees within these stands. Under endemic conditions, they affect single or small groups of individuals, helping to sustain succession, nutrient cycling, energy flows, biodiversity, and other ecosystem processes. At other times, however, these pests erupt into outbreaks that kill thousands of trees over vast areas, lasting several years, and impacting aesthetic values, water production, recreation, timber production, wildlife habitat, and other valuable resources.

Severe wildfires can impact the potential for insect and disease outbreaks. High intensity fires are more likely to damage overstory trees, which makes them more susceptible to bark beetle attack (Wallin and others 2003). Fire seldom eliminates root disease pathogens from a site, but it can reduce woody substrates that support pathogen growth and/or shift stand composition toward more disease tolerant seral species. Fire can also create scars on the boles of surviving trees, impact tree health, stimulate germination of heat resistant spores (for example, Rhizina root disease), or otherwise change conditions to increase diseases.

The current forest structure resultant from the altered fire regime can have detrimental consequences for other ecological processes (fig. 5). Several studies have attempted to describe conditions preferred by various insect pests and thus conducive to insect outbreaks (Furniss 1965; Negron and Popp 2004; Reynolds and Holsten 1996; Rudinsky 1966). One product of this research has been infestation hazard models. These models commonly show that infestations are associated with such factors as basal area, stand density, age, stem diameter, the sequential or concurrent presence of other disturbance agents (for example, root diseases; Lessard and others 1985), dwarf mistletoe (McCambridge and others 1982), and other variables. What triggers such outbreaks has been a source of speculation by generations of entomologists and pathologists. However, it is fairly clear that exclusion of fire in forest ecosystems is one such trigger. In locations where fire has been excluded and stands become overstocked or stand composition shifts toward shade-tolerant species, or both, root diseases often increase (Hansen and Goheen 2000; Otrosina and Ferrell 1995). Additionally, homogenous forest structure may cause insect outbreaks to be more synchronous across the landscape (Kaufmann and others 2000; Lundquist and Negron 2000; Schmid and Mata 1996; Swetnam and Lynch 1993).

\section{Biodiversity and Forage Production}

Increased canopy cover and duff accumulations limit opportunities for establishment and growth of plant species in the forest understory, which in turn, has negative impacts on both forage production and biodiversity (Alexander 1987; Keane and others 2002; Laughlin and others 2004, 2005; Severson and Uresk 1988; Uresk and Severson 1988). By some estimates, the increase in forest canopy cover throughout the $20^{\text {th }}$ century has led to as much as a 92 percent reduction in forage production in some pine stands in Arizona. Forests with high tree density may also reduce habitat quality for wildlife species adapted to forest openings and stands with large trees and snags (Dahms and Geils 1997). Some aspects of the altered forest structure may also negatively impact threatened and endangered species such as the Mexican spotted owl, northern goshawk, and Pawnee montane skipper (Colorado State Forest Service 2004; Reynolds and others 1996; Sheppard and Farnsworth 1997). Furthermore, many species of wildlife and plants are adapted to a variety of forest structural stages, from forest openings to forests with dense canopy cover (Anderson 1994). Thus, landscapes that contain a diverse mosaic of structural stages tend to support more species of birds and mammals than landscapes that are more homogenous (Finch and others 1997; Keane and others 2002). 


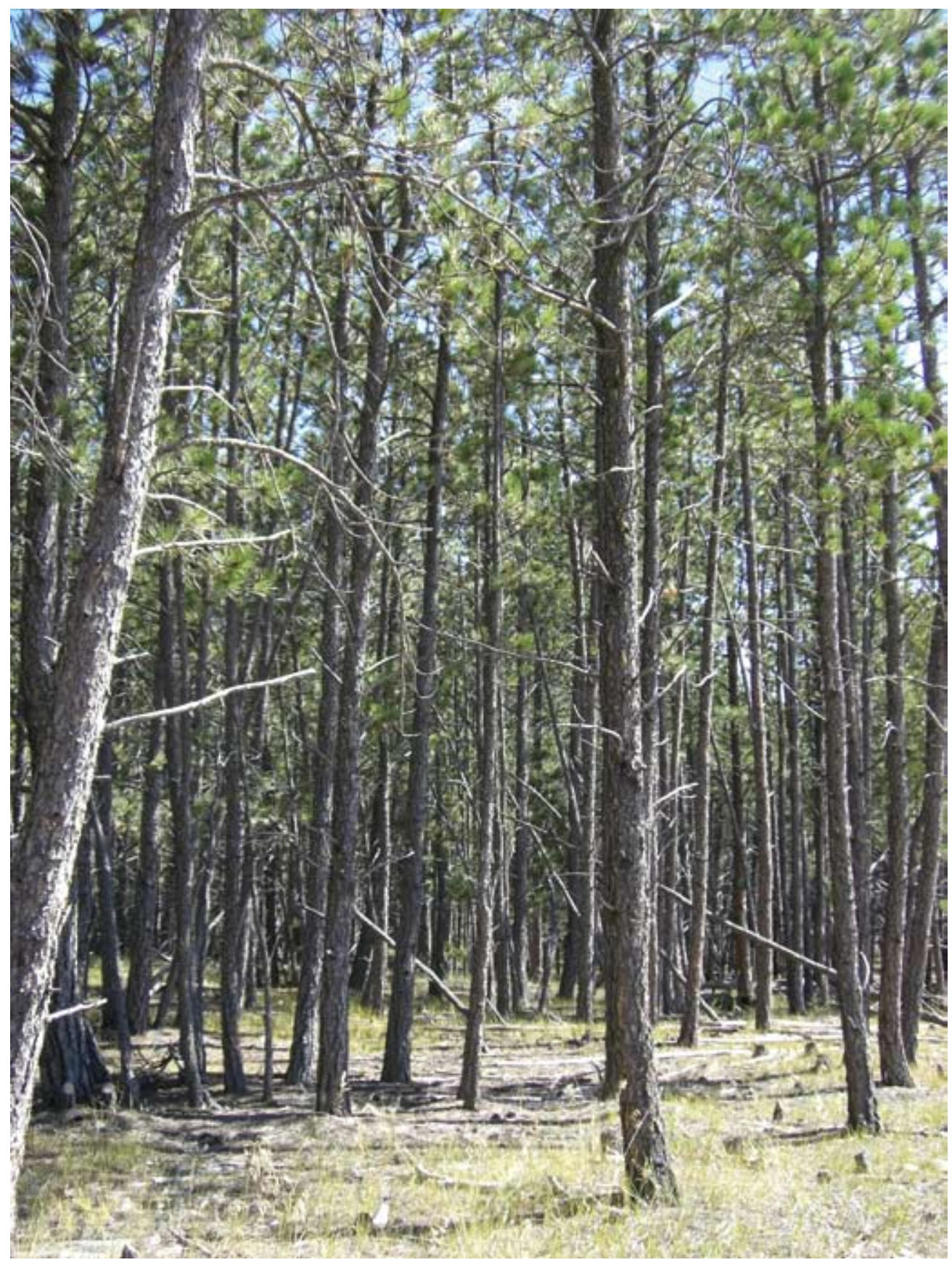

Figure 5. Example of overly stocked, homogenous forest in the Black Hills National Forest. This type of forest structure can have negative consequences for a variety of ecological attributes including hydrology, insect and disease outbreaks, and wildfire hazard. Photo credit: Molly Hunter. 


\section{Section III:}

\section{Fuel Treatment Objectives}

$\mathrm{T}$ The goal of any fuel treatment project is to alter fuels to reduce the potential for catastrophic wildfire spread. Depending on the objective, this can be achieved by practices that reduce fuel loading, continuity, and depth. While wildfire hazard reduction is a valid goal, agencies are also charged with meeting many other resource management objectives, such as wildlife habitat improvement and maintenance of species diversity. Restoring landscapes to conditions present prior to major disruptions by Euro-Americans may best meet these goals. For example, conditions under which the large variety of plants and animals found in ponderosa pine forests have evolved and adapted. In some cases, goals of forest restoration can be conducive with reducing wildfire hazard, especially for areas that historically burned with frequent low-severity fire regimes. However, where mixed-severity fire regimes were the norm, restoration may result in moderately dense forests with the potential to burn with high intensity on a small scale. The needs of reduced fire hazard may have to be balanced against the needs for restoration in such cases. However, other resource management objectives may still be met by altering fuel treatment prescriptions. Treatments that are multifaceted and consider many resource management objectives, along with fuel reduction, are likely more sustainable in the long term.

\section{Reduced Wildfire Hazard}

Wildfire hazard can be thought of as the potential fire behavior and effects based on existing fuel condition. Reduced wildfire hazard is the primary goal of forest fuel reduction treatments. In order to effectively achieve this goal, fuel treatments need to address needs at both local and landscape scales with attention to requirements for long-term sustained management. On the stand level, prescriptions need to be designed to reduce the potential for initiation of active crown fires. On the landscape scale, fuel treatments need to be strategically placed to protect values at risk from catastrophic fire. Long-term planning must take into account sustained management so that treatments maintain their effectiveness over time. In all cases, the goal is to reduce wildfire hazard, not to eliminate fire altogether. The degree of reduction that can be achieved requires consideration of a variety of factors and ecosystem values.

On the stand level, reduced fire hazard is accomplished through reductions in surface, ladder, and canopy fuels. Surface fuels include litter, duff, and woody debris that lie on the soil surface, as well as standing grasses, forbs, shrubs, and small trees. High fuel loading contributes to the potential for high intensity surface fire that can, in turn, have adverse effects on soil and vegetation through elimination of protective organic matter, and heat damage to soil organisms, roots and stems. Ladder fuels include large woody debris, large shrubs, small trees, and lower branches on large trees, all of which act to carry fire from the surface up into the canopy of trees, otherwise known as passive crown fire (Agee and Skinner 2005; Brown and others 2004). Canopy fuels include branches, leaves, and other materials that are in the forest canopy. Canopy bulk density, or the mass of material in a given volume of canopy space, contributes directly to the potential for fire to spread from tree canopy to tree canopy, otherwise known as active crown fire spread (Agee and Skinner 2005). To reduce wildfire hazard at the stand level, fuels need to be manipulated to reduce the potential for initiation of both active and undesired passive crown fire behavior. The appropriate level of hazard reduction will vary with any given treatment. Many have used the general rule of altering fuels such that surface fire is promoted under 90 percent fire weather conditions. A number of treatments are available that can be used to reduce loading of surface, ladder, and canopy fuels (see Section IV-Treatment Techniques) and thus, affect fire behavior.

Even though most fuel treatments occur on a stand level, it is important to consider each treatment in a landscape context, especially since many current wildfires dwarf the size of individual fuel treatment projects and cross jurisdictional boundaries (Sisk and others 2004). Placement of fuel treatments on every square inch of ponderosa pine landscapes will never be feasible nor would it be desirable given other resource management needs. Strategies for fuel treatment placement should be designed to maximize benefit gained from treatments in terms of meeting goals of reduced wildfire hazard. Not 
every acre requires treatment to effectively reduce the potential for severe wildfire spread. Researchers have modeled fire growth under different fuel treatment scenarios to determine how fuel treatments can be optimally placed to reduce fire spread. Results show that separate treatments that overlap slightly in the heading fire direction can reduce overall rate of fire spread (Finney 2001). Placement of linear fuel breaks in strategic locations (for example, ridgetops) has also been proposed to break up fuel continuity and aid in fire suppression tactics (Agee and others 2000).

Management of landscapes does not end with the initial implementation of strategically-placed fuel treatments across the landscape. Long-term planning is needed to ensure that the effectiveness of treatments is maintained. For example, prescribed fires are shown to reduce the severity of wildfires for up to 4 years in Arizona and New Mexico (Ffolliott and Guertin 1988; Finney and others 2005; Omi and others 2005) and 6 years in Colorado (Omi and others 2005). Once initial fuel treatments have sufficiently reduced fuel loads to promote low intensity fire, maintenance of low fuel loads should then be accomplished with repeated fuel treatments. The frequency of maintenance treatments will vary by region and can be determined by the historical fire frequency or rates of fuel accumulation. For example, it is recommended that maintenance treatments be conducted every 3 to 10 years in the Southwest where fires historically occurred with high frequency (Allen and others 1968; Biswell and others 1973; Harrington and Sackett 1990; Sackett and others 1996). This is also consistent with the rates of accumulation of surface fuels in this region (Ffolliott and others 1977; Ffolliott and Guertin 1988). In the Black Hills and Front Range where fire was historically less frequent, maintenance treatments occur at longer intervals. In the Black Hills, maintenance treatments are recommended every 15 to 25 years in the lower elevation forests (Bachelet and others 2000). In the Front Range, maintenance treatments should be conducted in intervals of 3 to 20 years or more depending on location and elevation (City of Boulder 1999; Kaufmann and others 2005). Tree seedling establishment and crown growth rates vary with locality, site conditions, and associate vegetation and may require modification of these maintenance treatment intervals.

\section{Restoration}

Restoring forests to their historical structure and reintroducing important ecological processes, such as fire, should promote viability of species that evolved under the historical forest conditions (Allen and others 2002; Brown and others 2004; Landres and others 1999; Swetnam and others 1999). Since pre-settlement ponderosa pine forests in the Southwest, Front Range, and Black Hills generally burned under low- to mixedseverity fire regimes, restoring historical forest structure should reduce the potential for large-scale crown fires (Allen and others 2002; Brown and others 2000; Brown and others 2001a; Fiedler and Keegan 2003; Fule and others 2001; Kaufmann and others 2003; Wienk and others 2004). However, adhering to strict restoration objectives will not result in reduced wildfire hazard in all stands since some ponderosa pine forests historically burned with infrequent fires of high severity (Baker and others 2007). Pre-Euro-American settlement forest structure provides a useful reference for thinning targets (Landres and others 1999), but there are limitations in the use of historical data since site specific information is often not available (Landres and others 1999; Swetnam and others 1999). However, there is general knowledge of the range of variability in historical forest structure and disturbance processes and this can be considered when planning site-specific fuels treatment activities.

Restoration projects at the stand level should attempt to mimic historical stand conditions in terms of tree density, tree age and size distribution, tree species composition, and spatial pattern (Allen and others 2002; Kaufmann and others 2003; Moore and others 1999). Since these conditions likely varied across the landscape, care should be taken to consider that variability and use local historical data when available. Managers should also consider other important historical components of stands, such as understory species and wildlife. Restoration involves much more than returning historical forest structure. For example, historical processes also require attention. Thus, dominant disturbance processes such as fire also need to be returned to the system in a manner that reflects historical disturbance regimes (Allen and others 2002; Moore and others 1999).

To approach historical conditions on a landscape level, managers should attempt to achieve the spatial heterogeneity in forest structures that were evident in the past. Although ponderosa pine forests in these regions, on the whole, have higher fuel loadings today, these forests did not historically exhibit homogenous structure on the landscape scale. In the Southwest, landscapes were likely composed of a mosaic of meadows, savannahlike forests with low tree density interspersed with more dense forests with higher canopy cover (Savage 1991). In the Front Range, forests were composed of a mixture of persistent old growth, openings, and dense stands (Kaufmann and others 2001). The Black Hills historically exhibited similar heterogeneity in forest structure 
(Parrish and others 1996). The variety of species of plants and wildlife found in these ponderosa pine forests were probably adapted to a wide range of forest structures (Finch and others 1997; Keane and others 2002). To maintain diverse wildlife and plant habitat, managers should strive to create habitat diversity across the landscape within the bounds of the historical range of variability in forest structure. This can be achieved by designing different treatment prescriptions (including no treatment) that result in structural and spatial patterns across the landscape that are consistent with historical conditions.

\section{Commercial Revenue}

Although commercial timber production can be obtained from silviculture treatments designed for restoration or hazardous fuel reduction, it is not the primary goal of these treatments. Maximizing commercial revenue is often contrary to wildfire hazard reduction and other resource management objectives (Allen and others 2002; Arno and Fiedler 2005; Brown and others 2004; Covington and others 1997; Graham and others 1999). This does not mean that cutting large fire-resistant trees should never be done. In some cases, larger, commercially viable trees need to be removed in order to create openings or to reduce canopy bulk density to levels that would significantly reduce the probability of active crown fire spread (Arno and Fiedler 2005; Hollenstein and others 2001; Lynch and others 2000; Scott 1998). The revenue gained from commercially viable trees in these cases can then be used to offset the cost of removing non-commercial trees and slash. Any silviculture treatment that reduces crown bulk density and surface or ladder fuels will have some effect on mitigating fire behavior. However, overstory removal and individual tree selection cuts that do not remove excess small- and intermediate-sized trees have previously been reported as ineffective in reducing the potential for extreme fire behavior (Graham and others 1999; Martinson and Omi 2003; Scott 1998; Stephens and Mogahaddas 2005a).

There is some potential to use conventionally nonmerchantable material (small trees, tree tops, branches, and shrubs) for bioenergy or other wood products such as particle board or paper (Graham and others 1998; Harrison 1975; Hollenstein and others 2001; Le VanGreen and Livingston 2003). With careful planning, development of a sustainable long-term biomass harvest cycle may be compatible with decreasing wildfire hazard while maintaining ecological integrity (Hollenstein and others 2001). However, selling biomass for energy is often not economically feasible when other sources of energy are inexpensive, processing plants are scarce, and access to biomass is restricted (Stokes 1992). Biomass heaters have been successfully used on a small scale in buildings at the Community College of Santa Fe, NM, and in Boulder County, CO. Chipped material can also be sold for garden mulch, but again the economical feasibility of this depends on available markets (USDA Forest Service 2003c).

\section{Other Objectives}

A host of other resource management objectives can be met with fuel management treatments. For example, fuel treatments can be used to increase forage or shrub production and nutritional quality important for a variety of wildlife species and domesticated animals (Harris and Covington 1983; Sieg and Severson 1996; Sieg and Wright 1996). Prescribed fire has been used to improve grass quality and quantity in the Southwest and Front Range (Biswell and others 1973), and to encourage shrub resprouting of mountain mahogany in the Front Range and bur oak in the Black Hills (Harper and others 1985; Sieg and Severson 1996). Fuel treatments can also be used to control outbreaks of insects and diseases. Heavier thinning targets have been justified in areas severely infested by dwarf mistletoe (Heidmann 1968; Myers 1974) and mountain pine beetle (McCambridge and Stevens 1982). Fuel treatments have been used to increase water yield from watersheds. Heavy cutting of trees in patches or strips have been justified for this purpose (Ffolliott and Malchus 2001; Orr 1975).

\section{Summary}

In concluding this section, we remind readers that forest ecosystems are not static, but dynamic systems that are constantly changing. Realistically, forests are populations of living organisms where new seedlings are constantly establishing, old trees are dying, and all trees are increasing in biomass through time. Management activities that alter the numbers, sizes, and species of trees on a site will have consequences in terms of resource allocation and the population dynamics of all organisms using the site. For example, a standard fuels treatment is a thinning from below to remove ladder fuels and reduce crown bulk density. This closely approximates the seed cut of a two-step shelterwood harvest where the objective is to open the forest canopy and provide a seed source to establish a new even-aged forest. We must therefore expect abundant natural regeneration to establish following the initial entry and be prepared to 
periodically re-treat the stand to keep the seedlings from growing into ladder fuels. We must also consider the remaining overstory trees. Although they are likely to live many decades, they will eventually die and require replacement to maintain the desired forest structure. In the long term, we must therefore balance the need for reducing wildfire risk with the need to maintain a healthy viable population of trees along with other resource considerations. 


\section{Section IV:}

\section{Fuel Treatment Techniques}

\section{Developing Landscape-wide Fuel Treatment Strategies}

E ven though most fuel treatments occur on a stand level, it is important to consider each treatment in a landscape context, especially since wildfires commonly dwarf in size individual fuel treatment projects (Sisk and others 2004). Historically, the primary scale of forest structural variation may have been broad and driven by landscape-level fire effects. Structural variation in contemporary forests exists at the stand level due to harvests and other management activities including fire exclusion (Hudak and others 2006). Historical ponderosa pine forests were seldom homogeneous in structure (Savage 1991). Thus, managers should strive to achieve greater landscape heterogeneity within the bounds of the historical range of variability in forest structure. Yet, landscape scale fuel management and restoration treatments have been slow to develop (Miller and others 2000). A highly heterogeneous landscape is associated with many desirable resource conditions, but achieving and sustaining this condition requires an understanding of the spatial dynamics of the factors that structure the environment. These include adequate tools to make good decisions about managing these factors, and a management philosophy that incorporates the long term and large scale (Lundquist 2005). Recently, much effort has been spent on developing landscape scale spatially explicit fuel distributions (for example, Reich and others 2004) and fire spread models, socioeconomic perceptual models of people affected by disturbances (for example, Flint 2006), and long-term impacts on functions and structure of landscapes (Keane and others 2006).

Diseases, insects, and other biotic and abiotic factors influence fire regimes, singly or in combination, sequentially or concurrently. Different biotic disturbances, for instance, commonly cause characteristic patterns of mortality and stand structure across the forest landscape that, in turn, change ignition potential, rate and direction of spread, and intensity of wildfires. The relative importance of different disturbance agents would probably vary among stands and/or landscapes. Wildfires, in turn, change a forest landscape in ways that often influence the occurrence, distribution, and epidemiology of forest diseases, insect pests, and other small-scale disturbances. This reciprocal relationship is well recognized, but is not well-studied primarily because quantitative tools to characterize such interactions are lacking. Ecological surprises arise when these events interact with other perturbations or agents. Understanding the role of compound disturbances is imperative, yet little research exists on this topic (Paine and others 1998).

\section{Models Used to Derive Landscape Strategies}

Several tools are available to help managers derive strategies for achieving maximum benefit for fuel treatments. One such approach is the Forest Ecological Restoration Analysis (ForestERA) project implemented by researchers at Northern Arizona University (Sisk and others 2004). In a pilot project conducted in northern Arizona, the researchers have amassed GIS spatial data layers that include vegetation composition, canopy cover, basal area, stem density, elevation, historical fires, ignition points, invasive plant locations, hydrology, and soil characteristics. These layers are used to develop models that predict risks (for example, fire risk, watershed effects, invasive plants) and values (for example, wildlife habitat, wilderness, recreation, and infrastructure) on the forested landscape. A framework is then developed where landscape scale objectives and criteria for meeting objectives are defined, and then through an iterative modeling process, fuel treatment locations are optimized across the landscape to maximize protection of values at risk while achieving management objectives.

The Wildfire Alternatives (WALTER) project is an approach developed at the University of Arizona and currently has assessments available for the Santa Catalina Mountains, Chiricahua Mountains, Huachuca Mountains in Arizona, and the Jemez Mountains in northern New Mexico (University of Arizona 2002). This model assesses fire risk across these landscapes based on climate, fire history, vegetation, fuels, and societal values. WALTER allows managers to assess fire risk in these landscapes under different climatic scenarios, making it useful for developing strategies for optimizing placement of fuel treatments across a landscape. 


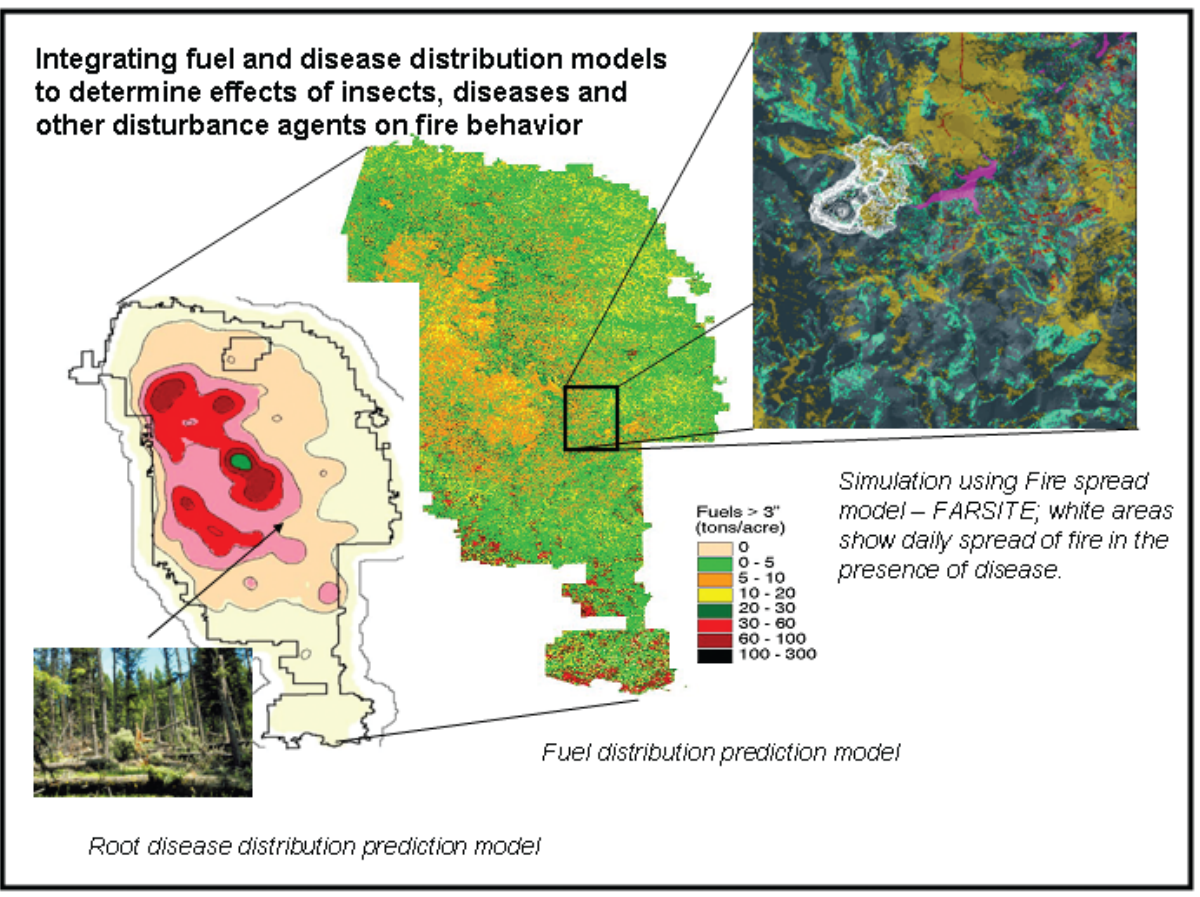

Figure 6. An example of how structural equation modeling can be used to measure the relative importance of individual agents (for example, insects and diseases) as drivers of wildfire. The effects of fuel generating disturbances are modeled and the predicted results can be used in a fire spread model.

While the above approaches are currently only available for specific landscapes in the Southwest, another approach currently in progress in southern New Mexico uses spatial data layers developed from the LANDFIRE project. While the data developed in LANDFIRE is less detailed than in the previous two examples, it will eventually be available for all of North America, making this process easily adapted to landscapes in other regions. The LANDFIRE project uses biophysical settings and simulation modeling to describe historical successional vegetation classes and estimates the proportion of the landscape that historically existed in each succession class. Simulation modeling, satellite imagery, and other tools are then used to determine existing vegetation and departure from historical conditions. With this process, GIS spatial data layers are developed that can be directly imported into FARSITE and FlamMap, allowing one to evaluate potential fire behavior and spread patterns. The data are easily accessible on the LANDFIRE website (www.landfire.gov).

Managers and researchers on the Gila National Forest have used LANDFIRE data and spatial data locating values at risk, including wildland urban interface and threatened and endangered species habitat, to develop strategies for placing fuel treatments across the landscape. Fuel treatment placement is prioritized adjacent to values at risk (for example, wildland urban interface, Mexican spotted owl habitat) to minimize the threat of damage from severe wildfire in areas where fuel hazard is greatest. Factors such as prevailing wind, dominant slope, and fuel condition, along with models like
FlamMap and FARSITE, are considered to determine the likelihood of severe fire occurrence and spread in any given area. An imperative component of this process is the inclusion of land managers that have worked in the area for a long time and are able to evaluate the accuracy of the LANDFIRE data and output from models like FlamMap and FARSITE based on their experience in, and knowledge of, fire behavior in the region.

Lundquist (in press) developed a method of measuring the relative importance of individual agents as drivers of wildfire using structural equation modeling when compound disturbances occur together in the landscape. The method was able to separate out the individual impacts of various agents acting concurrently. The method developed by Lundquist would certainly be able to identify the most important factors affecting the ecosystem, which might be the type of information needed to prioritize fire and fuel treatments (fig. 6).

\section{Prescribed Fire Techniques}

Differing levels of fire intensity may be desirable in a prescribed fire depending on the amount and type of fuel targeted for reduction and different secondary resource objectives that may be considered (DeBano and others 1998). Fire intensity can be controlled partly by environmental conditions in the prescription window. For example, higher fire intensity can be expected when fuel moisture is low, temperature is high, and winds are strong (Pyne and others 1996). Fire intensity can also be controlled through ignition techniques and firing patterns. 


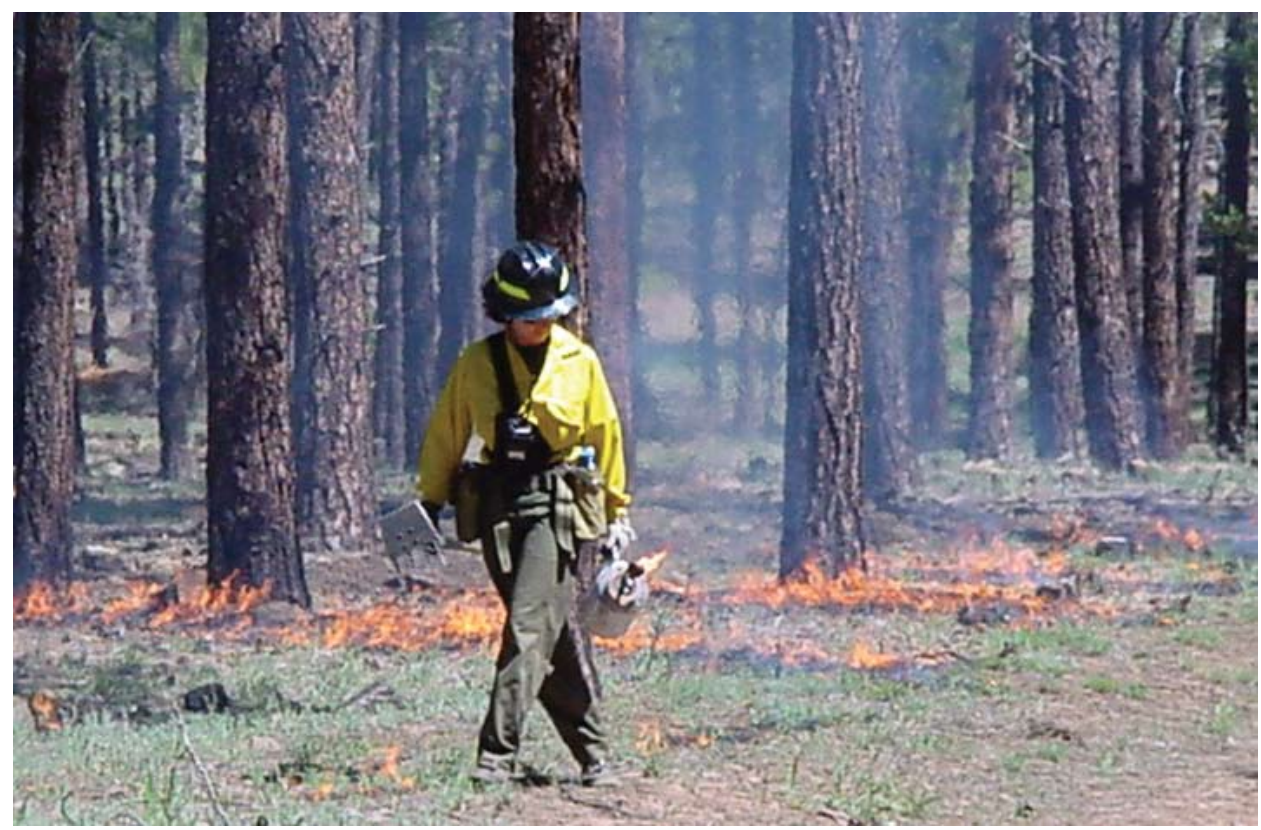

Figure 7. Low intensity prescribed fire consuming litter, duff, and woody debris. Photo credit: Paul Summerfelt.

\section{Low Intensity Prescribed Fire}

Low intensity prescribed fire can be used to reduce the potential for severe fire spread by reducing fuel loads, particularly for surface fuels, including litter, duff, and woody debris (Bastain 2001; Biswell and others 1973; Cooper 1961; Covington and Sackett 1984; Davis and others 1968; Harrington 1981; Sackett 1980) (fig. 7). They can also be used to consume small tree seedlings to slow development of ladder fuels (Arno and Harrington 1997; Arno and Fiedler 2005; Harrington 1981) (fig. 8) or to scorch the lower limbs of trees and saplings to increase crown base height and reduce the potential for torching of trees (Agee and Skinner 2005; Gaines and others 1958). Reduction in these fuels should reduce the potential for severe wildfire spread (fig. 9).

Low intensity prescribed fire may also be used to reduce unusually large accumulations of surface fuels, such as slash loadings after a thinning operation. However, excessively high fuel loading can promote surface fires of high intensity and undesirable fire effects, particularly on soil resources. Although many managers feel uncomfortable using prescribed fire in these situations, some have used broadcast burns to reduce slash loading within a year of the thinning operation. This can be safely done when larger diameter fuels and duff are sufficiently wet to prevent high intensity fire, but red needles attached to branches will facilitate the rate of fire spread. These fires generally consume only 1 - and 10-hour fuels, limiting fire intensity and damage to trees (Biswell and others 1973; Orozco and Carrillo 199293). Consumption of remaining slash and duff can be achieved with subsequent burns. Managers have been successful in experimentally burning red slash in the summer 2 to 4 days following rain events (Orozco and Carrillo 1992-93). Alternatively, the excess material can be put into piles that can then be burned. This generally carries less risk than broadcast burning, as piles can be burned in the winter when fire risk is lower.

Restoration objectives can be met by using low intensity prescribed fire. In most ponderosa pine forests, low intensity surface fire made up some component of the historical disturbance regime. Thus, returning low intensity fire to the landscape is a vital component of restoration. Fire can be effective in creating diversity in habitat structure on the stand scale (Severson and Rinne 1990) (fig. 10). Returning fire would be important for other ecological processes such as nutrient cycling and understory production (Covington and Sackett 1992; Harris and Covington 1983). The burning cycle conducted by managers should be consistent with the historical range of variability in fire frequency of a site (Arno and Fiedler 2005). Since surface fuels accumulate at relatively rapid rates in southwestern ponderosa pine forests (Ffolliott and others 1977; Ffolliott and Guertin 1988), researchers have recommended burning every 3 to 10 years, consistent with the historical range of variability in fire frequency (Allen and others 1968; Biswell and others 1973; Harrington and Sackett 1990; Sackett and others 1996). However, rates of surface fuel accumulation vary by region. In the Black Hills and Front Range, where natural fire was historically less frequent, prescribed fire can be repeated with longer intervals between fires. Here, conducting low intensity prescribed fire every 15 to 25 years in lower elevation forests is recommended (Bachelet and others 2000). In the Front 

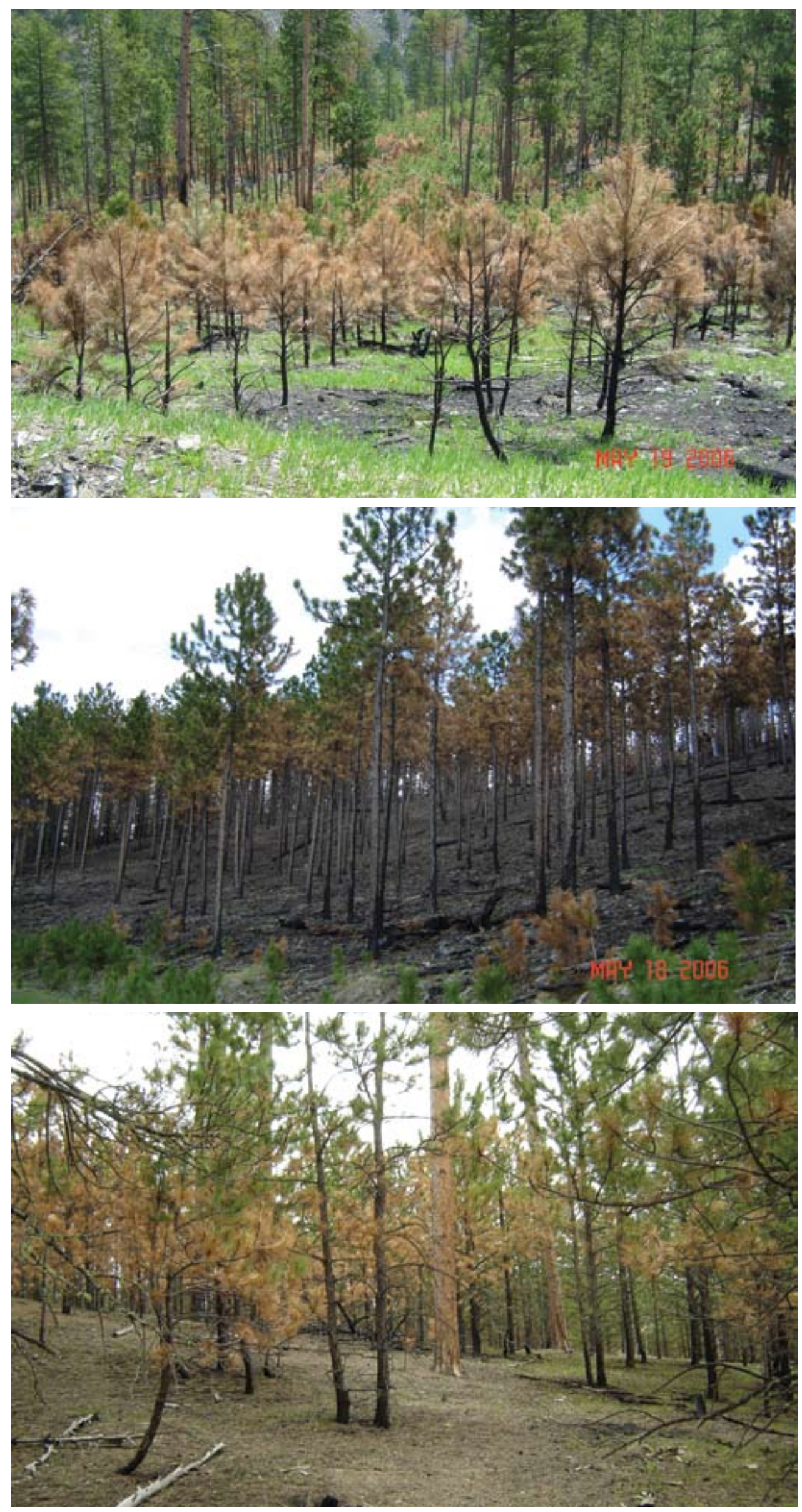

Figure 8. Low intensity prescribed fire kills tree saplings and can therefore slow development of ladder fuels. Photo credit: Mike Battaglia.

Figure 9. Relatively low to moderate intensity prescribed fire consumes the lower limbs of trees and can therefore reduce ladder fuels. Photo credit: Mike Battaglia.

Figure 10. Prescribed fire can be used to create or maintain important wildlife habitat features. In this example, prescribed fire creates habitat by providing openings while maintaining important habitat components such as large trees and woody debris. Photo credit: Mike Battaglia. 


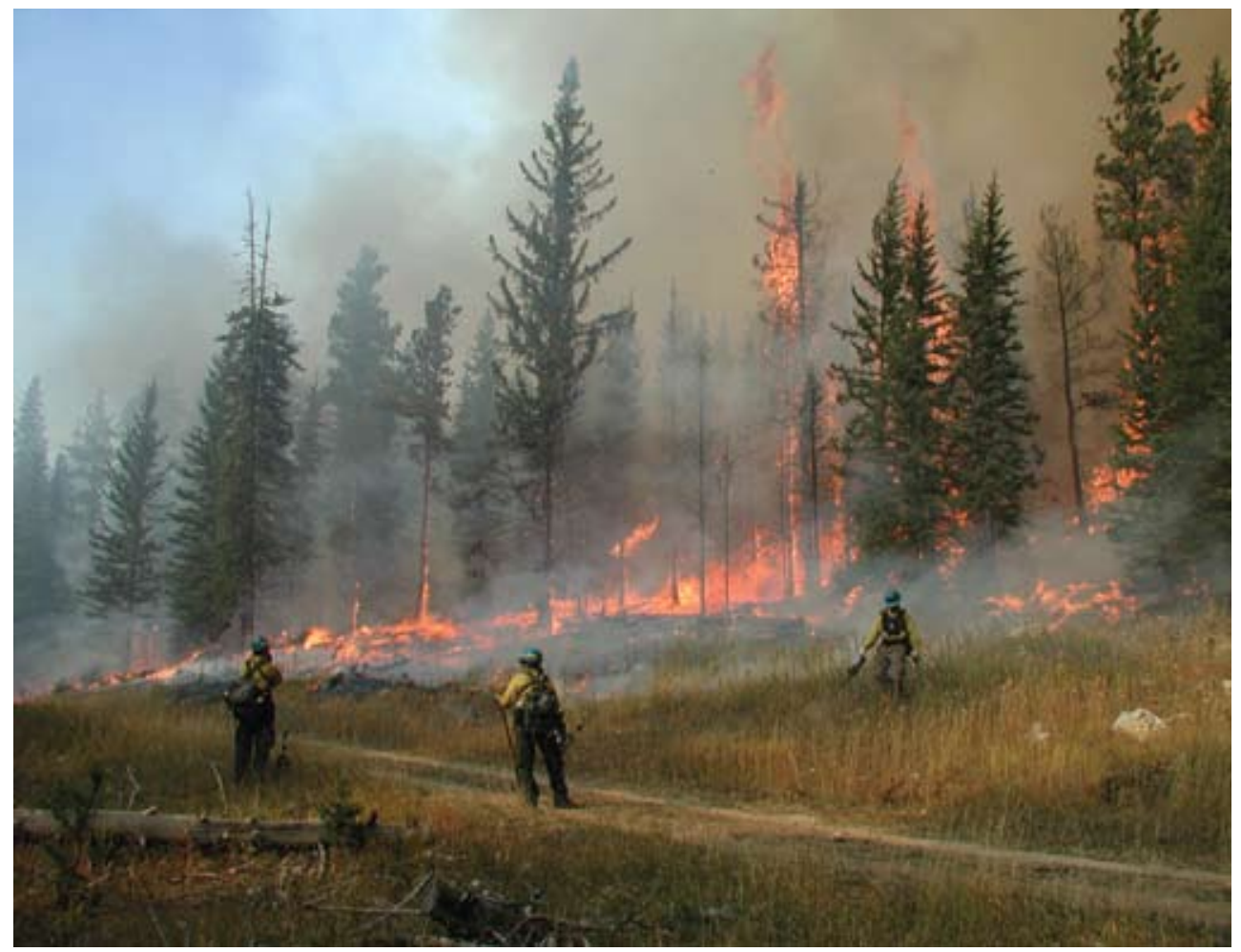

Figure 11. Higher intensity prescribed fire, which exhibits some torching, can be a useful tool for reducing tree density and ladder fuels and creating important wildlife habitat features. Photo credit: Gale Gire.

Range, low intensity prescribed fires are recommended at intervals of 3 to 20 years or more, consistent with the historical fire return interval at various locations and elevations (City of Boulder 1999; Kaufmann and others 2005). Historical fire regime can vary widely within a given region (see tables 1, 3, and 4). This variability should be considered in fuel treatments in order to achieve heterogeneity at the stand and landscape level.

\section{High Intensity Prescribed Fire}

High intensity prescribed fire that often exhibits some torching can be used to reduce the potential for highseverity wildfire spread by reducing ladder and some canopy fuels (Biswell and others 1973; Fule and others 2002a; Fule and others 2004; Harrington and Sackett 1990; Lindenmuth 1960; Morris and Mowat 1958; Woodridge and Weaver 1965) (fig. 11). Prescribed fire treatments with some torching may be appropriate when the use of mechanical equipment to thin trees is not feasible because of limited access or other restrictions (Aplet and Wilmer 2003; DellaSalla and Frost 2001; Fule and others 2002a). Opportunities for use of high intensity prescribed fire may be limited because of the risk of fire escape and the proximity of ponderosa pine forests to population centers in the Southwest, Front Range, and Black Hills. However, use of small-scale $(<5$ acres in size) high intensity fire has been achieved successfully in limited areas including ponderosa pine forests in the Arapaho-Roosevelt, San Juan, Prescott, Santa Fe, and Black Hills National Forests, and Bandelier National Monument. The torching pattern can create forest openings, stands with lower tree density, and increased structural diversity.

High intensity prescribed fire can also be used to meet restoration objectives. Relatively small-scale crown fires were a component of the historical fire regimes in certain ponderosa pine forests in the Front Range and Black Hills (Baker and others 2007; Huckaby and others 2001; Kaufmann and others 2000; Sherriff and Veblen 2007). From a restoration perspective, it may be desirable to duplicate some of this fire behavior and resultant fire effects where possible. High-severity crown fires were likely more common in higher elevation forests and on north-facing aspects where conditions were more mesic (Sherriff and Veblen 2007). The size of patches in these forests that experienced high fire severity is not well understood, but were likely variable in size (Kauffmann and others 2003). Since such events likely occurred with long return intervals and the historical extent of such events is not well understood, using this technique extensively under the guise of restoration is not recommended. Instead, high intensity prescribed fire may be used to a limited extent where feasible to create landscape heterogeneity that would have been more characteristic of historical forests (fig. 12). 

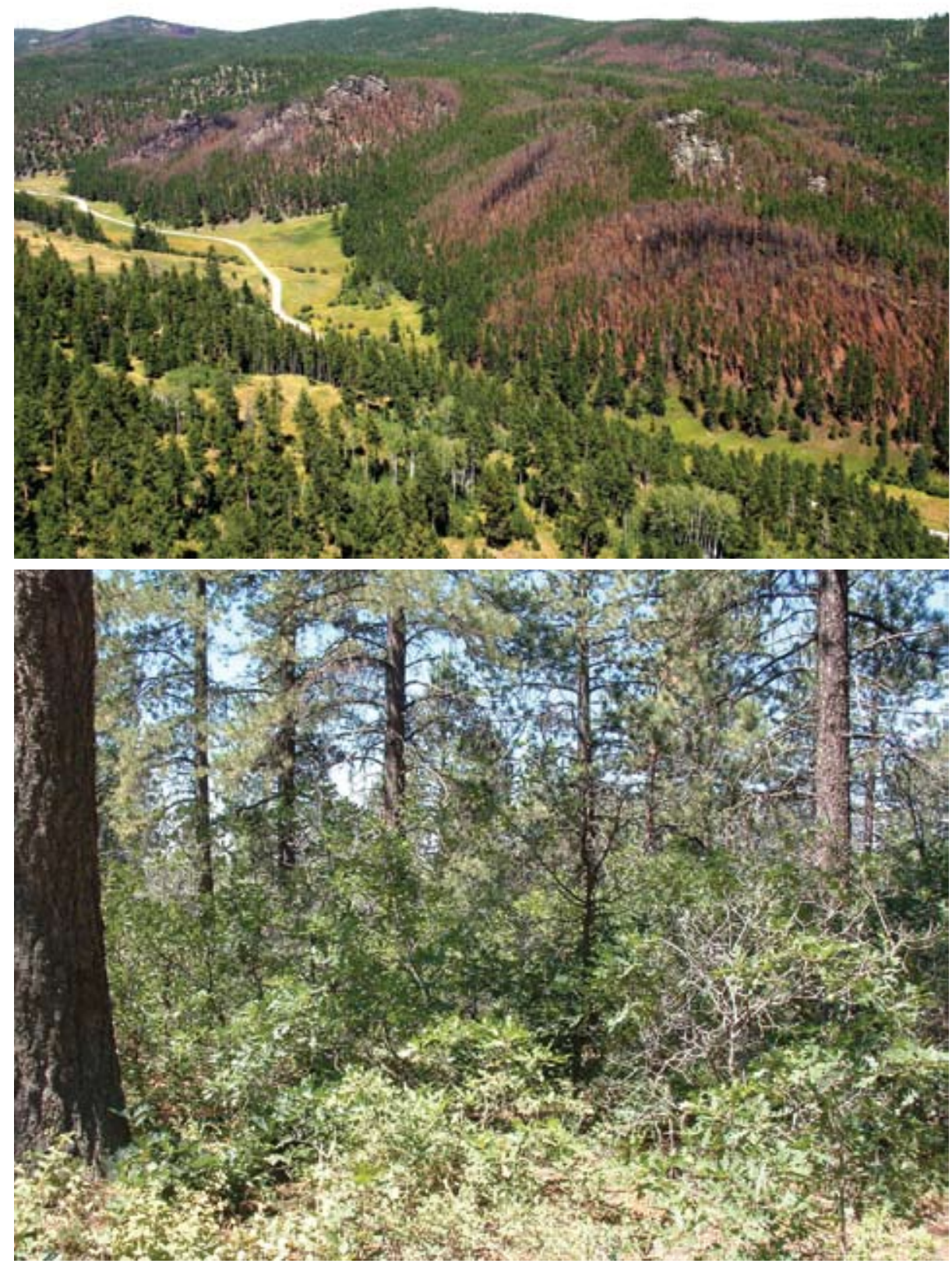

Figure 12. Higher intensity prescribed fire can be used to create a more heterogeneous landscape. Photo credit: Gale Gire.

Figure 13. Gambel oak, particularly in southwestern Colorado, can grow in dense thickets in the understory of ponderosa pine forests creating ladder fuels. Photo credit: Todd Gardiner.
Prescribed fires that exhibit some torching can be used to meet other resource management objectives as well. Such fires may be more effective in reducing dwarf mistletoe infection on trees in the Southwest and Front Range (Alexander and Hawksworth 1976; Conklin and Armstrong 2001). High intensity surface fires may be effective in stimulating sprouting of shrubs that are important browse for wildlife (Bock and Bock 1984; Harrington 1985; Sieg and Wright 1996; Young and Baily 1975). Higher intensity surface fire may also be needed to control dense thickets of Gambel oak in the Southwest that can act as a ladder fuel (Harrington 1985) (fig. 13).

\section{Controlling Fire Intensity}

Prescription window-Fire intensity can be controlled by burning under specific conditions of fuels, weather, and topography, all of which affect fire behavior and make up the prescription window. If lower fire intensity is desired, burns can be conducted when relative humidity and fuel moisture contents are high and wind speeds are low. Burning on a steep slope will result in faster rate of spread and fire intensity compared to burning on a gentle slope. A fire will burn with higher intensity when more heavy fuel is available to burn. Fuel loading or arrangement can be altered through various 


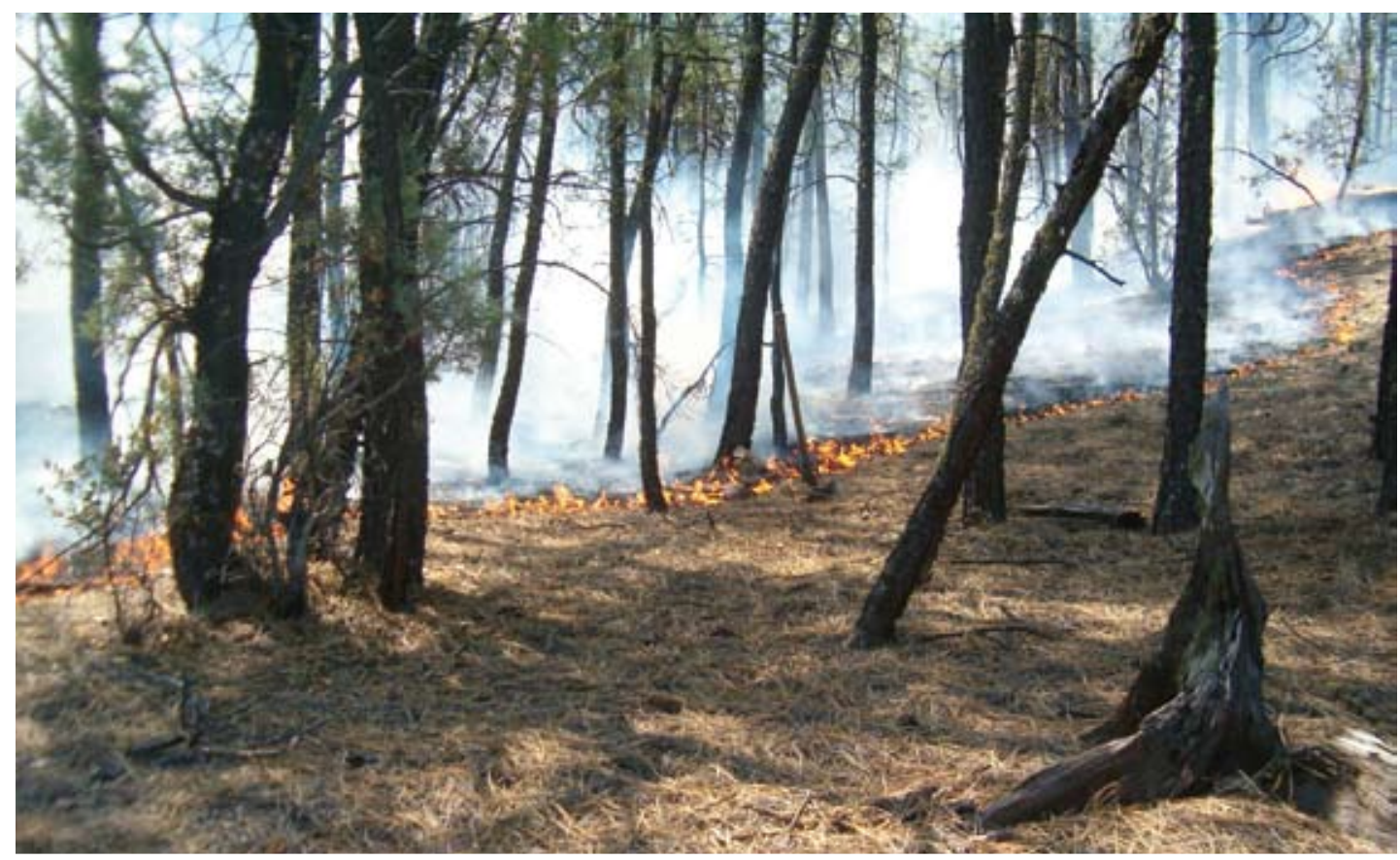

Figure 14. Backing fires tend to move relatively slowly with low flame lengths and tend to result in more complete combustion of surface fuels. Photo credit: Unaweep FUM.

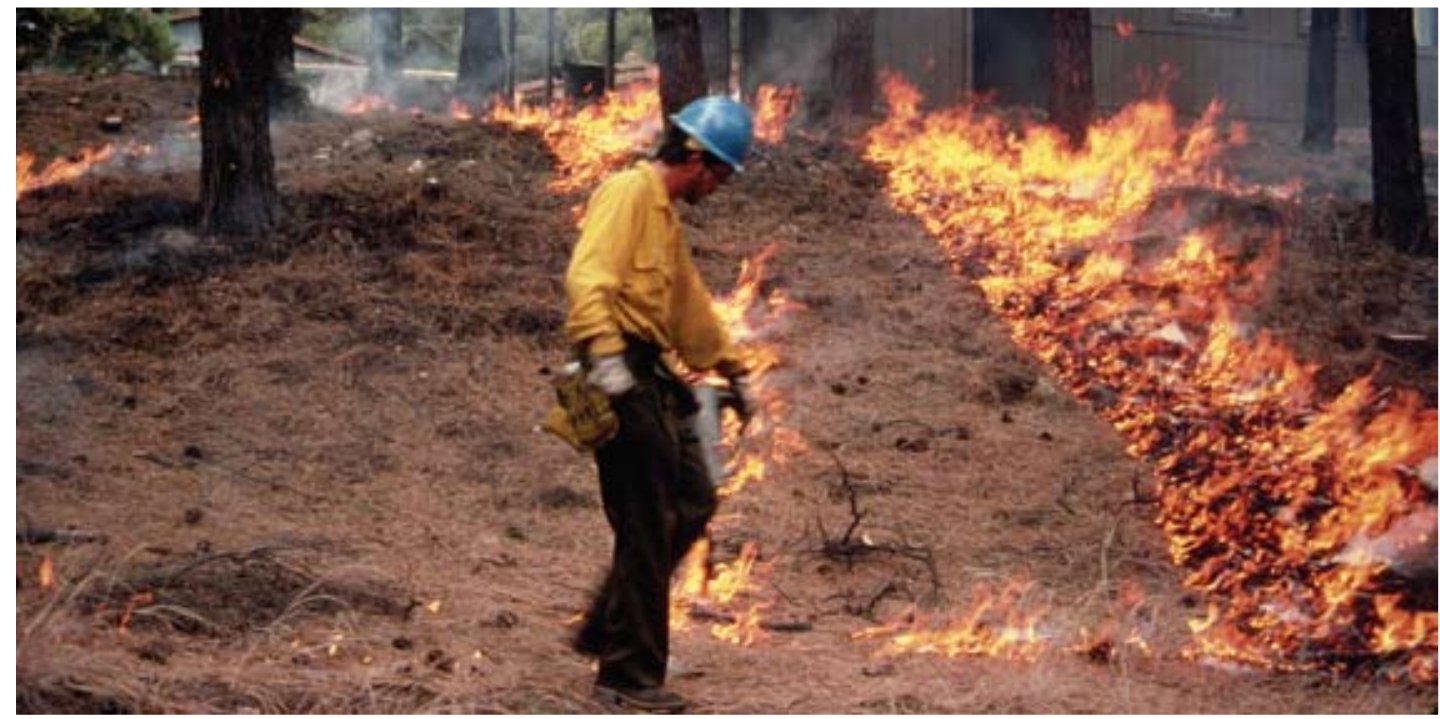

Figure 15. Example of a strip head fire. The rate of spread and intensity depends on the length between strips and type of fuel burning. Photo credit: Paul Summerfelt.

mechanical means (discussed elsewhere in this publication) to achieve desired fuel conditions and subsequent prescribed fire behavior. Less intensive actions can also be taken to alter fuel loading or structure. For example, managers on the Colorado State Forest often hand-remove heavy fuels from selected portions of a burn unit prior to ignition to prevent high fire intensity around sensitive areas (for example, old trees, fire lines, and so forth). This practice is common when managers conduct low intensity fires in open ponderosa pine forests with grassy understories.

Firing patterns and ignition techniques-Fire intensity can also be controlled on the ground through use of alternate firing patterns. Although many patterns are available, the most commonly used patterns are backing fires and strip head fires. Backing fires are set along a fuel break and allowed to spread against the wind or down a moderate slope (Brown and Davis 1973; Chandler and others 1983; Kilgore and Curtis 1987; Pyne and others 1996) (fig. 14). They generally result in a slow moving fire of minimal intensity with more complete combustion of fuels. This technique requires a steady wind and is often not suitable for very steep slopes. Backing fires are not often used exclusively in a project, as it takes a considerable amount of time to burn a large unit using this method. They are more commonly used to create black lines or to burn portions of units where extreme fire behavior poses a threat.

In contrast to backing fires, strip head fires are set so that the flaming front spreads in the direction of the wind or slope (Brown and Davis 1973; Chandler and others 1983) (fig. 15). Typically, a broad fuelbreak is burned at 


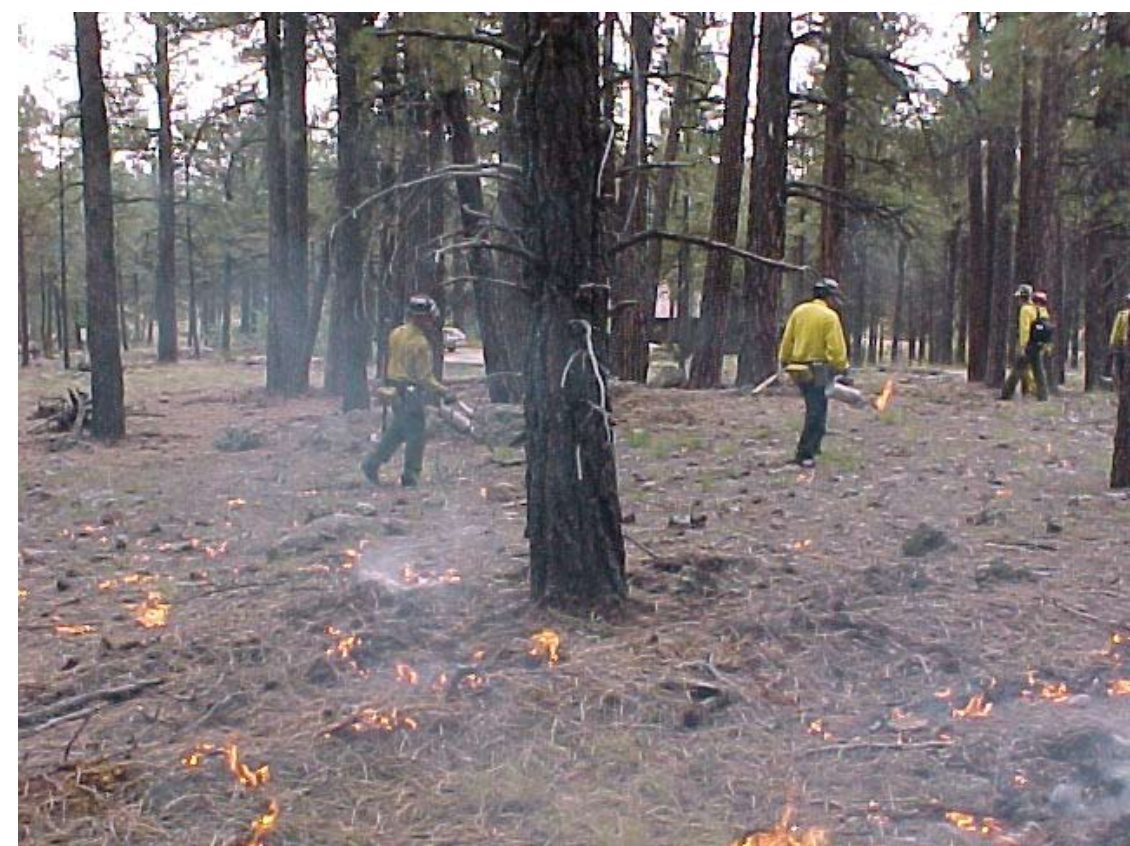

Figure 16. Example of spot firing. Depending on the type of fuel targeted and the number of ignitions, this firing technique can be used to create higher intensity. Photo credit: Paul Summerfelt.

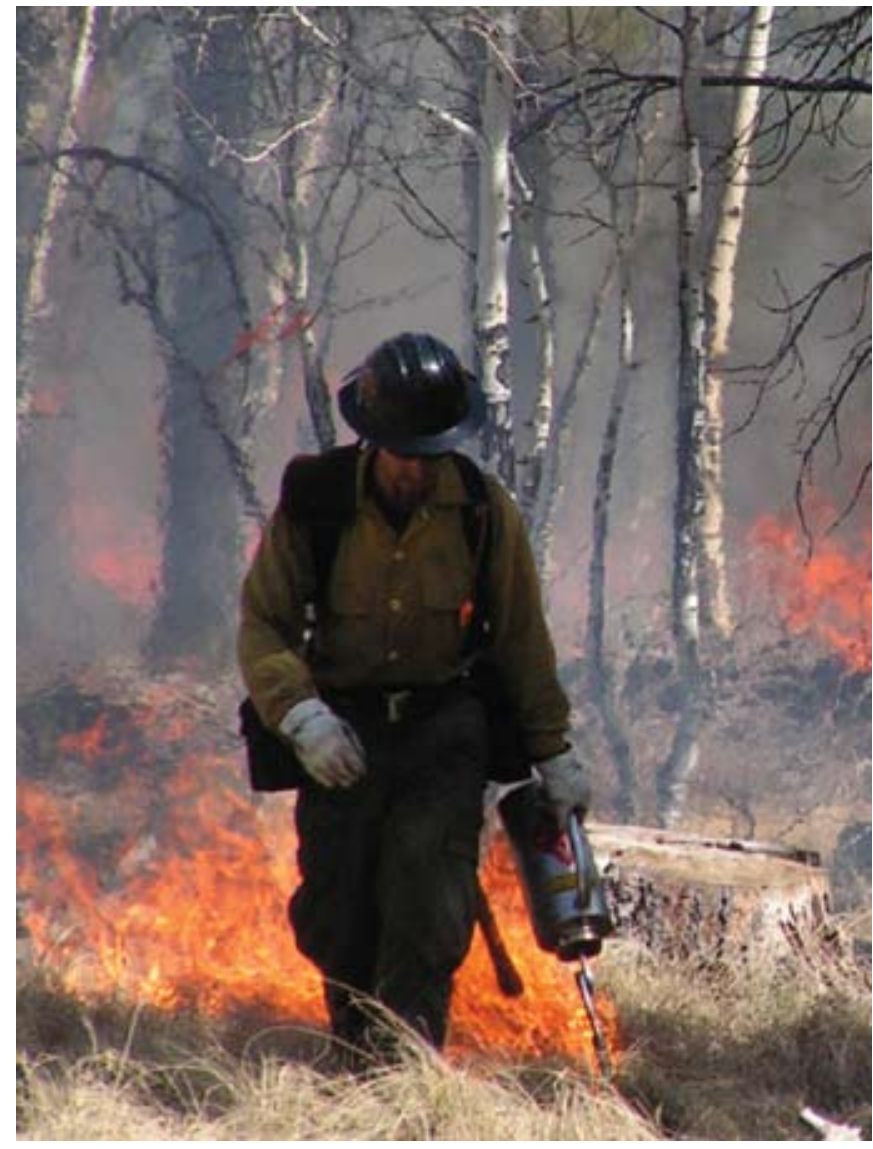

Figure 17. Drip torches can be used for implementing a variety of firing patterns. Photo credit: Mark Roper. the top of the unit before a head fire is set, or a natural firebreak is used as an anchor point. Head fires tend to be very intense and burn with a rapid rate of spread. For more control, head fires can be set in portions (strips). For example, a head fire can be lit somewhere below the fire break at the top of the unit and allowed to burn to the fire break. This process can then be repeated until the entire unit is burned. Fire intensity can be controlled by the spacing interval between strips, but will also vary with fuel loading and fuel moisture. Wide strips may reduce fire intensity in light fuels, but can increase intensity in heavier fuels. For example, wide spacings have been used in the Black Hills to complete a stand replacement prescribed burn in areas with heavier fuels (Henry Goehle, personal communication). Intervals between strips can range from 10 to 200 feet depending on desired fire behavior and fuel loading. Different firing patterns, such as jackpot and spot firing, can also be used to create higher fire intensity to thin stands (fig. 16).

Fire intensity can also be controlled by use of different ignition techniques. Certain ignition tools allow for more fire to be placed on the ground in a short amount of time, thereby increasing fire intensity (Brown 1984). Aerial ignition devices (for example, helitorch, pingpong balls) are likely to result in higher fire intensity than hand ignition devices (for example, drip torch, fuses) (fig. 17). Different ignition devices are discussed in the Tools Used in Burning section below.

\section{Wildland Fire Use}

In certain areas, managers use fires that are naturally ignited by lightning to achieve resource benefit. This practice is termed wildland fire use for resource benefit, or wildland fire use (WFU). Such fires typically burn for multiple days or weeks and exhibit varied fire behavior and resultant fire effects. WFU is often practiced in remote areas where risk of wildfire impacting humans is low and cost to suppress is high (fig. 18).

\section{Tools Used in Burning}

Burning and fuel break tools-Most prescribed fire treatments can be accomplished with hand crews using drip torches. For larger areas, aerial ignition devices may be used. These include delayed aerial ignition devices (DAID), or ping-pong ball system, and the helitorch, 


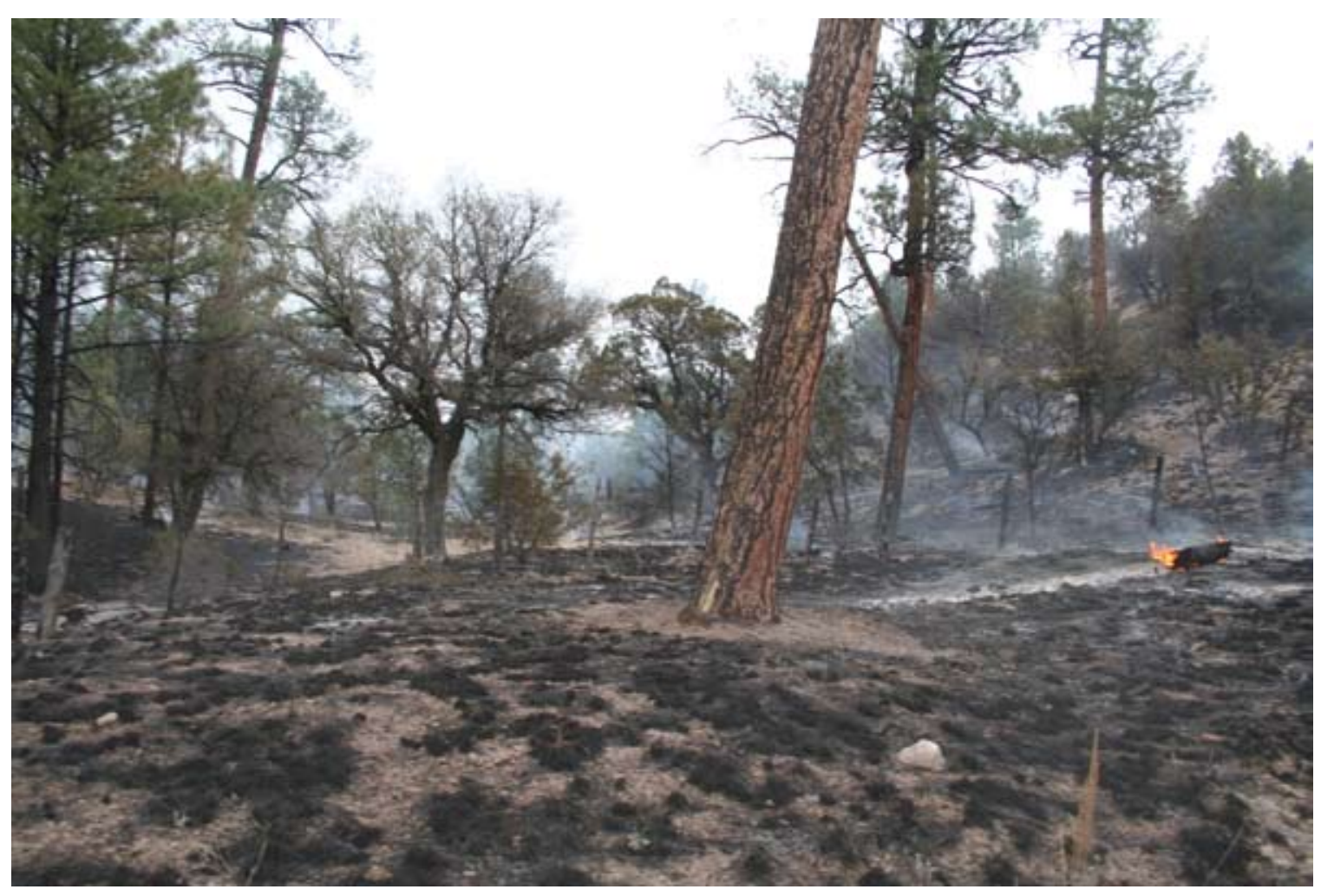

Figure 18. A wildland fire use (WFU) event (Taylor fire) on the Gila National Forest. WFU events often exhibit variable fire behavior and result in a wide array of fire effects. Photo credit: Michael Andreu.

or flying drip torch system. Aerial systems reduce the amount of time it takes to light an area and thus may be most efficiently used on large treatment units. For example, managers on the San Juan National Forest have found it cost effective to use aerial ignition devices when units are greater than 500 acres. Aerial ignition devices have also been used on smaller units in Wind Cave National Park in areas where topography creates unsafe conditions for hand crews. The ping-pong ball system is particularly useful when a mosaic burn pattern is desirable. In northern Arizona, the gentle terrain allows for frequent use of ATVs with mounted drip torches, which also can decrease the amount of time required to burn an area. ATVs have also been used in the Front Range on the Pike-San Isabel NF.

For building fuel breaks, hoses, foam, hand crews, or dozers can be used. Dozers are generally needed only to create fuel breaks if fuel treatments are conducted in heavily stocked stands and if there are values at risk near the treatment area. In northern Arizona, smaller fuel breaks are constructed with an ATV by dragging a truck wheel rim filled with concrete. This technique is more productive than hand crews, yet does not cause as much disturbance as dozers (soil compaction and tree damage). ATVs are more easily used on gentle terrain with light surface fuels where soils are not excessively rocky.
Dozers are more suited to construct fuel breaks in situations where fire intensities will be greater and terrain and soils are conducive to their use, as in the Black Hills.

Models used in planning-Different models can be used for planning prescribed fires at stand and landscape scales. On the stand level, the fire behavior prediction systems BehavePlus and NEXUS can be used to evaluate the effects of a range of fuel, weather, and topography variables on surface and crown fire behavior characteristics such as flame lengths, rate of spread, and fire intensity (Burgan and Rothermel 1984; Scott 1999). BehavePlus, in particular, is commonly used to derive a range of weather variables that will achieve desired fire behavior for a particular prescribed fire. NEXUS is commonly used to ensure treatments have effectively reduced the potential for active and passive crown fire initiation and spread. The effects of projected fire behavior characteristics on important fire effects such as tree mortality, fuel consumption, smoke production, and soil heating can be evaluated using the First Order Fire Effects Model (FOFEM) (Reinhardt and others 1997).

On a landscape scale, models like FlamMap and FARSITE can be used for a variety of planning purposes. FlamMap assesses wildlife risk across a landscape by creating maps of potential fire behavior characteristics (rate of spread, flame length) based on fuel structure, 
weather, and topography. FARSITE predicts spread patterns of fires over landscapes based on fuels, weather, and topography (Finney 1998). FARSITE is often used in management of large or complex fires to inform, for example, where resources may be best placed. Both models can also be used to assess the potential effectiveness of fuel treatments in reducing the potential for severe fire spread across a landscape (Stratton 2004). In the past, a limitation on the use of these models has been the availability of spatial GIS data layers needed to run the models. However, the LANDFIRE project is in the process of making such data available for the entire country. It is imperative to consult managers with a great deal of experience in, and knowledge of, a particular region to help verify model results. Models are useful, but they are often imprecise as is the data that goes into them and thus, they should never substitute for practitioner knowledge and experience.

\section{Thinning Techniques}

\section{Silviculture Background}

In the context of fuel treatment, thinning refers to the reduction of above-ground biomass by the removal of trees from a forest. Thinning affects fire behavior by changing both the amount and distribution of fuel available to burn. It is used primarily to lower the risk of crown fire by reducing crown bulk density. Although tree boles aren't often consumed in crown fires, increasing the spacing between trees and removing smaller trees whose crowns serve as ladder fuels can dramatically alter potential crown fire behavior in a conifer forest. Thinning also affects how trees grow and can profoundly affect how forests develop in the future, including how fuels will be distributed in those future forests. Use of traditional silvicultural methods is practical for fuels reduction because prescriptions can be communicated effectively across disciplines and agencies (Arno and Fiedler 2005). Therefore, we feel a short discussion of thinning from a silviculture standpoint will be beneficial in understanding its effects from a fuel treatment standpoint.

Thinning is an intermediate silviculture treatment intended to improve growing conditions in forests managed under even-aged systems where mature trees will eventually be removed and replaced by a new forest. There are six general methods of thinning originally developed for management of commercial timber, but they can also be used for restoration and to promote reduced crown fire potential. These methods include crown thinning or thinning from above, low thinning or thinning from below, selection thinning, free thinning, geometric thinning, and variable density thinning (Graham and others 1999; Peterson and others 2005; Smith and others 1997). In crown thinning, trees in the upper crown classes are targeted for removal to release trees in the same size class from competition and increase their growth rates. In low thinning, trees in the lower crown classes are mostly targeted for removal, although some co-dominant trees can be targeted depending on the intensity of the treatment. Free thinning is a highly variable treatment in which individual trees are targeted for removal for the purposes of releasing desirable trees from competition. In selection thinning, the most economically viable trees are removed to stimulate growth of suppressed and intermediate trees in the understory. In geometric thinning, tree removal is based on spacing or geometric pattern. Variable density thinning utilizes low thinning in combination with at least one of the other methods. In all cases, thinning under even-aged management is intended to promote the health and vigor of the forest until it matures, is harvested, and is replaced with a new forest.

In contrast to even-aged management, forests under uneven-aged management are maintained through time within a range of desired spatial and structural conditions where trees of all sizes and ages are represented in the overall forest structure. Periodic removals similar to thinning are used to maintain the desired conditions in uneven-aged forests, but differ in that trees of all sizes are typically removed.

Fuel reduction or restoration treatments may be applied in forests under both even- and uneven-aged management systems. Uneven-aged management is more appropriate when the intention is to maintain a diverse forest structure containing trees of various age classes continuously through time on a site to mimic historic conditions as occurred at various scales in ponderosa pine stands in the Black Hills, Front Range, and Southwest. On the other hand, even-aged systems, such as shelterwood and seed tree methods, are relatively easy to implement and have been used widely in the Black Hills, Front Range, and Southwest on lands suitable for timber production (Schubert 1974; Shepperd and Battaglia 2002). In both cases, when trees reach maturity they are removed in one or more entries after a new crop of seedlings has been established.

Periodic removals under uneven-aged management take the place of both thinning and harvest cuts under even-aged management. Although some old, large trees are removed in each entry, at no point in time are all mature trees harvested from the stand. Control of growing stock under uneven-aged management methods is 
a bit more complicated than with even-aged management. Stocking is controlled by diameter/age classes using either the BDQ method (Alexander and Edminster 1977) or Stand Density Index (SDI) (Long 1995; Shepperd 2007). In both methods, one needs to determine the range of diameters and the residual stocking desired for a given stand. The techniques differ in their method for determining the distribution of trees in different size classes, but both enable an infinite variety of stand configurations from very open to heavily-stocked. Uneven-aged removals can accomplish many of the fuels treatments done with even-aged thinning, although fuels managers need to appreciate the differences between the two management systems. Application of uneven-aged silviculture on the ground is not much harder than evenaged treatments, as diameter-class removals can often be collapsed into broad structure or size classes. Although both even- and uneven-aged management are appropriate for ponderosa pine forests, from a fuels standpoint, both systems will require periodic treatments to maintain desired fuels conditions. The main difference will be what the stand will look like in the long term and what mix of resource use and management emphasis is placed on a particular piece of ground.

\section{Reducing Wildfire Hazard}

Certain thinning methods can be used to reduce the potential for active crown fire spread through reductions in canopy fuel loading, in particular canopy bulk density. However, while all thinning treatments technically result in reductions in canopy fuels, they will not all be effective in reducing the potential for torching and crown fire spread (Graham and others 1999; Peterson and others 2005). Thinning treatments that use low, free, or variable density thinning methods are most likely to result in reduced potential for crown fire spread (Graham and others 1999; Peterson and others 2005; Scott 1998; Smith and others 1997; Stephens and Moghaddas 2005a), as are uneven-aged treatments that emphasize removal of small trees (Skog and others 2006). These methods can effectively increase canopy base height, decrease canopy bulk density, and decrease canopy continuity, factors that are needed to reduce the potential for torching, crown fire initiation, and crown fire spread (Agee and Skinner 2005; Skog and others 2006). Any removal of trees that results in reductions in canopy bulk density and continuity can be effective in reducing the potential for active crown fire spread. However, if these reductions only occur in the upper levels of the canopy, high crown fire spread rates may still be a factor in lower portions of the canopy. Tree removals often are not effective in increasing canopy base height unless smaller trees and lower limbs are removed as well. Thus, the potential for torching is generally not reduced after treatments that utilize crown, selection, or geometric thinning techniques where only large trees are removed. Subsequent treatment or removal of slash created by thinning operations is critical to maximize the benefits of the thinning. Slash left on ground will significantly increase fire behavior, even after 20 years and especially during drought conditions (Henry Goehle, personal communication).

Intensive treatments in which a great deal of material is removed in a short time period may be problematic as they can have detrimental impacts on native microbial and vegetation composition and diversity. For example, as disturbance intensity increases in fuel treatments, the potential for invasive species establishment tends to increase (Martinson and others, in press). However, if too little is removed, the treatment may be ineffective in reducing wildfire hazard. In order to be effective, multiple entries may be needed, increasing costs and prolonging environmental impacts.

There may be instances where reducing the threat of wildfire trumps other objectives. For example, in the wildland urban interface, protection of communities from wildfires is generally the primary objective. In such cases, the level of tree removal may justifiably be more intensive. Definitions of wildland urban interface vary, but it generally extends to at least 200 feet from structures and in some cases up to 1.5 miles from communities (Gatewood and Summerfelt 2005). In the wildland urban interface, particularly in areas within 200 feet of structures, thinning treatments may be designed to reduce the potential for crown fire spread and create "defensible space" that provide firefighters safe conditions for battling oncoming wildfires (Gatewood and Summerfelt 2005; Nowicki 2001). Some have recommended that treatments in the defensible zone include removal of ladder fuels and thinning so that tree canopy spacing is a minimum of 10 feet (Dennis 1999; Nowicki 2001). This should sufficiently reduce the potential for spread of crown fire in the wildland urban interface. Other treatment techniques may accomplish the same objectives, but many have not been sufficiently tested.

\section{Restoration}

Certain thinning techniques can be used to achieve objectives of restoring historical forest structure. Prescriptions designed to restore historical forest structure vary across the range of ponderosa pine, as historical disturbance processes and forest structures were very different in different regions (see Section II-Fire and Fuels Issues). Even within a region, landscapes were likely heterogeneous in forest structure and disturbance 


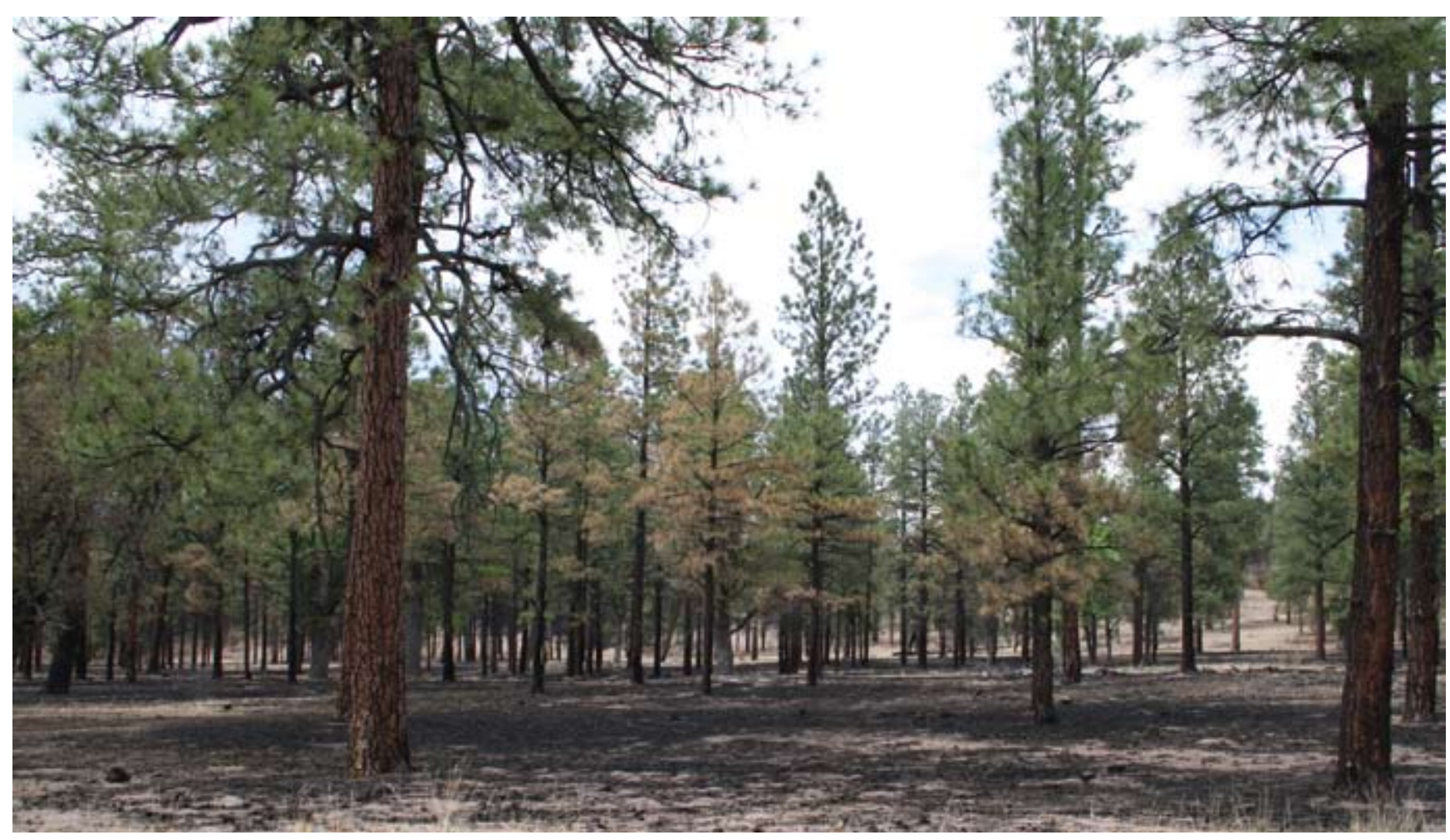

Figure 19. Thinned and recently prescribed burned forest stand in the Gila National Forest. Retaining large trees and trees in multiple size classes and maintaining low tree density are common prescriptions for restoration treatments. Photo credit: Michael Andreu.

processes in both time and space. Such heterogeneity should be met in current landscapes by creating variable prescriptions that fit within the natural variability in historical forest structure.

Southwest-Evidence of historical forest structure in a stand, such as pre-settlement trees, downed logs, stumps, and snags, should be used to restore historical structure in southwestern ponderosa pine forests. All pre-settlement trees should be retained in a thinning operation. Retaining post-settlement trees around pre-Euro-American settlement trees is recommended to restore the historical spatial pattern of trees (clumps of trees and openings), (Covington and others 1997; Fule and others 2002a; Moore and others 1999). The number of post-settlement trees retained can vary depending on historical tree density (table 2). It has also been recommended that post-settlement trees should be retained as replacement trees around large downed logs, stumps, or snags, which provide evidence as to where pre-settlement trees existed in the stand (Covington and others 1997; Fule and others 2002a; Moore and others 1999) (fig. 19).

In many cases, restoration options may be limited because of lack of old-growth trees and site specific historical data. In such cases, information about historical tree density, species composition, and other attributes from similar forests can be used as a guide. It is important to understand that historical forest structure likely varied throughout the Southwest at local and landscape scales, and local conditions should be considered when designing restoration treatments. For example, historical tree density in the northern Arizona ranged from 25 to 100 trees per acre and basal area varied from 34 to $125 \mathrm{ft}^{2}$ per acre (Fule and others 1997; Fule and others 2002a; Moore and others 2004). Trees were into 0.05 to 0.7 acre clumps of 2 to 40 trees (Covington and others 1997; White 1985). As a result, there has been a wide range in target basal areas (40 to $70 \mathrm{ft}^{2} /$ acre) and tree density (35 to 110 trees/acre) in restoration treatments throughout the Southwest (Edminster and Olsen 1996; Fiedler and Keegan 2003; Fight and others 2004; Schumann 2004). To mimic historical forest structure as best possible, most treatment prescriptions involve retaining the largest trees and leaving trees in a clumped distribution. In areas where tree density would likely have been higher historically, such as on north aspects or in canyon bottoms, basal area targets may be higher (fig. 20).

Most ponderosa pine forests in the Southwest historically exhibited uneven-aged forest structure at some scale. Treatments should be designed to mimic this structure as best possible. Uneven-aged management 


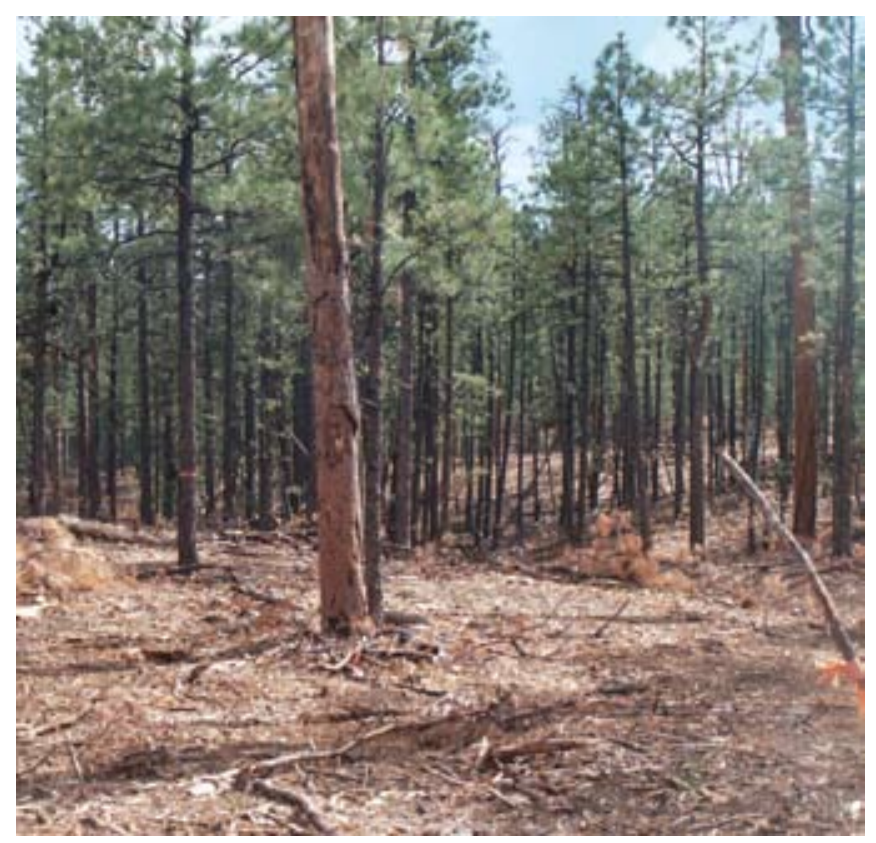

Figure 20. Recent mastication treatment in the Jemez Mountains, NM. Residual tree density was higher in drainages where historical tree density was also likely higher. Photo credit: Molly Hunter.

methods have been developed to create historical forest structures (Edminster and Olsen 1996) and to meet specific fuels treatment objectives (Shepperd and others 2005; Skog and others 2006) (see Techniques section).

On a landscape scale, ponderosa pine forests in the Southwest were historically composed of a mosaic of openings and forested stands with variable density (Savage 1991). For the purposes of restoration, managers should strive to recreate this landscape heterogeneity by designing and utilizing a variety of treatment prescriptions (including no treatment) across the landscape. Different management objectives (for example, wildlife habitat protection, and wildland urban interface) may facilitate use of different treatment strategies in different areas on the landscape and this may encourage landscape heterogeneity in forest structure. When available, localized data on historical forest structure should guide treatment prescriptions. If historical data is not available, managers can vary treatment prescriptions based on topographic features. For example, forests may have been denser historically on sites at higher elevations, on north-facing aspects, or on sites with productive soils.

Colorado Front Range-Based on historical forest structure and composition of low elevation montane forests in the central Front Range, Kaufmann and others (2003) recommends treatments that will create openings of various sizes so that they account for 15 to 25 percent of the landscape, reduce tree density so canopy cover is 10 to 30 percent across the landscape, remove Douglas-fir trees except on north aspects, and retain oldgrowth trees. Managers in the Front Range often take these recommendations into account for fuel reduction projects (USDA Forest Service 2004b, 2004c). Patch cuts are used to create openings up to 5 acres in size. Between patch cuts, stands are thinned from below to reduce tree density by 20 to 30 percent. Managers focus on achieving stand structure with a variety of age classes and spatial patterns, as forests were historically uneven-aged in structure (fig. 21). Both the BDQ and SDI methods can be used to develop targets for numbers

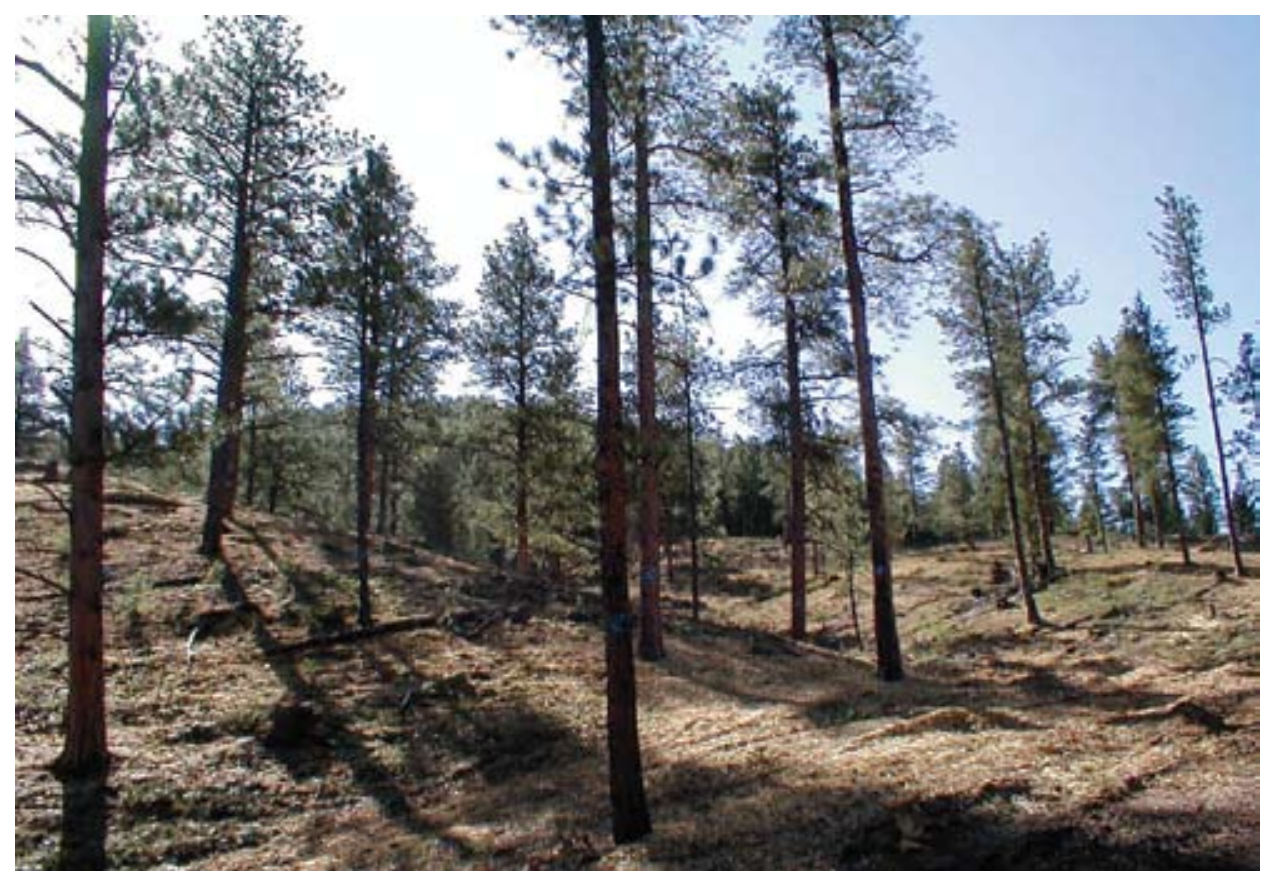

Figure 21. Recent thinning treatment in the Front Range. Photo credit: Wayne Shepperd. 
of trees desired in various age or size classes (Brown and others 2001a; Shepperd 2007; Shepperd and others 2005). To promote development of old growth conditions, large and old-growth trees should be retained (Brown and others 2001a; Kaufmann and others 2003; USDA Forest Service 2004b, 2004c). Managers can use the guide developed by Huckaby and others (2003) to identify old ponderosa pine trees.

In some portions of the northern Front Range, researchers have found that higher elevation forests (above $2100 \mathrm{~m}$ ) historically had much longer fire return intervals and thus, were likely controlled more by an infrequent high-severity fire regime (Ehle and Baker 2003; Sherriff and Veblen, in press). In these forests, dense even-aged cohorts of trees likely followed high intensity disturbance events. In such forests, researchers have recommended a more gentle approach to restoration. Such thinning will likely have some effect on crown fire risk factors, but will likely be inadequate to meet all fire risk reduction needs in areas where this type of ponderosa pine forest occurs in an urban interface. It is also unclear if this approach is appropriate for higher elevation montane forests in other portions of the Front Range (Kaufmann and others 2006) since the data from the above studies is limited.

Ponderosa pine forests in most of the Front Range were historically composed of a mosaic of persistent old growth, openings, and forests of pure ponderosa pine and mixtures of ponderosa pine and Douglas-fir with variable density (Huckaby and others 2001; Kaufmann and others 2000; Sherriff and Veblen, in press). For restoration purposes, managers should attempt to recreate this landscape heterogeneity in forest structure by designing a variety of treatment prescriptions appropriate for different conditions. For example, forests in the grassland/ forest ecotone and lower montane forests, ranging from 1700 m elevation in the southern Front Range to 2100 $m$ in the northern Front Range (Kaufmann and others 2006), likely had much lower tree density historically. Thus, heavier treatment prescriptions may be appropriate (Huckaby and others 2001; Kaufmann and others 2000; Mast and others 1998; Sherriff and Veblen 2007). In higher elevation montane forests and on north-facing aspects, tree density was likely higher historically (Ehle and Baker 2003; Huckaby and others 2001; Kaufmann and others 2000; Sherriff and Veblen 2007) and less intensive treatments would be more appropriate. The trade-off is that historically these latter forests were more likely subject to crown fires and would continue to be at higher risk to crown fire if higher densities are maintained. The key to dealing with this risk at the landscape scale is to make sure denser forests are isolated within the landscape by stands at lower risk to crown fire so that the risk of a landscape-wide crown fire is reduced.

Black Hills-The historical forest structure of the Black Hills included dense stands that may have been conducive to crown fire (Graves 1899; Parrish and others 1996; Progulske 1974). Given that crown fires were a component of the historical fire regime (Brown and Sieg 1996; Shinneman and Baker 1997), complete forest restoration may not be realistic for the Black Hills as it would conflict with current management objectives and land use. However, attempting to restore some aspects of historical forest structure and processes in Black Hills forests is likely to benefit native species that evolved with historical forest conditions and will positively affect current fire risk.

The current condition of the Black Hills has deviated from historical conditions in a variety of ways. Landscapes within the Black Hills are more homogenous in forest structure today than historically (Parrish and others 1996; Progulske 1974). Thus, thinning treatments can be designed to make the landscape more heterogeneous with stands of varying age structures interspersed throughout the landscape. In the drier portions of the Black Hills and in meadows, tree density is higher today than it was historically (McAdams 1995; Parrish and others 1996; Progulske 1974). In these cases, restoring historical forest structure would be consistent with reducing the potential for crown fires (fig. 22). Average tree size across the Black Hills is lower today than it was historically (Brown and Cook 2006; McAdams 1995). Recruitment of larger trees would not only reduce the potential for catastrophic wildfire, as large trees are more resistant to fire-induced mortality and have higher crown base heights, but it would also benefit many wildlife species that prefer large diameter trees and snags. This is particularly important for the northern goshawk, brown creeper, northern flying squirrel, and many woodpecker species (Shepperd and Battaglia 2002; USDA Forest Service 2003b).

\section{Other Thinning Objectives}

Reducing forest density also meets other resource management objectives. For example, the Flagstaff Fire Department treats mistletoe infested stands by completely removing small pockets of infestation (less than $1 / 4$ acre) or by isolating larger patches with a barrier of 50 feet to reduce further spread (Farnsworth and Summerfelt 2001). Pockets that are infested with Ips beetles or mountain pine beetles are often targeted for heavier thinning treatments (USDA Forest Service 2003a). Both of these treatments will reduce the potential for crown fire spread as well. 


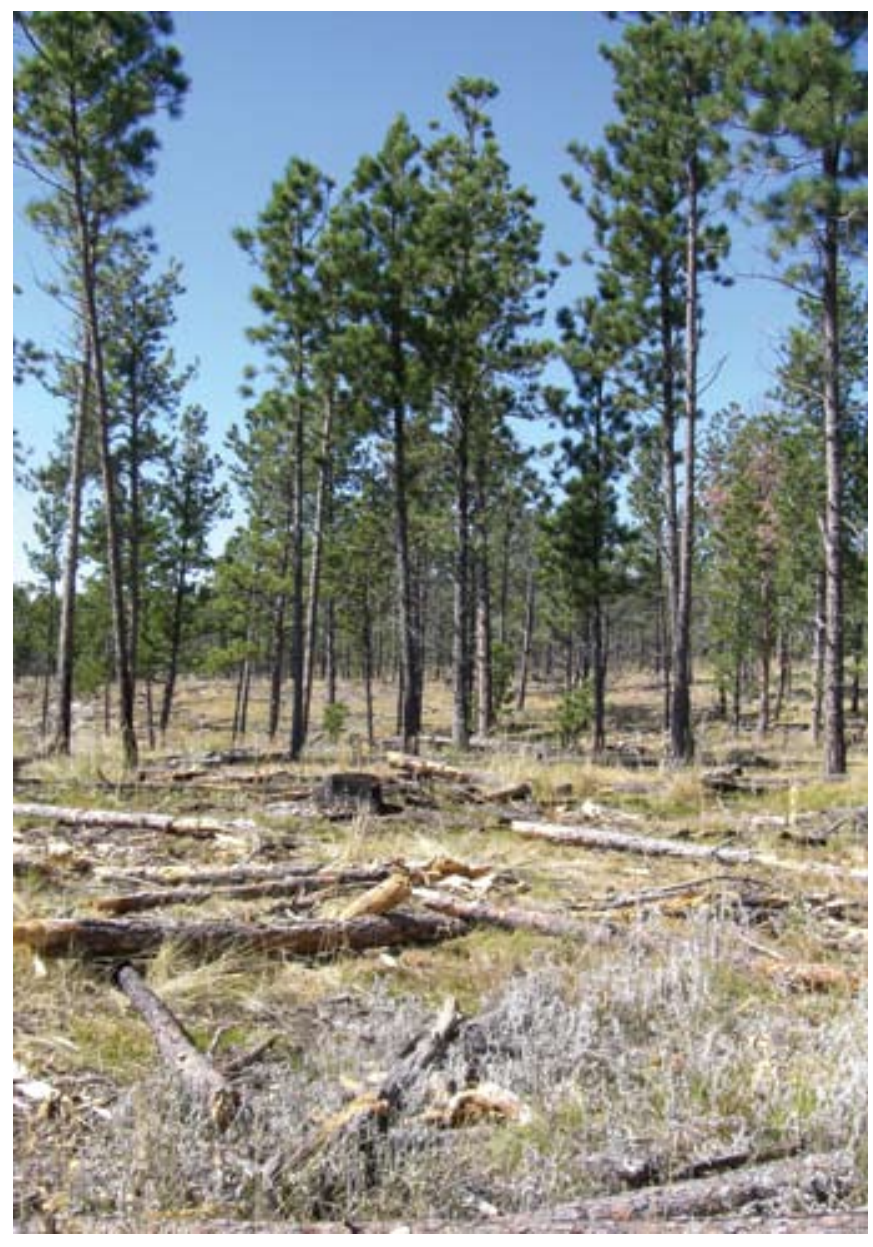

Figure 22. A recently thinned stand in the Black Hills National Forest. Photo credit: Molly Hunter.

As we mentioned earlier, regeneration of tree and shrub species in the forest understory may be a concern for land managers when the canopy is opened up. This can be particularly important for shrub species such as Gambel oak and Rocky Mountain juniper. These species act as ladder fuels, increasing fire hazard in open ponderosa pine stands. To prevent this, some managers maintain higher basal area targets in a thinning operation. For example, foresters in the Colorado State Forest often used higher residual stocking levels (Basal area $=$ $80 \mathrm{ft}^{2} /$ acre) when there are many shrubs in the understory and lower stocking levels (Basal area $=40 \mathrm{ft}^{2} /$ acre when there is mostly grass in the understory. The trade-off between maintaining open forests at lower risk to crown fire and avoiding buildups of surface and ladder fuels may be more frequent prescribed burning or mechanical treatments to keep regeneration and shrubs in check.

\section{Harvest Methods}

Trees can be cut, processed, and removed from the forest using a variety of methods, including whole-tree harvesting, cut-to-length systems, or cable yarding (Fight and others 1999; Hartsough and others 1998; Windell and Bradshaw 2000). Processing harvested trees involves removing the limbs and tops of trees and cutting them into merchantable lengths and can occur in the woods, or at a landing. With each method, a variety of equipment can be used to cut and remove the trees (Holtzscher and Lanford 1997). In whole-tree harvesting, trees are felled and immediately removed to a landing area where they are processed. In cut-to-length systems, trees are felled and processed at the stump before being transported to a landing. In cable yarding, trees are felled and removed via a skyline cable system and can be processed at the stump or at the landing. Cable yarding is generally reserved for steep slopes, where use of other types of mechanical equipment is restricted (Fiedler and others 1999). Smaller trees can be hand or machine felled, or processed using masticators, which grind trees to the stump and disperse the resulting small material on the site.

\section{Tools Used for Thinning}

Chainsaws-Hand felling of trees of many different sizes can be accomplished effectively using chainsaws (Arno and Fiedler 2005; Larson and Hallman 1980; Scott 1998; Stephens and Moghaddas 2005b). Using chainsaws is advantageous as it requires very little capital investment in equipment and they can be used in areas that are not accessible to mechanical equipment (for example, steep slopes and remote areas). However, hand felling is inherently dangerous as crews are directly exposed to multiple hazards during the logging. Furthermore, hand felling is labor intensive and generally not as productive as mechanical equipment. Thus, mechanical equipment is more economical, especially on large treatment units (Wang and others 1998). For large treatments accessible by road and in operable topography, mechanical equipment may be most appropriate.

Feller-bunchers and tree shears-Trees can be harvested mechanically using feller-bunchers or tree shears. Feller-bunchers use hydraulic grapple arms to hold the tree while it is cut (fig. 23). On some machines, a gathering device makes it possible to cut and collect several trees before they are dropped in a bunch. The cutting devices (for example, feller buncher and tree shear) can be attached to an articulating arm or boom, or directly to a tractor or other vehicle. A boom allows the machine to reach into stands to collect trees and minimizes travel over the site (fig. 24). Some mastication equipment can also be used to remove small trees. Commonly used mastication equipment is described in the following Other Mechanical and Combination Techniques section. 

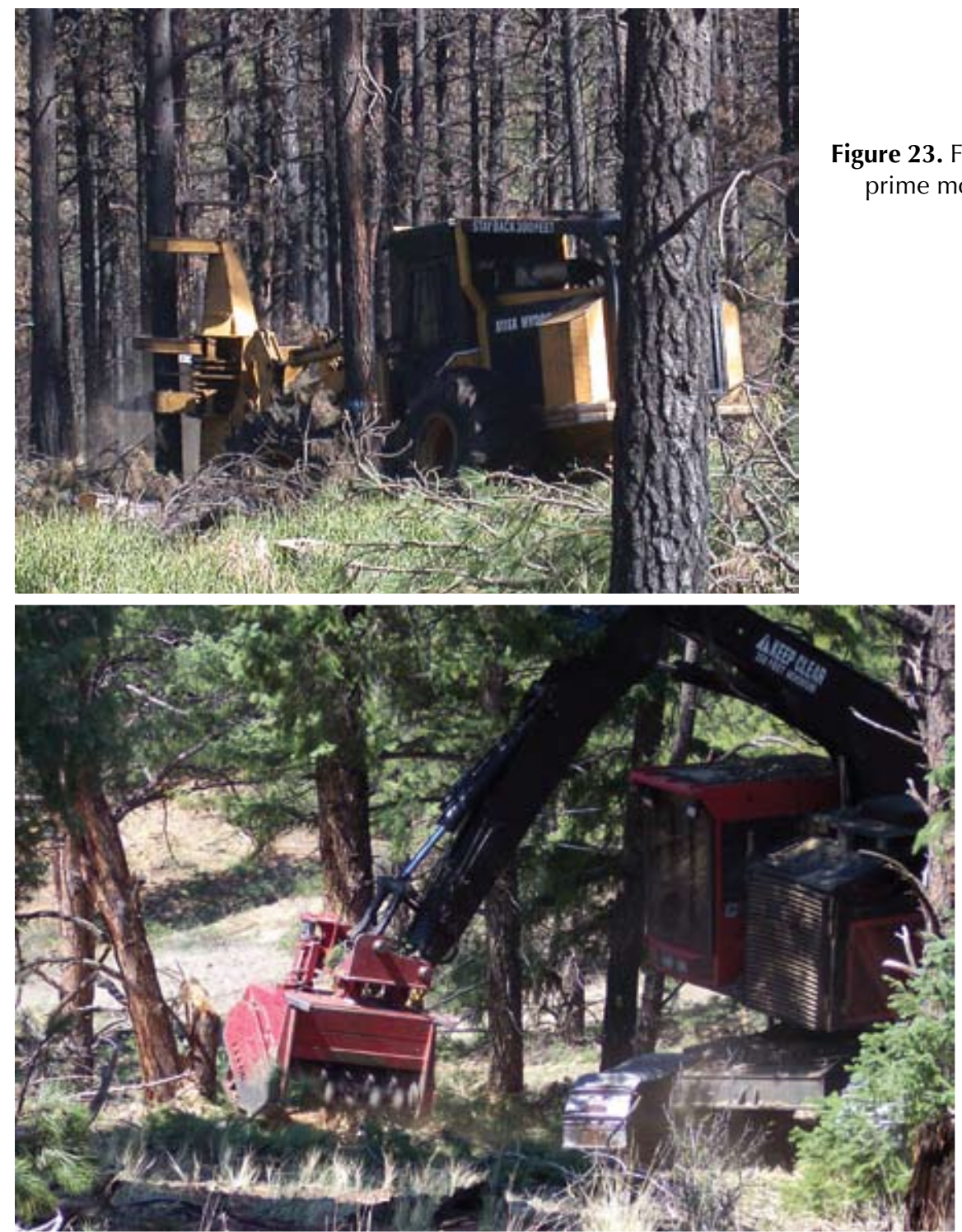

Figure 23. Feller-buncher head attached to a rubber-tired prime mover. Photo credit: Molly Hunter.
Figure 24. Mastication head attached to a boom or articulated arm of a Timbco( tracked timber harvester. Photo credit: Kristen Garrison.
Prime movers-Vehicles serving as prime movers for harvesting heads (for example feller-bunchers and tree shears) generally include excavators, all surface vehicles, or four-wheel drive tractors, and they provide both the maneuverability and power supply for the cutting heads. Smaller machines, appropriate for small diameter material, are generally more maneuverable and apply less ground pressure than large machines. Rubbertired machines disturb soil less than skid-steer tracked machines but have a smaller footprint and thus, may compact the soil to a greater extent. Use of larger machines is generally only appropriate and economical if large diameter material is being removed. It is important to contact the manufacturer to ensure a head is matched with an appropriate machine that will provide sufficient power. Windell and Bradshaw (2000) and Jones and Stokes (2004) provide a summary of commonly used feller-bunchers and tree shears and their specifications.
Tree harvesters-Trees can also be felled using tree harvesters (Larson and Hallman 1980). Use of these machines is advantageous because they can also delimb, sort, and buck logs in the woods. A disadvantage of harvesters is that they often have limited maneuverability and thus can cause considerable residual stem damage. Also, they are generally not effective in delimbing trees with large branches (Hartsough and others 1998) and often are not as productive as other methods (Holtzscher and Lanford 1997; Wang and others 1998). Tree harvesters leave branches and un-merchantable portions of trees scattered in the woods, which can significantly increase surface fuel loadings. Windell and Bradshaw (2000) and Jones and Stokes (2004) provide a summary of commonly used tree harvesters and their specifications.

Tree processors-Tree processing involves removal of limbs and tree tops and cutting logs to merchantable 


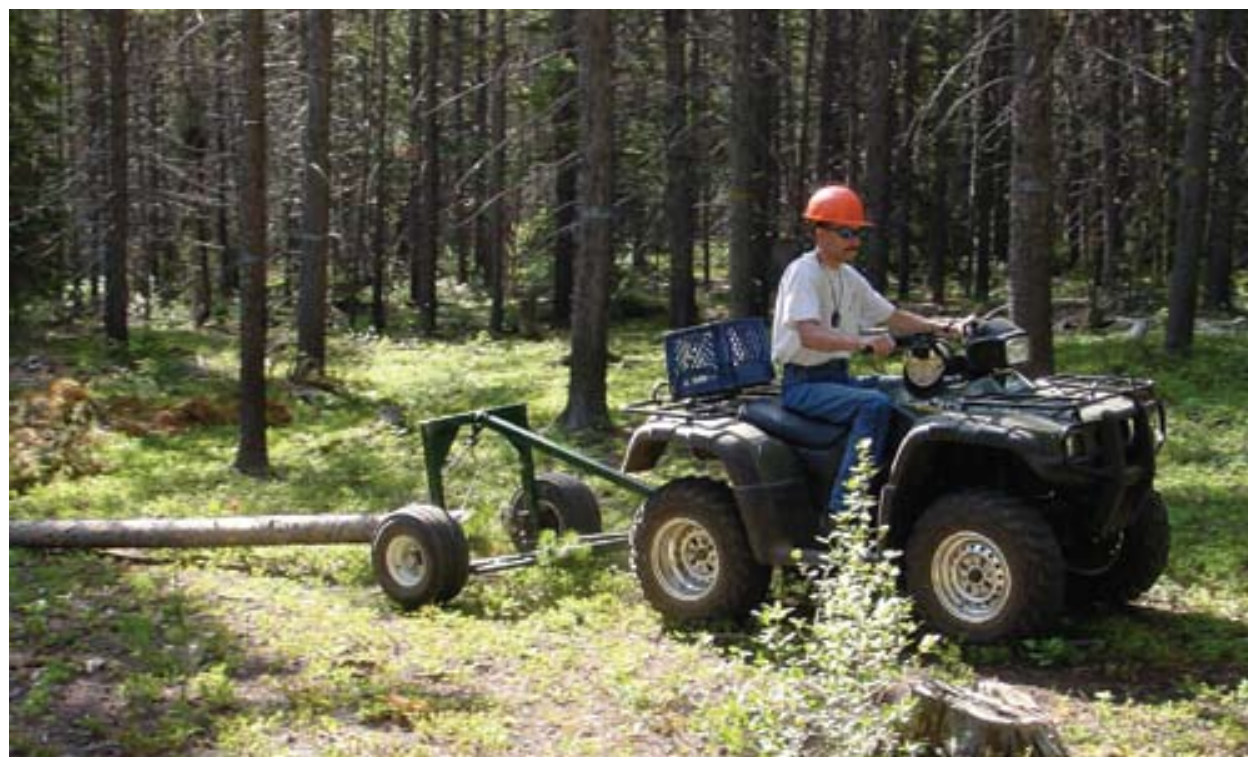

Figure 25. Cut trees can be removed from site using relatively simple technology such as this ATV and skidding arch. Photo credit: Wayne Shepperd.

lengths. This can be accomplished at the stump or at the landing. Tree processing can be accomplished effectively using hand crews with chain saws. Alternatively, tree processing can be achieved using a mechanized processor. Here again, using chainsaws is advantageous as it requires little capital investment, although their use poses a safety risk for hand crews and they are often not as productive as mechanical processors (Holtzscher and Lanford 1997). Mechanized equipment may be more appropriate for treating large areas. Landing-based processors, such as boom delimbers, process whole trees that have been skidded to a central landing, separating merchantable material from tops, branches, and unmerchantable sections of logs and piling the debris in large piles at the landing for later disposal by burning or further processing. This equipment has the advantage of concentrating all slash into one location and will not increase surface fuel loadings in the woods. Disadvantages of this system include concentrated machine activity around landings, with associate soil compaction and modification of the soil environment under burned piles (Massman and others 2003, 2006).

Skidders and forwarders-Once trees are felled, they need to be removed to a landing. This can be achieved through skidding, forwarding, or cable yarding (fig. 25). In skidding, logs or whole trees are dragged on the ground singly or in bunches by a skidder or crawler tractor. Traditional skidding uses wire rope or chain chokers to attach $\log$ s to the skidder, but modern grapple skidders are equipped with large hydraulic tongs that can pick up bunches of trees in one operation without the operator leaving the cab, making them much more productive.
Skid trails should be strategically placed to minimize soil disturbance over the site. If disturbance is a concern, logs can be removed with a forwarder. Forwarders pick up material and carry it to a landing. Forwarders can generally carry much more material than skidders, thus fewer passes across the site are needed. However, forwarders are designed to remove processed logs and are normally used in situations where unmerchantable material and slash is left scattered on-site. In cable yarding, trees are removed via a skyline cable system. Because this treatment is expensive, it is generally reserved for removing commercial material from steep slopes or where use of mechanical equipment is restricted (Fiedler and others 1999). At the landing, trees are loaded onto trucks or trailers using log loaders.

Computer models-The fire and fuels extension of the forest vegetation simulator (FVS-FFE) can be used to assess the impacts of various stand treatment options on potential fire behavior and fire effects (Reinhardt and Crookston 2003). This model can also be used to assess how different fuels, including trees, snags, and coarse woody debris, will change over time. FSVeg can also be used to assess how many trees need to be removed from a site. Both of these models require reliable stand exam data. When this is not available, the nearest neighbor analysis in INFORMS can be used to assess stand condition. FMAPlus can then be used to assess potential fire behavior of a treated stand. Models like FlamMap and FARSITE can be used to assess how fuel treatments will impact fire spread on a landscape scale. Models commonly used in fuel treatment projects are listed in Appendix A. 


\section{Other Mechanical and Combination (Fire + Mechanical) Techniques}

\section{Piling and Burning}

As discussed earlier, a common method of removing or reducing surface fuel loading is moving it into piles that are then individually burned (fig. 26). This mostly occurs with logging slash that is generated from thinning operations (Brown and Davis 1973; Fuller 1991). Relative to a broadcast burn, the potential for an escaped fire is low and the prescription window is wide, as piles can be kept dry by covering them with plastic and burning them when environmental conditions are likely to prevent fire spread (fall or winter). The piles should be strategically placed such that fire induced damage to trees is minimized (Allen and others 1968). Depending on the amount of fuel, the average size of fuel, size of the treatment unit, and accessibility of the site, fuels can be piled by hand or with a machine. Use of mechanical equipment is generally more appropriate for large units with large diameter material. Hand crews are also more appropriate when accessibility limits use of mechanical equipment,

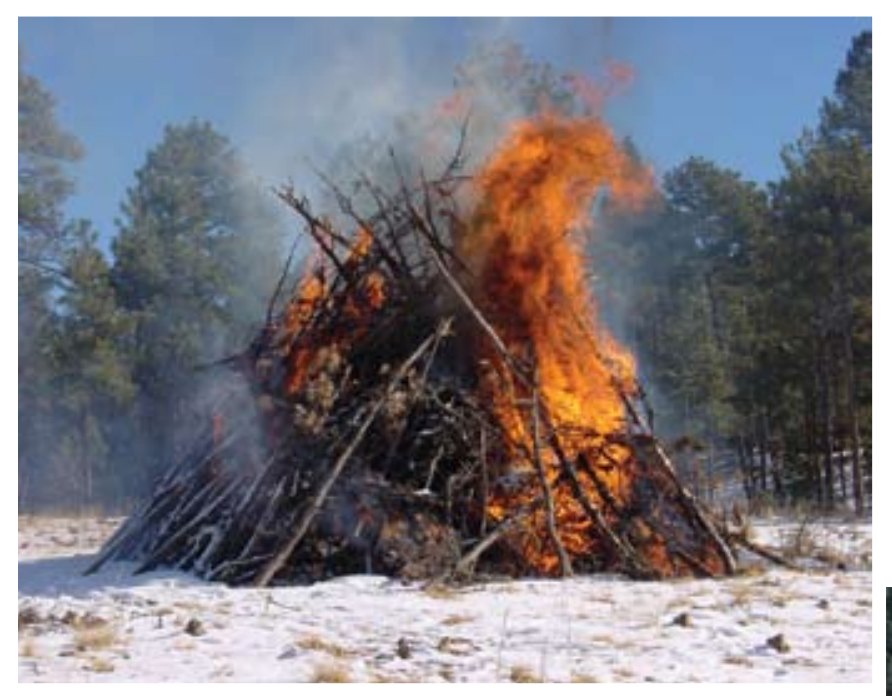

Figure 26. Excess surface fuels can be piled and burned when broadcast burning presents too much risk. Photo credit: Wayne Shepperd. either because of lack of roads or steep slopes (Jones and Stokes 2004; USDA Forest Service 1973; Windell and Bradshaw 2000).

The Flagstaff Fire Department has developed very specific guidelines for constructing slash piles to be burned in the wildland urban interface (Flagstaff Fire Department 2005). According to their best management practices guide, piles should be between 5 and 8 feet in height and diameter. Smaller branches and tree tops should be on the bottom, followed by larger branches in the middle of the pile and small diameter material on the top. Piles should be in the shape of a cone. In the wildland urban interface, hand piles can be burned any time of year, but larger machine piles are typically burned when there is some snow on the ground.

Given the heat fluxes that can occur when piles are burned (Massman and others 2003), care should be taken to locate piles far enough away from residual trees to avoid damage to foliage and roots.

\section{Removal}

Surface and ladder fuels in the form of slash can also be mechanically removed from a site. Merchantable trees can be removed from a site before removing tree tops and limbs via whole tree-skidding or cable yarding (Scott 1996; Windell and Bradshaw 2000). Tree tops and limbs can then be removed from harvested trees at a landing rather than on site. This material can then be piled and burned at the landing as described earlier, or chipped or bundled as biomass for other uses (fig. 27). This may be appropriate when burning on site is not feasible. If markets are available, this material can also be used for bioenergy or composted and used for garden mulch (Graham and others 1998; Hollenstein and

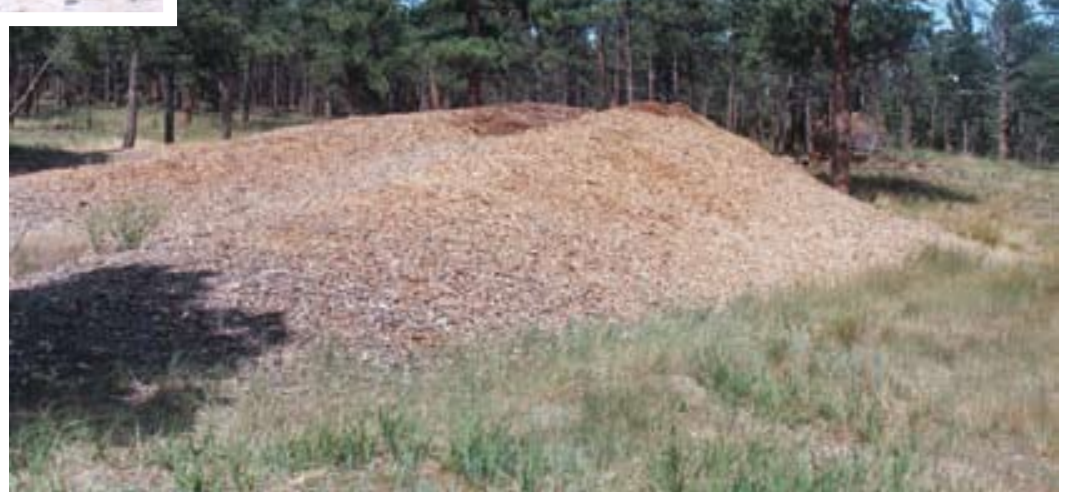

Figure 27. Excess fuels on Boulder County land are chipped and used for heating county offices. Photo credit: Molly Hunter. 
others 2001; Jones and Stokes 2004; LeVan-Green and Livingston 2003; Stokes 1992). If material is to be sold commercially, it is generally more cost efficient to collect material at a landing (Stokes 1992).

\section{Chipping, Mowing, and Mastication}

In mowing or mastication treatments, mechanical equipment is used to cut surface and ladder fuels into small chunks or chips that are then left on site (Jones and Stokes 2004; USDA Forest Service 2003c; Windell and Bradshaw 2000). Depending on the type of equipment used, slash or standing small trees and shrubs can be targeted in mastication/mowing treatments. Generally, mechanical equipment is effective for material averaging 10 inches in diameter; however, some equipment can be used on material up to 18 inches in diameter (Jones and Stokes 2004). The residual material can vary in size depending on the equipment used. Slower moving equipment with rapidly rotating blades will result in smaller material (Busse and others 2005). Mastication and mowing can be used to prepare sites for broadcast burns, as the treatments result in reduced ladder fuels (Bradley and others 2003; Busse and others 2005; Stephens and Moghaddas 2005b). Crushing understory biomass involves driving over material with heavy machinery to compact understory fuels (Jones and Stokes 2004; Windell and Bradshaw 2000). This is generally useful for treatment of cured slash or very brittle brush species, but is not effective in treating tree seedlings and saplings. Crushing generally results in reduced fuel bed depth and increased compactness.

\section{Tools Used in Mechanical and Combination Treatments}

Prime movers and cutting heads-Mechanical equipment used for mastication/mowing or piling of material involves a prime mover vehicle and a head or cutting/ moving attachment (Jones and Stokes 2004; Ryans and Cromier 1994). Prime movers generally include excavators, all surface vehicles, or four-wheel drive tractors. The prime mover is the power source and the carrier for the mastication head. A head can be attached directly to the prime mover or can be attached via an articulating arm or boom. Cutting heads can be classified according to the orientation of the main power shaft, vertical or horizontal, and the type of cutter, fixed or free swinging/ pivotal, containing knife blades, flails, hardened cutter teeth, and so forth mounted on rotating drums or disks. Some brush-cutting equipment is built for specific carriers while other equipment is sold as attachments for multi-purpose carriers. It is important to check with the manufacturer to ensure a given head will be appropriate for a prime mover. There are advantages and disadvantages of using vertical versus horizontal cutting heads and fixed versus free-swinging cutters for changing the fuel structure of small trees, brush, and slash. These trade offs should be carefully evaluated before a decision is made on which type of equipment is to be used. Windell and Bradsaw (2000) and Jones and Stokes (2004) provide a summary of common equipment used in fuel reduction treatments.

Prime movers can have rubber tires, rubber track, steel tracks, or can be stationary. It is important that the machine have enough power capability to move effectively at slow speeds while supplying adequate hydraulic or mechanical power to the cutting head (McKenzie 1991; Ryans and Cromier 1994). Tracked machines are advantageous because they apply less ground pressure than wheeled machines and they can operate on steeper slopes (McKenzie 1991; Windell and Bradshaw 2000). However, excessive soil compaction does not seem to be a problem on many of the soil types in the Front Range and Southwest. Tracked machines are also generally more maneuverable than wheeled machines, but wheeled machines are generally less expensive and more productive (Windell and Bradsahw 2000).

Vertical shaft cutting heads are generally lighter, and thus require less energy than horizontal shaft cutting heads (Ryans and Cromier 1994; Windell and Bradshaw 2000). Use of vertical shaft cutting heads requires a large safety zone because debris tends to be ejected in all directions. Thus, vertical shaft cutting heads may not be appropriate for use near structures (McKenzie 1991; Windell and Bradshaw 2000). Vertical shaft cutting heads can be attached to an articulating arm on an excavator that allows the machine to process material standing higher off the ground than horizontal-shaft machines. Standing trees can be ground to stumps with little damage to desirable trees and vegetation. The articulating arm also minimizes travel across the site (Windell and Bradshaw 2000). Mulching can be improved on vertical shaft cutters by reducing the size of rock guards on the shaft or increasing the rotating speed (fig. 28).

Horizontal shaft cutting heads provide more mulching action than vertical shaft cutting heads but are also more sensitive to wear and if bladed, will require more frequent sharpening than heads with hardened teeth. Horizontal shaft cutting heads are generally attached to a tracked machine or articulated tractor. These can be used to walk over brush, small trees, and slash. In general, front-mounted machine attachments provide better operator visibility than rear-mounted attachments (McKenzie 1991; Ryans and Cromier 1994) (fig. 29). 


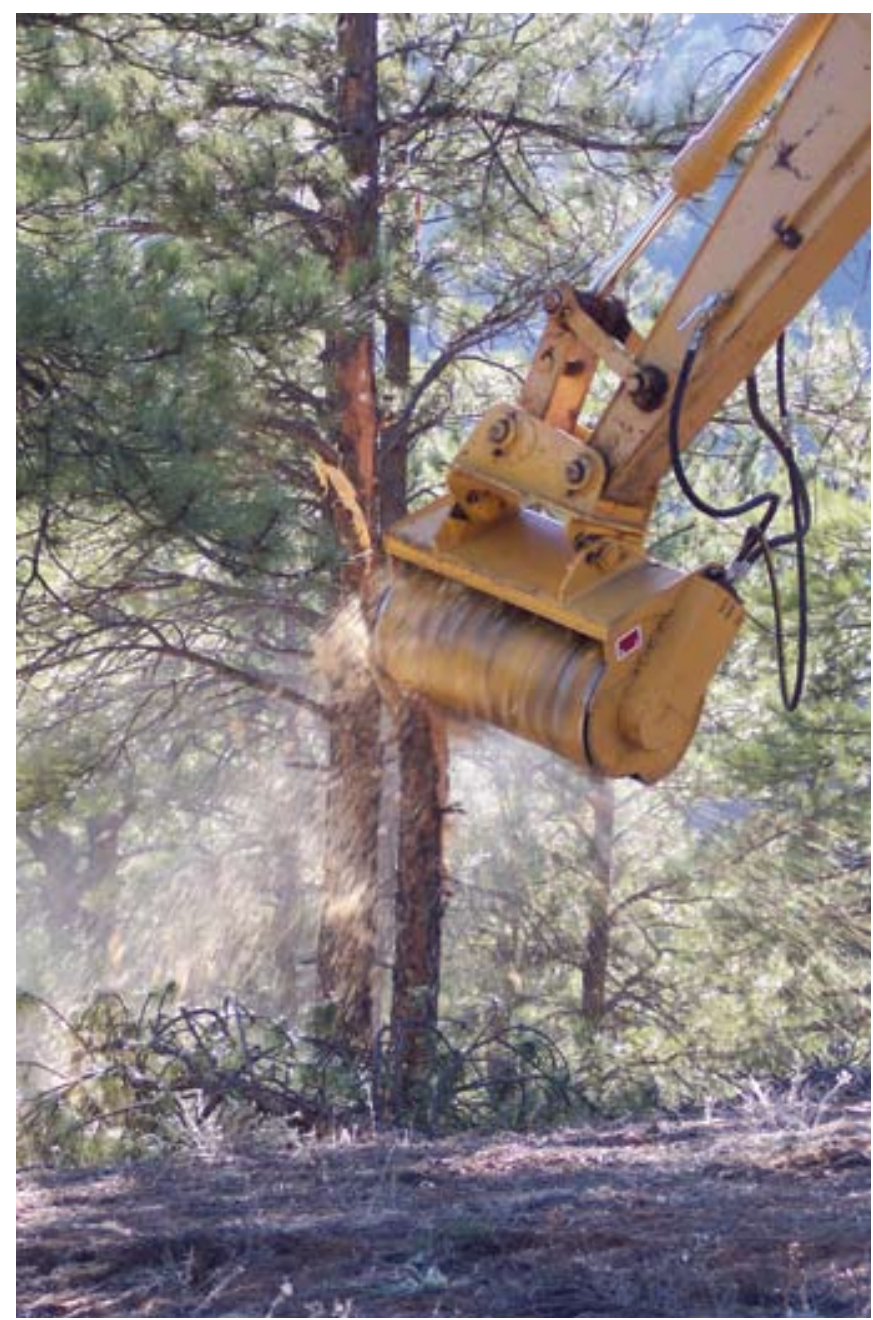

Figure 28. Example of a vertical shaft masticator, a Quadco@ brush cutter on a Timbco $\odot$ tracked harvester. Photo credit: Kristen Garrison.
Fixed cutters are typically circular saws and discs with fixed teeth (Ryans and Cromier 1994). Free swinging cutters consist of pivoted knives mounted on a central disc or bar. Fixed cutters generally have less mulching capability, but improved mulching often comes at a cost of higher energy requirements and possibly lower productivity (McKenzie 1991). Fixed cutters often require frequent sharpening as the blades easily dull with frequent contact with rocks and soil. Damage to knives is less likely with free swinging cutters. Fixed cutters do not throw material as far as free swinging cutters (McKenzie 1991).

Pruning and piling equipment-Pruning, piling of slash, and lop and scattering of slash can also be accomplished effectively with hand crews (Jones and Stokes 2004; USDA Forest Service 1973). Hand pruning saws and loppers can be used to prune the lower branches of trees. Managers have recommended that no more than 50 percent of the live crown should be removed. Chainsaws can be used to cut material (USDA Forest Service 1973; Jones and Stokes 2004). Biomass can then be placed into piles or scattered across the site by hand. If material is to be burned, it is important to place piles and scattered material away from residual trees to avoid fuel buildup under crowns or near the base of tree boles. When a high quantity of large diameter material is on site, piling by hand can be difficult. In such cases, piling can be better accomplished with a tractor, loader, or dozer with rake or grapple attachments. Grapples attached to excavators can also be used if tree spacing limits movement of larger equipment. Considerable amounts of dirt can be piled with the debris with certain types of equipment, making the piles more difficult to burn (Cammack 1978).

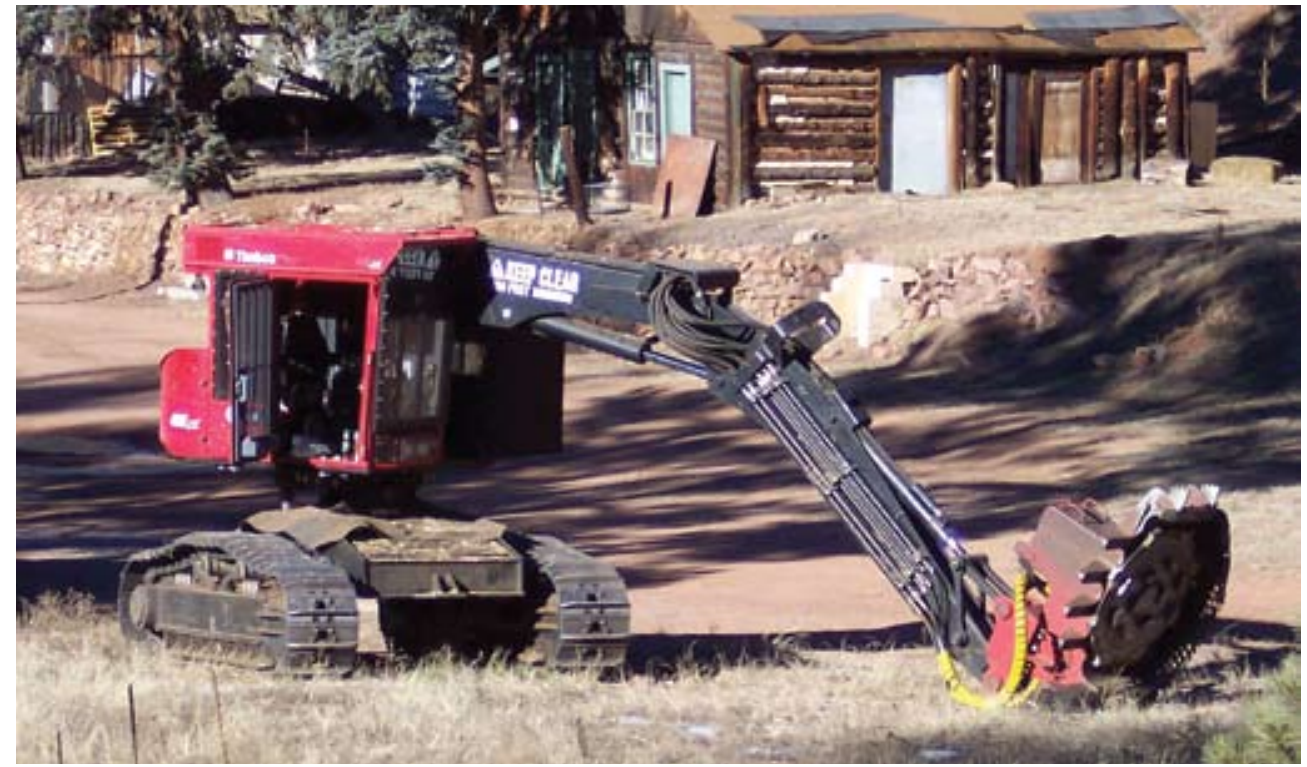

Figure 29. Example of a horizontal shaft masticator, a Wag Way@ drum grinder. Photo credit: Kristen Garrison
Less dirt tends to accumulate in piles when material is picked up with rakes rather than dragged across the ground.

Woody biomass and slash can also be fed into chippers. Material can be processed at a landing where the chips can be loaded into trucks or trailers. This is appropriate if chips are to be sold as garden mulch or for a bioenergy product. Alternatively, chips can be processed on site and distributed over the area. Whole tree chippers or hand fed chippers, made by a variety of manufacturers, 
are generally used at landings, although some specialized equipment can be used in the woods.

\section{Livestock Grazing and Chemical Treatment Techniques}

Livestock grazing and chemical treatments in association with fuels reduction treatments in ponderosa pine forests have been used to a very limited extent in the Southwest, Front Range, and Black Hills. Thus, an extensive list of treatment options is not available. However, there has been some experimentation with these treatments to control excessive sprouting of Gambel oak, which can develop into a ladder fuel if left unchecked, particularly in the southern Rocky Mountains.

\section{Livestock Grazing}

Livestock grazing can be an important management tool for manipulating the amount and extent of understory woody (shrubs and small trees) and herbaceous vegetation (Archer and Smeins 1991). Low to moderate levels of grazing can reduce tree and shrub establishment on a site by promoting growth in grasses, which increases their ability to preempt resources from trees and shrubs while increasing biomass and continuity of fine fuels and hence, fire frequency (Borman 2005; Madany and West 1983; Rummell 1951). In contrast, higher levels of grazing reduce the amount of fine fuels, which decreases fire frequency and intensity (Bachelet and others 2000), but can lead to increased establishment of trees and shrubs (Archer and Smeins 1991).

Two studies have documented successful use of goats to control dominance of Gambel oak in dense shrub thickets in the Southwest (Davis and others 1975; Riggs and Urness 1989). Goats are generally better to use than cattle or sheep because they will preferentially browse on Gambel oak. Use of 1,300 to 1,800 goat days per hectare (526 to 729 per acre) in the summer for two seasons was successful in defoliating oak (Riggs and Urness 1989). Since Gambel oak has low carbohydrate reserves in June and August, this may be the best time to graze goats (Davis and others 1975). Generally, more than one grazing season is needed to successfully control oak sprouts (Davis and others 1975; Riggs and Urness 1989). Alternatively, goats can be used following another treatment such as mechanical removal, herbicides, or prescribed fire (Davis and others 1975). This is particularly useful when much of the oak foliage is tall and not within reach of goats. More studies on use of goats to control Gambel oak are needed to better evaluate the effectiveness of this treatment in reducing wildfire risk. Obviously, the technique is not appropriate for use on large areas, but may have applicability in situations where other options are not available.

\section{Herbicides}

Several herbicides have been tested on Gambel oak to control dominance in dense shrub thickets in southwestern Colorado, including Silvex (2,4,5-T and 2,4,5-TP), Picloram, and glyphosate and glyphosate:triclopyrpicloram combinations (Lauver and others 1989). Foliar application of Tordon has also been effective (Marquiss 1973). Foliar applications are effective while soil treatments are generally not effective (Van Epps 1974). However, treatment results tend to be highly variable year to year (Harper and others 1985). Applications in July may be effective as this is when plants begin storage of carbohydrates and herbicides may be transported more easily through the plants (Kufeld 1983). More studies on use of herbicides to control Gambel oak are needed to better evaluate the effectiveness of this treatment in reducing wildfire risk. One of us (Shepperd) is aware of another test of the herbicide Arsenal $_{\odot}$ that effectively killed Gambel Oak in the San Juan NF in the 1980s.

Control of invasive weeds is a more common use of herbicides associated with fuels treatments in Black Hills, Front Range, and Southwest ponderosa pine forests. Managers typically spot-spray herbicide on individual plants or populations of invasive plants associated with areas disturbed by skid trails, landings, and pile burn sites. Application is usually accomplished by backpack, ATV, or truck mounted spraying equipment and is sometimes done cooperatively by trained personnel from other agencies or resources in collaboration with the fuels treatment program. 


\section{Section V:}

\section{Fuel Treatment Requirements}

$\mathrm{T}$ The success in meeting fuel treatment objectives as well as broader resource management objectives in each fuel treatment depends on how well a project treatment prescription is planned and implemented. While reduced wildfire risk is generally the primary objective, well planned projects tend to consider this objective in a broad framework that includes a suite of resource management objectives in a landscape context. Well implemented projects are successful in meeting objectives despite several limitations that are commonly encountered. In this section, we present information that should be considered in the planning and implementation of any fuel treatment project to ensure treatment and resource management objectives are met. This includes discussion of factors that influence treatment effectiveness in reducing severe wildfire risk and the resources needed to complete these treatments. We also discuss common limitations to effectively achieving resource and fuel treatment objectives and present examples of how managers have successfully overcome these limitations.

\section{Planning}

Before implementation of any fuel treatment can begin, most agencies require a thorough analysis of the potential effects of various treatments. Laws such as the National Environmental Policy Act, Endangered Species Act, and Clean Air Act often dictate these analyses. While the requirements for planning projects vary by agency, at least on federal lands, managers generally need to consult various resource management specialists (for example, wildlife biologists, archeologists, and hydrologists) and solicit public comments for each proposed treatment. Thorough surveys of valued resources in proposed treatment areas may be needed to fully understand the potential impacts of treatments on these resources. These actions can help determine what type of treatment would be most appropriate for any given situation and how it should be scheduled and implemented. It can also help identify critical factors to monitor posttreatment. In many cases, it can take a year or more to complete this process.

\section{Prescribed Fire}

\section{Effectiveness}

As described earlier, prescribed fire is generally used to reduce loading of surface, ladder, and canopy fuels with the ultimate goal of reducing the potential for spread of catastrophic wildfire. Prescribed fires are generally effective in reducing loading of surface fuels, and have been shown to reduce the size, severity, and resultant ecological effects of wildfires (Choromasnska and DeLua 2001; Kallander 1969; Pollet and Omi 2002; Omi and others 2005; Wagle and Eakle 1979). However, not all prescribed fires are equally effective in reducing wildfire hazard. This may be because prescribed fire does not always result in sufficient fuel reduction. The size of a prescribed fire may also be a factor. While small prescribed fires (less than 100 acres) are generally easier to implement and carry less risk of escape, large prescribed fires (greater than 800 acres) are more likely to be effective in reducing the potential for severe wildfire spread (Finney and others 2005; Martinson and others 2003). Use of prescribed fires also requires sustained management as effectiveness decreases with time since fire (Finney and others 2005). Prescribed fires were found to be effective in reducing subsequent wildfire severity for up to 4 years in Arizona and New Mexico (Ffolliott and Guertin 1988; Finney and others 2005; Omi and others 2005) and 6 years in Colorado (Omi and others 2005). Prescribed fires are less likely to be effective in sufficiently reducing fuel loads if they are conducted when fuels are too wet (Fernandes and Betelho 2003).

Prescribed fires have also been used effectively to reduce tree density. Because prescribed fire is relatively ineffective in reducing canopy bulk density (Agee and Skinner 2005; Fule and others 2002a; Sackett and others 1996), multiple high to moderate intensity fires may be needed to sufficiently reduce tree density before low intensity fires can be used exclusively to maintain desired conditions (USDA Forest Service 2003c). Similarly, multiple prescribed fires or fires of high intensity may be needed to reduce fuel loads to levels that would significantly impact wildfire behavior (Fule and others 2002a; 
Fule and others 2004; Harrington and Sackett 1990; Windell and Bradshaw 2000).

If reduction of shrub fuels is the objective, prescribed burns should be conducted with greater frequency to keep up with shrub sprouting (Harrington and Sackett 1990). For Gambel oak, control burns should be conducted every other year in the summer (Harrington 1985). Stimulation of new shrub sprouts may be desirable for wildlife forage. To stimulate shrub sprouting, prescribed burns generally need to be conducted in the dormant season when carbohydrate reserves that are stored in the roots should facilitate sprouting (Bock and Bock 1984; Harrington 1985; Sieg and Wright 1996; Young and Baily 1975).

\section{Resources Needed}

The personnel required to implement a prescribed fire is highly variable and dependent on the complexity of the prescribed fire, level of experience of available personnel, and perception of risk, among other things. For example, more people may be needed for prescribed fires that are closer to communities, in areas where fuel loading is particularly high, or in situations where more precise control of the burning process is needed to mitigate other resource needs. Internal agency policies are also a factor. The personnel needed to complete prescribed fires seems to be increasing, as some agencies now require contingency resources to be on site of the prescribed fire. Thus, enough resources need to be on hand to hold a fire should it go out of prescription. This will almost always include at least one engine, but the number often depends on the maximum area that will be allowed to burn. These requirements will increase the cost of conducting a prescribed fire, but will decrease the probability of fire having detrimental impacts to values at risk.

Cost of prescribed burning can be highly variable. Factors such as size of burn, type of equipment used, accessibility, and type firing pattern use all influence the cost of a prescribed fire. On the Gila National Forest, prescribed fire can cost anywhere from $\$ 25$ to $\$ 200$ per acre (Lolley and others 2006). Costs have been has high as $\$ 500$ per acre on the Santa Fe National Forest and average $\$ 300$ per acre on the Black Hills National Forest (table 5). A complete analysis of costs for various treatments in the Front Range was also recently compiled and is a valuable reference (Front Range Fuel Treatment Partnership Rountable 2006).

For many reasons, wildland fire use events tend to be much less expensive on a per acre basis than management ignited prescribed fires (Lolley and others 2006). Since wildland fire use fires tend to burn over multiple days or weeks, more acres are generally burned in a given event relative to a management ignited prescribed fire. As the number of acres burned increases in an event,

Table 5. Examples of treatment implementation costs. Numbers do not reflect cost of planning fuel treatments.

\begin{tabular}{|c|c|c|c|}
\hline Treatment & Cost/acre & Year & Site \\
\hline Prescribed fire ${ }^{a}$ & $\$ 300$ & 2006 & Black Hills NF \\
\hline Mastication ${ }^{\mathrm{a}}$ & $\$ 350$ & 2006 & Black Hills NF \\
\hline Prescribed fire ${ }^{b}$ & $\$ 75$ to 150 & 2006 & Colorado State Forest \\
\hline Thinning (no utilization) + prescribed fire ${ }^{b}$ & $\$ 600$ to 1200 & 2006 & Colorado State Forest \\
\hline Broadcast burn ${ }^{c}$ & $\$ 114$ & 2004 & CO Front Range \\
\hline Pile burn ${ }^{c}$ & $\$ 132$ & 2004 & CO Front Range \\
\hline Mastication ${ }^{\mathrm{c}}$ & $\$ 341$ & 2004 & CO Front Range \\
\hline Thinning (utilization) ${ }^{c}$ & $\$ 364$ & 2004 & CO Front Range \\
\hline Thinning (no utilization) ${ }^{c}$ & $\$ 654$ & 2004 & CO Front Range \\
\hline Broadcast burn ${ }^{d}$ & $\$ 100$ & 2003 & San Isabel NF \\
\hline Mastication $^{\mathrm{d}}$ & $\$ 250$ & 2003 & San Isabel NF \\
\hline Broadcast burne & $\$ 450$ to 500 & 2006 & Santa Fe NF \\
\hline WFU ${ }^{f}$ & $\$ 25$ & 2004 & Gila NF \\
\hline Broadcast burn ${ }^{f}$ & $\$ 25$ to 100 & 2004 & Gila NF \\
\hline Thinning & $\$ 200$ to 500 & 2004 & Gila NF \\
\hline
\end{tabular}

\footnotetext{
a Interview with Gwen Lipp, 2006

${ }^{\mathrm{b}}$ Interview with Christy Berggren and Andi Perry

c Front Range Fuel Treatment Partnership 2006

${ }^{\mathrm{d}}$ USDA Forest Service 2003a

e Interview with Lawrence Garcia, David Isackson, and Tom Johnston, 2006

${ }^{\mathrm{f}}$ Lolley and others 2006
} 
the cost per acre generally decreases as the same level of resources are used in each case (Wood 1988). Wildland fire use fires also do not generally require construction of fuel breaks, which can be costly.

Wildland fire use events require an upfront planning process in the fire management plan, but not a separate and lengthy environmental analysis for each event (USDA and USDI 2005). This would be impossible given that one cannot predict when and where wildland fire use opportunities will present themselves. This more streamlined planning process, relative to management ignited prescribed fires, also reduces the overall cost of wildland fire use events.

\section{Thinning}

\section{Effectiveness}

Thinning treatments have been tested in wildfire scenarios in ponderosa pine forests throughout the west and have been shown to be effective in mitigating fire severity (Cram and others 2006; Martinson and Omi 2003; Martinson and others 2003; Pollet and Omi 2002). However, different thinning treatments are not equally effective in reducing the potential for wildfire spread and intensity. For example, in treatments where only a few small trees are removed, the potential for crown fire spread may not be significantly reduced (Fule and others 2006). Treatments that focus on removal of smaller trees will generally be more effective than treatments that focus on overstory removal (Arno and Fiedler 2005; Graham and others 1999; Martinson and Omi 2003; Scott 1998), although specific effects are strongly dependent upon the number and distribution of tree sizes present before treatment (Shepperd and others 2005). However, some large trees may need to be removed to effectively reduce the potential for crown fire spread (Scott 1998; Arno and Fiedler 2005). Many studies (for example, Callaway and Davis 1993; Cram and others 2006; Odion and others 2004) have found that patterns of fire effects (severity) and post-fire vegetation recovery may be predisposed by topographical position and pre-fire vegetation structure. Stand density index, the number of large trees, and slope were the variables most closely associated with low and moderate burn severity under the severe weather conditions during a large, contemporary wildfire in Black Hills ponderosa pine forests (Lentile and others 2006). Although many stands were thinned, sapling and small tree density remained high and stands with low numbers of large trees on gentle slopes were most likely to burn at low or moderate burn severity. High density stands with either many large or small trees, in other words, with high canopy bulk density or fuel ladders, were more likely to burn severely (Lentile and others 2006).

Thinning operations can often dramatically increase surface fuel loading in the form of tree tops and limbs or slash and are generally not effective in reducing the potential for severe fire spread if the resultant slash is not subsequently treated (Graham and others 1999; Martinson and others 2003; Peterson and others 2005). If residual slash burns under hot and dry conditions, it can result in very extreme fire behavior (Martinson and others 2003). It is therefore necessary to remove or alter the structure of these surface fuels using prescribed fire or mechanical treatments in conjunction with thinning.

\section{Resources Needed}

The resources needed to complete a thinning operation depend on the treatment area size, the size and amount of treated material, and the accessibility and topography of the site. For example, on smaller treatment areas, hand crews using chainsaws or small, maneuverable equipment of low horsepower are generally sufficient. On larger treatment areas, larger mechanical equipment may be needed as they have higher production rates. The size of the material being removed can also dictate what type of equipment is needed (see previous Tools section). Mechanical equipment may be needed when there is a great deal of material that needs to be removed, again because of higher production rates. Use of mechanical equipment becomes problematic in areas that are inaccessible or have complex terrain. In such cases, hand crews may be needed. Alternatively, mechanical equipment specially made for complex terrain may be used (see previous Tools section).

Costs for thinning operations can be highly variable. Thinning operations in ponderosa pine forests on the Gila National Forest cost between $\$ 200$ and $\$ 500$ per acre (Lolley and others 2006). Treatments have cost up to $\$ 1,000$ per acre on the Santa Fe National Forest and up to $\$ 1,200$ per acre for projects managed by the Colorado State Forest. Treatments in the Black Hills National Forest on average cost around $\$ 350$ per acre (table 5).

\section{Other Mechanical and Combination Treatments}

\section{Effectiveness}

One of the more common ways to dispose of excess surface fuel is to move the material into piles constructed by hand or machine. These piles are then burned under 
relatively benign conditions. If trees are to be used commercially, the unusable portions of the tree (for example, tops, limbs) can be cut after the tree has been removed from the site, a process called whole tree removal. Both methods are effective in reducing the loading of slash.

In other methods, larger surface and ladder fuels are processed with chippers or masticators. The resultant material is then spread out over the site. This process is relatively new and the effectiveness of these methods in reducing fire risk has not been adequately tested. Such treatments have been shown to reduce the height of ladder fuels and thus the potential for initiation of torching and crowning fire behavior (Jerman and others 2004). However, others have found that chipped and masticated fuels in particular can burn completely with relatively high intensity during prescribed fires and this has been shown to have adverse effects on soil properties and tree mortality (Bradley and others 2003; Busse and others 2005; Stephens and Moghaddas 2005b). Concentrations of chips on the ground have also been found to dramatically alter the soil environment, even if they are not burned (Massman and others 2006) (fig. 30).

Fuels that are scattered or crushed have not been shown to burn with the same effect, perhaps because these fuels generally do not burn completely during a prescribed fire (Jerman and others 2004). Prescott National Forest personnel have found that burning masticated fuels with very high fuel moisture contents and high relative humidity (35 percent) results in rather complete consumption of surface fuels without detrimental impacts on soils. These treatments were conducted in chaparral fuels, and thus it is unclear if similar fuel consumption would be achieved in less volatile fuels. However, Shepperd (2004) reported that burning heavy surface fuels on saturated soils had no apparent detrimental effect on aspen roots at a low elevation mixed conifer site in southern Colorado that contained ponderosa pine. More research is needed to fully understand the impacts of mastication treatments on the potential for severe wildfire spread and other resources or ecological processes.

\section{Resources Needed}

Surface fuels can be treated using a variety of tools, from fire to mechanical treatments. Both hand crews and mechanical equipment can be used to cut ladder fuels such as large shrubs and small trees. Both can also be used to place material into piles that can later be burned. The necessity of using hand crews versus mechanical equipment will depend on the size of the treatment area and the type and amount of material being removed. In addition, there is a wide range of useful equipment that varies in power capacity and other features (see

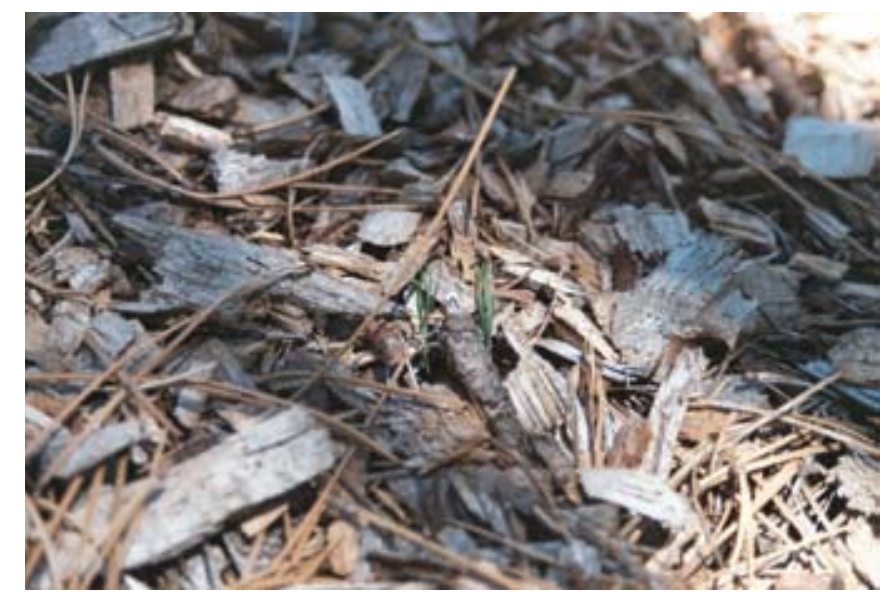

Figure 30. Compact layers of wood chips may have adverse effects on the soil environment. Wood chip layers (2 to 3 inches in depth) did not appear to inhibit seedling establishment of ponderosa pine in Boulder County. Photo credit: Molly Hunter.

previous Tools section). More powerful mechanical equipment may be needed when a lot of material over a large area needs to be treated. Specialized equipment may be needed on steeper terrain. The type of equipment used will also depend on the desired condition of fuels after treatment. For example, a chipper would be preferred if smaller material, a neater appearance, and low-intensity burning conditions were wanted while a hydro-axe would suffice if larger material could be left on-site. Costs of combined treatments may vary widely as well. Mastication treatments can range from $\$ 100$ to $\$ 1,000$ per acre and pile burning can range from $\$ 100$ to $\$ 750$ per acre (USDA Forest Service 2003c) (table 5). Chipping is generally more expensive than mastication or pile burning. Programs such as My Fuel Treatment Planner (MyFTP) can be used to assess and compare the costs of various treatments (Fight and Barbour 2005).

\section{Livestock Grazing and Chemical Treatments}

\section{Effectiveness}

The use of livestock grazing and chemical treatments for fuels reduction has been limited in ponderosa pine systems, thus it is difficult to fully evaluate the effectiveness of these treatments along with the resource needs and limitations. There seems to be some potential to reduce fuel loading in dense thickets of Gambel oak. Gambel oak grows in the understory of ponderosa pine forests in Arizona, New Mexico, and Colorado. This species is very important as browse and habitat for a variety of wildlife species (Reynolds and others 1996). However, 
after decades of fire exclusion, stands of Gambel oak can become impenetrable to wildlife, produce poor browse quality, prevent regeneration of ponderosa pine trees, and develop into potentially threatening ladder fuels (Harper and others 1985). Thus, in some regions, managers have attempted to control the density and height of Gambel oak stands using herds of goats and herbicides to control dense thickets of Gambel oak, but such treatments have been limited and have not been sufficiently evaluated to determine their effectiveness in reducing the potential for severe fire spread and their effects on other resources or processes.

\section{Limitations and Examples of Overcoming Them}

\section{Access and Topography}

Mechanical equipment is more restricted by access and terrain than are hand crews. Use of mechanical equipment is generally not feasible on slopes greater than 35 percent (Fight and others 1999). Some machines can be used on steeper slopes, but such machines generally require greater capital investment that can only be recuperated if sustained commercial products are obtained from treatments (Fight and others 1999; Fight and others 2003). Mechanical treatments are also restricted by access and cannot be used on isolated sites surrounded by other ownerships unless owners agree to let equipment cross their land. Costs of treatments increase as distance to roads increases, yet constructing new roads to facilitate mechanical fuel treatments may have detrimental effects on other ecological resources (DellaSalla and Frost 2001; Hartsough and others 1998; Trombulak and Frissell 2000) and will require extensive study in some jurisdictions.

Use of prescribed fire is less restricted by access and topography and thus may be more feasible than use of mechanical treatments in certain situations. However, it can be more difficult to construct fuel breaks in inaccessible terrain, and steep and rugged topography can make conditions unsafe for firefighters. Despite the need, implementation of fuel treatments is not an option in certain areas because of access and topography.

Allowing wildfires to burn and reduce fuel loads may be a viable option in such cases. These limitations necessitate development of strategies to determine where to implement fuel treatments across a landscape while maximizing the benefits gained from such treatments. An example of this process is taking place in management units such as the Prescott and Coconino National Forests in northern Arizona. Intensive mechanical treatments, often in combination with prescribed fire, are being focused around values at risk, including power lines, municipal water sources, and communities. Access and topography are generally not restrictive factors around such infrastructure in these areas. Once these values are sufficiently protected from the risk of severe wildfire, there should be greater opportunities to use natural or management ignited fire to treat fuels in more remote areas. While use of fire alone without mechanical treatments carries some risk of extreme fire behavior, such events should be less threatening to communities or other values at risk if a buffer of intensively treated forest surrounds them. This practice has also been endorsed by others (Aplet and Wilmer 2003; DellaSalla and Frost 2001).

\section{Resource Limitations}

Most management agencies have limited resources available for fuel treatment activities and this often restricts the number of acres that can be treated and can dictate the type of treatment used. Ideally, managers would have enough resources to treat all the acres that are in need of fuel reduction and to use the tools that are most appropriate for meeting all resource management objectives. In reality, managers need to derive strategies for maximizing benefits for natural resources given the capital they have because available funding will always be an issue.

One strategy for maximizing benefit of resources is to leverage funds for fuels treatments with funds allocated for other resources, such as wildlife habitat or timber management, thereby increasing the number of acres that are treated. For example, fuel managers on the Black Hills National Forest and in Custer State Park, both in South Dakota, coordinate efforts with their timber management staffs. This allows managers to share resources while meeting multiple objectives (for example, timber targets and fuels reduction). Managers are also able to partially offset the cost of treatments by producing some commercially viable material.

The ability to use merchantable material from fuel reduction treatments is often limited by availability of processing plants and consistent long-term markets (Hollenstein and others 2001; Le Van-Green and Livingston 2003; USDA Forest Service 2003c). The proportion of material removed that is sawlog-sized versus product other than logs (POL) often determines whether or not there is profit from restoration or fuel reduction treatments. In southwestern Colorado, for example, treatments have been profitable when a maximum of 60 percent of the material removed from a site is POL (Lynch 2001). Even in areas where selling timber is 
not a viable option because of poor markets or absence of viable material, there may be unique opportunities to offset costs. For example, in Boulder County, CO, small diameter material harvested from county lands is processed as chips that are then used to heat some county-owned buildings.

While prescribed fires are generally less expensive than mechanical treatments on a per acre basis, the cost of such treatments can still be substantial. There are many things that can be done to minimize burning costs. For example, the Colorado State Forest Service minimizes costs by using local volunteer fire departments for their prescribed fires. This helps the volunteer fire departments by allowing their personnel to gain experience and advance in their training. Costs of prescribed fires can be highly variable depending on numerous factors. For example, larger prescribed fires generally cost less on a per acre basis (Cleaves and others 2000; Wood 1988). Smaller fires can be more costly than large fires, even though the required crew sizes may be smaller, because the same level of holding equipment (for example, engines, dozers) is needed as on larger fires (Wood 1988).

Construction of fireline also affects prescribed fire costs. The proportion of fireline created per area burned is higher for smaller fires (Wood 1988) and can significantly effect prescribed fire cost. The cost of burning can be reduced substantially if fireline construction is minimized by using natural or existing fuel breaks. This can include roads, trails, rivers, and snow. Managers of the Coconino National Forest organize prescribed fire units in stacked blocks so that prescribed fires conducted early in the season can be used as fire breaks for subsequent prescribed fires later in the season.

Distance traveled to a treatment site can substantially increase the cost of prescribed fire treatments as well. If units are far away, care should be taken to ensure that the prescribed fire can be completed in the fewest number of days possible to minimize travel time and costs. This can be achieved by increasing the size of crews, using aerial ignition, or burning for longer periods of time each day.

\section{High Fuel Loading}

Use of prescribed fire is often restricted in areas where fuel loading is unusually high. In such cases, if prescribed fire is initiated under relatively benign conditions (for example, high relative humidity, low temperature), then resulting fire behavior often does not achieve the desired effect in terms of reduction in tree density or loading of surface fuels. Conversely, if prescribed fires are initiated under drier and warmer conditions, there is a greater risk of extreme fire behavior. Such intense prescribed burns may have undesirable effects on watershed and ecological processes and can increase threats to firefighter and community safety (DellaSalla and Frost 2001; Fule and others 2002b; USDA Forest Service 2003c).

If high fuel loadings are present in areas adjacent to communities, prescribed fire may be implemented only after significant amounts of fuel are removed or rearranged mechanically (Allen and others 2002). For example, some managers on the Coconino National Forest told us they feel more comfortable using prescribed fire in or near the wildland urban interface when canopy cover is less than 50 percent and fuel bed depth is less than 1-foot conditions that can only be met by applying mechanical treatments prior to burning. The city of Flagstaff also conducts broadcast burns in and around the city after areas have been treated mechanically and heavy fuels have been burned in piles (Farnsworth and Summerfelt 2001) (fig. 31).

Use of prescribed natural fire may be appropriate in more remote areas with high fuel loading. For example, in the Gila National Forest, managers have been very successful in using naturally ignited fires to treat areas with excessively high fuel loads. This practice has been going on in this area since the 1970s. Several areas have burned in two or three fire events since the program began. Since the fires initiate with natural lightning strikes, they typically start during the summer monsoon season when relative humidity and fuel moisture is high, which may prevent very extreme fire behavior. Managers have noticed that while the initial fire is generally not very effective in reducing fuel loads (particularly tree density) areas that have seen multiple fires have significant reductions in fuel loads.

Prescribed fire has also been used in stands with high fuel loads in areas that are not as remote. Examples of this can be seen in the Black Hills National Forest, Santa Fe National Forest, and Bandelier National Monument (fig. 32). Using fire to reduce fuel loads often means accepting the possibility of some extreme fire behavior, such as tree torching and crowning, within the treated area. This process creates heterogeneity on the landscape that restores some of the historical diversity of ponderosa pine forests and is beneficial for wildlife habitat and other resource uses. Such pockets of intense prescribed fire can be created with individual ignitions or as part of a larger prescribed fire.

\section{Prescription Windows}

Prior to conducting a prescribed fire, managers need to define a set of objectives (for example, percent tree mortality or percent black) and fire behavior characteristics 
Figure 31. The Flagstaff Fire Department has been successful in implementing prescribed fire in the wildland urban interface. Broadcast burns or burning of piles near structures is typically done only after a thinning operation. Photo credit: Paul Summerfelt.

Figure 32. High intensity prescribed fire, with some torching and small scale crowning, has been used to reduce tree density in more remote forested areas. Photo credit: Mike Battaglia.
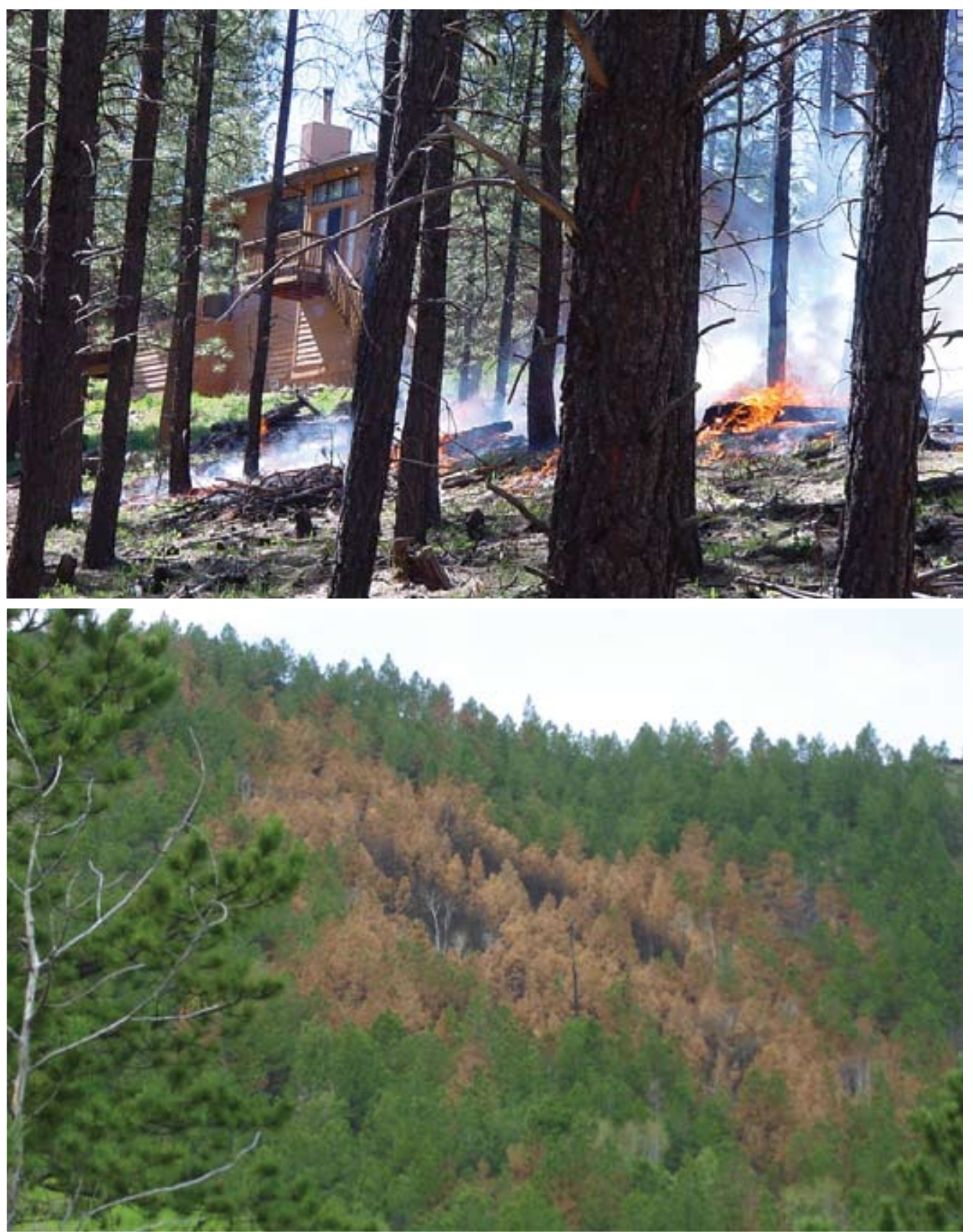

(for example, flame length, rate of spread) that will allow fuel treatment goals to be met without severe risk of escape fire or extreme fire behavior. Managers then define a prescription window, or a range of values for relative humidity, temperature, wind, and slope that will result in the desired fire behavior. Managers should bear in mind that it can be very difficult to complete prescribed fires if a prescription window is very narrow, or if there are few days during a burning season when a prescription window can be met. This is particularly problematic in areas with high fuel loading. Narrow prescription windows can ultimately restrict the number of acres that can be treated in a given year. This is especially true if all planned projects have the same narrow prescription window. If such is the case, managers need to realistically assess the likelihood of completing planned projects and investigate other fuels treatment alternatives.

Managers have learned to overcome such obstacles by designing their prescription windows to be as wide as possible. The general approach of managers on the San Juan National Forest, for example, is to start with desired fire behavior (from BehavePlus output) and work backward to find a wide range of weather parameters that will produce the desired fire behavior. Another approach is to burn as many acres as possible when you are in prescription. For example, managers in northern 
Arizona sometimes will burn piles concurrent with a broadcast burn if prescription windows are very narrow, or extend the burn period if prescription window conditions persist. Widening the prescription window can also be achieved by expanding the burning season into summer and winter and planning to expanding the hours in a day when burning is typically done. For example, managers with the Coconino National Forest often burn at night to be within their prescription. San Juan National Forest personnel have considered broadcast burning on south-facing slopes when they are snow-free in dry winters. Innovative thinking can result in strategies like these to help widen the prescription window. It is important to note however that burning in a season not consistent with the historical fire regime may result in very different fire effects. For example, certain species may be more susceptible to fire damage during the growing season (Harrington 1987).

Overcoming the limitations of narrow prescription windows requires planning. Treatments can be planned with flexibility so an entire treatment area does not need to be shut down when only a portion of it is out of prescription. In the past, managers on the Santa Fe National Forest have often broken up treatments into units based on topography. Breaking up a treatment area in this fashion decreases the likelihood that a burn will be cancelled because average conditions do not fit a prescription window. For example, one portion of the unit may be out of prescription (south aspect), yet another portion may be in prescription (north aspect). This approach may require more intensive collection of fuel moisture and weather data than normal, but may result in accomplishments that otherwise could not be achieved.

Another very innovative approach is currently in the planning process on the Coronado National Forest. Managers there are attempting to plan for several projects across a broad scale. Having several projects ready to be implemented would allow some flexibility in treating areas in a given year. If, for example, if they are not able to conduct a planned prescribed fire because prescription windows are not met, they can instead use available resources to implement a planned thinning project. Having several implementation-ready projects on hand allows for this flexibility. In order to accomplish this, they have had to expand the scope of fuel treatment planning from the ranger district level to the forest level and beyond.

\section{Public and Agency Resistance}

Both the general public and agency personnel can be resistant to fuel treatments for a variety of reasons. In some cases, prescribed fires and mechanical treatments have had detrimental impacts on valued resources. For example, the 2000 Cerro Grande fire in northern New Mexico was a prescribed fire that went out of prescription and resulted in the evacuation of the city of Los Alamos and the destruction of over 200 structures. Fires in the Southwest (including wildland fire use fires) have also necessitated the emergency removal of threatened fish species in effected streams. Inadvertent loss of property in prescribed fires has resulted in the threat of criminal prosecution of personnel conducting the burn. Even though such events are rare, their high profile and the attention given by the media give the public and resource managers within agencies the impression that the risk of detrimental effects of such treatments outweigh the benefits. Since comments from the public and other resource managers are solicited in any fuel treatment project, this resistance can create substantial barriers to implementating fuel treatments.

Managers are more successful in gaining acceptance for fuel treatments when they actively engage the public and agency officials during the entire fuel treatment or restoration process, from planning to implementation. While collaborative projects often require a lot of up-front investment in time, these efforts generally pay off by reducing overall resistance to prescribed fire and other fuel treatments. Ultimately, engaging multiple stakeholders forces managers to consider multiple resource management objectives and thus operate in a framework that considers sustainability of the whole forest system.

There are many examples of planning processes that have involved multiple collaborators. On the Gila National Forest, a landscape pre-planning process was designed to provide recommendations to the forest service on where to place fuel treatments. This involved a collaborative effort that included managers with the Forest Service, non-profit groups, local governments, environmental advocacy groups, and forest industry companies that use small diameter material. Another collaborative effort on the Coronado National Forest included members from agencies with adjoining land units, including the National Park Service, Department of Defense, Nature Conservancy, and Audubon Society. Our interviews with practitioners have shown repeatedly that outside resistance to proposed projects is reduced when multiple stakeholders have played a key role in planning fuel treatment activities and feel their concerns have been addressed.

Another important aspect of acceptance of fuel treatments is the level of trust that is given to those implementing and planning treatments. Generally, trust in agency officials is not given easily and often only 
develops over time and after relationships based on mutual respect have been established with the public and other resource managers. Once trust is established, it is imperative to maintain it by following through with intended treatments, monitoring their success or failings, and openly sharing the results. Once trust is lost, it is extremely difficult to regain again. Managers on the San Juan National Forest invest a great deal of time and energy in actions that establish and maintain trust with the public. They take time to ensure that the public and other interested parties understand exactly what they plan to do and why they plan to do it. For example, prior to implementing a restoration project, personnel organize field trips to the proposed treatment area. They also bring historical photos to show what the area might have looked like prior to Euro-American settlement and discuss the consequences of the proposed change. They provide photos of treatment areas 1,2 , and 3 years after treatment so that people have a sense of what the area will look like after treatment. This helps avoid the public perception that agency officials can not be trusted, a perception that can develop when there are misconceptions about what fuel treatments are supposed to accomplish.

\section{Smoke}

Depending on the region, smoke from a prescribed fire can be subject to regulation by various state and federal laws. Smoke production is a serious matter because it can affect public health, visibility for road and air traffic, and contribute to "bad air" days in metropolitan areas subject to EPA regulations. The public can also have low tolerance for smoke in their communities even when smoke production is within acceptable limits. Both of these factors can seriously limit the number of areas that can be burned in a season. In addition, managers often have to consider factors that affect smoke dispersal to ensure that sensitive municipalities are not adversely impacted by smoke.

As with other limiting factors, innovative thinking is key to dealing with smoke production. Recognizing this limitation, managers from different agencies in northern Arizona coordinate their burns to ensure that certain areas do not receive excessive smoke impacts in any given period of time. Conversely, if conditions are favorable for smoke dispersal, they will coordinate to accomplish as much burning as possible. To comply with air quality standards imposed by state and federal laws, in northern Arizona, managers coordinate prescribed fire plans on a daily basis to ensure that certain areas do not receive excessive smoke impacts in any given period of time. This can be challenging, especially when adjacent management units tend to have the same narrow prescription windows in northern Arizona. Managers have also been able to take advantage of local weather phenomenon to maximize smoke dispersal. For example, the Coconino National Forest has experimented with, and been successful in, implementing prescribed fires ahead of approaching cold fronts, which disperse smoke away from sensitive areas during windy periods before the front passes. To contain the fires, they also take advantage of colder, wetter, and calmer conditions after the front. This type of detailed knowledge and understanding of local weather processes and fire behavior patterns is gained only after years of working in a particular locale, and emphasizes the value of confident, experienced personnel in completing fuels treatment projects.

In some cases, it will be impossible to limit smoke impact from prescribed fire on communities. The public can become more accepting of smoke if they fully understand its necessity, and if agencies take steps to minimize smoke impacts on communities. For example, the city of Flagstaff, AZ, has been successful in increasing public acceptance of smoke through an extensive public outreach and education program that emphasizes the need for prescribed fire to reduce the risk of severe wildfire. They also take care to minimize smoke impacts to sensitive areas, such as schools and hospitals, and coordinate activities as discussed above to limit the number of smoky days. They maintain a call list to notify those individuals in the community that are particularly sensitive to smoke several days before they conduct a prescribed fire. They have noticed that when people are forewarned, there is general tolerance of smoke for 1 day, but after 2 or 3 days, people begin to complain (Farnsworth and Summerfelt 2001). Thus, they take several additional steps in the wildland urban interface to minimize the number of days impacted by smoke. For example, they will burn no more than 150 piles per day no more than once a week in a neighborshed, an area they define as within a neighborhood or geographic area where smoke will accumulate and remain visible for at least four hours following the burn (Flagstaff Fire Department 2005).

\section{Wildlife Habitat}

While it is recognized that high-severity wildfire poses a serious threat to threatened and endangered species habitat, there is also some concern for the impacts of fuel treatments on these species (Ganey and others 1999). Thus, restrictions are often imposed on use of some treatments in sensitive wildlife habitat. For example, fuels treatment activities are restricted in Mexican spotted owl habitat in some national forests of 
the Southwest. The owl is a federally threatened species that occurs throughout the Southwest and is a significant focus of management efforts in the region. These owls typically breed from March to August in mixed conifer forests and pine-oak forests. Because they are thought to have a low tolerance for heat, they generally prefer closed canopy forests with old-growth characteristics such as large trees, snags, and down woody material. The primary threats to the long-term survival of the species include timber harvest, particularly even-aged harvest methods, and catastrophic wildfire. Yet, the objectives of thinning to reduce wildfire hazard need to be balanced against the need to maintain critical owl habitat, which consists of rather dense forests stands. Guidelines developed in the Mexican spotted owl recovery plan (USDI Fish and Wildlife Service 1995) are aimed at maintaining Mexican spotted owl habitat and protecting it from catastrophic wildfire. Since Mexican spotted owls generally do not nest in pure ponderosa pine stands, the restrictions on fuel treatments in owl habitat generally apply only to pine forests that have a Gambel oak component, or those in steep canyons (slope $>40$ percent). The guidelines suggest restricting thinning operations in 100 acre areas surrounding identified nest sites. In addition, thinning should be limited to trees that are less than 9 inches dbh and restricted to the non-breeding season (Sept. to Feb.) in protected activity centers (PACs) that are 600 acre areas surrounding designated nest sites. Pine forests with a significant Gambel oak component are considered "restricted habitat" where thinning should be limited to trees less than 24 inches dbh and removal of trees between 18 inches and 24 inches dbh should be minimal. It is also recommended that large oak trees be protected and that canopy cover should be at least 40 percent. Similar restrictions on fuel treatments are recommended in northern goshawk habitat (Reynolds and others 1992) as well. Some fire managers have found that these restrictions limit opportunities to reduce wildfire risk at landscape scales.

Management strategies that successfully achieve multiple management objectives are often accomplished only when different resource managers work closely together and recognize the need to balance these objectives. One example comes from the Gila National Forest in New Mexico. Here, during wildland fire use events, fire managers constantly consult with wildlife biologists to ensure that the fire not only reduces fuel loads but also benefits or does not adversely impact wildlife habitat. This exchange has allowed the development of strategies to allow fire to move into Mexican spotted owl habitat. But achieving desired results may require altering fire behavior to ensure that important owl habitat components (for example, large snags, logs, oaks) are protected. By working together, fire managers and wildlife biologists developed fuels treatments that would be acceptable from both the perspective of fuels reduction and wildlife habitat improvement.

\section{Wildland Urban Interface}

The risk of escaped prescribed fire threatening structures is higher when burning in the wildland urban interface (WUI). This often makes managers uncomfortable conducting prescribed burns in these areas. In addition, many managers we interviewed suggested that the public is generally unhappy with the increased risk and exposure to smoke. However, many of these areas are in need of treatment in order to adequately protect communities from the threat of wildfire. Mechanical treatment is an option, but is expensive and cannot meet management objectives in all cases.

Management agencies around Flagstaff, AZ, have been very successful in conducting broadcast and pile burns near structures (Gatewood and Summerfelt 2005). Almost all treatments require some mechanical treatment prior to burning. A typical treatment in ponderosa pine forests near Flagstaff includes a thinning operation, followed by pile burning, and then broadcast burning, all completed within a year. The mechanical treatments reduce canopy and ladder fuels and alter potential fire behavior during subsequent prescribed burning. The managers' perception of risk is low because their experience igniting fire under such conditions is extensive. As further insurance, they use more personnel on these urban projects than they would to treat areas farther away from structures. An extensive outreach and public education program has been key in gaining public support for these mechanical fuel treatments and prescribed burns in the Flagstaff wildland urban interface. In fact, agencies managing neighboring public lands (for example, the Forest Service) have likely benefited from these efforts as well.

\section{Cross-agency Issues and Collaboration}

Wildfires occur on landscape scales and do not obey jurisdictional boundaries. In order to be most effective, managers therefore need to derive strategies that reduce wildfire risk across landownership boundaries. Yet, there are often no incentives in place for working outside one's management unit. Collaboration among adjacent landowners can greatly increase the effectiveness of fuel treatments across landscapes. Collaboration can allow partners to share resources (for example, equipment, personnel, money). Collaboration can also lead to 
greater effectiveness of fuel treatments as strategies for mitigating fire spread patters are developed at more appropriate scales (in other words, landscapes).

We encountered several examples of managers successfully working across jurisdictional boundaries to more effectively reduce wildfire hazard. For example, the Gila National Forest allowed a wildland fire use event to spread onto adjacent private land with the support of the landowner to reduce surface fuels. The city of Flagstaff, AZ, will also conduct prescribed fires on private land with the landowner's cooperation to reduce surface fuel loading. Because managers facilitated treatments closer to structures, both of these examples did much more to protect structures from wildfire than if they had occurred exclusively on federal or city land. The sharing of resources essentially provided greater leverage for implementing fuel treatment projects.

A similar process is occurring on a much broader scale on the Coronado National Forest and surrounding lands in southern Arizona where future fuel treatments across the landscape are being planned. Rather than complete the process in isolation, the Forest has invited managers from adjacent landowners to the table. This includes managers from the Nature Conservancy, Department of Defense, Audubon Society, and National Park Service. Their joint environmental analysis will cover all jurisdictions and allow all agencies to use the information in their own planning process. Thus, strategies for fuel treatment placement can be developed across jurisdictional boundaries to more effectively reduce wildfire hazard on a landscape scale.

A stellar example of interagency collaboration in the Front Range would be the Front Range Fuels Treatment Partnership, comprising a collation of federal, state, and local agencies working with private landowners, conservation organizations, and other stakeholders to reduce wildfire risk. The partnership has sponsored workshops, compiled data on forest condition and treatment techniques, needs, and costs (Front Range Fuel Treatment Partnership Roundtable 2006), and has served as clearinghouse to educate stakeholders on fuels treatment issues.

Coordinating fuel treatments across agency boundaries through efforts like these will maximize benefits gained in reducing wildfire risk and improve ecological integrity across landscapes, regardless of ownership. If the collaborative effort is extended to sharing resources during implementation, further savings will result. This could include extending fuel treatment contracts across jurisdictional boundaries, or conducting joint prescribed burns using personnel and equipment from cooperating agencies. 


\section{Fuel Treatment Impacts, Mitigation, and Monitoring}

$\mathrm{W}$ hile the overall outcome of fuel or restoration treatments may be beneficial in terms of reducing wildfire hazard and improving ecosystem health, unintended and undesirable effects, such as introduction of invasive species or excessive tree mortality can also occur. However, measures can be taken to ensure undesirable effects do not materialize or to mitigate unintended effects should they occur. In this section, we review several unintended outcomes of fuel and restoration treatments and present some successful measures taken to mitigate these effects.

Monitoring of treatment effects is vital to ensure that restoration and fuel reduction treatments have the intended effect. When undesirable effects do occur, the monitoring data allows documentation of the effect and modification of treatment prescriptions so the undesirable effect does not occur in future treatments. Monitoring of treatment effects should be an integral part of any restoration or fuel reduction treatment and should include post-treatment recovery as well as evaluation of direct treatment objectives. Despite this need, it is not uncommon for managers to neglect monitoring because of operational time and resource constraints. Yet in many cases, sufficient information can be gained from simple protocols that require relatively little investment in time and resources.

\section{Undesirable Impacts of Fuel Treatments}

\section{Tree Mortality}

Protection of large and old growth trees and those with other desirable characteristics is often a priority of restoration treatments because such trees provide important ecosystem amenities including wildlife habitat, opportunities for large snag recruitment, greater genetic diversity, retention of cultural artifacts, and enhanced aesthetics. Under certain conditions, smoldering duff can damage tree roots and ultimately cause high levels of mortality of old growth trees (Graham and others 2004; Lindenmuth 1960; Sackett and others 1996). Burning stands with high loading of surface fuels can also cause excessive tree scorch that can result in tree mortality (Harrington 1987; Jerman and others 2004; Swezy and Agee 1991; Wienk and others 2004; Wyant and others 1986). High levels of tree scorch can also leave trees more susceptible to bark beetle attack (Wallin and others 2003). Use of prescribed fire can be tenuous when there is high density of saplings. Under safe burning conditions, it is often difficult to achieve fire behavior hot enough to kill tree seedlings and saplings under dense forest canopies and thus meet treatment objectives (Agee and Skinner 2005; Sackett and others 1996). However, burning under more extreme conditions can lead to undesirable ecological effects. If smaller trees ignite, they can act as ladder fuels, carrying fire into the canopy of larger trees. Tree mortality is not limited to prescribed fire treatments alone. Undesired mortality and damage to residual trees can also occur during mechanical treatments (fig. 33). Large equipment can knock over trees and damage roots, bark, and branches to the point of causing tree mortality.

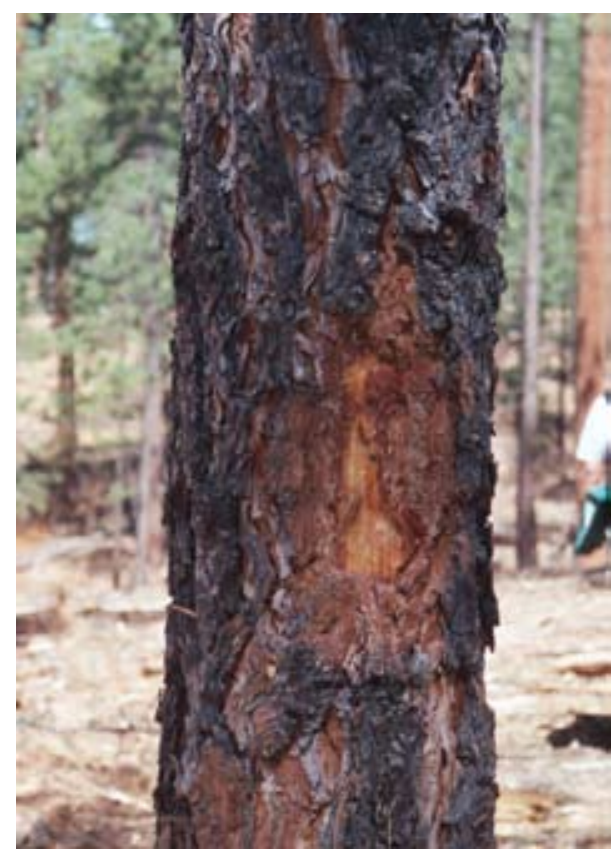

Figure 33. Care should be taken to limit damage to residual trees when maneuvering mechanical equipment through forests. Photo credit: Molly Hunter. 


\section{Non-native Species}

Non-native species are often adapted to disturbed environments with increased availability of resources such as light, nitrogen, and water (Hobbs and Huenneke 1992). Since fuel treatments constitute a disturbance, they can also encourage establishment of invasive species that may ultimately have negative consequences to native species and biodiversity (Mack and others 2000). Cover of non-native plants has been found to increase following prescribed fire and mechanical treatments in ponderosa pine forests (Crawford and others 2001; Griffis and others 2001; Hunter and others 2006; Keeley and others 2003; Metlen and Fiedler 2006) (fig. 4). If disturbance intensity is high, non-native plants do seem to be even more likely to establish and spread. For example, non-native plants have been found to establish following high intensity wildfires (Crawford and others 2001; Griffis and others 2001; Hunter and others 2006; Keeley and others 2003) and following particularly aggressive mechanical treatments where a great deal of the existing basal area is removed (Abella and Covington 2004; Fule and others 2005). Establishment of non-native species is also a function of the number of available propagules, or seeds, of non-native species at a site. Areas with a long history of disturbance have been reported to have more non-native species stored in the seedbank than in more pristine areas (Korb and others 2005). This may explain why non-native species have not been found following wildfires in more remote areas in northern Arizona (Laughlin and others 2004, 2005). Fuel treatments also carry the risk of transporting seeds of non-native species attached to mechanical equipment or people to a site.

\section{Air Quality}

Smoke produced from prescribed fires is problematic because it can pose threats to human health and impair visibility and thus, is regulated under state and federal laws. In addition, the public's negative reaction to smoke can threaten prescribed fire programs. When fuels burn efficiently, the smoke is composed mostly of carbon dioxide and water. While these are greenhouse gasses, they are not considered pollutants and are not regulated as such. Fuels burn efficiently when most of the fuel is combusted in the flaming stage (DeBano and others 1998; Mahaffey and Miller 1994). When fuels are combusted during a smoldering fire, they burn inefficiently, more smoke is produced, and other pollutants, such as particulates, carbon monoxide, and nitrogen and sulfur oxides, are released with the smoke. These pollutants are often subject to regulation under federal and state laws.

\section{Aesthetics}

There are several aspects of prescribed fire and mechanical fuel treatments that should be considered from an aesthetics perspective. This is particularly important for treatment areas that are readily visible by the public. Public acceptance of fuel treatment programs is vital for long-term support of these programs and is often a function of the perceived aesthetics (Winter and others 2002). Managers with the Flagstaff Fire Department have noticed that the public tends not to support prescribed fire efforts when they result in excessive tree scorch or mortality, particularly of large trees. Many managers have found that the public does not like the way treated areas look immediately after prescribed fires, but find the aesthetics acceptable 1 or 2 years later. Managers of the Colorado State Forest have noticed that residual tree damage from mechanical equipment is also a factor that can impact the public's perception of aesthetics. Freshly shredded trees, scattered debris, and disturbed soil also affect aesthetics in mechanically treated areas, especially when large volumes of material remain (fig. 34).

\section{Wildlife Habitat}

Prescribed fire and mechanical treatments can have negative impacts on many important components of wildlife habitat, such as snags, downed logs, and old growth or large trees (Horton and Mann 1988; Randall-Parker and Miller 2002). Snags are particularly important for cavity nesting birds and bats. Downed logs provide habitat for small mammals, reptiles, amphibians, and insects. Large trees are used by a variety of wildlife species for nesting, feeding, foraging, and roosting. Prescribed fires tend to consume snags and downed logs and can cause mortality of large trees through damage to fine roots. While some new snags can be recruited from killed trees and downed logs can result from fallen snags, the gain in new snags and downed logs generally does not offset the loss from prescribed burning (Randall-Parker and Miller 2002). This is particularly true for large snags (Horton and Mann 1988). The impacts of multiple prescribed fires on snags and downed logs are not well understood. However, Holden and others (2006) found that even after multiple burns, snag density was within the range adopted by the U.S. Forest Service as necessary to maintain viable populations of cavity nesting birds.

While control of dense thickets of Gambel oak is sometimes desirable in ponderosa pine forests (see Livestock Grazing and Chemical Treatment section), large and isolated Gambel oak trees provide very important wildlife habitat in ponderosa pine forests of the Southwest (Harper and others 1985). Bird diversity tends 


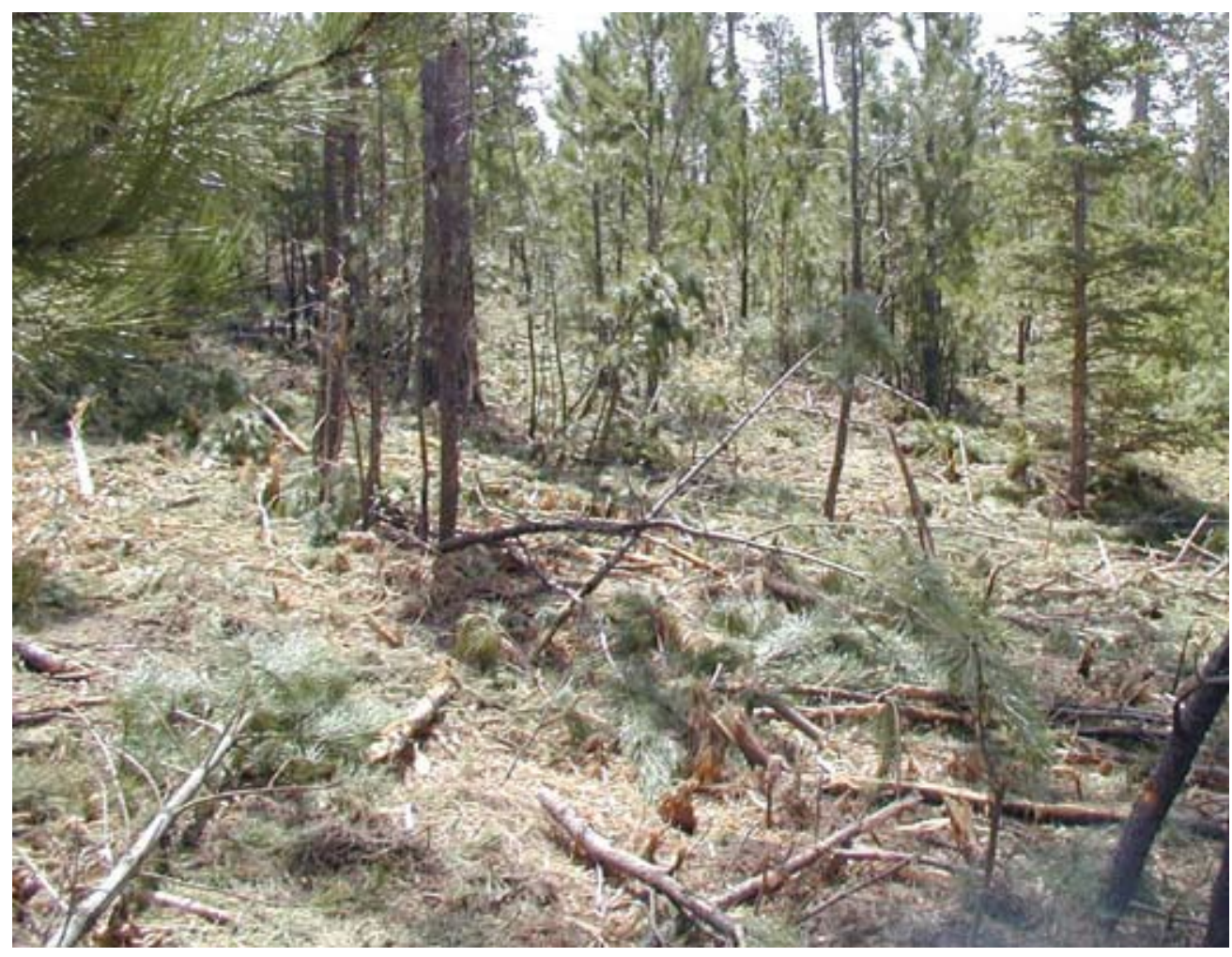

Figure 34. Scattered debris left after a thinning operation is generally not considered aesthetically pleasing to the public. Photo credit: Deb Tinker.

to be higher in ponderosa pine forests that have some Gambel oak component (Rosenstock 1998), and small mammals tend to prefer large Gambel oaks (Chambers 2002). There is some indication that prescribed burning may increase mortality of large and old Gambel oak trees (Randall-Parker and Miller 2002).

Wildlife species found throughout ponderosa pine forests can be adapted to a wide variety of forest conditions, from openings to relatively dense forest stands. For example, while many ungulates prefer open stands or small openings for feeding, they also need more dense stands for protective and thermal cover (Ffolliott 1997). It is important to maintain a variety of stand structures and spatial distributions across the landscape to maintain sufficient habitat for the wide range of species in these forests. When uniform treatment prescriptions are used, there is danger in creating a homogenous landscape in which important habitat for many species is lost.

\section{Cultural Resources}

Preservation of prehistoric and historical sites and artifacts is important for understanding past societies and our cultural heritage. Such sites and resources are prominent in western landscapes. Prehistoric cultural resources include artifacts, ceremonial or residential sites, and rock art panels including pictographs and petroglyphs. Historical resources include old cabins, homesteads, logging camps, battlegrounds, trails, mining claims, and artifacts from such sites (Hanes 1994). Prescribed fire and mechanical fuel treatment activities have the potential to damage these resources in a variety of ways. Cultural resources can be directly scorched, altered, or consumed by prescribed fire and heavy equipment. The potential for damage depends on the type of artifact material, whether it is above or below ground, the intensity of a fire, or the type of mechanical treatment. For example, organic materials have much less capacity to retain heat than stone or ceramic materials. Stone is subject to damage at temperatures above $700^{\circ} \mathrm{F}$, while ceramic is subject to damage at temperatures above $925^{\circ} \mathrm{F}$ (Hanes 1994). Pictographs are especially vulnerable to damage from prescribed fire. However, prescribed fire is not likely to reach temperatures that would result in damage to artifacts that are buried below the surface. In general, higher fire intensity will increase the potential for damage to cultural and historical resources. Mechanical treatment activities and equipment that does not disturb or compact the soil will have minimal effect on artifacts compared to tracked vehicles, bulldozers, fire line plows, and so forth.

Accurate dating of prehistoric sites and artifacts can also be compromised by prescribed fire. For example, carbon dating of charcoal remains is often done to determine the approximate age of prehistoric sites. However, this process can be compromised if the charcoal is contaminated with ash and charcoal from more recent fires. Pollen preserved in prehistoric sites can be 
used in paleoenvironmental and dietary studies. Pollen is generally destroyed when exposed to temperatures above $600^{\circ}$ F. Similarly, dating of pottery fragments, obsidian, and other materials becomes highly inaccurate if these materials are subject to intense heat (Hanes 1994). Both prescribed fire and mechanical treatments can destroy valuable tree ring records of past climate, fires, insect outbreaks, and other disturbances. This occurs most often when sound stumps, logs, and snags are burned or destroyed. For example, the 2002 Hayman Fire in Colorado destroyed nearly all dead wood that was sampled to develop fire history chronologies presented in Brown and others (1999). Evidence of early fires no longer exists in the severely burned portion of the Hayman Fire where all surface fuels were consumed.

\section{Soil Resources}

When heavy equipment drives over the soil surface, it may compact or physically displace soil. Increased soil compaction can make it harder for plants to extract water and nutrients from the soil and thus decrease the productivity of a site (Poff 1996). This effect is dependent upon the number and type of vehicle passes and can last years to decades (Shepperd 1993). However, soil compaction is not a serious problem on all soil types. For example, soils containing high levels of organic matter, surface rock fragments, and sand or clay content are generally less susceptible to compaction (Greacean and Sands 1980; Lull 1959; Poff 1996). Displaced soil also has long-term consequences for site productivity. Displaced soil can ultimately be deposited in lakes or streams and impair water quality. Since scarified seedbeds favor natural ponderosa pine seedling establishment (Shepperd and others 2006), excessive soil disturbance in fuels treatment areas can result in quicker re-establishment of ladder fuels.

Mastication, chipping, and mowing all result in large increases in woody material on the soil surface. This increase in woody biomass has the potential to impact a variety of ecological attributes. For example, the availability of nitrogen in the system may initially decrease as nitrogen is tied up in decomposing organisms and a subsequent increase in nutrient availability once the material is completely decomposed (Resh and others 2005). However, if the layer of material is excessively thick, decomposition may be slow and nutrients may be tied up for some time (Graham and others 2004). This material often acts as mulch, resulting in increases in soil moisture and decreases in daily temperature fluctuations. It may also prevent establishment of tree seedlings and understory vegetation, particularly if material is left in a thick layer. There is some evidence to suggest that the wood material provides habitat for insects and pathogens that may then impact standing trees.

Often, masticated fuels are subsequently burned to increase the rate of decomposition. There is some concern that burning high loadings of masticated fuels can result in high fire intensity and thus, adverse fire effects on soils and vegetation. Burning thick layers of masticated fuels often results in large heat pulses to the soil that can potentially kill soil organisms, seeds, and plant roots (Busse and others 2005). Similar effects can be seen under burned slash piles (Korb and others 2004; Massaman and others 2003). The resultant conditions may provide ideal opportunities for establishment of invasive species (Korb and others 2004; Wolfson and others 2005). In addition, there is some concern that burning masticated material would smolder and create smoke management problems.

\section{Insect and Disease Outbreaks}

Several studies have been conducted on how fire affects the risk and hazard of insect infestations and how insects influence the probability of fire ignition, spread, and severity (Billings and others 2004; Cunningham and others 2005; Mathew 2003; Moretti and Barbalat 2004). Some of these studies have examined the impacts of fuels treatments, especially prescribed fires (Boyle and others 2004; Sullivan and others 2003). These studies have shown that fire can injure or kill insects directly, cause them to leave burning areas, or attract them (Evans 1971). Different insect species respond differently to fire. Huff and Smith (2000) list six responses of animal communities to fire: invade, exploit, resist, endure, avoid, and vacillate. These categories are applicable to insects as well. Some insects are vulnerable only at certain stages of their life cycle. For example, bark beetles can be protected from fire and many other threats while feeding under bark. Some insects live for periods of their life, or even their entire life, underground where their survival during a fire depends on the fire severity. Many insects can flee an approaching fire. Others are attracted to the heat, smoke, or carbon dioxide emitted by a fire. Understanding these behavioral responses offers a core for developing fire management options aimed at reducing fire risk and hazard by managing insect populations or managing the probability of insect infestation. 


\section{Mitigation of Undesirable Fuel Treatment Impacts}

\section{Tree Mortality}

Some researchers have recommended mechanically removing duff around the base of old growth trees before prescribed fire is initiated (Covington and others 1997). While such treatments have been successful in reducing tree mortality, many managers find this practice very labor intensive and too expensive given the resources they have to complete projects. Thus, this practice may not be feasible in all situations. Others have been able to achieve appropriate mortality levels without duff removal by conducting prescribed fires under conditions that promote low fire intensity (for example, high relatively humidity and low air temperature) (Bastain 2001; Davis and others 1968; Kaufmann and Covington 2001; Swezy and Agee 1991). However, such fires may not be effective in reducing surface fuel loadings to levels sufficient for reducing wildfire hazard. Thus, multiple prescribed fires may be needed. Season of burning can also be taken into account, as trees are often more susceptible to the stress of fire during the growing season (spring and summer) (Harrington 1987).

Even when density of saplings is high, there seems to be some potential for use of high intensity fire exhibiting some torching to reduce tree density. This may also pose a threat to mortality of larger and desirable trees, especially if torching of smaller trees occurs and increases the potential for fire to spread into the canopies of larger trees. Reintroduction of fire may be possible only after some of the smaller trees have been mechanically removed (Covington and others 1997; Fule and others 2001; Graham and others 2004; Wallin and others 2004). Alternatively, it may be used under conditions that promote a fire that mainly affects smaller trees through cambial damage or some scorching of tree canopy, while posing little impact on larger trees. Burning under such moderate conditions may not be sufficient in killing smaller trees and reducing stand density as many trees can survive these burning conditions. Instead, multiple low intensity prescribed fires may be needed to successfully kill small trees and reduce tree density without harming overstory trees (Fule and others 2002a).

\section{Non-native Plants}

Spread of non-native plants can be handled by taking measures to limit seed dispersal and establishment, or by eliminating populations of non-natives before they establish and spread throughout the treatment area. A very effective pre-emptive measure is to limit the degree to which people and mechanical equipment disperse seeds in a site. For example, many management agencies require that equipment be washed to remove seeds before entering a treatment unit. On the Prescott National Forest, managers take further measures to ensure that seed spread by humans will be minimal by avoiding obvious non-native plant populations when placing landings and fuel breaks or holding personnel briefings.

Spread of non-native plants following fuel treatments can be expected if seeds are already on site. To mitigate these potential impacts, individual non-native plants should be quickly controlled before populations spread and reach uncontrollable levels. Managers in northern Arizona have successfully controlled for non-native species in slash pile scars by amending them with arbuscular mycorrhizal fungi and seeds from native species (Korb and others 2004). In Custer State Park, SD, large machine pile scars are generally sprayed with herbicide to control non-natives and then amended with native seeds. Several years after the treatment, the former burn scars were indistinguishable in a native grass meadow in the park. Only certified weed-free native seed mixes should be used. Further caution is needed as some mixes have been suspected of contamination with seeds from non-native plants (Hunter and others 2006; Springer and others 2001). Mechanical removal of invasive plants, mowing to prevent seed ripening, or introduction of biological agents that kill specific invasive plants are all additional measures that can control non-native plant populations.

\section{Air Quality}

Problems associated with smoke can be alleviated by burning under conditions that result in more efficient combustion of fuels (DeBano and others 1998; Mahaffey and Miller 1994). The efficiency of combustion can be influenced by ignition techniques, fuel structure, and burning conditions. For example, head fires tend to be fast moving while back fires move much more slowly. Little fuel is burned in the flaming front of a fast moving head fire compared to a slow moving backing fire. In a heading fire, more fuels tend to burn in a smoldering manner after the flaming front has passed. Thus, head fires tend to produce more smoke and pollutants than back fires.

Fuel structure also determines the amount of smoke and pollutants produced in a fire (Mahaffey and Miller 1994). Fine fuels tend to burn efficiently while large diameter fuels tend to smolder. Tightly packed fuels tend to smolder more than loosely packed fuels. Dry fuels tend to burn more completely than wet fuels. The amount of smoke produced from a fire can be controlled by burning 
when conditions favor certain fuels and not others. For example, if reduction of fine fuels is the primary goal, a fire can be set when fuel moisture of the fine fuels is low and fuel moisture of the large fuels is high. Smoke production would thus be lessened if larger fuels were not available to burn.

When large amounts of smoke production are inevitable from a prescribed fire, care should be taken to ensure that smoke does not drift into sensitive areas such as scenic vistas, urban areas, or road corridors (DeBano and others 1998; Mahaffey and Miller 1994). This can be accomplished by burning when wind is not blowing in the direction of the sensitive area. If smoke drifts into sensitive areas, care should be taken to ensure that the smoke plume mixes with substantial amounts of air before it reaches the sensitive area. This can be accomplished by burning when the atmosphere is somewhat unstable and will promote rapid mixing. However, burns should not be conducted when the atmosphere is extremely unstable, as this can promote extreme fire behavior. Mixing of the smoke with air can also be encouraged by creating burning conditions that promote development of a convection column that allows smoke to rise rapidly to the upper atmosphere. For example, mass ignitions are more likely to create convective conditions than line ignitions.

The Flagstaff Fire Department has been very successful in managing smoke production from prescribed fires in the wildland urban interface by adhering to several management practices (Flagstaff Fire Department 2005). In general, prescribed burns are avoided adjacent to sensitive areas such as medical centers and nursing homes. If burns are conducted near schools, they are done when school is not in session. If possible, burns are conducted in the summer when day lengths are long. This reduces the risk of nighttime smoke inversions. Burns are also conducted when forecasts for ventilation are good or excellent. To reduce smoke emission, backing fires are normally used and some woody material may be removed or isolated prior to burning. Managers adhere to maximum burn guidelines by burning no more than 150 piles per day no more than once a week in a neighborshed and no more than 50 acres per week on a broadcast burn in a neighborshed. In addition, managers notify the media and the public about planned prescribed fires and possible smoke impacts before burns are conducted. One of the reasons the program is so successful is the time and energy put into the extensive public outreach and education program.

Smoke management is an integral part of the prescribed fire planning process. With careful planning and experience, problems associated with smoke can be avoided or at least minimized. Several models are available to help predict the amount of smoke likely to be released from a fire and the direction the smoke should spread although they have had varying success. A relatively new model increasingly being used by managers, the Smoke Impact Spreadsheet (SIS), has shown some success in accurately predicting particulate matter emissions from prescribed fires. This model incorporates the First Order Fire Effects Model (FOFEM) and CONSUME to predict downwind emissions of particulate matter from wildfires, broadcast burns, and pile burns (Wickman and Acheson 2005).

\section{Aesthetics}

In general, a fuels treatment that is good for the ecosystem can also be aesthetically pleasing, if applied properly. Avoiding excessive scorch or mechanical damage to residual trees is beneficial from a variety of resource standpoints. Excessive residual surface fuel loading is probably not acceptable from either an aesthetic or a fire hazard perspective. In heavily used or visible areas, care should be taken to maintain stand characteristics that contribute to the aesthetic quality of the forest, including retention of large trees, spatial and structural diversity, and minimizing surface debris. Measures can also be taken in such areas to limit tree mortality. For example, managers in Bandelier National Monument have removed heavy loadings of duff around old growth trees in highly visible areas to limit mortality from prescribed fires. While this practice is generally too labor intensive to practice on all prescribed fires, it has been done in areas that are more visible. To avoid residual tree damage, foresters with the Colorado State Forest Service recommend being very specific in contracts about acceptable residual tree damage and holding contractors responsible for unacceptable levels of damage. Negative results can be avoided by having a detailed contract, stringent enforcement, and a mutual understanding with the contractor as to what is expected. In some cases, the Colorado State foresters will treat a test plot prior to treating the entire unit to ensure the contractor understands the desired treatment effects.

The choice of fuel treatment technique can also affect resulting aesthetics. For example, the Pike National Forest uses public firewood sales to clean up tree boles dropped by Forest Service crews in accessible (and highly visible) units along highways. This highly effective technique meets public demand for firewood, builds goodwill and acceptance of fuels treatments, and dramatically reduces heavy fuel loading. Subsequent low intensity prescribed burns are then used to eliminate 
remaining surface fuels with minimal adverse smoke effects and residual tree damage.

\section{Wildlife Habitat}

Measures can be taken to ensure prescribed burns do not result in excessive loss of these important wildlife habitat components. Burning snags can be prevented by removing fuels from the base of snags prior to burning (Anderson 1994; Randall-Parker and Miller 2002), or by black lining snags prior to burning the entire unit. Large diameter snags, which are often preferred by cavity nesting birds, may be in particular need of protection as there is little potential for large snag recruitment given the lack of large diameter trees in many areas (Horton and Mann 1988). The same can be done to large or old growth trees to prevent mortality. Foresters with the Colorado State Forest occasionally removed fuels around large pieces of coarse woody debris to protect them in prescribed fires. Burns can also be conducted when moisture contents of fuels are such that only small diameter fuels will burn and large fuels will be spared (Anderson 1994; RandallParker and Miller 2002). Burning in early spring shortly after snowmelt can be effective in accomplishing this result (Shepperd 2004). If surface fuels are to be removed through burning of piles, large diameter logs can be intentionally left out of the piles to create wildlife habitat. To limit mortality of large oak trees during prescribed fire, managers in northern Arizona often create fuel breaks around large oak trees prior to burning. To do this in a cost effective manner, they use an innovative ATV fire line plow created from an old truck wheel (see SECTION IV, Tools Used in Burning). In addition, care can be taken so that oak litter is not directly ignited and instead, fire is allowed to creep through it. Managers on the Coconino National Forest have found that this practice limits mortality of large oak trees.

When treating ponderosa pine landscapes to reduce fire hazard, it is important to ensure such activities result in a mosaic of forest cover types across the landscape that are likely to be the most beneficial in providing habitat for a variety of species (Fiedler and Cully 1995; Shepperd and Battaglia 2002; Sieg and Severson 1996). Heterogeneity in stand structure should also be a management goal on the stand level. Rather than promoting a uniform treatment prescription, managers should strive to create heterogeneity by using a variety of treatment prescriptions and in some cases, conducting no treatment at all. Historical forest structure can be used as a guide in this process. For example, heavier thinning prescriptions may be justified in areas that would have had low tree density historically (for example, south-facing slopes, meadows), while less intensive thinning prescriptions may be more appropriate in other portions of the landscape (for example, north-facing slopes). Managers on the Santa Fe National Forest have accomplished this by designing treatment prescriptions so areas in the forest that may have historically had higher tree density, like drainages, would have fewer trees removed.

\section{Cultural Resources}

Damage to cultural and historical resources from prescribed fire can be easily avoided by knowing the number, type, and distribution of cultural resources in a management area. Extensive archeological surveys in proposed treatment areas can substantially increase the cost of fuel treatments, but must be done if artifacts are suspected in the area. Sensitive materials can be removed from a site prior to treatment. If this is not possible, sensitive areas can be excluded from prescribed burning or mechanical treatment efforts. Fuel breaks can also be constructed around sensitive areas or high fuels loads can be manually removed around sensitive areas. Similarly, tree ring collections can be made prior to treatment, or potential sample specimens can be avoided. On the other hand, we should not forget potential positive cultural resource benefits resulting from fuels treatments. Managers at Bandelier National Monument have actually justified use of prescribed fire to protect sensitive areas that would otherwise be subject to much more extreme heat from a wildfire.

\section{Soil Resources}

Soil disturbance and compaction can be easily avoided by using hand crews in lieu of machines to fell and process trees. This may be a valid choice in very sensitive areas or on smaller treatment units. However, in some cases, use of mechanical equipment may be justified. While some soil compaction and disturbance is inevitable when heavy equipment is used for thinning or understory biomass alteration/removal, certain procedures or equipment can minimize the amount of soil compaction across a site. For example, using equipment that has longer reach and more maneuverability reduces the percentage of the area that the equipment needs to traverse. If boom-mounted machines are not available, care should be taken to ensure that machines stay in designated paths designed to minimize machine movement across the site. Felling trees in the direction of the skid trail can also minimize soil disturbance and compaction by minimizing skidding distance (Minard 2003).

Several agencies in northern Arizona limit damage to soil resources using a technique developed on the Mormon Lake Ranger District of the Coconico National 
Forest (Farsworth and Summerfelt 2001). With this method, trees are directionally felled into a windrow and are then pushed into large piles by a dozer during a single pass. Few ruts are made because the dozer is not constantly spinning and turning. Smaller, more maneuverable machines apply less ground pressure and lead to less soil compaction than larger machines. However, the effects of large machines are not as severe if the ground pressure is applied over a larger area (Poff 1996; Windell and Bradshaw 2000). Track-mounted machines tend to lead to less soil compaction than wheel-mounted machines as they allow the machine weight to be distributed over a larger area, but their skid-steering design can disturb soil to a greater extent. Soil compaction can also be minimized by conducting treatments when the soil is frozen or extremely dry, or by driving machines over protective layers of litter, slash, or snow (Poff 1996; Windell and Bradshaw 2000). Even on gentle slopes, road access or landings should be downhill of the treatment area. Skidding or forwarding logs uphill can result in substantial soil erosion and treatment costs (Fight and others 2003).

Some of the effects of burning masticated fuels may be avoided by burning multiple times under relatively wet conditions so that fuels are removed in stages. For example, a first burn can be accomplished when the top layer of masticated fuel is dry but the bottom layers are wet and thus, not readily ignited. Residual fuels can then be burned in subsequent burns, at 2- to 3-year rotations. Managers on the San Juan National Forest have achieved some success by using this technique. Adverse effects of burning slash piles can be avoided by keeping piles relatively small or burning larger piles when the soil is frozen or there is some snow on the ground (Farnsworth and Summerfelt 2001). This results in fewer piles per acre that can be ignited under snowier and wetter conditions than traditional hand piles. This method is also more productive than hand piling. However, managers should note that burning any pile results in very high soil temperatures and associated adverse soil effects (Massman and others 2003, 2006).

\section{Insect and Disease Outbreaks}

Few studies have examined insect-fire interactions at the landscape scale, although this subject has recently received increased attention (Howe and Baker 2003; Saint-Germain and others 2004; Sturtevant and others 2004). At the landscape scale, insects create, and are affected by, the spatial patterns of suitable and unsuitable habitat patches. Large fires seldom affect all burned areas equally, but the burned area usually arises from crown fires, severe surface fires, stand replacing fires, and understory fires that create a patchy spatially patterned environment composed of a variety of potential insect habitats. This spatial heterogeneity and variety of habitats helps to maintain insect populations, diversity of insect behavioral traits including wood-feeders, and genetic diversity among local insect populations. The configuration of suitable habitat, distance between suitable patches, and the nature of the landscape matrix between patches all influence the abundance, dispersal, and survivability of insect populations. These landscape attributes also determine the potential for insect outbreaks. Understanding how to make use of spatial patterns to manage fire and insect risk and hazard are fundamental to landscape fire and insect management, but much still needs to be developed.

\section{Monitoring}

Agencies often implement fuel treatment activities without fully knowing about their effectiveness or their potential impact on other values at risk. Monitoring of treatment effects is imperative to determine treatment effectiveness and to ensure undesirable effects do not materialize. Managers who have made monitoring efforts a priority have been able to operate more in an adaptive management framework by altering management actions when ineffectiveness or undesirable outcomes have been documented. Such data helps build public confidence and acceptance of fuels treatments, especially when it is shared openly among stakeholders and is used to help plan and implement future activities.

Several monitoring protocols have been developed specifically for monitoring the effects of fuels treatments. The most commonly used protocols within government agencies include the fire effects monitoring guide developed by the National Park Service (USDI National Park Service 2003) and FIREMON (Lutes and others 2006). While both protocols were developed for monitoring of prescribed fires, wildfires, and wildland fire use fires, they could be easily adapted for other fuel treatments (for example, thinning and grazing). These monitoring protocols recommend a basic level of monitoring that includes data on vegetation (for example, species composition and cover), stand structure (for example, tree density and size class distribution), fuels (for example, loading and depth), and basic fire effects (for example, scorch height and char height). These programs also provide detailed instruction for plot layout, data organization, and analysis.

This basic level of monitoring allows one to assess a wide variety of fuel treatment objectives. Data on fuels can be used to determine whether treatments are 
effective in reducing fuel loading to desired levels. Data on fire effects can be used to assure treatments result in desirable levels of tree mortality. Data on vegetation can be used to ensure treatments result in desirable levels of understory production while discouraging establishment of non-native, invasive species. Of course, in order to assess change, one must collect data before treatments are implemented, immediately after treatments are implemented, and again at regular time intervals following treatment, typically every year for up to 5 years or more.

Our observation in gathering information for this report is that with the exception of the National Park Service, most agencies struggle to allocate time and money to monitoring efforts, even while recognizing their importance. In response to this shortcoming, some have designed protocols that are flexible and can be altered depending on resources available for monitoring. For example, FIREMON describes three levels of monitoring designed for different levels of resources (Lutes 2006). Managers can alter monitoring protocols depending on resources available in several ways. If few resources are available for monitoring, managers may decide to collect data from fewer plots or not to collect data from a control plot. This will likely mean that it will be more difficult to detect treatment effects statistically, and results will have to be described in qualitative rather than quantitative terms. While this may not be ideal, it is still more desirable than collecting no data in conjunction with fuel treatments. FIREMON specifically discusses the number of plots that should be assessed given the level of resources available and the desired robustness of data. Managers can also collect data on fewer variables if resources for monitoring are scarce. However, some have noted that much of the cost associated with monitoring can be attributed to transporting crews to and from monitoring sites. It is often a more efficient use of resources to collect as much data as possible while at the monitoring site (USDI National Park Service 2003).

The level of monitoring recommended by the National Park Service and other agencies may still be too detailed for the needs of other smaller organizations. The Collaborative Forest Restoration Program (CFRP) has attempted to meet monitoring needs of other organizations in New Mexico. This granting program supports restoration projects on federal, state, municipal, and tribal lands in New Mexico. An integral requirement for funding under this program is a multiparty monitoring protocol. Simple protocols for a variety of variables are available at http://www.fs.fed.us/r3/spf/cfrp/ (accessed 10-25-06). While developed in New Mexico, these protocols could also be adapted for other regions.

In some cases, the basic protocols discussed above may not be useful for meeting other monitoring objectives. This may particularly be true if a management area is managed for a very specific resource such as Native American ruins or sensitive wildlife habitat. These monitoring protocols will not be useful for determining whether or not prescribed fire damages sensitive Native American artifacts. In such special cases, more specific monitoring protocols need to be developed to assure treatments are benefiting the desired resource, or at least not harming it.

Responsibility for monitoring does not end with the field data collection. It should include archiving and cataloging of results in a permanent database available and readable to future generations of fuel managers. Another advantage of using developed programs such as FIREMON and the National Park Service monitoring protocol is that data archiving and analysis applications have been developed with the protocols. This allows for a systematic framework for archiving data. 


\section{Section VII:}

\section{Comprehensive Management Principles}

D uring our conversations with managers throughout the Southwest, Front Range, and Black Hills, we discovered that while many managers are driven by similar resource management objectives, very different approaches are taken to achieve these objectives. There is no one method for effectively meeting management objectives, but we have noticed that success is more likely to be achieved when several broad management principles are followed. We attempt to summarize those principles here as broad guidelines that can be applied to any management scenario and are imperative to consider in any fuel treatment or restoration project. We also present specific examples we encountered of how managers are implementing these principles.

\section{Integrating Ecological Knowledge and Principles into Fuel Projects}

Fuel treatments should be designed to accomplish more than reduced wildfire risk or hazard. When other resource management objectives are incorporated into projects, fuels treatments will ultimately be more ecologically sustainable. This is best achieved through restoration of forested systems to conditions that were seen prior to major disruptions often associated with Euro-American settlement. We recognize that restoration will not always be compatible with reducing wildfire hazard. However, where reducing wildfire hazard takes precedent over restoration, attempts can still be made to restore certain features of historical stands. For example, in areas where habitat features such as large trees and snags have been lost, development of these important habitat components should be encouraged.

In ponderosa pine forests adapted to historical surface fire regimes, ecological restoration goals include surface and canopy fuel reduction, protection of old trees, recovery of native understory vegetation, and the reintroduction of surface fire as a key ecological process (Allen and others 2002; Covington and others 1997; Fule and others 2006). If managers are to mimic the effects of natural disturbances, they must integrate the timing and severity of prescribed disturbances with the ecological requirements of the desired landscape composition and condition (Hudak and others 2006). Understanding the effects of different types of disturbances and associated alteration of key processes may help to promote ecosystem resiliency through improved management decisions. Fuel reduction treatments influence vegetation succession, and the individual and cumulative effects of these treatments may have positive and negative implications for ecosystem character and function (Noss and others 2006). Development of sustainable relationships between humans and their environments requires knowledge of successional consequences and planning on a broad spatial scale.

Goals of restoration and reduced wildfire hazard may not always overlap in mixed-severity fire regimes more commonly found in the Front Range and Black Hills. While some portions of these forests burned historically with low intensity surface fire, pockets with high intensity crown fire on a small scale were also common (Brown and Sieg 1996; Brown and others 1999; Huckaby and others 2001). This likely resulted in a landscape mosaic composed of openings, stands with low tree density, and stands with relatively high tree density. Thus, a fully restored landscape is not likely to result in acceptable levels of wildfire hazard reduction given the patchwork of public and private land found in these landscapes. However, certain aspects of historical structure and processes can and should be incorporated into fuel treatments, particularly on a landscape scale. For example, care may be taken to maintain patches of densely stocked forest in areas where they would not pose an undue hazard to human communities.

\section{Case Study}

Many fire managers recognize that re-establishing appropriate fire regimes to fire-adapted ecosystems is imperative for allowing natural processes to shape ecosystems. Fire is likely the best tool available to create the natural heterogeneity in forest structure at stand and landscape scales. Managers on the Gila National Forest have been very successful in allowing naturally ignited fire to shape the landscape. Since their wildland fire use program has been implemented (over 30 years ago), multiple areas have burned in two or three wildland 
fire use events. This has created a forest structure that is more characteristic of historical conditions. Managers here work closely with wildlife biologists and adjacent landowners to ensure that wildland fire use events do not threaten sensitive wildlife habitat or communities. Allowing natural fires to return to these ponderosa pine forests will allow the many plants and animals adapted to this system to thrive under current and future climatic conditions.

\section{Planning Fuel Treatments Within a Broad Landscape Context}

The degree to which fuels treatments and other vegetation conditions have influenced fire effects across landscapes is little understood, yet has tremendous implications for the efficacy of fuels management designed to achieve multiple resource objectives, including the moderation of future fire effects. Planning fuel treatments on a landscape scale and across jurisdictions is needed because most wildfires dwarf the size of individual fuel treatment projects and don't obey human defined boundaries. It will never be feasible to treat every square inch of fire-prone landscapes. Strategies should be developed to maximize benefit gained from fuel treatments, both in terms of reducing the threat of wildfire and improving ecological integrity. Fuel treatments can be strategically placed across landscapes so the historical heterogeneity in forest structure can also be recreated. Many studies (for example, Callaway and Davis 1993; Cram and others 2006; Odion and others 2004) have found that patterns of fire effects (for example, severity) and post-fire vegetation recovery may be predisposed by topographical position and pre-fire vegetation structure. These studies suggest that, at the very least, forest managers should consider the spatial arrangement and size of harvest and other management units, as well as topographic characteristics, when planning for fuel treatments and other fire mitigation measures.

\section{Case Study}

Managers with the Coronado National Forest are currently involved with multiple parties in a planning process that will strategically place fuel treatments across the landscape. This effort is in collaboration with managers from neighboring landowners, including Department of the Defense, National Park Service, Nature Conservancy, Audubon Society, Bureau of Land Management, and Arizona State Parks. Collaborators are planning future fuel treatment projects to maximize benefit across jurisdictional boundaries. This approach has several other benefits: the costs per acre are kept low with broad-scale projects; natural and logical project boundaries (rather than jurisdictional) can be used for fire management; staff and equipment are used more efficiently across agencies; monitoring efforts can be coordinated; and a consistent message is delivered to the public.

\section{Encouraging Innovative Approaches to Fuels Treatment}

Many areas in ponderosa pine landscapes in most need of treatment are also the most difficult to treat because of topography or proximity to values at risk. While innovative approaches can be used to treat such areas, there often is no agency incentive for pursuing innovative options. Innovative and perhaps somewhat risky approaches need to be attempted in order to learn what can effectively reduce the threat of severe wildfire in some landscapes. Managers should not be penalized for attempting innovative treatments or be held personally liable if such treatments fail. Encouraging innovation means using an adaptive management approach that allows managers to try new approaches and learn from the experience. Restricting them to fuels treatments that are without risk stifles innovation. The probability of innovative treatments failing can be reduced by using experienced fire managers and resource specialists on the project team. Our conversations with managers revealed that the most successful fuel treatment programs always had a cadre of experienced personnel participating in the planning and on-the-ground execution of fuel treatment projects. Their knowledge of local conditions and confidence in what could be done strongly influenced the success of their programs.

\section{Case Study}

Managers on the Santa Fe National Forest advocate the pairing of very experienced fire managers with younger individuals in the field. The experienced managers often provide the detailed knowledge of a particular region and typical fire behavior in different circumstances in that locality. Working with younger members in the field ensures that this knowledge is passed to the next generation of fire managers. The working relationship is not a one way interaction, however. Younger managers often have the advantage of training in newer methods and models being used in the field of fire management. When this mix of expertise and new perspectives is combined, there is generally more confidence in the outcome and less aversion to the risks that are always associated with 
prescribed fire. While managers should always proceed with caution and be fully aware of the risks associated with their activities, they should focus on the importance of innovation in order to effectively achieve objectives.

\section{Monitoring Treatment Effects and Effectiveness of Fuel Projects}

Managers can not truly determine whether they are meeting management objectives with their treatments without monitoring their effectiveness. Quantitative data showing that treatments have been effective in meeting management objectives can serve to justify the need for more and similar treatments. Similarly, monitoring can document whether treatments are having adverse effects on other resource values such as wildlife habitat or biodiversity. Justification can be made for altering treatment prescriptions if monitoring data suggest that desired results are not being achieved. This allows managers to work in an adaptive management framework. Monitoring should not be restricted to fire weather and behavior, but should document treatment effects on other resources and ecosystem values as well. Monitoring should not begin with the treatment action, but should first document pre-treatment conditions to serve a benchmark for anticipated outcomes. Responsibility for monitoring does not end with the final data collection. It should include archiving and cataloging results in a permanent database available and readable to future generations of fuel managers.

\section{Case Study}

The fire effects monitoring protocol developed by the National Park Service and FIREMON provide very effective monitoring protocols that can be easily adapted to monitor for a variety of treatment effects. The protocols describe in detail every step of the monitoring process, including developing monitoring objectives, randomization, plot layout, data collection, data archiving and analysis, and more. These protocols can also be adapted depending on the level of resources devoted to monitoring. FIREMON, in particular, provides strategies for adapting monitoring protocols based on the level of resources available to conduct monitoring and the need for robust data. Both protocols also provide computer applications for archiving data that also include basic data analysis procedures.

The Collaborative Forest Restoration Program, a granting program that facilitates restoration projects on federal and tribal lands in New Mexico, requires monitoring be included in all proposed projects. To facilitate this process, the program members have developed protocols for monitoring a variety of ecological attributes. These protocols provide a common framework for monitoring, ensure treatments have been effective in meeting objectives, and document any detrimental impacts on other resources. Recognizing that many managers often have limited time and resources to do monitoring, these protocols have been designed to be relatively easy to implement. The monitoring guide developed by the program is available at http://www.fs.fed.us/r3/spf/cfrp/ (accessed 06-21-07).

\section{Collaboration with Other Resource Managers and Interested Parties to Improve Results}

Fuel treatment projects that are multi-faceted will best meet the needs of sustaining forested ecosystems. To be effective in meeting multiple resource management objectives, managers should solicit input from resource specialists with expertise in varying fields and from other interested parties outside the management agency. Establishing relationships with managers and stakeholders within and outside the agency, including the general public and non-profit organizations, can take a great deal of time and energy and reaching consensus can be difficult. However, we have noticed that managers who invested time in these relationships benefit immensely in the long run. With collaboration, fuel treatment projects are generally better in meeting multiple objectives and internal and external resistance to fuel treatments is lessened. Collaboration gives stakeholders ownership in the process and pride in the outcome.

Collaboration has a long history in fire management, evidenced by partnerships like the National Interagency Fire Center and the National Wildfire Coordinating Group. More recent policy directives (for example the National Fire Plan and Healthy Forest Restoration Act) have further emphasized the need for collaboration in fuel treatment projects, particularly on a local level. There are several benefits to collaborative efforts in the context of wildland fire. Collaboration tends to mobilize people to generate funds, allows for sharing of data and expertise, leads to a broader understanding of different attitudes and values toward natural resources, and allows for increased efficiency and effectiveness of fuel treatments (Sturtevant and others 2005). Collaboration tends to be effective in relatively small groups of people. Collaboration is time consuming and can be difficult if there is a history of unresolved conflict, if partners are not willing to compromise, or if partners have no power 
to implement decisions. However, overcoming these obstacles builds trust and ownership in the process and will inevitably lead to a successful outcome.

\section{Case Study}

Gila National Forest managers are developing strategies for implementing fuel treatments on the Silver City Ranger District. Multiple stakeholders are involved in the process including environmental advocates, local government officials, commercial wood products users, and scientists. This collaborative process ensures that the concerns of all interested parties are addressed. Working together in this setting, members from different parties often gain a better understanding for the needs and concerns of other stakeholders and compromises are more easily attained. In this case, we find that all collaborative partners understand the need to balance protection of communities, sensitive wildlife habitat, and important watersheds with other resource management needs and they work together to make sure these needs are met.

A number of excellent resources are available on establishing and maintaining collaborative relationships, including handbooks and guides specifically structured to the requirements and policies of Federal agencies. The following website has links to a number of publications and documents on collaboration and building partnerships. This website includes materials specific to fuels treatment projects and Forest Service agreements: http:// www.partnershipresourcecenter.org/resources

A particularly useful publication available at this site is the Partnership Guide, published jointly by the National Forest Foundation and USDA Forest Service National Partnership Office (National Forest Foundation and USDA Forest Service 2005). Yet another publication specific to building collaboration and preparing and implementing community wildfire protection plans is the handbook published by the Society of American Foresters, which can be found at: http://www.safnet.org/policyandpress/ cwpp.cfm.

We urge readers to use these resources to plan, build, and maintain collaborative relationships with stakeholders that have an interest in fuels treatment activities. Our experiences in completing this document have convinced us that including stakeholder ideas and input in a project and acknowledging their need for ownership in the decision-making process will ultimately ensure a successful outcome to any fuels treatment activity.

\section{Conclusion}

In our attempt to elucidate comprehensive management practices for fuels treatments in ponderosa pine forests in the Black Hills, Front Range, and Southwest, we have combed all available published literature and have journeyed throughout the regions where these forests grow to gather information from managers and fuels treatment practitioners. Our experiences have convinced us that while much is known, there is more to be learned. On the one hand, there are physical, biologic, regulatory, and societal limitations on what can be done to reduce the risk of catastrophic wildfire in these systems. On the other, there is innovation, collaboration, and a wealth of experience that can be drawn upon to find solutions to those limitations. What we have presented here is a static summary of existing knowledge. It is useful to a point today. Management practices will, and should, evolve as we gain new knowledge in the future. Our efforts should therefore be viewed only as a beginning point in that continuum. 
Abella, S.R.; Covington, W.W. 2004. Monitoring and Arizona ponderosa pine restoration: Sampling efficiency and multivariate analysis of understory vegetation. Restoration Ecology. 12: 359-367.

Agee, J.K. 1998. The landscape ecology of western forest fire regimes. Northwest Science. 72: 24-34.

Agee, J.K.; Skinner, C.N. 2005. Basic principles of fuel reduction treatments. For. Ecol. Manag. 211: 83-96.

Agee, J.K.; Bahro, B.; Finney, M.A.; Omi, P.N.; Sapsis, D.B.; Skinner, C.N.; van Wagtendonk, J.W. 2000. Use of shaded fuel breaks in landscape fire management. For. Ecol. Manag. 127: 55-66.

Alexander, M.E.; Hawksworth, F.G. 1976. Fire and dwarf mistletoes in North American coniferous forests. Journal of Forestry 74: 446-449.

Alexander, R.R. 1987. Silvicultural systems, cutting methods, and cultural practices for Black Hills ponderosa pine. Gen. Tech. Rep. RM-139. Fort Collins, CO: U.S. Department of Agriculture, Forest Service, Rocky Mountain Forest and Range Experiment Station. 32 p.

Alexander, R.R.; Edminster, C.B. 1977. Regulation and control of cut under uneven-aged management. Res. Pap. RM-182. Fort Collins, CO: U.S. Department of Agriculture Forest Service, Rocky Mountain Forest and Range Experiment Station. 7 p.

Allen, C.D. 1989. Change in the landscape of the Jemez Mountains, New Mexico. Berkeley, CA: University of California at Berkeley. Dissertation.

Allen, C.D. 2002. Lots of lightning and plenty of people: An ecological history of fire in the upland Southwest. In: T.R. Vale, ed. Fire, native peoples, and the natural landscape. Island Press, Washington D.C.

Allen, C.D.; Savage, M.; Falk, D.A.; Suckling, K.F.; Swetnam, T.W.; Schulke, T.; Stacey, P.B.; Morgan, P.; Hoffman, M.; Klingel, J.T. 2002. Ecological restoration of southwestern ponderosa pine ecosystems: A broad perspective. Ecological Applications. 12: 1418-1433.

Allen, M.H.; Berry, R.W.; Gill, D.; Hayes, G.L.; Truesdell, P.S.; Zwolinski, M.; Pierovich, J.M. 1968. Guide to prescribed fire in the Southwest. Southwest interagency fire council. $58 \mathrm{p}$.

Anderson, L. 1994. Chapter VII-Terrestrial wildlife and habitat. In: Miller, M. ed. Fire effects guide, PMS 481, NFES 2395, National Interagency Fire Center, Boise, ID.

Aplet, G.H.; Wilmer, B. 2003. The wildfire challenge: Focus on reliable data, community protection, and ecological restoration. The Wilderness Society, Washington, D.C. $40 \mathrm{p}$.
Archer, S.; Smeins, F.E. 1991. Ecosystem-level processes. In: Heitschmidt, R.K; Stuth, J.W. eds. Grazing management: An ecological perspective. Timber Press, Portland OR.

Arno, S.F.; Fiedler, C.E. 2005. Mimicking nature's fire: Restoring fire prone forests in the west. Island Press, Washington, D.C.

Arno, S.F.; Harrington, M.G. 1997. The interior west: Managing fire-dependent forests by simulating natural disturbance regimes. In: Forest management into the next century: What will make it work? Nov. 19-21, Spokane, WA. Forest Products Society and the U.S. Department of Agriculture, Forest Service.

Arnold, J.F. 1950. Change in ponderosa pine bunchgrass in northern Arizona resulting from pine regeneration and grazing. Journal of Forestry. 48: 118-126.

Bachelet, D.; Lenihan, J.M.; Daly, C.; Neilson, R.P. 2000. Interactions between fire, grazing and climate change at Wind Cave National Park, SD. Ecological Modeling. 134: 229-244.

Baisan, C.H.; Swetnam, T.W. 1990. Fire history on a desert mountain range-Rincon Mountain Wilderness, Arizona, USA. Can. J. For. Res. 20: 1559-1569.

Baisan, C.H.; Swetnam, T.W. 1997. Interactions of fire regimes and land use in the central Rio Grande Valley. Res. Pap. RM-RP-330. Fort Collins, CO: U.S. Department of Agriculture, Forest Service, Rocky Mountain Forest and Range Experiment Station. 20 p.

Baker, W.L. 2002. Indians and fire in the Rocky Mountains: The wilderness hypothesis renewed. In: T.R. Vale, ed. Fire, native peoples, and the natural landscape. Island Press, Washington, D.C.

Baker, W.L. 2003. Fires and climate in forested landscapes of the U.S. Rocky Mountains. In: T.T. Veblen, W.L. Baker, G. Montenegro, T.W. Swetnam, eds. Fire and climate change in temperate ecosystems of the western Americas. Springer, New York, NY.

Baker, W.L.; Veblen, T.T.; Sherriff, R.L. 2007. Fire, fuels, and restoration of ponderosa pine-Douglas fir forests in the Rocky Mountains, USA. Journal of Biogeography. 34: 251-269.

Bastian, H.V. 2001. Effects of low intensity prescribed fires on ponderosa pine forests in wilderness areas of Zion National Park, Utah. In: R.K. Vance, C.B. Edminster, B. Carleton, W.W. Covington, J.A Blake, eds. Ponderosa pine ecosystem restoration and conservation: Steps toward stewardship. Proc. RMRS-P-22. Fort Collins, CO: U.S. Department of Agriculture, Forest Service, Rocky Mountain Research Station. 
Betancourt, J.L.; Dean, J.S.; Hull, H.M. 1986. Prehistoric long-distance transport of construction beams, Chaco Canyon. American Antiquity. 51: 370-375.

Billings, R.F.; Clarke, S.R.; Espino-Mendoza, V.; CordonCabrera, P.; Melendez-Figueroa, B.; Ramon-Campos, J.; Baeza, G. 2004. Bark beetle outbreaks and fire: A devastating combination for Central America's pine forests. Unasylva. 55: 15-21.

Biswell, H.H.; Kallander, H.R.; Komarek, R.; Vogle, J.; Weaver, H. 1973. Ponderosa fire management: A task force evaluation of controlled burning in ponderosa pine forests of central Arizona. Misc. Pub. No. 2. Tall Timbers Research Station, Tallahassee, FL.

Bock, J.H.; Bock, C.E. 1984. Effect of fire on woody vegetation in the pine-grassland ecotone of the southern Black Hills. Am. Midl. Nat. 112: 35-42.

Boldt, C.E.; Van Deusen, J.L. 1974. Silviculture of ponderosa pine in the Black Hills: The status of our knowledge. Res. Pap. RM-124. Fort Collins, CO: U.S. Department of Agriculture, Forest Service, Rocky Mountain Forest and Range Experiment Station. 45 p.

Bonnet, V.H.; Schoettle, A.W.; Shepperd, W.D. 2005. Postfire environmental conditions influence the spatial pattern of regeneration for Pinus ponderosa. Can. J. For. Res. 35: 37-47.

Borman, M.R. 2005. Forest stand dynamics and livestock grazing in historical context. Conservation Biology. 19: 1659-1662.

Boyle, M.F.; Hedden, R.L.; Waldrop, T.A. 2004. Impact of prescribed fire and thinning on host resistance to the southern pine beetle: preliminary results of the National Fire and Fire Surrogate Study. USDA Forest Service, Southern Research Station, Asheville, NC . General Technical Report SRS-71: 60-64.

Bradley, T.; Gibson, J.; Bunn, W. 2003. Fire severity and intensity in natural and manipulated fuels during spring burning in mixed shrub woodlands. Poster presentation at the 2nd International Wildland Fire Ecology and Management Congress, Nov 16-20, 2003, Orlando, FL.

Brown, A.A.; Davis, K.P. 1973. Forest fire control and use. McGraw Hill Book Company, New York, NY.

Brown, J.K. 1984. A process for designing fire prescriptions. In: R.W. Mutch, ed. Proceedings: Prescribed fire by aerial ignition, Oct. 30-Nov. 1, 1984, Missoula, MT. Intermountain Fire Council.

Brown, P.M. 2003. Fire, climate, and forest structure in ponderosa pine forests of the Black Hills. Fort Collins, CO: Colorado State University. Dissertation.

Brown, P.M.; Cook, B. 2006. Early settlement forest structure in the Black Hills ponderosa pine forests. For. Ecol. Manag. 223: 284-290.

Brown, P.M.; Seig, C.H. 1996. Fire history in interior ponderosa pine communities of the Black Hills, South Dakota, USA. Int. J. Wildland Fire. 6: 97-105.

Brown, P.M.; Seig, C.H. 1999. Historical variability in fire and the ponderosa pine-northern Great Plains prairie ecotone, southeastern Black Hills, South Dakota. EcoScience. 6: 539-547.

Brown, P.M.; Shepperd, W.D. 2001. Fire history and fire climatology along a five degree gradient in latitude in Colorado and Wyoming, U.S.A. Paleobotanist. 50: 133-140.

Brown, P.M.; D’Amico, D.R.; Carpenter, A.T.; Andrews, D. 2001a. Restoration of montane ponderosa pine forests in the Colorado Front Range: A forest ecosystem management plan for the city of Boulder. Ecological Restoration. 19: 19-26.

Brown, P.M.; Kaufmann, M.R.; Shepperd, W.D. 1999. Longterm, landscape patterns of past fire events in a montane ponderosa pine forest of central Colorado. Landscape Ecology. 14: 513-532.

Brown, P.M.; Kaye, M.W.; Huckaby, L.S.; Baisan, C.H. 2001b. Fire history along environmental gradients in the Sacramento Mountains, New Mexico: Influences of local patterns and regional processes. EcoScience. 8: 115-126.

Brown, P.M.; Ryan, M.G.; Andrews, T.G. 2000. Historical surface fire frequency in ponderosa pine stands in research natural areas, central Rocky Mountains and Black Hills, USA. Natural Areas Journal. 20: 133-139.

Brown, R.T.; Agee, J.K.; Franklin, J.F. 2004. Forest restoration and fire: Principles of context of place. Conservation Biology. 18: 903-912.

Buchholtz, C.W. 1983. Rocky Mountain National Park: A history. Colorado Associated University Press, Boulder, CO.

Burgan, R.E.; Rothermel, R.C. 1984. BEHAVEPLUS: Fire behavior prediction and fuel modeling system-FUEL subsystem. Gen. Tech. Rep. INT-167. Ogden, UT: U.S. Department of Agriculture, Forest Service, Intermountain Forest and Range Experiment Station. 126 p.

Busse, M.D.; Hubbert, K.R.; Fiddler, G.O.; Shestak, C.J.; Powers, R.F. 2005. Lethal soil temperatures during burning of masticated forest residues. Int. J. Wildland Fire. 14: 267-276.

Callaway, R.M.; Davis, F.W. 1993. Vegetation dynamics, fire and the physical environment in central California. Ecology. 74: 1567-1578.

Cammack, C.F. 1978. Grapples for forest residues concentration and removal. 7824 1210. U.S. Department of Agriculture, Forest Service, San Dimas Equipment and Development Center.

Chambers, C.L. 2002. Forest management and dead wood resources in ponderosa pine forests: Effects on small mammals. In: W.L. Laudenslayer et al. eds. Proceedings of the symposium on the Ecology and Management of Dead Wood in Western Forests, Nov. 2-4, 1999, Reno, NV. Gen. Tech. Rep. PSW-GTR-181. U.S. Department of Agriculture, Forest Service, Pacific Southwest Research Station.

Chandler, C.; Cheney, P.; Thomas, P.; Trabaud, L.; Williams, D. 1983. Fire in forestry: Volume II forest fire management and organization. John Wiley \& Sons, New York, NY. 
Choromanska, U.; DeLuca, T.H. 2001. Prescribed fire alters the impact of wildfire on soil biochemical properties in a ponderosa pine forest. Soil Sci. Soc. Am. J. 65: 232-238.

City of Boulder, CO. 1999. Forest ecosystem management plan. Open space and mountain parks, Boulder, CO.

Cleaves, D.A.; Martinez, J.; Haines, T.K. 2000. Influences on prescribed burning activity costs in the national forest system. Gen. Tech. Rep. SRS-GTR-37. Asheville, NC: U.S. Department of Agriculture, Forest Service, Southern Research Station. 26 p.

Colorado State Forest Service. 2004. Report on the health of Colorado's forests. Denver, CO: Colorado State Forest Service. $36 \mathrm{p}$.

Conklin, D.A.; Armstrong, W.A. 2001. Effects of three prescribed fires on dwarf mistletoe infection in southwestern ponderosa pine. R3-01-02. U.S. Department of Agriculture, Forest Service, Southwest Region.

Cooper, C.F. 1960. Changes in vegetation, structure, and growth of southwestern ponderosa pine forests since white settlement. Ecological Monographs. 30: 130-164.

Cooper C.F. 1961. Pattern in ponderosa pine forests. Ecology. 42: 493-497.

Covington, W.W.2003. The evolutionary and historical context. In: P. Friederici, ed. Ecological restoration of southwestern ponderosa pine forests. Island Press, Washington, D.C.

Covington, W.W.; Moore, M.M. 1994a. Postsettlement changes in natural fire regimes and forest structure: Ecological restoration of old-growth ponderosa pine forests. J. Sustain. For. 2: 153-181.

Covington, W.W.; Moore, M.M. 1994b. Southwestern ponderosa pine forest structure-changes since EuroAmerican settlement. Journal of Forestry. 9: 39-47.

Covington, W.W.; Sackett, S.S. 1984. The effect of a prescribed burn in southwestern ponderosa pine on organic matter and nutrients in woody debris and forest floor. Forest Science. 30: 183-192.

Covington, W.W.; Sackett, S.S. 1992. Soil mineral changes following prescribed burning in ponderosa pine. For. Ecol. Manag. 54: 175-191.

Covington, W.W.; Everett, R.L.; Steele, R.W.; Irwin, L.I.; Daer, T.A.; Auclair, A.N.D. 1994. Historical and anticipated changes in forest ecosystems of the inland west of the United States. J. Sustain. For. 2: 13-63.

Covington, W.W.; Fule, P.Z.; Moore, M.M.; Hart, S.C.; Kolb, T.E.; Mast, J.N.; Sackett, S.S.; Wagner, M.R. 1997. Restoring ecosystem health in ponderosa pine forests of the Southwest. Journal of Forestry. 95: 23-29.

Cram, D.S.; Baker, T.T.; Boren, J.C. 2006. Wildland fire effects in silviculturally treated vs. untreated stands of New Mexico and Arizona. Res. Pap. RMRS-RP-55. Fort Collins, CO: U.S. Department of Agriculture, Forest Service, Rocky Mountain Forest and Range Experiment Station. 28 p.

Crawford, J.S.; Wahren, C.H.A.; Kyle, S.; Moir, W.H. 2001. Response of exotic plant species to prescribed fire in ponderosa pine forests of northern Arizona. J. Veg. Sci. 12: 261-268.
Cunningham, C.A.; Jenkins, M.J.; Roberts, D.W. 2005. Attack and brood production by the Douglas-fir beetle (Coleopter: Scolytidae) in Douglas-fir, Pseudotsuga menziesii var. glauca (Pinaceae), following a wildfire. West. N. Am. Nat. 65: 70-79.

Dahms, C.W.; Geils, B.W. 1997. An assessment of ecosystem health in the Southwest. Gen. Tech. Rep. RM-GTR-295. Fort Collins, CO: U.S. Department of Agriculture, Forest Service, Rocky Mountain Forest and Range Experiment Station. 97 p.

Davis, G.G.; Lawrence, E.B.; Cook, C.W. 1975. Control of Gambel oak sprouts by goats. J. Range Manag. 28: 216-218.

Davis, J.R.; Ffolliott, P.F.; Clary, W.P. 1968. A prescription for consuming ponderosa pine duff. Res. Note RM-RN-115. Fort Collins, CO: U.S. Department of Agriculture, Forest Service, Rocky Mountain Forest and Range Experiment Station. 4 p.

DeBano, L.F. 1991. The effects of fire on soil properties. In: Proceedings - Management and productivity of western montane forest soils. Gen. Tech. Rep. INT-GTR-280. Ogden, UT: U.S. Department of Agriculture, Forest Service, Intermountain Research Station.

DeBano, L.F.; Neary, D.G.; Ffolliott, P.F. 1998. Fire's effects on ecosystems. John Wiley \& Sons, New York, NY.

DellaSalla, D.A.; Frost, E. 2001. An ecologically based strategy for fire and fuels management in national forest roadless areas. Fire Management Today. 61: 12-23.

Denevan, W.M. 1967. Livestock numbers in 19th century New Mexico, and the problem of gullying in the Southwest. Ann. Assoc. Am. Geogr. 57: 691-703.

Dennis, F.C. 1999. Creating wildfire-defensible zones. Natural Resource Series no. 6.302. Colorado State University Cooperative Extension, Fort Collins, CO. 6 p.

Dieterich, J.M. 1980. Chimney springs forest fire history. Res. Pap. RM-RP-220. Fort Collins, CO: U.S. Department of Agriculture, Forest Service, Rocky Mountain Forest and Range Experiment Station. 8 p.

Donnegan, J.A.; Veblen, T.T.; Sibold, J.S. 2001. Climatic and human influences on fire history in Pike National Forest, central Colorado. Can. J. For. Res. 31: 1526-1539.

Dutton, W.L. 1953. Forest grazing in the United States. Journal of Forestry. 51: 248-251.

Edminster, C.B.; Olsen, W.K. 1996. Thinning as a tool in restoring and maintaining diverse structure in stands of southwestern ponderosa pine. In: W.W. Covington; P.K. Wagner, eds. Conference on adaptive ecosystem restoration and management: Restoration of Cordilleran conifer landscapes of North America. Gen. Tech. Rep. RM-GTR-278. Fort Collins, CO: U.S. Department of Agriculture, Forest Service, Rocky Mountain Forest and Range Experiment Station.

Ehle, D.S.; Baker, W.L. 2003. Disturbance and stand dynamics in ponderosa pine forests in Rocky Mountain National Park, U.S.A. Ecological Monographs. 73: 543-566.

Evans, W.G. 1971. The attraction of insects to forest fires. In Proceedings, Tall Timbers conference on ecological animal 
control by habitat management. Feb. 25-27, 1971. Tall Timbers Research Station, Tallahahassee, FL. Number 3: 115-127.

Farnsworth, A.; Summerfelt, P. 2001. Flagstaff interface treatment prescription: Results in the wildland urban interface. Flagstaff Fire Department, Flagstaff, AZ. 14 p.

Fernandes, P.M.; Botelho, H.S. 2003. A review of prescribed fire effectiveness in fire hazard reduction. Int. J. Wildland Fire. 12: 117-128.

Ffolliott, P.F. 1997. Guidelines for manageing wildlife habitats in southwestern ponderosa pine forests of the United States. J. For. Res. 8: 108-110.

Ffolliott, P.F.; Guertin, D.P. 1988. Prescribed fire in Arizona pine forests: a 24-year case study. In: J.S. Krammes, ed. Effects of fire management of southwestern natural resources, proceedings of the symposium. Gen. Tech. Rep. RM-191. Fort Collins, CO: U.S. Department of Agriculture, Forest Service, Rocky Mountain Forest and Range Experiment Station.

Ffolliott, P.F.; Malchus, B.B. 2001. Stripcut-thinning of ponderosa pine stands: An Arizona case study. Res. Pap. RMRS-RP-34. Fort Collins, CO: U.S. Department of Agriculture, Forest Service, Rocky Mountain Research Station. 7 p.

Ffolliott, P.F.; Clary, W.P.; Larson, F.R. 1977. Effects of a prescribed fire in an Arizona ponderosa pine forest. Res. Note RM-RN-336. Fort Collins, CO: U.S. Department of Agriculture, Forest Service, Rocky Mountain Forest and Range Experiment Station. 4 p.

Fiedler, C.E.; Cully Jr, J.F. 1995. A silvicultural approach to develop Mexican spotted owl habitat in southwestern forests. West. J. Appl. For. 10: 144-148.

Fiedler, C.E.; Keegan, C.E. 2003. Reducing crown fire hazard in fire-adapted forests of New Mexico. In: P.N. Omi and L.N. Joyce, eds. Fire, fuel treatments, and ecological restoration: Conference proceedings. Proc. RMRS-P-29. Fort Collins, CO: U.S. Department of Agriculture, Forest Service, Rocky Mountain Research Station.

Fiedler, C.E.; Keegan, C.E.; Robertson, S.H.; Morgan, T.A.; Woodall, C.W.; Chmelik, J.T. 2002. A strategic assessment of fire hazard in New Mexico. Final report submitted to the Joint Fire Science Program.

Fiedler, C.E.; Keegan, C.E.; Wichman, D.P.; Arno, S.F. 1999. Product and economic implications of ecological restoration. Forest Products Journal. 49: 19-23.

Fight, R.D.; Barbour, R.J. 2005. Fuels planning: Science synthesis and integration. Economic uses fact sheet 4. My fuel treatment planner. Res. Note RMRS-RN-20-4-wwwrevised. Fort Collins, CO: U.S. Department of Agriculture, Forest Service, Rocky Mountain Research Station. 2 p.

Fight, R.D.; Barbour, R.J.; Christensen, G.A.; Pinjuv, G.L.; Nagubadi, R.V. 2004. Thinning and prescribed fire and projected trends in woody product potential, financial return, and fire hazard in New Mexico. Gen. Tech. Rep. PNW-GTR-605. Portland, OR: U.S. Department of Agriculture, Forest Service, Pacific Northwest Research Station. 17 p.
Fight, R.D.; Gicqueau, A.; Hartsough, B.R. 1999. Harvesting costs for management planning for ponderosa pine plantations. Gen. Tech. Rep. PNW-GTR-467. Portland, OR. U.S. Department of Agcirculture, Forest Service, Pacific Northwest Research Station. 8 p.

Fight, R.D.; Xiaoshan, Z.; Hartsough, B.R. 2003. Users guide for STHARVEST: Software to estimate the cost of harvesting small timber. Gen. Tech. Rep. PNW-GTR582. Portland, OR: U.S. Department of Agriculture, Forest Service, Pacific Northwest Research Station. 12 p.

Finch, D.M.; Ganey, J.L.; Yong, W.; Kimball, R.T.; Sallabanks, R. 1997. Effects and interactions of fire, logging, and grazing. In: W.M. Block and D.M. Finch, eds. Songbird ecology in Southwest ponderosa pine forests: A literature review. Gen. Tech. Rep. RM-GTR-292. Fort Collins, CO: U.S. Department of Agriculture, Forest Service, Rocky Mountain Research Station. 152 p.

Finney, M.A. 1998. FARSITE: Fire Area Simulator-model development and evaluation. Res. Pap. RMRS-RP-4. Ogden, UT: U.S. Department of Agriculture, Forest Service, Rocky Mountain Research Station. 47 p.

Finney, M.A. 2001. Design of regular landscape fuel treatment patterns for modifying fire growth and behavior. Forest Science. 47: 219-228.

Finney, M.A.; McHugh, C.W.; Grenfell, I.C. 2005. Standand landscape-level effects of prescribed burning on two Arizona wildfires. Can. J. For. Res. 35: 1714-1722.

Fisher, R.F.; Jenkins, M.J.; Fisher, W.F. 1987. Fire and the prairie-forest mosaic of Devils Tower National Monument. Am. Midl. Nat. 117: 250-257.

Flagstaff Fire Department. 2005. Hazard mitigation best management practices - Operational guidelines. Flagstaff, AZ. 37 p.

Flint, C. 2006. Community perspective on spruce beetle impacts on the Kenai peninsula, Alaska. For. Ecol. Manag. 227: 207-218.

Friederici, P. 2003. The "Flagstaff model." In: P. Friederici, ed. Ecological restoration of southwestern ponderosa pine forests. Island Press, Washington, D.C.

Fritts, H.C.; Swetnam, T.W. 1989. Dendroecology: A tool for evaluating variations in past and present forest environments. Adv. Ecol. Res. 19: 111-188.

Froiland, S.G. 1990. Natural history of the Black Hills and Badlands. The Center for Western Studies, Sioux Falls, SD.

Front Range Fuel Treatment Partnership Rountable. 2006. Living with fire: Protecting communities and restoring forests. Final Report, May 2006. 38 p. Available at: http://www.tws.org/Library/Documents/upload/ ROUNDTABLE_finalreport.pdf.

Fule, P.Z.; Cocke, A.E.; Heilein, T.A.; Covington, W.W. 2004. Effects of an intense prescribed fire: is it ecological restoration? Restoration Ecology. 12: 220-230.

Fule, P.Z.; Covington, W.W.; Moore, M.M. 1997. Determining reference conditions for ecosystem management of southwestern ponderosa pine forests. Ecological Applications. 7: 895-908. 
Fule, P.Z.; Covington, W.W.; Smith, H.B.; Springer, J.D.; Heinlein, T.A.; Huisinga, K.D.; Moore, M.M. $2002 \mathrm{a}$. Comparing ecological restoration alternatives: Grand Canyon, Arizona. For. Ecol. Manag. 170: 19-41.

Fule, P.Z.; Covington, W.W.; Stoddard, M.T.; Bertolette, D. 2006. "Minimal-impact" restoration treatments have limited effects on forest structure and fuels at Grand Canyon, USA. Restoration Ecology. 14: 357-368

Fule, P.Z.; Crouse, J.E.; Heilein, T.A.; Moore, M.M.; Covington, W.W.; VerKamp, G. 2003a. Mixed severity fire regime in a high elevation forest of Grand Canyon, Arizona, USA. Landscape Ecology. 18: 465-485.

Fule, P.Z.; Heinlein, T.A.; Covington, W.W.; Moore, M.M. 2003b. Assessing fire regimes on Grand Canyon landscapes with fire scar and fire record data. Int. J. Wildland Fire. 12: 129-145.

Fule, P.Z.; Laughlin, D.C.; Covington, W.W. 2005. Pine-oak forest dynamics five years after ecological restoration treatments, Arizona, USA. For. Ecol. Manag. 218: 129145.

Fule, P.Z.; Verkamp, G.; Waltz, A.E.M.; Covington, W.W. 2002b. Burning under old-growth ponderosa pines on lava soils. Fire Management Today. 62: 47-49.

Fule, P.Z.; Waltz, A.E.M.; Covington, W.W.; Heilein, T.A. 2001. Measuring forest restoration effectiveness in reducing hazardous fuels. Journal of Forestry. 99: 24-29.

Fuller, M. 1991. Forest fires: An introduction to wildland fire behavior, management and prevention. John Wiley \& Sons, New York, NY.

Furniss, M.M. 1965. Susceptibility of fire-injured Douglas-fir to bark beetle attack in southern Idaho. Journal of Forestry. 63: 8-11.

Gaines, E.M.; Kallander, H.R.; Wagner, J.A. 1958. Controlled burning in southwestern ponderosa pine: Results from the Blue Mountain plots, Fort Apache Indian Reservation. Journal of Forestry. 56: 323-327.

Ganey, J.L. 1999. Snag density and composition of snag populations on two National Forests in northern Arizona. For. Ecol. Manag. 117: 169-178.

Gartner, F.R.; Thompson, W.W. 1973. Fire in the Black Hills forest-grass ecotone. Tall Timbers Fire Ecology Conference Proceedings. 12: 37-68.

Gatewood, S.; Summerfelt, P. 2005. Community wildfire protection plan for Flagstaff and surrounding communities in the Coconino and Kaibab National Forests of Coconino County, Arizona. Greater Flagstaff Forest Partnership and Ponderosa Fire Advisory Council. 132 p.

Goldblum, D.; Veblen, T.T. 1992. Fire history of a ponderosa pine/Douglas-fir forest in the Colorado Front Range. Physical Geography. 13: 133-148.

Grafe, E.; Horsted, P. 2002. Exploring with Custer: The 1874 Black Hills expedition. Golden Valley Press, Custer, SD.

Graham, R.T.; Harvey, A.E.; Jain, T.B.; Tonn, J.R. 1999. The effects of thinning and similar stand treatments on fire behavior in western forests. Gen. Tech. Rep. PNW-GTR463. Portland, OR: U.S. Department of Agriculture, Forest Service, Pacific Northwest Research Station. 27 p.
Graham, R.T.; Huff, D.D.; Kaufmann, M.R.; Shepperd, W.D.; Sheehan, J. 1998. Bioenergy and watershed restoration in the mountainous region of the west: What are the environmental/community issues? In: Proceedings of BioEnergy '98: Expanding bioenergy partnerships, Madison, WI, Oct. 4-8, 1998.

Graham, R.T.; McCaffrey, S.; Jain, T.B. 2004. Science basis for changing forest structure to modify wildfire behavior and severity. Gen. Tech. Rep. RMRS-GTR-120. Fort Collins, CO: U.S. Department of Agriculture, Forest Service, Rocky Mountain Research Station. 43 p.

Graves, H.S. 1899. The Black Hills forest reserve. In: The nineteenth century annual report to the survey, 1897-1898. Part V. Forest Reserves. Washington, D.C.: U.S. Geological Survey.

Greacean, E.L.; Sands, R. 1980. Compaction of forest soils: A review. Australian Journal of Forest Soils. 18: 163-189.

Griffis, K.L.; Crawford, J.A.; Wagner, M.R.; Moir, W.H. 2001. Understory response to management treatments in northern Arizona ponderosa pine forests. For. Ecol. Manag. 146: 239-245.

Grissino-Mayer, H.D.; Swetnam, T.W. 2000. Century-scale climate forcing of fire regimes in the American Southwest. Holocene. 10: 213-220.

Hadley, K.S. 1994. The role of disturbance, topography, and forest structure in the development of a montane forest landscape. B. Torrey Bot. Club. 121: 47-61.

Hanes, R.C. 1994. Chapter VIII-Cultural resources. In: M. Miller, ed. Fire effects guide. PMS 481, NFES 2395. National Interagency Fire Center, Boise, ID.

Hansen, E.M.; Goheen, E.M. 2000. Phellinus weirii and other native root pathogens as determinants of forest structure and process in western North America. Annu. Rev. Phytopathol. 38: 515-539.

Harper, K.T.; Wagstaff, F.J.; Kunzler, L.M. 1985. Biology and management of Gambel oak vegetation type: A literature review. Gen. Tech. Rep. INT-179. Ogden, UT: U.S. Department of Agriculture, Forest Service, Intermountain Forest and Range Experiment Station. 31 p.

Harrington, M.G. 1981. Preliminary burning prescriptions for ponderosa pine fuel reductions in southeastern Arizona. Res. Note RM-RN-402. Fort Collins, CO: U.S. Department of Agriculture, Forest Service, Rocky Mountain Forest and Range Experiment Station. 7 p.

Harrington, M.G. 1985. The effect of spring, summer, and fall burning on Gambel oak in a southwestern ponderosa pine stand. Forest Science. 31: 156-163.

Harrington, M.G. 1987. Ponderosa pine mortality from spring, summer, and fall crown scorching. West. J. Appl. For. 2: 14-16.

Harrington, M.G.; Sackett, S.S. 1990. Using fire as a management tool in southwestern ponderosa pine. In: J.S. Krammes, ed. Effects of fire management of southwestern natural resources, proceedings of the symposium. Gen. Tech. Rep. RM-191. Fort Collins, CO: U.S. Department of Agriculture, Forest Service, Rocky Mountain Forest and Range Experiment Station. 
Harris, G.R.; Covington, W.W. 1983. The effect of a prescribed fire on nutrient concentration and standing crop of understory vegetation in ponderosa pine. Can. J. For. Res. 13: 501-507.

Harrison, R.T. 1975. Slash: Equipment and methods for treatment and utilization. Report 7120-7. San Dimas, CA. U.S. Department of Agriculture, Forest Service, Equipment and Development Center.

Hartsough, B.R.; Gicqueau, A.; Fight, R.D. 1998. Productivity and cost relationships for harvesting ponderosa pine plantations. Forest Products Journal. 48(9): 87-93.

Heidmann, L.J. 1968. Silvicultural control of dwarf mistletoe in heavily infested stands of ponderosa pine in the Southwest. Res. Pap. RM-36. Fort Collins, CO: U.S. Department of Agriculture, Forest Service, Rocky Mountain Forest and Range Experiment Station. 11 p.

Hertert, H.D.; Miller, D.L.; Partridge, A.D.1975. Interactions of bark beetles (Coleoptera: Scolytidae) and root pathogens in grand fir in northern Idaho. Can. Ent. 107: 899-904.

Hobbs, R.J.; Huenneke, L.F. 1992. Disturbance, diversity and invasion: Implications for conservation. Conservation Biology. 6: 324-337.

Holden, Z.A.; Morgan, P.; Rollins, M.G.; Wright, R.G. 2006. Ponderosa pine snag densities following multiple fires in the Gila Wilderness, New Mexico. For. Ecol. Manag. 221: 140-146.

Hollenstein, K.; Graham, R.L.; Shepperd, W.D. 2001. Biomass flow in western forests: simulating the effects of fuel reduction and presettlement restoration treatments. Journal of Forestry. 99: 12-19.

Holtzscher, M.A.; Lanford, B.L. 1997. Tree diameter effects on cost and productivity of cut-to-length systems. Forest Products Journal. 47(3): 25-30.

Horton, S.P.; Mann, R.W. 1988. Effects of prescribed fire on snags and cavity-nesting birds in southeastern Arizona pine forests. Wildlife Society Bulletin. 16: 37-44.

Howe, E.; Baker; W.L. 2003. Landscape heterogeneity and disturbance interactions in a subalpine watershed in Northern Colorado, USA. Ann. Assoc. Am. Geogr. 93(4): 797-813.

Huckaby, L.S.; Kaufmann, M.R.; Fornwalt, P.J.; Stoker, J.A.; Dennis, C. 2003. Identification and ecology of old ponderosa pine trees in the Colorado Front Range. Gen. Tech. Rep. RMRS-GTR-110. Fort Collins, CO: U.S. Department of Agriculture, Forest Service, Rocky Mountain Research Station. 47 p.

Huckaby, L.S.; Kaufmann, M.R.; Stoker, J.A.; Fornwalt, P.J. 2001. Landscape patterns of montane forest age structure relative to fire history at Cheesman Lake in the Colorado Front Range. In: R.K. Vance, C.B Edminster, W.W. Covington, J.A Blake, eds. Ponderosa pine ecosystems restoration and conservation: Steps toward stewardship. Proc. RM-P-22. Ogden, UT: U.S. Department of Agriculture, Forest Service, Rocky Mountain Research Station.

Hudak, A.T.; Morgan, P.; Bobbitt, M.; Lentile, L. 2006. Characterizing stand-replacing harvest and fire disturbance patches in a forested landscape: A case study from Cooney Ridge, Montana. In: M.A. Wulder and S.E. Franklin, eds. Understanding Forest Disturbance and Spatial Patterns: Remote Sensing and GIS Approaches, Taylor \& Francis, London. 246 p.

Huff, M.H.; Kapler Smith, J. 2000. Chapter 5: Fire effects on animal communities. pp. 35-42. In: Smith, J. K. Wildland fire in ecosystem: effects of fire on fauna. Gen. Tech. Rep. RMRS-GTR-42-vol.1. Ogden, UT: USDA Forest Service, Rocky Mountain Research Station. 83 p.

Hunter, M.E.; Omi, P.N.; Martinson, E.J.; Chong, G.W. 2006. Establishment of nonnative plant species after wildfires: effects of fuel treatments, abiotic and biotic factors, and post-fire grass seeding treatments. Int. J. Wildland Fire. 271-281.

Jerman, J.L.; Gould, P.J.; Fule, P.Z. 2004. Slash compression treatment reduced tree mortality from prescribed fire in southwestern ponderosa pine. West. J. Appl. For. 19: 149-153.

Johnson, E.A.; Gutsell, S.L. 1994. Fire frequency models, methods, and interpretation. Adv. Ecol. Res. 25: 239-287

Jones and Stokes. 2004. Nonburning alternatives to prescribed fire on wildlands in the western United States. Sacramento, CA. 55 p.

Kallander, H.R. 1969. Controlled burning of the Fort Apache Indian Reservation. Tall Timbers Fire Ecology Conference Proceedings. 9: 241-249.

Kaufmann, G.A.; Covington, W.W. 2001. Effects of prescribed burning on mortality of presettlement ponderosa pines in Grand Canyon National Park. In: R.K. Vance et al., eds. Ponderosa pine ecosystem restoration and conservation: Steps toward stewardship. Proc. RMRS-P-22. Fort Collins, CO: U.S. Department of Agriculture, Forest Service, Rocky Mountain Research Station.

Kaufmann, M.R.; Fornwalt, P.J.; Huckaby, L.S.; Stoker, J.M. 2001. Cheesman Lake-A historical ponderosa pine landscape guiding restoration in the South Platte watershed of the Colorado Front Range. In: R.K. Vance et al., eds. Ponderosa pine ecosystems restoration and conservation: Steps toward stewardship. Proc. RMRS-P-22. Fort Collins, CO: U.S. Department of Agriculture, Forest Service, Rocky Mountain Research Station.

Kaufmann, M.R.; Fule, P.Z.; Romme, W.H.; Ryan, K.C. 2005. Restoration of ponderosa pine forests in the interior western U.S. after logging, grazing, and fire suppression. In: J.A. Stanturf, P. Madsen, eds. Restoration of boreal and temperate forests. CRC Press, Boca Raton, FL.

Kaufmann, M.R.; Huckaby, L.S.; Fornwalt, P.J.; Stoker, J.M.; Romme, W.H. 2003. Using tree recruitment patterns and fire history to guide restoration of an unlogged ponderosa pine/ Douglas fir landscape in the southern Rocky Mountains after a century of fire suppression. Forestry. 76: 231-241.

Kaufmann, M.R.; Huckaby, L.S.; Regan, C.M.; Popp, J. 1998. Forest reference conditions for ecosystem management in the Sacramento Mountains, New Mexico. Gen. Tech. Rep. RMRS-GTR-19. Fort Collins, CO: U.S. Department 
of Agriculture, Forest Service, Rocky Mountain Research Station. 87 p.

Kaufmann, M.R.; Regan, C.M.; Brown, P.M. 2000. Heterogeneity in ponderosa pine/Douglas fir forests: Age and size structure in unlogged and logged landscapes of central Colorado. Can. J. For. Res. 30: 698-711.

Kaufmann, M.R.; Veblen, T.T.; Romme, W.H. 2006. Historical fire regimes in ponderosa pine forests of the Colorado Front Range, and recommendations for ecological restoration and fuels management. Front Range Fuel Treatment Partnership Roundtable, findings of the ecology workgroup. http:// www.frftp.org/roundtable/pipo.pdf.

Kaye, M.W.; Swetnam, T.W. 1999. An assessment of fire, climate, and Apache history and Sacramento Mountains, New Mexico. Physical Geography. 20: 305-330.

Keane, R.E.; Holsinger, L.M.; Pratt, S.D. 2006. Simulating historical landscape dynamics using the landscape fire succession model LANDSUM version $4.0 \mathrm{Gen}$. Tech. Rep. RMRS-GTR-171CD. Fort Collins, CO: USDA Forest Service, Rocky Mountain Research Station. 73p. (Online). Available: http://www.fs.fed.us/ rm/pubs/rmrs_gtrl171. html (May 18, 2006).

Keane, R.E.; Ryan, K.C.; Veblen, T.T.; Allen, C.D.; Logan, J.; Hawkes, B. 2002. Cascading effects of fire exclusion in Rocky Mountain ecosystems: Aliterature review. Gen. Tech. Rep. RMRS-GTR-91. Fort Collins, CO: U.S. Department of Agriculture, Forest Service, Rocky Mountain Research Station. 24 p.

Keeley, J.E.; Lubin, D.; Fotheringham, C.J. 2003. Fire and grazing impacts on plant diversity and alien plant invasions in southern Sierra Nevada. Ecological Applications. 13: 1355-1374.

Kilgore, B.M.; Curtis, G.A. 1987. Guide to understory burning in ponderosa pine/larch-fir forests in the intermountain west. Gen. Tech. Rep. INT-GTR-233. Ogden, UT: U.S. Department of Agriculture, Forest Service, Intermountain Research Station. 29 p.

Kime, W.R. [ed.] 1996. The Black Hills journal of Colonel Richard Irving Dodge. University of Oklahoma Press, Norman, OK.

Korb, J.E.; Johnson, N.C.; Covington, W.W. 2004. Slash pile burning effects on soil biotic and chemical properties and plant establishment: Recommendations for amelioration. Restoration Ecology. 12: 52-62.

Korb, J.E.; Springer, J.D.; Powers, S.R.; Moore, M.M. 2005. Soil seed banks in Pinus ponderosa forests in Arizona: Clues to site history and restoration potential. Appl. Veg. Sci. 8: 103-112.

Kufeld, R.C. 1983. Response of elk, mule deer, cattle, and vegetation to burning, spraying, and chaining of Gambel oak rangeland. Technical Pub. 34. Colorado Division of Wildlife.

Landres, P.B.; Morgan, P.; Swanson, F.J. 1999. Overview of the use of natural variability concepts in managing ecological systems. Ecological Applications. 9: 1179-1188.

Landsberg, J.D.; Tiedemann, A.R. 2000. Fire management. In: G.E. Dissmeyer, ed. Drinking water from forests and grasslands: A synthesis of the scientific literature. Gen. Tech. Rep. SRS-GTR-39. Asheville, NC: U.S. Department of Agriculture, Forest Service, Southern Research Station.

Larson, J.; Hallman, R. 1980. Equipment for reforestation and timber stand improvement. U.S. Department of Agriculture, Forest Service, Equipment and Development Center, Missoula, MT.

Laughlin, D.C.; Bakker, J.D.; Fule, P.Z. 2005. Understory plant community structure in lower montane and subalpine forests, Grand Canyon National Park, USA. Journal of Biogeography. 32: 2083-2102.

Laughlin, D.C.; Bakker, J.D.; Stoddard, M.T.; Daniels, M.L.; Springer, J.D.; Gildar, C.N.; Green, A.M.; Covington, W.W. 2004. Toward reference conditions: Wildfire effects on flora in an old-growth ponderosa pine forest. For. Ecol. Manag. 199: 137-152.

Lauver, C.L.; Jameson, D.A.; Rittenhouse, L.R. 1989. Management strategies for Gambel oak communities. Rangelands. 11: 213-216.

Laven, R.D.; Omi, P.N.; Wyant, J.G.; Pinkerton, A.S. 1980. Interpretation of the fire scar data from a ponderosa pine ecosystem in the central Rocky Mountains, Colorado. In: M.A. Stokes; J.H. Dieterich, eds. Proceedings of the fire history workshop. Gen. Tech. Rep. RM-GTR-81. Fort Collins, CO: U.S. Department of Agriculture, Forest Service, Rocky Mountain Forest and Range Experiment Station.

Le Van-Green, S.L.; Livingston, J.M. 2003. Uses for small diameter and low value forest thinnings. Ecological Restoration. 21: 34-38.

Lentile, L.B. 2004. Casual factors and consequences of mixed-severity fire in Black Hills ponderosa pine forests. Fort Collins, CO: Colorado State University. Dissertation.

Lentile L.B.; Smith F.W.; Shepperd, W.D. 2006. The influence of topography and forest structure on patterns of mixedseverity fre in the South Dakota Black Hills. Int. J. Wildland Fire. 15(4): 557-566.

Lessard, E.D.; Johnson, D.W.; Hinds, T.E.; Hoskins, W.H. 1985. Association of Armillaria root disease with mountain pine beetle infestations on the Black Hills National Forest, South Dakota. USDA Forest Service, Technical Report 85-4. Forest Pest Management, Lakewood, CO. 6 p.

Li, H.; Reynolds, J.F. 1995. On definition and quantification of heterogeneity. Oikos. 73: 280-284.

Lindenmuth, A.W. 1960. A survey of the effects of intentional burning on fuels and timber stands of ponderosa pine in Arizona. Sta.Pap. No.54. Fort Collins, CO:U.S. Department of Agriculture, Forest Service, Rocky Mountain Forest and Range Experiment Station. 22 p.

Lolley, M.R.; McNicoll, C.; Encinas, J.; Monzingo, J.; Koury, C.; Partido, G.; Levesque, M.; Bradley, A.; McCarthy, P. 2006. Restoring the functionality of fire adapted ecosystems, Gila National Forest restoration needs and opportunity. Unpublished report. Gila National Forest. 130 p.

Long, J.N. 1995. Using stand density index to regulate stocking in uneven-aged stands. In: K.L. O'Harea, ed. Uneven-aged management opportunities, constraints, and 
methodologies. The University of Montana, Montana Forest and Conservation Experiment Station Misc. Pub. 56.

Lull, H.W. 1959. Soil compaction on forest and range lands. U.S. Department of Agriculture, Forest Service, Misc. Pub. 768. Washington, D.C. 33 p.

Lundquist, J.E. 2005. Landscape pathology in the era of landscape ecology. pp. 155-165. In: J.E. Lundquist and R.C. Hamelin, eds. Forest Pathology-From Genes to Landscapes, APS Press, St. Paul.

Lundquist, J.E. The relative influence of diseases and other small-scale disturbances on fuel loading in the Black Hills. Plant Disease. In press.

Lundquist, J.E.; Negron, J.F. 2000. Endemic forest disturbances and stand structure of ponderosa pine (Pinus ponderosa) in the Upper Creek Natural Area, South Dakota, USA. Natural Areas Journal. 20: 126-132.

Lutes, D.C.; Keane, R.E.; Caratti, J.F.; Key, C.H.; Benson, N.C.; Sutherland, S.; Gangi, L.J. 2006. FIREMON: Fire effects monitoring and inventory system. Gen. Tech. Rep. RMRS-GTR-164-CD. Fort Collins, CO: U.S. Department of Agriculture, Forest Service, Rocky Mountain Research Station. 1 CD.

Lynch, D.L. 2001. Financial results of ponderosa pine forest restoration in southwestern Colorado. In: R.K. Vance et al., eds. Ponderosa pine ecosystem restoration and conservation: steps toward stewardship. Proc. RMRS-P22. Ogden, UT: U.S. Department of Agriculture, Forest Service, Rocky Mountain Research Station.

Lynch, D.L.; Romme, W.H.; Floyd, M.L. 2000. Forest restoration in Southwest ponderosa pine. Journal of Forestry. 98: 17-24.

Mack, R.N.; Simberloff, D.; Lonsdale, W.M.; Evans, H.; Clout, M.; Bazzaz, F.A. 2000. Biotic invasions: Causes, epidemiology, global consequences, and control. Ecological Applications. 10: 689-710.

Madany, M.H.; West, N.E. 1983. Livestock grazing and fire regime interactions within montane forests of Zion National Park, Utah. Ecology. 64: 661-667.

Mahaffey, L.; Miller, M. 1994. Chapter IV - Air quality. In: M. Miller, ed. Fire effects guide. PMS 481, NFES 2395. National Interagency Fire Center, Boise, ID.

Marquiss, R.W. 1973. Gambel oak control studies in southwestern Colorado. J. Range Manag. 26: 57-58.

Martinson, E.J.;Omi,P.N. 2003. Performance of fuel treatments subject to wildfires. In: P.N. Omi and J.A. Joyce, eds. Fire, fuel treatments, and ecological restoration. Proc. RMRSP-29. Fort Collins, CO: U.S. Department of Agriculture, Forest Service, Rocky Mountain Research Station.

Martinson, E.J.; Hunter, M.E.; Freeman, J.P.; Omi, P.N. Effects of fuel and vegetation management activities on non-native plant invasions. In: Wildland fire in ecosystems - fire and nonnative invasive plants. Gen. Tech. Rep. RMRS-GTR42 vol. 6. Fort Collins, CO: USDA Forest Service, Rocky Mountain Research Station. In press.

Martinson, E.J.; Omi, P.N.; Shepperd, W.D. 2003. Part 3: Effects of fuel treatments on fire severity. In: R.L. Graham, ed. Hayman Fire case study. Gen. Tech. Rep. RMRS-GTR114. Ogden, UT: U.S. Department of Agriculture, Forest Service, Rocky Mountain Research Station.

Massman, W.J.; Frank, J.M.; Jimenez Esquilin, A.E.; Stromberger, M.E.; Shepperd, W.D. 2006. Long term consequences of a controlled slash burn and slash mastication to soil moisture and $\mathrm{CO} 2$ at a southern Colorado site. In: 27th conference on agricultural and forest meteorology, AMS, Boston. (Manuscript available on $\mathrm{CD}$, paper 2.2)

Massman, W.J.; Frank, J.M.; Shepperd, W.D.; Platten, M.J. 2003. In situ soil temperatures and heat flux measurements during controlled surface burns at a southern Colorado forest site. In: P.N. Omi and L.A. Joyce, eds. Fire, fuel treatments, and ecological restoration. Proc. RMRS-P-29. Fort Collins, CO: U.S. Department of Agriculture, Forest Service, Rocky Mountain Research Station.

Mast, J.N.; Veblen, T.T.; Linhart, Y.B. 1998. Disturbance and climatic influences on age structure of ponderosa pine at the pine/grassland ecotone, Colorado Front Range. Journal of Biogeography. 25: 743-755.

Mathew, G.; Rugmini, R.; Binoy, C.F. 2003. Impact of forest fire on insect species diversity - a study in the Silent Valley National Park, Kerala, India. Entomon. 28(2): 105-114.

McAdams, A.G. 1995. Changes in ponderosa pine forest structure in the Black Hills, South Dakota, 1874-1995. Flagstaff, AZ: Northern Arizona University. Thesis.

McCambridge, W.F.; Stevens, R.E. 1982. Effectiveness of thinning ponderosa pine stands in reducing mountain pine beetle caused tree losses in the Black Hills - preliminary observations. Res. Note RM-414. Fort Collins, CO: U.S. Department of Agriculture, Forest Service, Rocky Mountain Forest and Range Experiment Station. 3 p.

McCambridge, W.F.; Hawksworth, F.G.; Edminster, C.B.; Laut, J.G. 1982. Ponderosa pine mortality resulting from a mountain pine beetle outbreak. Res. Note RM-144. USDA Forest Service, Rocky Mountain Forest and Range Research Station, Fort Collins, CO. 3 p.

McKenzie, D.W. 1991. Precommercial thinning and slash treatment machine-a prospectus. 9124 1204. U.S. Department of Agriculture, Forest Service, Technology and Development Center. Missoula, MT.

Metlen, K.L.; Fiedler, C.E. 2006. Restoration treatment effects on the understory of ponderosa pine/Douglas-fir forests in western Montana, USA. For. Ecol. Manage. 222: 355-369.

Miller, C.; Landres, P.B.; Alaback, P.B. 2000. Evaluating risks and benefits of wildland fire at landscape scales. Proceedings -Crossing the millennium: Integrating spatial technologies and ecological principles for a new age in fire management comp. L.F. Neuenschwander and K.C. Ryan, eds. Pp. 78-87, Moscow, ID: University of Idaho.

Minard, A. 2003. Limiting damage to forest soils during restoration. Working papers in southwestern ponderosa pine forest restoration. No. 5. Ecological Restoration Institute, Northern Arizona University, Flagstaff, AZ. 5 p. 
Moore, M.M.; Covington, W.W.; Fule, P.Z. 1999. Reference conditions and ecological restoration: A southwestern perspective. Ecological Applications. 9: 1266-1277.

Moore, M.M.; Huffman, D.W.; Fule, P.Z.; Covington, W.W. 2004. Comparison of historical and contemporary forest structure and composition on permanent plots in southwestern ponderosa pine forests. Forest Science. 50: 162-176.

Moretti, M.; Barbalat, S. 2004. The effects of wildfires on wood-eating beetles in deciduous forests on the southern slope of the Swiss Alps. For. Ecol. Manag. 187: 85-103.

Morris, W.G.; Mowat, E.L. 1958. Some effects of thinning a ponderosa pine thicket with a prescribed fire. Journal of Forestry. 56: 203-209.

Myers, C.A. 1974. Multipurpose silviculture in ponderosa pine stands of the montane zone of central Colorado. Res. Pap. RM-132. Fort Collins, CO: U.S. Department of Agriculture, Forest Service, Rocky Mountain Forest and Range Experiment Station. 15 p.

National Forest Foundation and USDA Forest Service. 2005. Partnership guide: the power of people working together, a living document. Washington, DC: USDA Forest Service, National Partnership Office. 104 p. (PDF available at http:// www.partnershipresourcecenter.org/resources/partnershipguide/)

Negron, J.F.; Popp, J.B. 2004. Probability of ponderosa pine infestation by mountain pine beetle in the Colorado Front Range. For. Ecol. Manag. 191: 17-27.

Noss R.F.; Beier, P.; Covington, W.W.; Grumbine, R.E.; Lindenmayer, D.B.; Prather, J.W.; Schmiegelow, F.; Sisk, T.D.; Vosick, D.J. 2006. Recommendations for integrating restoration ecology and conservation biology in ponderosa pine forests of the southwestern United States. Restoration Ecology. 14(1): 4-10.

Nowicki, B. 2001. Protecting communities from forest fire: Effectively treating the wildland urban interface. Southwest Forest Alliance, Flagstaff, AZ. 11 p.

Odion, D.C.; Frost, E.J.; Strittholt, J.R.; Jiang, H.; Dellasala, D.A.; Moritz, M.A. 2004. Patterns of fire severity and forest conditions in the western Klamath Mountains, California. Conservation Biology. 18(4): 927-936.

Omi, P.N.; Martinson, E.J.; Hunter, M.E.; Chong, G.W.; Kalkahn, M.A.; Stohlgren, T.J. 2005. Spatial interactions among fuels, wildfire, and non-native plants. Final report submitted to the Joint Fire Science Program. 41 p.

Orozoco, P.; Carrillo, R. 1992-93. Prescribed burning of ponderosa pine red slash on the Gila National Forest. Fire Management Notes. 53-54: 3-8.

Orr, H.K. 1975. Watershed management in the Black Hills: The status of our knowledge. Res. Pap. RM-RP-141. Fort Collins, CO: U.S. Department of Agriculture, Forest Service, Rocky Mountain Forest and Range Experiment Station. 12 p.

Otrosina, W.J.; Ferrell, G.T. 1995. Root diseases: Primary agents and secondary consequences of disturbance. pp. 8792. In: Eskew,L.G., comp. Forest health through silviculture. Proceedings of the 1995 National Siliviculture Workshop;
1995 May; Mescalero, New Mexico. Gen. Tech. Rep. RMGTR-267. Fort Collins, CO, USA: U.S. Department of Agriculture, Forest Service, Rocky Mountain Forest and Range Experiment Station. 246 p.

Paine, R.T.; Tegner, M.J.; Johnson, E.A. 1998. Compounded perturbations yield ecological surprises. Ecosystems. 1: 535-545.

Parker, K.C. 2002. Fire in the pre-European lowlands of the American Southwest. In: T.R. Vale, ed. Fire, native peoples, and the natural landscape. Island Press, Washington, D.C.

Parrish, J.B.; Herman, D.J.; Reyher, D.J. 1996. A century of change in the Black Hills forest and riparian ecosystems. USDA Forest Service, Agriculture Experiment Station, South Dakota State University.

Peet, R.K. 1981. Forest vegetation of the Colorado Front Range-composition and dynamics. Vegetatio. 45: 3-75.

Peterson, D.L.; Johnson, M.C.; Agee, J.K.; Jain, T.B.; McKenzie, D.; Reinhardt, E.D. 2005. Forest structure and fire hazard in dry forests of the western United States. Gen. Tech. Rep. PNW-GTR-628. Portland, OR: U.S. Department of Agriculture, Forest Service, Pacific Northwest Research Station. 38 p.

Pollet, J.; Omi, P.N. 2002. Effect of thinning and prescribed burning on crown fire severity in ponderosa pine forests. Int. J. Wildland Fire. 11: 1-10.

Poff, R.J. 1996. Effects of silvicultural practices and wildfire on productivity of forest soils. In: Sierra Nevada Ecosystem Project: Final report to congress, Vol. II, assessments and scientific basis for management options. University of California, Davis, CA.

Progulske, D.R. 1974. Yellow ore, yellow hair, and yellow pine: A photographic study of a century of forest ecology. Bull. 616. Brookings, SD: Agricultural Experiment Station, South Dakota State University.

Pyne, S.J. 1997. America's fires: Management on wildlands and forests. Forest History Society, Durham, NC.

Pyne, S.J. 2004. Tending fire: Coping with America's wildland fire. Island Press, Washington D.C.

Pyne, S.J.; Andrews, P.J.; Laven, R.D. 1996. Introduction to wildland fire. John Wiley \& Sons, New York, NY.

Randall-Parker, T.; Miller, R. 2002. Effects of prescribed fire in ponderosa pine on key wildlife habitat components: Preliminary results and a method for monitoring. In: W.F. Laudenslayer et al. eds. Proceedings of the symposium on ecology and management of dead wood in western forests, Nov 2-4, 1999, Reno, NV. Gen. Tech. Rep. PSW-GTR181. Albany, CA: U.S. Department of Agriculture, Forest Service, Pacific Southwest Research Station.

Rasmussen, D.I. 1941. Biotic communities of the Kaibab Plateau, Arizona. Ecological Monographs. 11: 229-275.

Raventon, E. 1994. Island in the plains: A Black Hills natural history. Johnson Printing Co. Boulder, CO.

Reice, S.R. 1994. Nonequilibrium determinants of biological community structure. American Scientist. 82: 424-435.

Reich, R.M.; Lundquist, J.E.; Bravo, V.A. 2004. Spatial models for estimating fuel loads in the Black Hills, South Dakota. Int. J. Wildland Fire. 13: 119-129. 
Reinhardt, E.D.; Crookston, N.L. 2003. The fire and fuels extension of the forest vegetation simulator. Gen. Tech. Rep. RMRS-GTR-116. Fort Collins, CO: U.S. Department of Agriculture, Forest Service, Rocky Mountain Research Station. 220 p.

Reinhardt, E.D.; Keane, R.E.; Brown, J.K. 1997. First Order Fire Effects Model: FOFEM 4.0 user's guide. Gen. Tech. Rep. INT-GTR-344. Ogden, UT: U.S. Department of Agriculture, Forest Service, Intermountain Research Station. 65 p.

Resh, S.G.; Ryan, M.G.; Joyce, L.A.; Binkley, D. 2005. Chipping and mastication in forested ecosystems-A synthesis. Unpublished report.

Reynolds, K.M.; Holsten, E.H. 1996. Classification of spruce beetle hazard in Lutz and Sitka spruce stands on the Kenai Peninsula, Alaska. For. Ecol. Manag. 84: 251-262.

Reynolds, R.T.; Block, W.M.; Boyce, D.A. 1996. Using ecological relationships of wildlife as templates for restoring southwestern forests. In: W.W. Covington and P.K. Wagner, eds. Conference on adaptive ecosystem restoration and management: Restoration of Cordilleran conifer landscapes of North America. Gen. Tech. Rep. RM-GTR-278. Fort Collins, CO: U.S. Department of Agriculture, Forest Service, Rocky Mountain Forest and Range Experiment Station.

Reynolds, R.T.; Graham, R.T.; Reiser, M.H.; Bassett, R.L.; Kennedy, P.L.; Boyce, D.A.; Goodwin, G.; Smith, R.; Fisher, E.L. 1992. Management recommendations for the northern goshawk in the southwestern United States. Gen. Tech. Rep. RM-GTR-217. Fort Collins, CO: U.S. Department of Agriculture, Forest Service, Rocky Mountain Forest and Range Experiment Station. 90 p.

Riggs, R.A.; Urness, P.J. 1989. Effects of goat browsing on Gambel oak communities in northern Utah. J. Range Manag. 42: 354-360.

Robinson, M.S.; Chavez, J.; Velazquez, S.; Jayanty, R.K.M. 2004. Chemical speciation of PM2.5 collected during prescribed fires of the Coconino National Forest near Flagstaff, Arizona. Journal of the Association of Air and Waste Management. 54: 1112-1123.

Romme, W.H.; Knight, R.L.; Baker, W.L.; Smith, F.W.; Buskirk, S.W. 2000. What have we learned about forest fragmentation in southern Rocky Mountains? In: R.L. Knight, F.W. Smith, S.W. Buskirk, W.H. Romme, and W.L. Baker, eds. Forest fragmentation in the southern Rocky Mountains. University of Colorado Press, Boulder, CO.

Rosenstock, S.S. 1998. Influence of Gambel oak on breeding birds in ponderosa pine forests of northern Arizona. The Condor. 100: 485-492.

Rudinsky, J.A. 1966. Host selection and invasion by the Douglas-fir bark beetle, Dendroctonus psuedotsugae Hopkins, in coastal Douglas-fir forests. Can. Entomol. 98: 98-111.

Rueth, H.M.; Baron, J.S.; Joyce, L.A. 2002. Natural resource extraction: Past, present and future. Pp. 85-112. In: J.S. Baron, ed. Rocky Mountain futures: An ecological perspective. Island Press, Washington, D.C.
Rummell, R.S. 1951. Some effects of livestock grazing on ponderosa pine forest and range in central Washington. Ecology. 32: 594-607.

Ryans, M.; Cormier, D. 1994. A review of mechanized brushcutting equipment for forestry. Special Report SR-101. Forest Engineering Research Institute of Canada.

Sackett, S.S. 1980. Reducing natural ponderosa pine fuels using prescribed fire: Two case studies. Res. Note RM-RN-392. Fort Collins, CO: U.S. Department of Agriculture, Forest Service, Rocky Mountain Forest and Range Experiment Station. 61 p.

Sackett, S.S.; Haase, S.M.; Harrington, M.G. 1996. Lessons learned from fire use for restoring southwestern ponderosa pine ecosystems. In: W.W. Covington and M.R. Wagner, eds. Conference on adaptive ecosystem restoration and management: Restoration of Cordilleran conifer landscapes of North America. Gen. Tech. Rep. RM-GTR-278. Fort Collins, CO: U.S. Department of Agriculture, Forest Service, Rocky Mountain Forest and Range Experiment Station.

Saint-Germain, M.; Drapeau, P.; Hebert, C. 2004. Xylophagous insect species composition and patterns of substratum use on fire-killed black spruce in central Quebec. Can. J. For. Res. 34: 677-685.

Savage, M. 1991. Structural dynamics of a southwestern ponderosa pine forest under chronic human influence. Ann. Assoc. Am. Geogr. 81: 271-289.

Savage, M.; Swetnam, T.W. 1990. Early 19th century fire decline following sheep pasturing in a Navajo ponderosa pine forest. Ecology. 71: 2374-2378.

Schmid, J.M.; Mata, S.A. 1996. Natural variability of specific forest insect populations and their associated effects in Colorado. Gen. Tech. Rep. RM-GTR-275. Fort Collins, CO: U.S. Department of Agriculture, Forest Service, Rocky Mountain Forest and Range Experiment Station. 14 p.

Schoennagel, T.; Veblen, T.T.; Romme, W.H. 2004. The interaction of fire, fuels, and climate across Rocky Mountain forests. BioScience. 54: 661-676.

Schubert, G.H. 1974. Silviculture of southwestern ponderosa pine: The status of our knowledge. Res. Pap. RM-RP-123, Fort Collins, CO: U.S. Department of Agriculture, Forest Service, Rocky Mountain Range and Experiment Station.

Schumann, M. 2004. Fuel reduction projects in southwestern ponderosa pine forests: Adescription of sites and treatments. National Community Forestry Center, Southwest Region Working Paper No. 9. 66 p.

Scott, J.H. 1996. Restoring recreation and residential forests. In: C.C. Hardy and S.F. Arno (eds.) The use of fire in forest restoration. Gen. Tech. Rep. INT-GTR-341. Ogden, UT: U.S. Department of Agriculture, Forest Service, Intermountain Research Station.

Scott, J.H. 1998. Fuel reduction in residential and scenic forests: A comparison of three treatments in a western Montana ponderosa pine stand. Res. Pap. RMRS-RP-5. Fort Collins, CO: U.S. Department of Agriculture, Forest Service, Rocky Mountain Research Station. 19 p. 
Scott, J.H. 1999. NEXUS: A system for assessing crown fire hazard. Fire Management Notes. 59: 20-24.

Severson, K.E.; Rinne, J.N. 1990. Increasing habitat diversity in Southwest forests and woodlands via prescribed fire. In: J.S. Krammes, ed. Effects of fire management of southwestern natural resources, proceedings of the symposium. Gen. Tech. Rep. RM-191. Fort Collins, CO: U.S. Department of Agriculture, Forest Service, Rocky Mountain Forest and Range Experiment Station.

Severson, K.E.; Uresk, D.W. 1988. Influence of ponderosa pine overstory on forage quality in the Black Hills, South Dakota. Great Basin Naturalist. 48: 78-82.

Shepperd, W.D. 1993. The effect of commercial harvest activities on root compaction and suckering of aspen. West. J. Appl. For. 8(2): 62-66.

Shepperd, W.D. 2004. Techniques to restore aspen forests in the western U.S. Transactions of the Western Section of the Wildlife Society. 40: 52-60.

Shepperd, W.D. 2007. SDI-Flex: A new technique of allocating growing stock for developing treatment prescriptions in uneven-aged forest stands. In: Powers, R. tech. ed. Restoring fire-adapted ecosystems: Proceedings of the 2005 National Silviculture Workshop, Tahoe City, CA, June 6-10, 2005. PSW-GTR-203. Alburn, CA: USDA Forest Service, Pacific Southwest Experiment Station. p. 171-180.

Shepperd, G.; Farnsworth, A. 1997. Fire effects and the use of fire in Mexican spotted owl habitat. In: J.M. Greelee, ed. Proceedings-Fire effects on rare and endangered species and habitats. Nov. 13-16, 1995, Coeur d'Alene, ID. International Association of Wildland Fire, Fairfield, WA.

Shepperd, W.D.; Battaglia, M.A. 2002. Ecology, silviculture, and management of Black Hills ponderosa pine. Gen. Tech. Rep. RMRS-GTR-97. Fort Collins, CO: U.S. Department of Agriculture, Forest Service, Rocky Mountain Research Station. 112 p.

Shepperd, W.D.; Edminster, C.B.; Mata, S.A. 2006. Long-term seedfall, establishment, survival and growth of natural and planted ponderosa pine in the Colorado Front Range. West. J. Appl. For. 21(1): 19-26

Shepperd, W.; Abt, K.; Barbour, R.J.; Fight, R.; Huggett, R.; Miles, P.; Reinhardt, E.; Skog, K. 2005. The fuel treatment evaluator-a silvicultural approach to reducing fire hazard. In: Proceedings, Society of American Foresters National Convention, October 19-22, 2005, Ft. Worth, TX. Bethesda MD. Society of American Foresters. (http://store.safnet. org/merchant.mv)

Sherriff, R.L.; Veblen, T.T. 2007. A spatially-explicit reconstruction of historical fire occurrence in the ponderosa pine zone of the Colorado Front Range. Ecosystems. 10: 311-323.

Shinneman, D.L.; Baker, W.L. 1997. Nonequilibrium dynamics between catastrophic disturbances and oldgrowth forests in ponderosa pine landscapes of the Black Hills. Conservation Biology. 11: 1276-1288.

Sieg, C.H.; Severson, K.E. 1996. Managing habitats for whitetailed deer: Black Hills and Bear Lodge Mountains of South Dakota and Wyoming. Gen. Tech. Rep. RM-GTR-274.
Fort Collins, CO: U.S. Department of Agriculture, Forest Service, Rocky Mountain Forest and Range Experiment Station. 24 p.

Sieg, C.H.; Wright, H.A. 1996. The role of prescribed burning in regenerating Quercus macrocarpa and associated woody plants in stringer woodlands in the Black Hills, South Dakota. Int. J. Wildland Fire. 6: 21-29.

Sisk, T.D.; Hampton, H.M.; Prather, J.W.; Aumak, E.N.; $\mathrm{Xu}$, Y.; Loeser, M.R.; Munoz-Erikson, T.; Dickson, B.; Palumbo, J. 2004. Forest Ecological Restoration Analysis (ForestERA) Project Report 2002-2004. Center for Environmental Sciences and Education, Northern Arizona University, Flagstaff, AZ. 105 p.

Skog, K.E.; Barbour, R.J.; Abt, K.L.; Bilek, E.M.; Burch, F.; Fight, R.D.; Hugget, R.J.; Miles, P.D.; Reinhardt, E.D.; Shepperd, W.D. 2006. Evaluation of silvicultural treatments and biomass use for reducing fire hazard in western states. Res. Pap. FPL-RP-634. Madison, WI: U.S. Department of Agriculture, Forest Service, Forest Products Laboratory. $29 \mathrm{p}$.

Smith, D.M.; Larson, B.C.; Kelty, M.J.; Ashton, P.M.S. 1997. The practice of silviculture: Applied forest ecology 9th edition. John Wiley and Sons, New York, NY.

Snider, G.B.; Wood, D.B.; Daugherty, P.J. 2003. Analysis of costs and benefits of restoration based hazardous fuel reduction treatments: Treatment vs. no treatment. Progress report no. 1. Northern Arizona University, Flagstaff, AZ. $14 \mathrm{p}$.

Springer, J.D.; Waltz, A.E.M.; Fule, P.Z.; Moore, M.M.; Covington, W.W. 2001. Seeding versus natural regeneration: A comparison of vegetation change following thinning and burning in ponderosa pine. In: Vance, R.K., C.B. Edminster, W.W. Covington, and J.A. Blake, comps. Ponderosa pine ecosystem restoration and conservation: Steps toward stewardship; 2000 April 25-27; Flagstaff, AZ. Proc. RMRSP-22. Ogden, UT: U.S. Department of Agriculture, Forest Service, Rocky Mountain Research Station.

Stednick, J.D. 1996. Monitoring the effects of timber harvest on annual water yield. Journal of Hydrology. 176: 79-95.

Stephens, S.L.; Moghaddas, J.J. 2005a. Silvicultural and reserve impacts on potential fire behavior and forest conservation: Twenty-five years of experience from Sierra Nevada mixed conifer forests. Biological Conservation. 125: 369-379.

Stephens, S.L.; Moghaddas, J.J. 2005b. Experimental fuel treatment impacts on forest structure, potential fire behavior, and predicted tree mortality in a California mixed conifer forest. For. Ecol. Manag. 215: 21-36.

Stokes, B.J. 1992. Harvesting small trees and forest residues. Biomass and Bioenergy. 2: 131-147.

Stratton, R.C. 2004. Assessing the effectiveness of landscape fuel treatments on fire growth and behavior. Journal of Forestry. 102: 32-40.

Sturtevant, B.R.; Gustafson, E.J.; He, H.S. 2004. Modelling disturbance and succession in forest landscapes using LANDIS. Ecological Modeling. 180: 229. 
Sturtevant, V.; Moore, M.; Jakes, P.; Cheng, A.S. 2005. Social science to improve fuels management: A synthesis of research on collaboration. Gen. Tech. Rep. NC-257. St. Paul, MN: U.S. Department of Agriculture, Forest Service, North Central Research Station. 84 p.

Sullivan, B.T.; Fettig, C.J.; Otrosina, W.J.; Dalusky, M.J.; Berisford, C.W. 2003. Association between severity of prescribed burns and subsequent activity of coniferinfesting beetles in stands of longleaf pine. For. Ecol. Manag. 185: 327-340.

Swetnam, T.W. 1990. Fire history and climate in the southwestern United States. In: J.S. Krammes, ed. Proceedings of the symposium on effects of fire management of southwestern United States natural resources. Gen. Tech. Rep. RM-GTR-191. Fort Collins, CO: U.S. Department of Agriculture, Forest Service, Rocky Mountain Forest and Range Experiment Station.

Swetnam, T.W.; Baisan, C.H. 1996. Historical fire regime patterns in the southwestern United States since AD 1700. In: C.D. Allen, ed. Fire effects in southwestern forests: Proceedings of the La Mesa fire symposium. Gen. Tech. Rep. RM-GTR-286. Fort Collins, CO: U.S. Department of Agriculture, Forest Service, Rocky Mountain Forest and Range Experiment Station.

Swetnam, T.W.; Betancourt, J.L. 1998. Mesoscale disturbance and ecological response to decadal climate variability in the American Southwest. Journal of Climate. 11: 3128-3147.

Swetnam, T.W.; Dieterich, J.H. 1985. Fire history of ponderosa pine forests in the Gila Wilderness, New Mexico. In: J.E. Lotan, B.M. Kilgore, W.C. Fischer, and R.W. Mutch, eds. Proceedings - symposium and workshop on wilderness fire. Gen. Tech. Rep. INT-GTR-182, Ogden, UT: U.S. Department of Agriculture, Forest Service, Intermountain Forest and Range Experiment Station.

Swetnam, T.W.; Lynch, A.M. 1993. Multicentury, regionalscale patterns of western spruce budworm outbreaks. Ecological Monographs. 63: 399-424.

Swetnam, T.W.; Allen, C.D.; Betancourt, J.L. 1999. Applied historical ecology: using the past to manage for the future. Ecological Applications. 9: 1189-1206.

Swezy, D.M.; Agee, J.K. 1991. Prescribed-fire effects on fineroot and tree mortality in old-growth ponderosa pine. Can. J. For. Res. 21: 626-634.

Touchan, R.; Allen, C.D.; Swetnam, T.W. 1996. Fire history and climatic patterns in ponderosa pine and mixed-conifer forests of the Jemez Mountains, northern New Mexico. In: C.D. Allen, ed. Fire effects in southwestern forests: Proceedings of the La Mesa fire symposium. Gen. Tech. Rep. RM-GTR-286, Fort Collins, CO: U.S. Department of Agriculture, Forest Service, Rocky Mountain Forest and Range Experiment Station.

Trombulak, S.C.; Frissell, C.A. 2000. Review of ecological effects of roads on terrestrial and aquatic communities. Conservation Biology. 14: 18-30.

University of Arizona. WALTER: Wildfire Alternatives. 2002. (http://walter.arizona.edu/) (cited 7/12/06).
Uresk, D.W.; Severson, K.E. 1989. Understory-overstory relationships in ponderosa pine forests, Black Hills, South Dakota. J. Range Manag. 42: 203-208.

USDA and USDI. 2005. Wildland fire use: Implementation and procedures guide. $75 \mathrm{p}$.

USDA Forest Service. 1973. Fuel management planning and treatment guide-specific methods and procedures. Region 1.

USDA Forest Service. 1994. Draft environmental impact statement for the Black Hills National Forest revised land and resource management plan (with appendices).

USDA Forest Service. 2003a. Black Mountain/Devil's Hold fuels and watershed project environmental assessment, San Isabel National Forest, Canon City, Colorado.

USDA Forest Service. 2003b. Fanny Project Area, Draft environmental assessment, Hell Canyon Ranger District, Black Hills National Forest, Custer County, South Dakota.

USDA Forest Service. 2003c. A strategic assessment of forest biomass and fuel reduction treatments in western states. USDA Forest Service, Research and Development and the Western Forestry Leadership Coalition. http://www.fs.fed. us/research/infocenter.html

USDA Forest Service. 2004a. Geranium project area draft environmental assessment, Black Hills National Forest.

USDA Forest Service. 2004b. James Creek fuel reduction project environmental assessment, Arapaho and Roosevelt National Forest.

USDA Forest Service. 2004c. Sugarloaf fuel reduction project environmental assessment, Arapaho and Roosevelt National Forest.

USDI Fish and Wildlife Service. 1995. Recovery plant for the Mexican spotted owl: Vol I. Albuquerque, New Mexico. $172 \mathrm{p}$.

USDI National Park Service. 2003. Fire monitoring handbook. Boise, ID: Fire Management Program Center, National Interagency Fire Center. 274 p.

Van Epps, G.A. 1974. Control of Gambel oak with three herbicides. J. Range Manag. 27: 297-301.

Veblen, T.T. 2000. Disturbance patterns in southern Rocky Mountain forests. In: R.L. Knight, F.W.Smith, S.W. Buskirk, W.H. Romme, and W.L. Baker, eds. Forest fragmentation in the southern Rocky Mountains. University of Colorado Press, Boulder, CO.

Veblen, T.T. 2003. Key issues in fire regime research for fuels management and ecological restoration. In: P.N. Omi and L.A. Joyce, eds. Fire, fuel treatments, and ecological restoration: Conference proceedings. Proc. RMRS-P-29. Fort Collins, CO: U.S. Department of Agriculture, Forest Service, Rocky Mountain Research Station.

Veblen, T.T.; Kitzberger, T. 2002. Inter-hemispheric comparison of fire history: The Colorado Front Range, U.S.A. and the northern Patagonian Andes, Argentina. Plant Ecology. 163: 187-207.

Veblen, T.T.; Lorenz, D.C. 1986. Anthropogenic disturbance and recovery patterns in montane forests, Colorado Front Range. Physical Geography. 7: 1-23. 
Veblen, T.T.; Lorenz, D.C. 1991. The Colorado Front Range: A century of ecological change. University of Utah Press, Salt Lake City, UT.

Veblen, T.T.; Kitzberger, T.; Donnegan, J. 2000. Climatic and human influences on fire regimes in ponderosa pine forests in the Colorado Front Range. Ecological Applications. 10: 1178-1195.

Wagle, R.F.; Eakle, T.W. 1979. A controlled burn reduces the impact of subsequent wildfire in a ponderosa pine vegetation type. Forest Science. 25: 123-129.

Wallin, K.F.; Kolb, T.E.; Skov, K.R.; Wagner, M.R. 2003. Effects of crown scorch on ponderosa pine resistance to bark beetles in northern Arizona. Environmental Entomology. 32: 652-661.

Wallin, K.F.; Kolb, T.E.; Skov, K.R.; Wagner, M.R. 2004. Seven-year results of thinning and burning restoration treatments on old ponderosa pines and the Gus Pearson Natural Area. Restoration Ecology. 12: 239-247.

Wang, J.; Greene, W.D.; Stokes, B.J. 1998. Stand, harvest, and equipment interactions in simulated harvesting prescriptions. Forest Products Society. 48: 81-85.

Weaver, H. 1951. Fire as an ecological factor in southwestern ponderosa pine forests. Journal of Forestry. 49: 93-98.

Westerling, A.L.; Hidalgo, H.G.; Cayan, D.R.; Swetnam, T.W. 2006. Warming and earlier spring increases western U.S. forest wildfire activity. Science. 313: 940-943.

White, A.S. 1985. Presettlement regeneration patterns in a southwestern ponderosa pine stand. Ecology. 66: 589-594.

Wickman, T.; Acheson, A. 2005. Smoke Impact Spreadsheet (SIS) model; Environmental consequences factsheet: 11. Research Note RMRS-RN-23-11-www. U.S. Department of Agriculture, Forest Service, Rocky Mountain Research Station. 1 p.
Wieder, W.R.; Bower, N.W. 2004. Fire history of the Aiken Canyon grassland-woodland ecotone in the southern foothills of the Colorado Front Range. Southwestern Naturalist. 49: 239-243.

Wienk, C.L.; Sieg, C.H.; McPherson, G.R. 2004. Evaluating the role of cutting treatments, fire, and soil seed banks in an experimental framework in ponderosa pine forests of the Black Hills, South Dakota. For. Ecol. Manag. 192: 375-393.

Windell, K.; Bradshaw, S. 2000. Understory biomass reduction methods and equipment. 0051-2828-MTDC. USDA Forest Service, Technology and Development Program, Missoula, MT.

Winter, G.J.; Vogt, C.; Fried, J.S. 2002. Fuel treatments at the wildland urban interface-common concerns in diverse regions. Journal of Forestry. 100: 15-21.

Wolfson, B.A.S.; Kolb, T.E.; Sieg, C.H.; Clancy, K.M. 2005. Effects of post-fire conditions on germination and seedling success of diffuse knapweed in northern Arizona. For. Ecol. Manag. 216: 342-358.

Wood, D.B. 1988. Costs of prescribed burning in southwestern ponderosa pine. West. J. Appl. For. 3: 115-119.

Woodridge, D.D.; Weaver, H. 1965. Some effects of thinning a ponderosa pine thicket with prescribed fire, II. Journal of Forestry. 63: 92-95.

Wyant, J.G.; Omi, P.N.; Laven, R.D. 1986. Fire induced tree mortality in a Colorado ponderosa pine Douglas fir stand. Forest Science. 32: 49-59.

Young, D.L.; Baily, J.A. 1975. Effects of fire and mechanical treatment on Cercocarpus montanus and Ribes cereum. J. Range Manag. 28: 495-497. 


\section{Appendix A: Models Used in Fuel Treatment Planning and Implementation}

\section{BehavePlus}

BehavePlus uses inputs of fuel characteristics and weather and topography to predict surface fire and crown fire spread and intensity. This model has a variety of applications for wildland fire suppression and training. For prescribed fire, it is typically used to develop prescription windows that will result in desired fire behavior. This model is available to download at www.fire.org.

\section{CONSUME}

CONSUME is a model that predicts fuel consumption and emission based on fuel and weather conditions. This model is available to download at http://www. fs.fed.us/pnw/fera/products/consume.html.

\section{FARSITE}

FARSITE uses spatial information on fuels and topography and weather indices to simulate fire spread across a landscape. This model is particularly useful for simulating spread of fires used for resource benefit and for landscape planning of fuel treatments. This model is available to download at www.fire.org.

\section{FFE-FVS}

The Fire and Fuels Extension of the Forest Vegetation Simulator (FFE-FVS) links the growth and yield models of FVS with models that predict fire behavior, fire effects, fuel loading, and snag dynamics. This model is particularly useful for examining the potential short- and long-term effects of fuel treatments. This model is available to download at www.fs.fed.us/ fmsc/fvs/index.shtml.

\section{FIREMON}

FIREMON is monitoring program designed to enable managers to develop a monitoring protocol, collect data, and store and analyze fire effects. This model is available to download at www.fire.org.

\section{FlamMap}

FlamMap computes potential fire behavior characteristics over a FARSITElandscape. FlamMap is particularly useful for prioritizing fuel treatment areas across a landscape and assessing their effectiveness in preventing severe wildfire spread. This model is available to download at www.fire.org.

\section{FMAPlus}

Fuels Management Analyst (FMAPlus) is a model that can estimate loading of surface and canopy fuels and then predict surface and canopy fire behavior and fire effects. This model is available to purchase at http://www.fireps.com/fmanalyst3/index.htm.

\section{FOFEM}

The First Order Fire Effects Model (FOFEM) predicts the effects of fire on tree mortality, fuel consumption, smoke production, and soil heating. This model is useful for ensuring prescribed fires will result in desired fire effects. This model is available to download at www.fire.org.

\section{FSVeg}

FSVeg is a program that can be used by managers in the Forest Service. It contains data on trees, surface cover, down woody material, vegetation composition, and fuel loading for stands on Forest Service land. FSVeg data can be used directly in the Forest Vegetation Simulator (FVS) and the Integrated Forest Resource Management System (INFORMS). This program is very useful for fuel treatment planning. Information on this program is available at http://www.fs.fed.us/ emc/nris/products/fsveg/index.shtml.

\section{INFORMS}

The Integrated Forest Resource Management System (INFORMS) was designed for the Forest Service to support the entire NEPA process. This model is particularly useful in generating maps of fire hazard for different treatment alternatives. It also generates 
FARSITE ready data. This model is available to download at http://www.fs.fed.us/informs/index.php.

\section{MYFTP}

My fuel treatment planner (MyFtp) can be used to assess the cost associated with mechanical treatments and prescribed fire. It is available for downloading at http://www.fs.fed.us/fire/tech_transfer/synthesis/ economic_utilization_team/MyFTP_home.htm.

\section{NEXUS}

NEXUS links surface and crown fire behavior models to create indices of relative crown fire potential. This model can be used to examine the crown fire potential of stands treated for fuels reduction. This model is available to download at www.fire.org. 


\section{Appendix B: Species Referenced in Best Management Practices Guide}

\section{Plants}

Scientific Name

Abies concolor

Abies lasiocarpa

Cercocarpus montanus

Juniperus scopulorum

Picea engelmannii

Pinus ponderosa

Populus tremuloides

Pseudotsuga menziesii

Quercus gambellii

Quercus macrocarpa

\section{Birds}

Accipiter gentiles

Cervus canadensis

Odocoileus spp.

Strix occidentalis lucida

\section{Mammals}

Antilocarpa Americana

Bison bison

Cervus elaphus

Sciurus aberti

Insects

Choristoneura occidentalis

Dendroctonus spp.

Dendroctonus ponderosae

Ips spp.

Hesperia leonardus montana

Fish

Oncorhynchus gilae

\section{Diseases}

Arceuthobium spp.

\section{Common Name}

white fir

subalpine fir

mountain mahogany

Rocky Mountain juniper

Engelmann spruce

ponderosa pine

quaking aspen

Douglas-fir

Gambel oak

bur oak

northern goshawk

elk

deer

Mexican spotted owl

pronghorn

American bison

elk

Abert's squirrel

spruce budworm

bark beetles

mountain pine beetle

Ips beetles

Pawnee montane skipper

\section{Distribution}

AZ, CO, NM

$\mathrm{AZ}, \mathrm{CO}, \mathrm{NM}$

AZ, CO, NM, SD

AZ, CO, NM, SD

AZ. CO, NM

AZ, CO, NM, SD

AZ, CO, NM, SD

$\mathrm{AZ}, \mathrm{CO}, \mathrm{NM}$

$\mathrm{AZ}, \mathrm{CO}, \mathrm{NM}$

$\mathrm{NM}, \mathrm{SD}$
AZ, CO, NM, SD

AZ, CO, NM, SD

AZ, CO, NM, SD

AZ, NM

AZ, CO, NM, SD

$\mathrm{SD}$

AZ, CO, NM, SD

$\mathrm{AZ}, \mathrm{CO}, \mathrm{NM}$

AZ, CO, NM

AZ, CO, NM, SD

AZ, CO, NM, SD

$\mathrm{AZ}, \mathrm{CO}, \mathrm{NM}, \mathrm{SD}$

$\mathrm{CO}$

AZ, NM

Gila trout

dwarf mistletoe
AZ, NM, CO 


\section{Appendix C: Managers Interviewed}

\section{Name}

Craig Allen

Goeff Bell

Kristy Berggren

Anne Bradley

Blaine Cook

Russ Copp

Michael Creach

Don Falk

Lawrence Garcia

Steve Gatewood

Brook Gebow

Gale Gire

Craig Goodell

William Hill

David Isackson

Tom Johnston

Gary Kemp

Lowell Kendall

Paul Langowski

Andrew Leiendecker

Randy Lewis

Gwen Lipp

John Lissoway

Dennis Mauch

Cecilia McNicoll

Dan Morford

Shane Olpin

Andy Perri

Toby Richards

Marla Rodgers

Orlando Romero

Melissa Savage

Paul Schmidtke

Todd Schulke

Martha Schumann

Scott Spleiss

Paul Summerfelt
Title

Research Ecologist

Fire Management Officer

Forester

SW fire learning network

Forest Silviculturalist

Forest Fuels Specialist

Fuels Management Specialist

Adjuct Professor

District FMO

Program Director

Preserves

Silviculturalist

Assistant FMO

Silviculturalist

Assistant District FMO

Forest Fuels Specialist

FMO

Assistant FMO

Branch Chief-Fuels/Fire ecology

Assistant FMO

Natural Resource Specialist

Fuels Specialist

Fire Program Manager

Forest Technician

Forest Planner

Prescribed fire specialist

Assistant FMO

Forester

District FMO

Assistant FMO

Senior Forester

Fire Staff Officer

SW NM field rep.

Assistant FMO

Fuel Management Officer
Agency

USGS

Arapaho-Roosevelt National Forest

Colorado State Forest Service

The Nature Conservancy

Black Hills National Forest

Coconino National Forest

Prescott National Forest

University of Arizona

Santa Fe National Forest

Greater Flagstaff Forests Partnership

The Nature Conservancy

Black Hills National Forest

San Juan National Forest

Custer State Park

Santa Fe National Forest

Santa Fe National Forest

Bandelier National Monument

Coconino National Forest

USFS-Rocky Mountain Region

Coronado National Forest

Bureau of Land Management

Black Hills National Forest

National Park Service

Black Hills National Forest

Gila National Forest

Wind Cave National Park

Black Hills National Forest

Colorado State Forest Service

Gila National Forest

Bandelier National Monument

Forest Guild

Four Corners Institute

Lincoln National Forest

Center for Biological Diversity

The Nature Conservancy

Prescott National Forest

Flagstaff Fire Department 


Tracy Swenson
Walker Thornton
Jeff Thumm
Terry Tompkins
Russell Truman
Sherry Tune
Scott Wagner
Gordon West
Brenda Wasielewski
Craig Wilcox
Jim Williams
Ros Wu

Zone FMO

Fuels Specialist

Natural Resource Specialist

Assistant FMO

Assistant FMO

Forest Fire and Fuels Planner

Forester

Assistant District Forester

Assistant FMO

Forest Technician

Fire ecologist
Arapaho-Roosevelt National Forest

Coconino National Forest

Coconino National Forest

Black Hills National Forest

Kaibab National Forest

Coronado National Forest

San Juan National Forest

Santa Clara Woodworks

Colorado State Forest Service

Coronado National Forest

Black Hills National Forest

San Juan National Forest 


\section{Publishing Services Staff}

Managing Editor · Lane Eskew

Page Composition \& Printing · Nancy Chadwick

Editorial Assistant · Loa Collins

Contract Editor · Kristi Coughlon

Page Composition \& Printing - Connie Lemos

Distribution - Richard Schneider

Online Publications \& Graphics · Suzy Stephens 


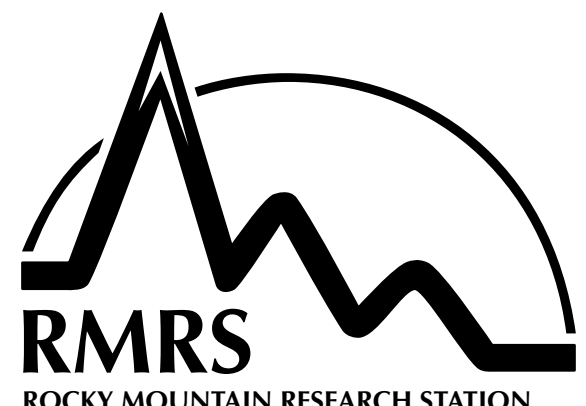

The Rocky Mountain Research Station develops scientific information and technology to improve management, protection, and use of the forests and rangelands. Research is designed to meet the needs of the National Forest managers, Federal and State agencies, public and private organizations, academic institutions, industry, and individuals.

Studies accelerate solutions to problems involving ecosystems, range, forests, water, recreation, fire, resource inventory, land reclamation, community sustainability, forest engineering technology, multiple use economics, wildlife and fish habitat, and forest insects and diseases. Studies are conducted cooperatively, and applications may be found worldwide.

\section{Research Locations}

Flagstaff, Arizona Fort Collins, Colorado* Boise, Idaho

Moscow, Idaho

Bozeman, Montana

Missoula, Montana
Reno, Nevada

Albuquerque, New Mexico Rapid City, South Dakota

Logan, Utah

Ogden, Utah

Provo, Utah

*Station Headquarters, Natural Resources Research Center, 2150 Centre Avenue, Building A, Fort Collins, CO 80526.

The U.S. Department of Agriculture (USDA) prohibits discrimination in all its programs and activities on the basis of race, color, national origin, age, disability, and where applicable, sex, marital status, familial status, parental status, religion, sexual orientation, genetic information, political beliefs, reprisal, or because all or part of an individual's income is derived from any public assistance program. (Not all prohibited bases apply to all programs.) Persons with disabilities who require alternative means for communication of program information (Braille, large print, audiotape, etc.) should contact USDA's TARGET Center at (202) 720-2600 (voice and TDD). To file a complaint of discrimination, write to USDA, Director, Office of Civil Rights, 1400 Independence Avenue, S.W., Washington, DC 20250-9410, or call (800) 795-3272 (voice) or (202) 720-6382 (TDD). USDA is an equal opportunity provider and employer. 